\author{
Universidade de São Paulo \\ Instituto de Física
}

\title{
Estudo do efeito da composição das partículas primárias na distribuição lateral de chuveiros atmosféricos do Observatório Pierre Auger
}

\author{
Diogo Bernardes Tridapalli
}

Orientador: Prof. Dr. Philippe Gouffon

Tese de doutorado apresentada ao Instituto de Física para a obtenção do título de Doutor em Ciências

Banca Examinadora:

Prof. Dr. Philippe Gouffon

(IFUSP)

Prof. Dr. Otaviano Augusto Marcondes Helene

(IFUSP)

Profa. Dra. Ivone Freire Albuquerque

(IFUSP)

Profa. Dra. Carola Dobrigkeit

(UNICAMP)

Prof. Dr. Carlos Todero Peixoto

(IFSC - USP)

São Paulo

2012 
Autorizo a reprodução ou divulgação total e parcial deste trabalho, por qualquer meio convencional ou eletrônico, desde que citada a fonte.

\section{FICHA CATALOGRÁFICA \\ Preparada pelo Serviço de Biblioteca e Informação do Instituto de Física da Universidade de São Paulo}

Tridapalli, Diogo Bernardes

Estudo do efeito da composição das partículas primárias na distribuição lateral de chuveiros atmosféricos extensos do Observatório Pierre Auger - São Paulo, 2012

Tese (Doutorado) - Universidade de São Paulo. Instituto de Física-Dept ${ }^{\circ}$ Física Experimental.

Orientador: Prof. Dr. Philippe Gouffon

Área de Concentração: Física

Unitermos:

1. Observatórios;

2. Partículas Elementares;

3. Física Experimental;

4. Simulação (Estatística);

5. Distribuições (Probabilidade).

USP/IF/SBI-010/2012 
Never send a human to do a machine's job.

Agent Smith 
Aos meus amigos,

Jairo e Priscila. 


\section{Agradecimentos}

Agradeço à FAPESP pela bolsa de doutorado e pela prorrogação da mesma, pena que não poderia ser por dois anos.

Ao meu orientador Philippe Gouffon que me deu muito mais liberdade e confiança do que eu acho que merecia e sempre esteve disponível para discutir sobre física, estatística ou tecnologia (barcos também). Depois desses cinco anos de convivência acabei ficando com o humor mais refinado.

Ao professor Vitor de Souza por me permitir monopolizar o cluster de São Carlos por tantos meses. Sem o cluster eu iria demorar mais uns três anos para terminar todas as simulações.

Ao Carlos Todero Peixoto pela paciência e boa vontade em responder minhas dúvidas sobre o $\overline{\mathrm{Off}} \underline{\underline{l n} \text {, }}$, que não foram poucas.

Aos professores Otaviano Helene e Vito Vanin pelas discussões sobre estatística, análise de dados e instrumentação.

Ao Cacá, Edu e Renato da eletrônica, pelas incontáveis vezes que eu os perturbei para conseguir alguma ferramenta para desmontar algum micro que tinha quebrado.

Ao pessoal do CCIFUSP pela conexão gigabit e em especial ao Leonel pela atenção.

Ao amigo Gabriel de Barros pela paciência em ouvir minhas ideias de análises nada ortodoxas e fazer de conta que o que eu dizia tinha algum sentido.

À Juliana Peçanha, que sempre me ajudou com a burrocracia e depois de muito ouvir minhas reclamações acabou virando minha amiga.

Aos meus amigos Jairo e Priscila pelas inúmeras discussões sobre física, estatística e programação e, principalmente, por me mostrarem a realidade 
viii

mesmo contra minha vontade.

Ao meu tio Rogério que virou meu chefe no fim da tese que compreendeu a importância do doutorado para mim e sempre me liberou quando eu precisei.

Ao meu tio Carlinhos, nós dois sabemos porque.

À Flávia com quem eu aprendi o valor do tempo e a priorizar o que é realmente importante.

Ao meu pai pelo exemplo de responsabilidade e determinação. À minha mãe pela minha primeira aula de física há quinze anos, quando um doutorado em física era inimaginável. A ambos pelo apoio incondicional às minhas decisões.

Aos meus irmãos, minha família e meus amigos que nos momentos difíceis me apoiaram muito mais do que eu poderia imaginar.

E como não poderia faltar, ao Murphy $^{1}$ por fazer minha vida e essa tese muito mais divertidas.

\footnotetext{
${ }^{1}$ Murphy é quem você culpa pelas coisas improváveis que acontecem na sua vida.
} 


\section{Sumário}

Sumário ix

Resumo xi

Abstract xiii

1 Introdução 1

1.1 Espectro de energia . . . . . . . . . . . . . . . 2

1.2 Fontes e processos de aceleração . . . . . . . . . . . . . 3

1.3 Propagação e o efeito GZK . . . . . . . . . . . . . . . 5

1.4 Chuveiros Atmosféricos Extensos . . . . . . . . . . . . 10

1.5 Detecção . . . . . . . . . . . . . . . . . . . . . . 11

1.6 O Observatório Pierre Auger . . . . . . . . . . . . . . . . 13

1.7 Distribuição lateral . . . . . . . . . . . . . . . . . . . . . . 14

2 Reconstrução de eventos $\quad 19$

2.1 Offline . . . . . . . . . . . . . . . . . . . 20

2.2 Módulos utilizados na reconstrução . . . . . . . . . . . . . . 21

2.2.1 LDFFinder . . . . . . . . . . . . . . . . . . 22

2.2.2 SdRecTree . . . . . . . . . . . . . . . 32

3 Eventos reais 33

3.1 Cortes . . . . . . . . . . . . . . . . . . 33

3.2 Resíduos . . . . . . . . . . . . . . . . . . 35

3.3 Incerteza do sinal das estações . . . . . . . . . . . . . . . . . . . 38

3.4 Resíduos ao longo dos anos . . . . . . . . . . . . . . . . . . . . . . . . . . . . . . . 46

3.5 Parametrizações da LDF . . . . . . . . . . . . . . . . . . 46

4 Eventos simulados $\quad 49$

4.1 Simulação de EAS . . . . . . . . . . . . . . . . 50

4.1 .1 SIBYLL vs EPOS . . . . . . . . . . . . . 52

4.1 .2 Biblioteca de EAS . . . . . . . . . . . . 54

ix 
4.2 Simulação de eventos . . . . . . . . . . . . . . . . . 55

4.3 Reconstrução dos eventos simulados . . . . . . . . . . . . . 56

5 Análise $\quad 63$

5.1 Influência das estações silenciosas . . . . . . . . . . . . . . . 64

5.2 A função NKG com variáveis parametrizadas . . . . . . . . . . 67

5.3 Modelagem das diferenças de sinal . . . . . . . . . . . . . 74

5.3.1 Modelo baseado apenas no sinal . . . . . . . . . . 74

5.3.2 Modelo baseado na função NKG . . . . . . . . . . . . . 88

5.4 Perfil dos resíduos . . . . . . . . . . . . . . . . . . . . . 100

5.4.1 Perfil em função da distância ao centro do chuveiro . . 101

5.4 .2 Perfil em função do ângulo zenital . . . . . . . . . . . . 103

5.4.3 Perfil em função da energia da partícula primária . . . 105

5.5 Viés no sinal médio próximo ao trigger . . . . . . . . . . . . . 112

5.5.1 Alteração no $\overline{\mathrm{Offl}} \underline{\mathrm{lne}}$. . . . . . . . . . . . . . . . 115

5.5.2 Perfil dos resíduos em ajustes com sinal corrigido . . . 120

6 Conclusão 127

6.1 Flutuações da distribuição lateral . . . . . . . . . . . . . . . . 127

6.2 Composição e modelos de interação hadrônica . . . . . . . . . 128

A Funções de probabilidade e geratrizes 133

A.1 Função geratriz . . . . . . . . . . . . . . . . . . . . . . . . . . . . . . . . . . . . . . . . . . .

A.2 Poisson . . . . . . . . . . . . . . . . . . . . . . . . 134

A.3 Soma de um número aleatório de variáveis aleatórias . . . . . 135

A.4 Binomial onde N é Poisson . . . . . . . . . . . . . . . . . 135

A.5 Poissons compostas . . . . . . . . . . . . . . . 136

A.6 Variância do sinal de uma estação do SD . . . . . . . . . . . 137

B Gráficos complementares 141

B.1 Ajustes com a função NKG sem correção . . . . . . . . . . . . 143

B.2 Ajustes com a função NKG corrigida . . . . . . . . . . . . . . 151

C Cálculo do Q para ajuste 159

$\begin{array}{ll}\text { Lista de Tabelas } & 161\end{array}$

$\begin{array}{ll}\text { Lista de Figuras } & 163\end{array}$

$\begin{array}{ll}\text { Referências Bibliográficas } & 171\end{array}$ 


\section{Resumo}

No estudo dos raios cósmicos de ultra alta energia utilizando detectores de superfície a energia da partícula primária é estimada pela distribuição lateral (LDF - Lateral Distribution Function), que descreve a amplitude do sinal das estações em função da distância ao centro do chuveiro. Entretanto, com exceção da estimativa do centro do chuveiro, não se utiliza a LDF para obter mais nenhuma informação sobre o chuveiro, talvez porque ela não possua uma parametrização que a descreva completamente, especialmente para os chuveiros com energias mais altas.

As primeiras interações dos raios cósmicos com a atmosfera são determinantes para o desenvolvimento dos chuveiros atmosféricos extensos. Tais interações dependem, entre outras coisas, da composição química dos raios cósmicos. Diferenças nessas interações podem causar alterações nas flutuações da distribuição lateral. Através de simulações dos chuveiros com diferentes partículas primárias pode ser possível estimar a composição dos raios cósmicos de ultra alta energia, comparando as flutuações das distribuições laterais de eventos reais com as de eventos simulados.

Uma das grandezas relevantes para a flutuação da LDF é a incerteza do sinal das estações. O framework de análise do Observatório Pierre Auger aplica uma correção parametrizada empiricamente à incerteza do sinal das estações. Neste trabalho foi apresentada uma justificativa estatística para esta correção, que está relacionada à distribuição do sinal não ser uma Poisson, mas uma composição de processos com diferentes distribuições.

Para a realização deste trabalho foi gerada uma biblioteca de chuveiros produzidos por dois simuladores de chuveiros atmosféricos, AIRES e CORSIKA, sendo que o AIRES utilizou o SIBYLL como modelo de interação hadrônica enquanto o CORSIKA utilizou o EPOS. Foram produzidos chuveiros iniciados por prótons e núcleos de ferro com os dois simuladores, e suas distribuições angulares foram consideradas isotrópicas. A distribuição de energia desses eventos segue uma lei de potência e varia entre 1 e $200 \mathrm{EeV}$.

Utilizando a função de Nishimura, Kamata e Greisen (NKG) como parametrização para a LDF se observa resíduos sistematicamente positivos nas 
estações mais distantes do centro do chuveiro, que também têm o sinal mais próximo do trigger. Uma das hipóteses levantadas em outros trabalhos para esse comportamento é que ele estaria relacionado à influência das estações silenciosas, mas este trabalho mostra que o uso dessas estações tem pouca influência na flutuação da LDF. Na verdade esse efeito é causado porque as

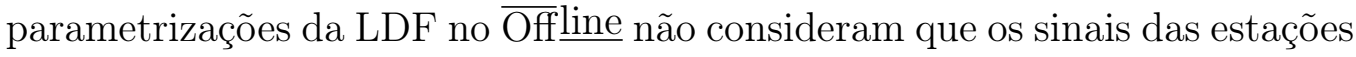
possuem um corte devido o trigger, isto é, que a função de densidade de probabilidade que descreve o sinal real não é a mesma que descreve o sinal que é observado. Neste trabalho é proposta uma correção para as parametrizações da LDF que é implementada no Offline. Como resultado desta correção é observada uma redução significativa dos resíduos que eram sistematicamente positivos e que, após a correção, passam a ser compatíveis com zero.

Neste trabalho foram realizadas três análises independentes para comparar os eventos reais com os simulados, das quais duas não dependem diretamente do ajuste da LDF e também não são sensíveis à energia. Elas permitem uma comparação entre os sinais supondo uma relação simples entre eles. No primeiro caso supõe-se que a diferença no sinal é devido à componente muônica do chuveiro e no segundo supõe-se que os dois conjuntos de eventos comparados são bem descritos por funções NKG mas com parâmetros $S_{1000}$ diferentes. A terceira análise utiliza os resíduos dos ajustes da LDF e permite observar a composição em função da energia da partícula primária. Essa última análise foi realizada utilizando a função NKG com e sem correção do efeito do trigger.

As diferentes análises utilizadas para estimar a composição dos raios cósmicos apresentaram resultados consistentes entre si, apesar das limitações encontradas em algumas delas. Todos esses indicadores de composição da partícula primária obtidos pelo detector de superfície são consistentes com os resultados obtidos pelas análises de $X_{\max }$ do detector de fluorescência, reforçando a tese de que a composição dos raios cósmicos é predominantemente de próton entre 1 e $10 \mathrm{EeV}$ e entre próton e ferro para energias acima de aproximadamente $10 \mathrm{EeV}$. 


\section{Abstract}

The energy of ultra high energy cosmic rays can be estimated from the lateral distribution function (LDF) of the shower as measured by surface detectors. The LDF describes the particle density as a function of the distance from the shower center. However, with the exception of the position of the shower center, no other information is extracted from it, may because it does not have a parametrization or an analytic function that describes it completely.

The first interactions of cosmic rays with the atmosphere are decisive for the development of the extensive air showers. Such interactions, among other things, depend on the chemical composition of comic rays. Differences in these interactions can cause changes in the fluctuation shape of lateral distribution. Through simulations of showers with different primary particles it may be possible to estimate the composition of ultra high energy cosmic rays comparing the fluctuation shape of the lateral distributions of real events with those from simulated ones.

One of the quantities relevant to the fluctuation of the LDF signal is the uncertainty of the stations. The analysis framework of the Pierre Auger Observatory applies a correction to the signal uncertainty of the signal. The parameterization of this correction is obtained empirically. In this work a statistical justification for this correction is proposed and is related to distribution of the signal which is not Poisson, but a composition of processes with different distributions.

For this work a library of showers using two simulators of air showers, AIRES and CORSIKA, was produced. The showers simulated with the AIRES used SIBYLL as a hadronic interaction model while COSIKA used EPOS. Showers initiated by protons and iron nuclei with the two simulators were produced, and their angular distribution was considered isotropic. The energy distribution of these events follows a power law and ranges from 1 to $200 \mathrm{EeV}$.

Using the Nishimura, Kamata and Greisen (NKG) function as a parameterization for the LDF, one obtains residues that are systematically positive at stations further from the center of the shower. These stations have a signal 
close to the trigger level. One of the hypothesis raised in other works for this behavior is that it is related to the influence of the silent stations, but this work shows that their use has little impact on the fluctuation shape of the LDF. In fact, this effect is caused because the parametrizations of LDF in the

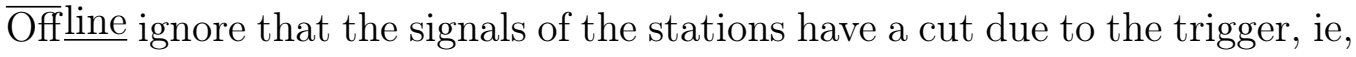
the probability density function that describes the real signal is not the same that describes the observed signal. This work proposes a correction to the parameterizations of the LDF and implements it in the $\overline{\mathrm{Off}} l i n e$. As a result of this correction, the residues, which were always positive, are significantly reduced and compatible with zero.

In this study three independent analysis were performed to compare real and simulated events, two of them not dependent directly of the LDF fit and also not sensitive to the primary particle energy. They allow a comparison between the signals assuming a simple relationship between them. The first case assumes that the difference in signal is due to the muonic component of the shower and the second assumes that the two compared sets of events are well described by NKG functions but with different $S_{1000}$. The third analysis uses the residues of the LDF fits and is able to observe the composition of as a function of primary particle energy. This last analysis was performed using the NKG function with and without correction of the trigger effect.

The different analysis used to estimate the composition of cosmic rays showed results consistent, despite the limitations found in some of them. The primary particle composition obtained from the surface detectors in this work is consistent with the results derived from the elongation rate measured by the fluorescence detectors, supporting the hypotesis that the composition of cosmic rays is predominantly proton becoming heavier for energies above $10 \mathrm{EeV}$. 


\section{Capítulo 1}

\section{Introdução}

As primeiras interações dos raios cósmicos com a atmosfera são determinantes para o desenvolvimento dos chuveiros atmosféricos extensos. Tais interações dependem, entre outras coisas, da composição química dos raios cómicos. Por exemplo, em um núcleo de ferro com 1 EeV cada núcleon possui 1/56 EeV enquanto um próton com mesma energia possui $1 \mathrm{EeV}$ por núcleon e certamente as seções de choque das possíveis interações nesses casos são diferentes. Essas diferenças podem causar alterações nas flutuações da distribuição lateral. Através de simulações dos chuveiros com diferentes partículas primárias pode ser possível estimar a composição dos raios cósmicos de ultra alta energia, comparando as flutuações das distribuições laterais de eventos reais com as de eventos simulados.

Essa tese se propõe a estudar metodologias para comparar eventos reais com simulados com o objetivo de estimar a composição das partículas iniciadoras dos chuveiros atmosféricos extensos medidos pelo detector de superfície do Observatório Pierre Auger, e para isso são estudadas simulações com dois modelos de interações hadrônicas (SIBYLL e EPOS) e as flutuações e erros sistemáticos nos ajustes da distribuição lateral.

Essa tese está dividida em seis capítulos. O Capítulo 1 apresenta uma introdução geral aos conceitos relevantes sobre raios cósmicos e o Observatório Pierre Auger. No Capítulo 2 é descrito o processo de reconstrução de eventos

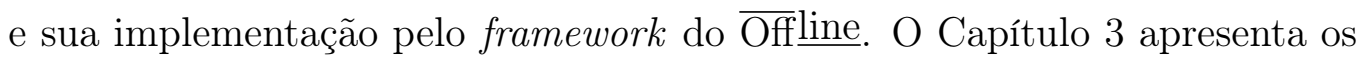


resultados da reconstrução de eventos reais medidos pelo Observatório Pierre Auger, com discussões sobre seus resíduos e sobre a incerteza do sinal das estações. As simulações são tema central do Capítulo 4. Nele é descrito o processo de simulação de um chuveiro atmosférico extenso, os diferentes modelos de interações hadrônicas e suas limitações e também são apresentados os resultados da reconstrução de eventos simulados, assim como seus resíduos. O Capítulo 5 é o mais extenso da tese e nele estão as principais análises que possuem três focos principais: estudar as opções do procedimento de reconstrução; comparar eventos reais e simulados; e identificar e corrigir erros sistemáticos na reconstrução. Por último, no Capítulo 6 são apresentadas as conclusões deste trabalho.

\subsection{Espectro de energia}

Victor Hess no ano de 1912 [1, 2], utilizando balões atmosféricos, observou que, com o aumento da altitude, havia um aumento da ionização do ar. Ele deduziu que a radiação que estava ionizando o ar era proveniente do espaço. Conta-se que em 1926, Robert Millikan chamou esta radiação de raios cósmicos[3]. Desde então as partículas, geralmente carregadas, que penetram na atmosfera terrestre são chamadas de raios cósmicos. A descoberta rendeu ao austríaco Victor Francis Hess o prêmio Nobel de Física em 1936.

No fim da década de 1930, Pierre Auger e seus colaboradores mediram sinais em coincidência de detectores espaçados por até $300 \mathrm{~m}$ de distância $[4,5]$. Eles concluíram que tais sinais eram causados por raios cósmicos com energias maiores que $10^{15} \mathrm{eV}$, provavelmente partículas carregadas, que produziam cascatas de partículas secundárias. Essas cascatas foram denominadas chuveiros atmosféricos extensos.

O espectro de raios cósmicos abrange partículas com energias entre $10^{8} \mathrm{eV}$ e mais de $10^{20} \mathrm{eV}$, como mostra a figura 1.1. Partículas com energias menores que $10^{10} \mathrm{eV}$ possuem uma significativa variação de fluxo devido à interação com o campo magnético dos ventos solares [6]. A intensidade do vento solar varia de acordo com o ciclo solar de 11 anos e é observado que o fluxo de raios cósmicos possui uma correlação negativa com a atividade solar. 
Apesar da gigantesca variação de energia (aproximadamente 12 ordens de grandeza) e de intensidade (mais de 30 ordens de grandeza), raios cósmicos originados por diferentes processos de aceleração têm seu espectro razoavelmente bem descrito por uma lei de potência $E^{-\gamma}$, com variações no expoente $\gamma$ entre 2,7 e 3 . No espectro apresentado na figura 1.1 observam-se duas mudanças de expoente $\gamma$. Próximo de $5 \cdot 10^{15} \mathrm{eV}$, o coeficiente muda de 2,7 para 3,0 e esse ponto é conhecido como o "joelho" (knee) do espectro. As razões que causam esse efeito ainda estão em debate. As teorias mais aceitas [7] são: mudanças nos processos de aceleração; possibilidade dos raios cósmicos passarem a possuir energia para escapar da galáxia; interações dos raios cósmicos com partícula de fundo na galáxia; e a produção de novas partículas exóticas nos chuveiros atmosféricos que não são detectadas. Em torno de $4 \cdot 10^{18} \mathrm{eV}$, ocorre uma nova alteração, conhecida como "tornozelo" (ankle) e o expoente volta a valer 2,7. A causa do "tornozelo" normalmente é atribuída à mudança de fontes galácticas para fontes extra-galácticas ou à propagação dos raios cósmicos extragalácticos através da radiação de fundo de microondas [8].

\subsection{Fontes e processos de aceleração}

Os processos capazes de produzir raios cósmicos com energias maiores que $10^{18} \mathrm{eV}$ ainda são objeto de estudo da física. Os diversos modelos de aceleração podem ser divididos em duas categorias: top-down e bottom-up. Nos modelos top-down, os raios cósmicos seriam produzidos em decaimentos de partículas extremamente massivas, que seriam relíquias do Big Bang com meia vida comparável com a idade do universo que, ao decaírem, produziriam fótons de alta energia, neutrinos, léptons leves e, com pouca probabilidade, nêutrons e prótons, os quais seriam raios cósmicos de altíssima energia. Entretanto esses modelos perderam credibilidade porque prevêem uma grande produção de fótons de alta energia $\left(>10^{19} \mathrm{eV}\right)$ [10], enquanto que os dados do Observatório Pierre Auger indicam que a fração de fótons nos raios cósmicos com energia maior que $10^{18} \mathrm{eV}$ tem um limite superior de $8,9 \%$ [11].

Diferentemente dos modelos top-down, onde os raios cósmicos já são pro- 


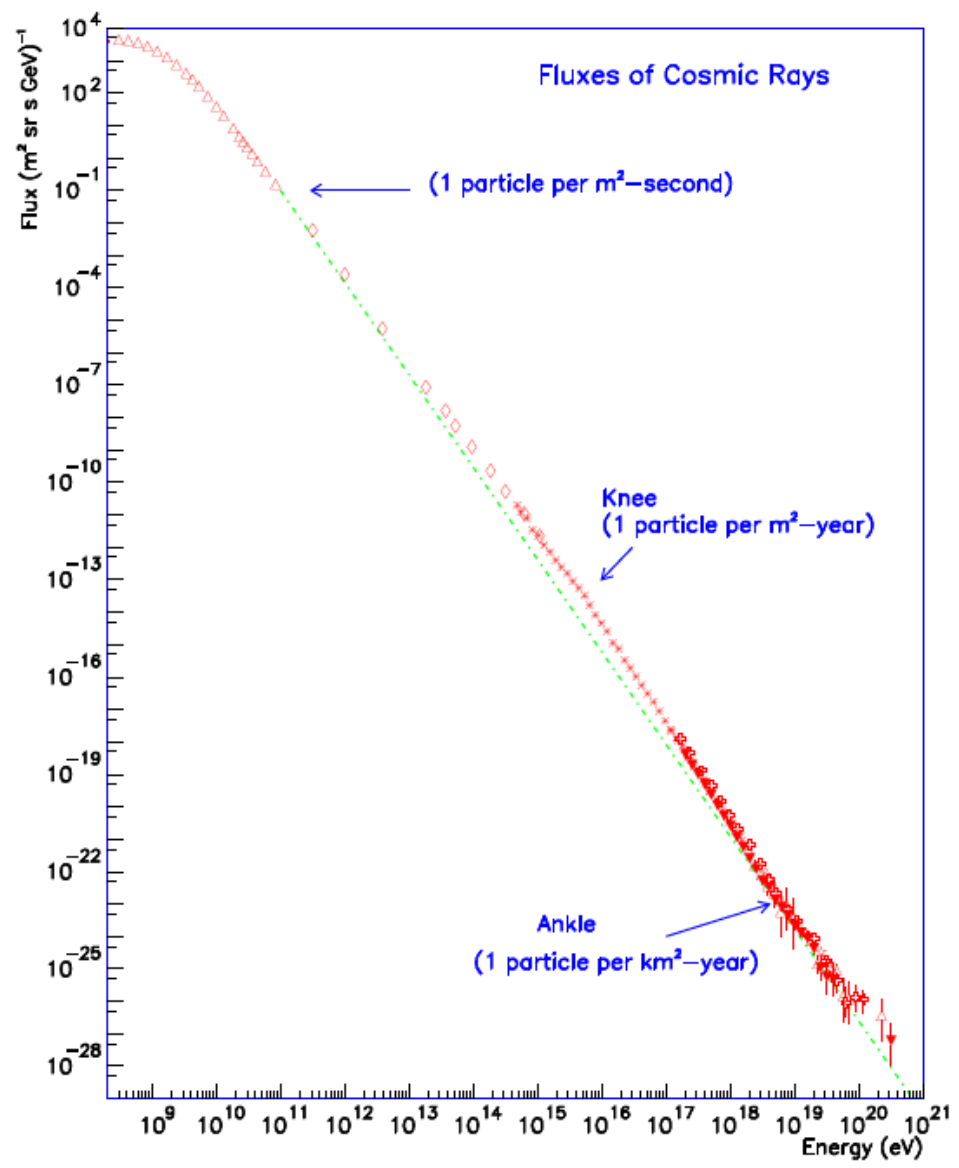

Figura 1.1: Compilação de medidas do fluxo de raios cósmicos em função da energia. A linha tracejada indica uma lei de potência do tipo $\mathrm{E}^{-3}$, figura obtida da referência [9].

duzidos com sua energia final, nos modelos bottom-up as partículas carregadas são aceleradas por campos eletromagnéticos. Um dos mecanismos de transferir energia para essas partículas é a aceleração de Fermi [12], que se baseia em múltiplas interações das partículas com campos magnéticos em movimento, de maneira análoga à que se utiliza para um satélite ganhar velocidade ao passar pela órbita de um planeta (estilingue gravitacional). Existem também os modelos bottom-up com os denominados mecanismos diretos. Nestes, a aceleração se dá com a interação da partícula com campos elétricos muito intensos gerados pela rotação de objetos compactos com 
grandes campos magnéticos, como estrelas de nêutrons e núcleos ativos de galáxias (AGN) [13].

Para facilitar a compreensão e procurar que tipo de objetos astrofísicos poderiam fornecer aos raios cósmicos energias tão impressionantes, Hillas [14] propôs uma aproximação para a energia máxima $\left(E_{\max }\right)$ que uma partícula com carga $Z$ pode conseguir de um objeto com dimensão característica $L$, campo magnético $B$ e velocidade de deslocamento ou eficiência de aceleração $\beta$ :

$$
E_{\text {max }} \approx \beta Z B L
$$

Na figura 1.2 estão plotados alguns dos objetos astrofísicos candidatos a fontes de raios cósmicos ultra energéticos. Os objetos abaixo das linhas não são capazes de fornecer $10^{20} \mathrm{eV}$ às partículas indicadas.

No diagrama não são consideradas as perdas de energia durante o processo de aceleração como, por exemplo, a interação com a matéria e campos e emissão de radiação síncrotron. É o que acontece com as estrelas de nêutrons: os raios cósmicos são acelerados por diferenças de potenciais geradas pelo movimento do campo magnético. Entretanto, a emissão de radiação síncrotron em sistemas compactos como esse é significativa.

Dentre os outros candidatos, os núcleos ativos de galáxias (AGN) merecem algum destaque, pois foi medida pela Colaboração Pierre Auger [16] uma correlação entre as direções de chegada de raios cósmicos com energia maior que $6 \cdot 10^{19} \mathrm{eV}$ e AGNs próximos, menos de $75 \mathrm{Mpc}$. Apesar dos dados indicarem apenas correlação de chegada dentro de uma janela angular, não se pode negar que os AGNs estão relacionados de alguma maneira com pelo menos parte das fontes de raios cósmicos ultra energéticos.

\subsection{Propagação e o efeito GZK}

Existem diversos processos de interação aos quais os raios cósmicos estão sujeitos em sua propagação. O processo mais simples é a deflexão causada por campos magnéticos. Se considerarmos um raio cósmico com energia $E_{18}$ 


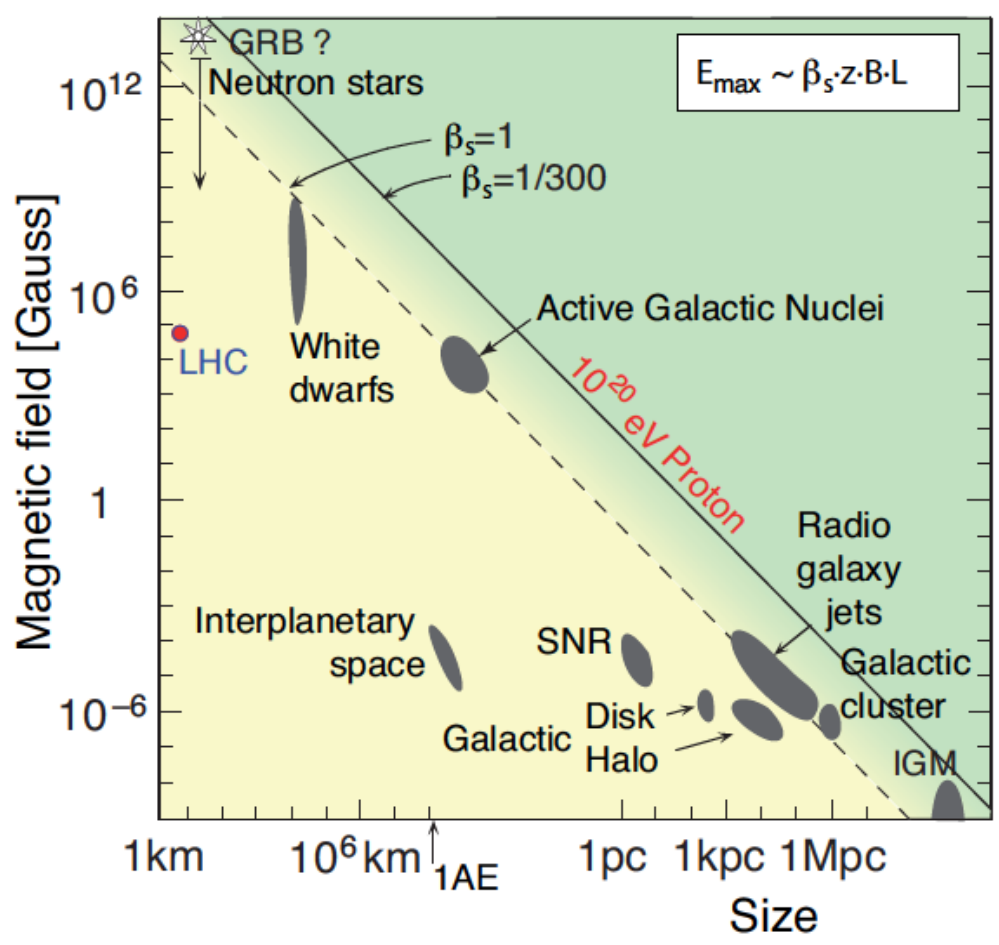

Figura 1.2: Diagrama de Hillas, com tamanho e intensidade do campo magnético de alguns objetos astrofísicos que seriam capazes de acelerar raios cósmicos de ultra alta energia. As retas mostram o limite inferior de tamanho/campo para aceleração de partículas carregadas com energia de $10^{20} \mathrm{eV}$. Obtido da referência [15].

(em unidades de $10^{18} \mathrm{eV}$ ) e carga $Z$ se propagando num campo magnético com intensidade $B_{\mu G}($ em $\mu \mathrm{G})$, o raio de Larmor dessa partícula em kiloparsecs (kpc) será:

$$
R_{k p c} \approx \frac{E_{18}}{Z B_{\mu G}}
$$

Um próton com $10^{18} \mathrm{eV}$ viajando no meio galáctico, cujo campo magnético médio é da ordem de $\mu \mathrm{G}$ [17], tem o raio de Larmor da ordem da espessura da Via Láctea, aproximadamente 0,6 kpc. Esta estimativa indica que, se todas fontes de raios cósmicos acima dessa energia estivessem na nossa galáxia, deveríamos observar uma correlação significativa entre a direção de chegada dos raios cósmicos e aglomerados existentes no plano galáctico. En- 
tretanto, os dados existentes até o momento não indicam isso.

No caso dos campos magnéticos extragalácticos estima-se que sua intensidade seja da ordem de nG [17], entretanto, a sua estrutura é desconhecida. Dependendo do tamanho da região onde o campo possui uma direção coerente e da intensidade do mesmo, os raios cósmicos podem entrar em regimes difusivos ou sofrer apenas pequenos desvios de suas trajetórias. Então, se os raios cósmicos são oriundos de fontes extragalácticas, os estudos de anisotropia podem ajudar a descrever a estrutura e estimar a intensidade dos campos magnéticos extragalácticos.

Pouco tempo após a descoberta da radiação cósmica de fundo Greisen [18], paralelamente a Zatsepin e Kuzmin [19], em 1966, publicou estudos sobre a influência dessa radiação no espectro dos raios cósmicos. Os artigos mostraram que, devido à radiação cósmica de fundo, o universo se tornaria opaco para partículas com energias maiores que $10^{19} \mathrm{eV}$.

O espectro da radiação cósmica de fundo é bem descrito pelo de um corpo negro com temperatura aproximada de $2,7 \mathrm{~K}$. Os fótons na moda deste espectro possuem energia da ordem de meV e a distribuição angular é isotrópica. Um fóton com $\mathrm{meV}$ proveniente da radiação cósmica de fundo sofre um boost no referencial de repouso do raio cósmico. Sendo assim, o processo $x+\gamma \rightarrow \pi+x$, onde $x$ pode ser um próton ou um nêutron, passa a ser possível quando a energia dos fótons, no referencial de repouso do núcleon, é maior que $0,15 \mathrm{GeV}$. Na figura 1.3 vemos que a seção de choque possui um pico próximo de $0,2 \mathrm{GeV}$. Essa ressonância está associada à produção de $\Delta^{+}$ que decai em um $\pi^{0}$ mais um próton ou $\pi^{+}$mais um nêutron. Ao mudar para o referencial onde os fótons da radiação cósmica de fundo têm energia da ordem de meV, o núcleon precisa ter uma energia da ordem de $6,8 \cdot 10^{19} \mathrm{eV}$ para que a fotoprodução de píons seja possível.

A produção de píons degrada a energia do raio cósmico e, no caso de prótons, ocorre uma perda média de $20 \%$ de energia a cada interação. Aharonian e Cronin[21] fizeram uma simulação da propagação de prótons interagindo com a radiação cósmica de fundo e apresentaram o gráfico da figura 1.4. Observa-se que, após uma distância percorrida maior que $100 \mathrm{Mpc}$, prótons com energias iniciais de $10^{20}, 10^{21}$ ou $10^{22} \mathrm{eV}$ perdem energia e tendem a ficar 


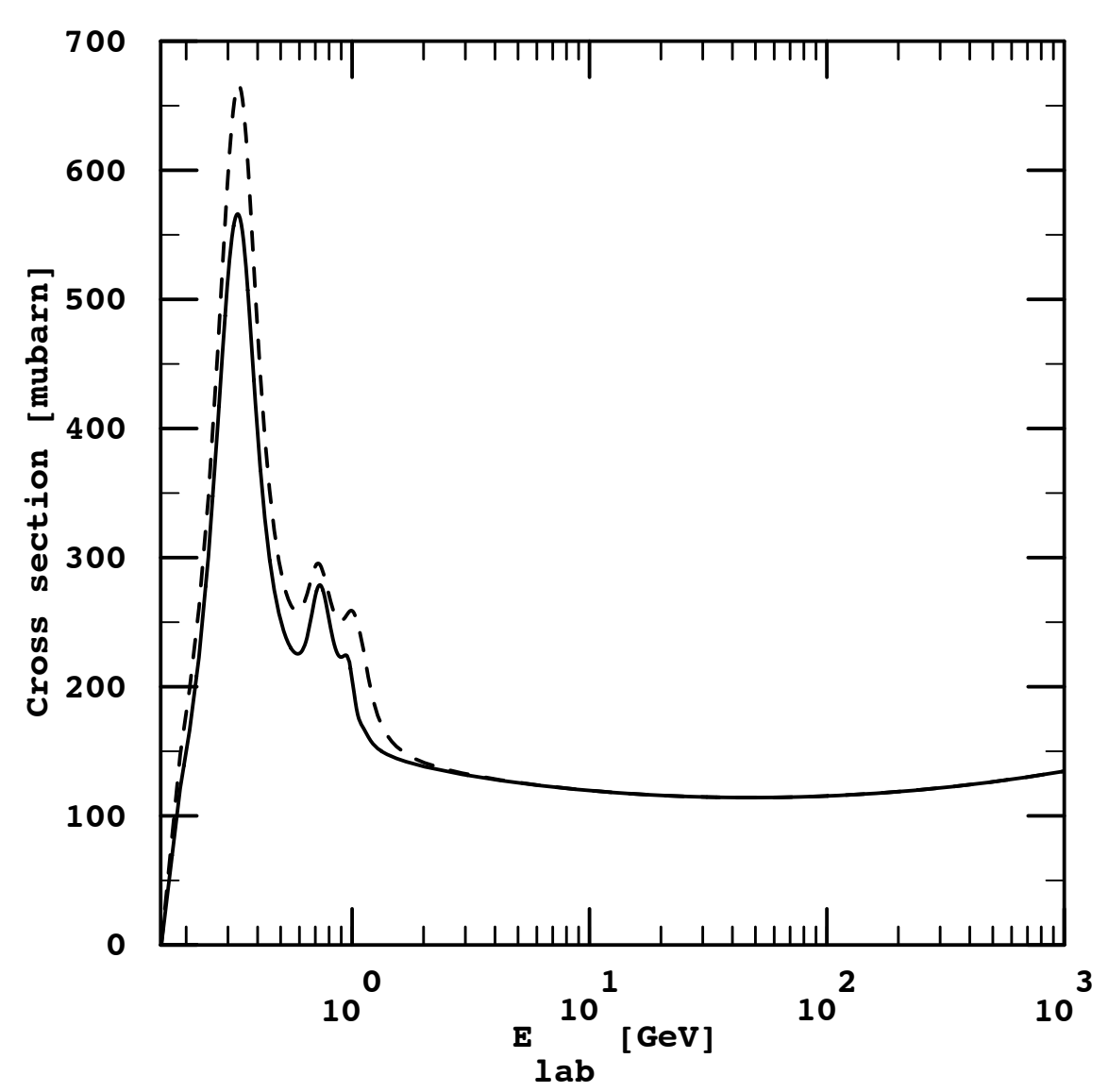

Figura 1.3: Seção de choque total para fotoprodução de píons para prótons (linha contínua) e para nêutrons (linha tracejada), em função da energia do fóton incidente (referencial do núcleon). Figura obtida da referência [20].

com a mesma energia, menor que $10^{20} \mathrm{eV}$. Então, se as fontes de raios cósmicos ultra energéticos estão distantes a mais de $100 \mathrm{Mpc}$, devemos observar uma queda abrupta no espectro de raios cósmicos em torno de $10^{20} \mathrm{eV}$. Esse efeito é conhecido como corte GZK (Greisen-Zatsepin-Kuzmin).

Medidas do observatório HiRes sugerem que o corte GZK exista no espectro de raios cósmicos [22], entretanto, dados do experimento AGASA indicam o contrário [23].Porém esses dados devem ser olhados com cautela, pois um estudo de De Marco, Blasi e Olinto [24] mostra que os experimentos não possuem estatística suficiente para comprovar suas indicações. Em 2008 a 


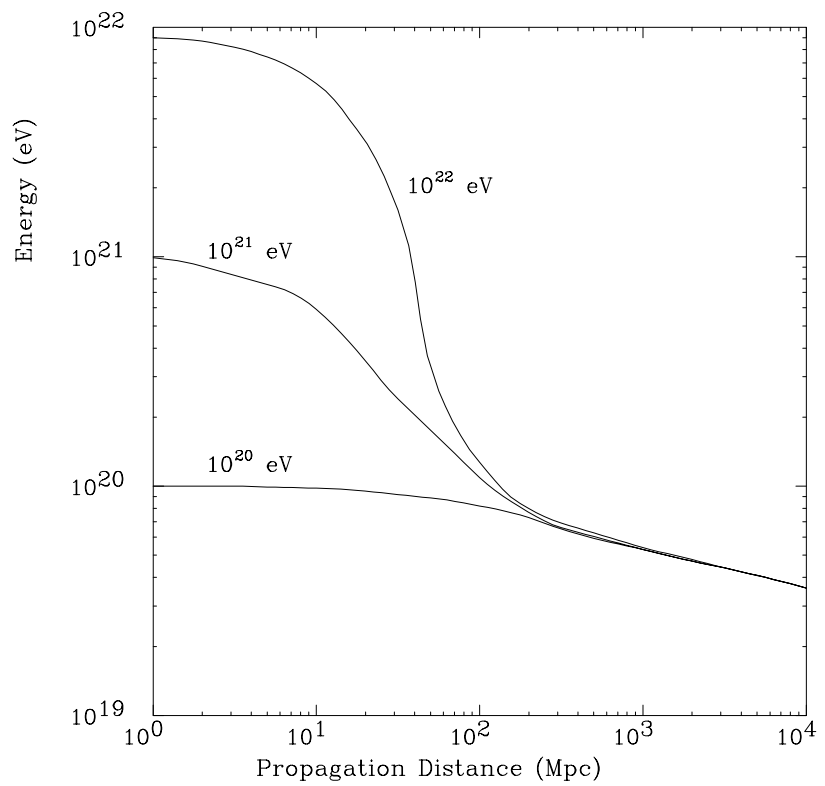

Figura 1.4: Simulação da perda de energia de prótons em função da distância percorrida [21]. Figura obtida da referência [9].

Colaboração Pierre Auger publicou dados compatíveis com a existência do corte GZK [25], o que fortalece a hipótese da existência do corte GZK. Na figura 1.5 é apresentado um espectro com os dados da Colaboração Pierre Auger e do HiRes. 


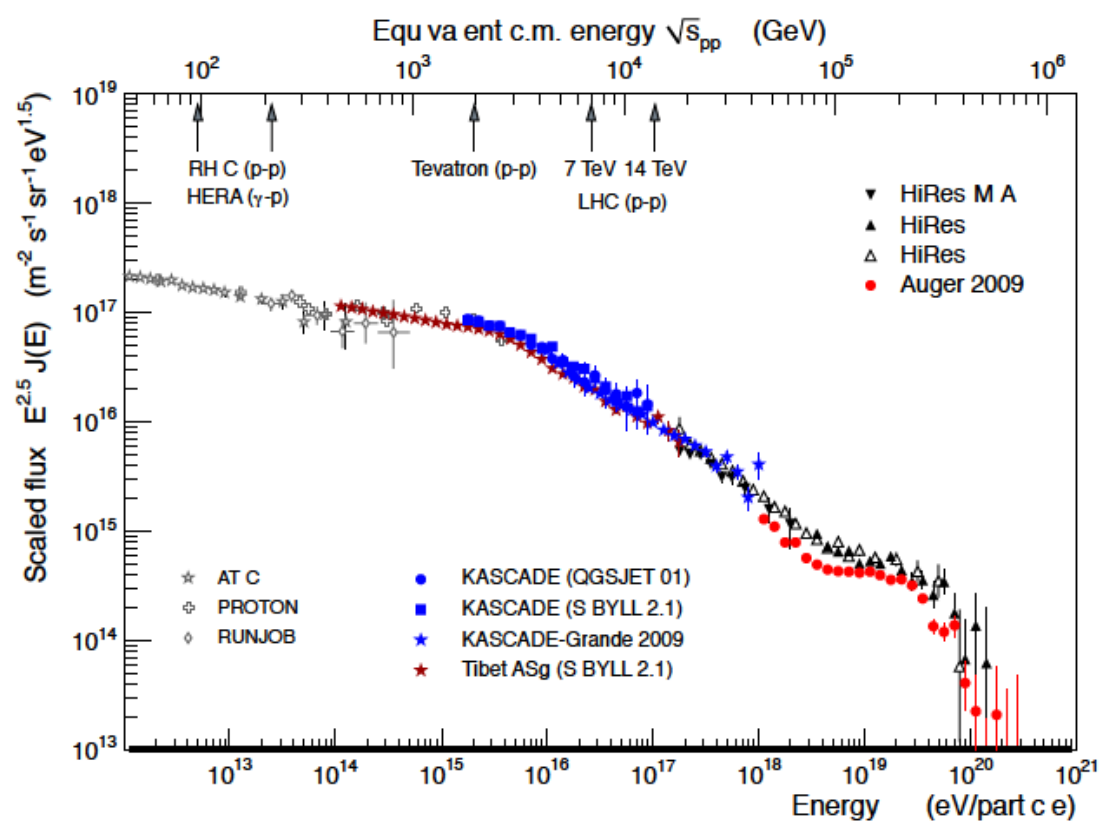

Figura 1.5: Fluxo dos raios cósmicos ultra energéticos compatíveis com o corte GZK. Gráfico obtido de [8].

\subsection{Chuveiros Atmosféricos Extensos}

Quando partículas altamente energéticas atingem nossa atmosfera, elas interagem com os átomos do ar criando partículas secundárias também muito energéticas. Estas interagem com a atmosfera criando outras partículas, e esse ciclo se repete formando uma cascata de partículas até o momento em que a energia disponível não é suficiente para alimentar o produção. Então o número de partículas começa a diminuir devido a decaimentos e a absorção pela atmosfera, como ilustrado na figura 1.6. Esse fenômeno é chamado de chuveiro atmosférico. Geometricamente, um chuveiro atmosférico é bem descrito por um disco fino de partículas que se move na velocidade da luz. Um raio cósmico com energia de $5 \cdot 10^{17} \mathrm{eV}$ produz bilhões de partículas secundárias, distribuídas por dezenas de $\mathrm{km}^{2}$.

Quando o raio cósmico é composto por um ou mais hádrons, a primeira interação com a atmosfera é do tipo hadrônica, gerando hádrons e outras 


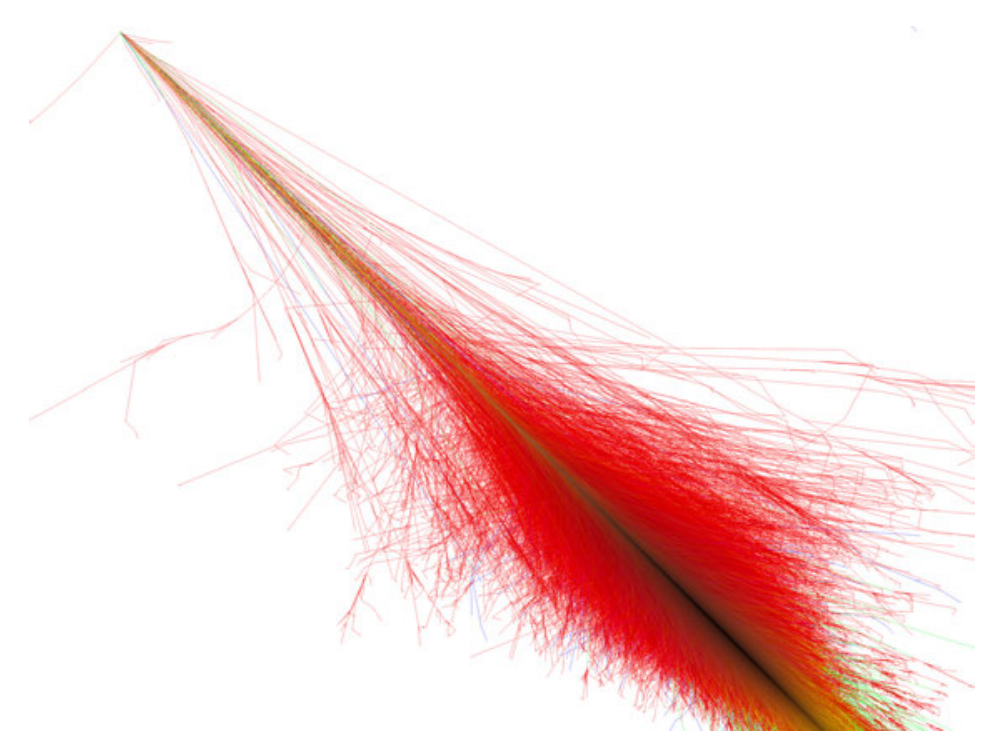

Figura 1.6: Simulação de um chuveiro atmosférico causado por um próton de $10^{15} \mathrm{eV}$. Os traços vermelhos representam elétrons, pósitrons e fótons; os traços verdes representam múons; e os azuis, hádrons. Obtida da referência $[26]$.

partículas, como mostra o esquema da figura 1.7. Nas interações hadrônicas, cerca de $30 \%$ da energia é transferida para a componente eletromagnética do chuveiro, através do decaimento dos $\pi^{0}$. Cerca de $90 \%$ da energia do chuveiro é dissipada na ionização gerada pela componente eletromagnética.

As fontes de flutuações mais importantes no desenvolvimento de chuveiros atmosféricos são a profundidade na atmosfera e o tipo das primeiras interações, isso porque elas têm um grande peso no comportamento médio do chuveiro. Já as interações posteriores não são tão impactantes nas flutuações do chuveiro, pois como elas são ordens de grandeza mais comuns, a flutuação de cada uma delas é "diluída" na média do conjunto.

\subsection{Detecção}

Os raios cósmicos podem ser medidos diretamente, com detectores instalados na superfície terrestre, quando sua energia é menor que $10^{13} \mathrm{eV}$. Raios cósmicos com energias maiores só podem ser observados indiretamente, pois 


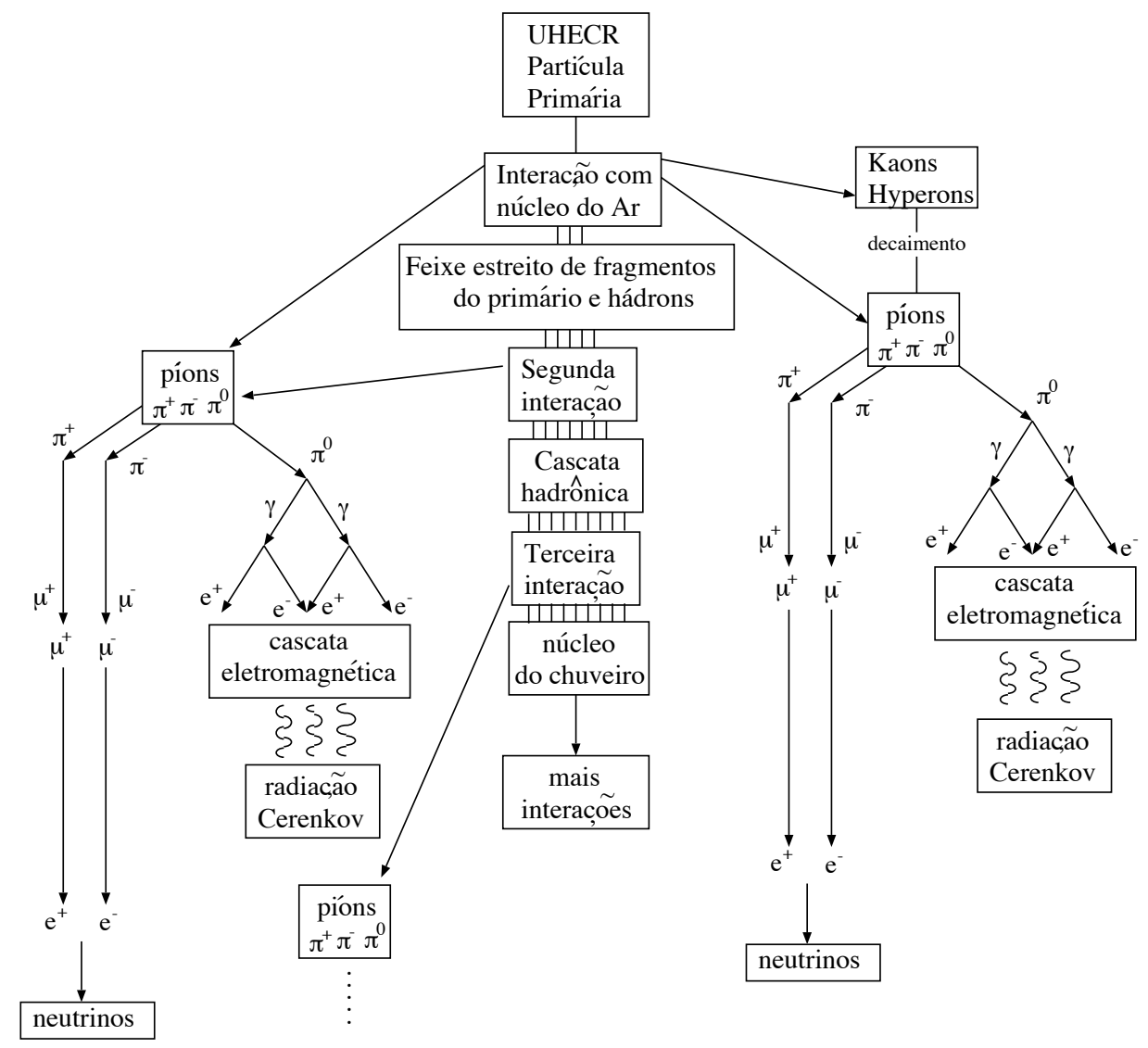

Figura 1.7: Esquema do desenvolvimento de um chuveiro atmosférico gerado por um raio cósmico de altíssima energia, figura obtida da referência [27].

eles interagem com a atmosfera produzindo um chuveiro extenso. Existem duas técnicas mais usadas para observação dos chuveiros extensos: uma delas utiliza detectores de superfície (SD) para amostrar a densidade de partículas secundárias na superfície terrestre e outra que utiliza telescópios de fluorescência (FD) que medem a luz fluorescente emitida pelas moléculas de nitrogênio ionizadas durante o desenvolvimento do chuveiro.

O experimento HiRes (High Resolution Fly's Eye [28]) localizado em Dugway, Estados Unidos, utiliza FD. A produção de luz fluorescente é muito pequena e limita a observação de chuveiros gerados por raios cósmicos com energias maiores que $10^{17} \mathrm{eV}$ e mesmo assim a observação é limitada a noites de céu limpo e sem lua. Esta restrição limita o fator de utilização (duty cy- 
cle) do experimento entre $10 \%$ e $15 \%$ do tempo. Uma grande vantagem dessa técnica é uma melhor estimativa da energia do chuveiro. Essa é calculada através da luz integrada medida pelo detector e, apesar da intensidade da luz fluorescente produzida pelo chuveiro e da atenuação da mesma durante a propagação até o detector dependerem das condições atmosféricas, esses processos são razoavelmente bem conhecidos.

Já o experimento AGASA (Akeno Giant Air Shower Array [29]), na vila de Akeno, Japão, utiliza a técnica de SD. Diferentemente do FD, os detectores de superfície possuem um fator de utilização de 100\%, entretanto, a estimativa de energia do chuveiro possui uma maior incerteza. Nessa técnica a energia é estimada utilizando um parâmetro da distribuição lateral, como explicado na subseção 1.7. Mas a calibração deste parâmetro depende de simulações das interações e essas simulações utilizam dados obtidos de aceleradores extrapolados para energias várias ordens de grandeza acima. Essas extrapolações podem causar erros sistemáticos e/ou incertezas grandes. Devido a essa grande dependência de modelos nas extrapolações, as estimativas de energia do SD possuem incertezas maiores que as do FD.

$\mathrm{O}$ fato de que tais eventos com energias maiores que $10^{20} \mathrm{eV}$ ocorrem em uma taxa menor que 1 por $\mathrm{km}^{2}$ por século dificulta a observação experimental do fluxo e a identificação das fontes dessas partículas, implicando na construção de observatórios gigantes como o Observatório Pierre Auger com $3000 \mathrm{~km}^{2}$, cerca de 2 vezes a área da cidade de São Paulo.

\subsection{O Observatório Pierre Auger}

A Colaboração Pierre Auger conta com mais de 350 pesquisadores em 17 países. O Observatório Sul se encontra próximo à cidade de Malargüe, na província de Mendoza, Argentina. Diferentemente dos outros experimentos, o Observatório Pierre Auger utiliza as técnicas de FD e SD de maneira conjunta. Assim, têm-se as vantagens das duas técnicas, fator de utilização de 100\% para do SD e uma boa calibração para as estimativas de energia vindas do FD. Além disso, é possível fazer uma calibração cruzada entre as duas técnicas. No Observatório Sul o SD é formado por 1600 estações distribuídas 
por mais de $3000 \mathrm{~km}^{2}$ em uma grade triangular de 1,5 km. Esse array do SD é observado por 24 telescópios de fluorescência divididos em 4 estações localizadas na periferia, como mostra a figura 1.8. Cada uma das estações do SD possui um tanque de $10 \mathrm{~m}^{2}$ e $12000 \mathrm{l}$ de água purificada onde 3 fotomultiplicadoras observam a radiação Cherenkov produzida quando as partículas do chuveiro atmosférico atravessam o tanque. Essas características fazem com que o Observatório Pierre Auger seja o maior observatório de raios cósmicos de altíssimas energias do mundo.

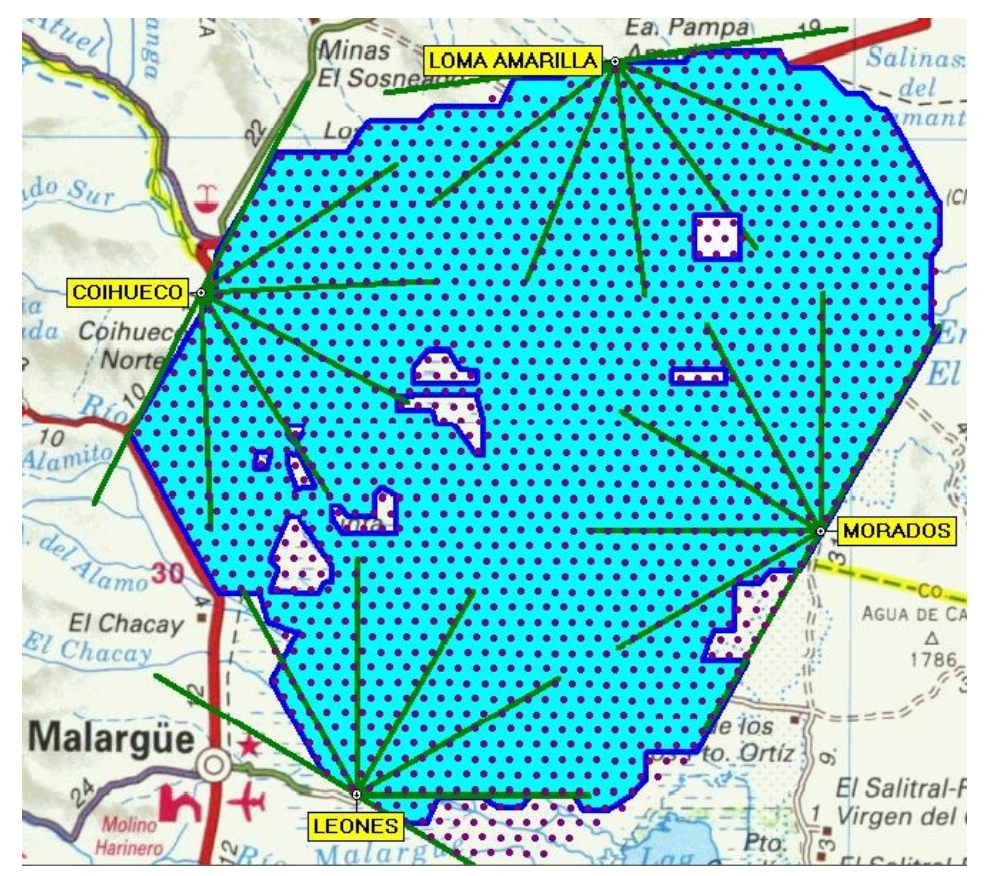

Figura 1.8: Observatório Pierre Auger do hemisfério Sul. Os pontos indicam os 1600 detectores de superfície, a área em azul indica a região coberta pelos estações SD em operação no 11 de junho de 2008. As regiões de observação dos telescópios de fluorescência são indicadas pelas linha verdes.

\subsection{Distribuição lateral}

Um das da informações que se obtém do SD é a densidade de partículas na superfície. Com esta informação é possível levantar a função de distribuição 
lateral (LDF) do chuveiro. A distribuição lateral é a densidade de partículas (ou sinal das estações) em função da distância ao centro do chuveiro, como ilustrado na figura 1.9. Ainda não foi encontrada uma parametrização para a LDF que descreva em detalhe os dados experimentais, mas existem algumas aproximações, como a função NKG e leis de potência que são discutidas na seção 2.2.1. A energia da partícula primária é proporcional à integral da LDF. Entretanto, a integral da LDF de um chuveiro é sujeita a grandes flutuações, principalmente porque a densidade de partículas próximas ao centro do chuveiro flutua muito. Em 1970, A. M. Hillas propôs utilizar o sinal que um tanque localizado a uma determinada distância do centro do chuveiro teria como parâmetro para estimar a energia da partícula primária. Este enfoque possui uma grande vantagem: existe uma distância ótima, na qual a flutuação da LDF é mínima, pois as flutuações individuais de cada tanque são "diluídas" quando é feito o ajuste da LDF. Essa distância ideal ao centro do chuveiro pode ser estimada através de simulações de Monte Carlo e, no caso do Observatório Pierre Auger, é 1000 m. O parâmetro que se obtém do ajuste da LDF é chamado S(1000). 


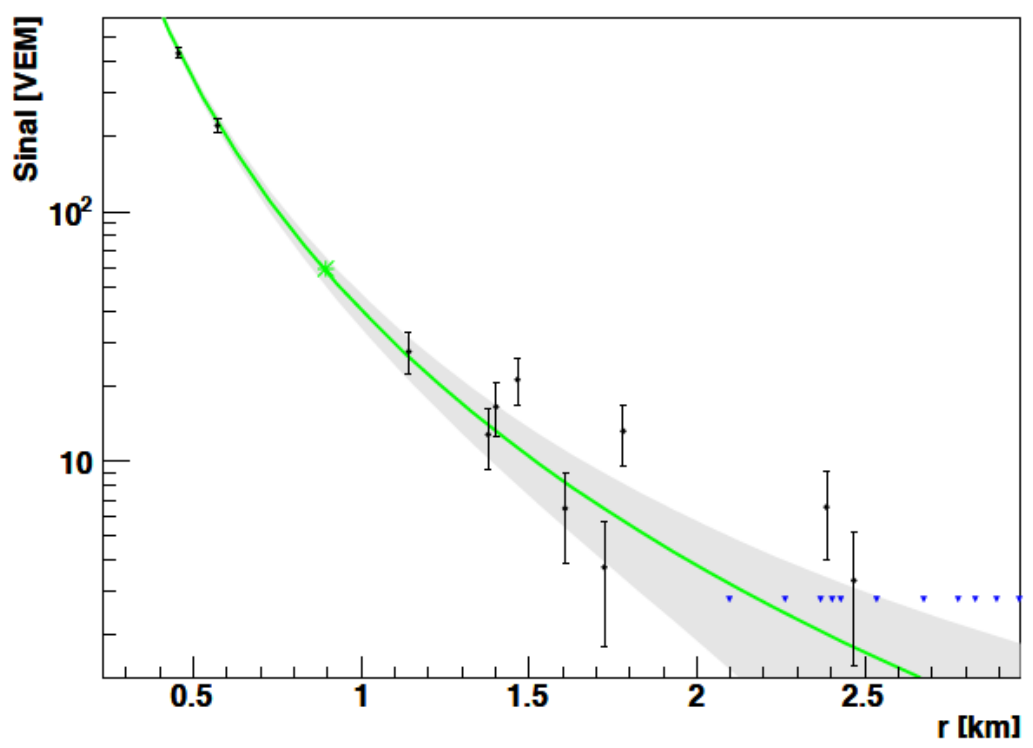

Figura 1.9: Ajuste da função de distribuição lateral de um evento do Observatório Pierre Auger. A energia estimada desse evento é de $3,76(19) \cdot 10^{19} \mathrm{eV}$.

O valor de $\mathrm{S}(1000)$ depende da energia do chuveiro e da espessura efetiva da atmosfera atravessada pelo chuveiro, a espessura variando com a inclinação do chuveiro. Então, para poder fazer uma calibração de energia, é feita uma correção em $\mathrm{S}(1000)$ para que ele equivalha ao $\mathrm{S}(1000)$ de um chuveiro com uma inclinação de um ângulo de referência. Esse ângulo de referência é $38^{\circ 1}$, e o parâmetro corrigido se chama $S_{38}$. Na figura 1.10 observamos a correlação do parâmetro $S_{38}$ e da energia estimada pelo FD em 387 eventos vistos por ambos os detectores (eventos híbridos).

\footnotetext{
${ }^{1}$ Ângulo médio dos chuveiros observados em um céu isotrópico entre $0^{\circ}$ e $60^{\circ}$.
} 


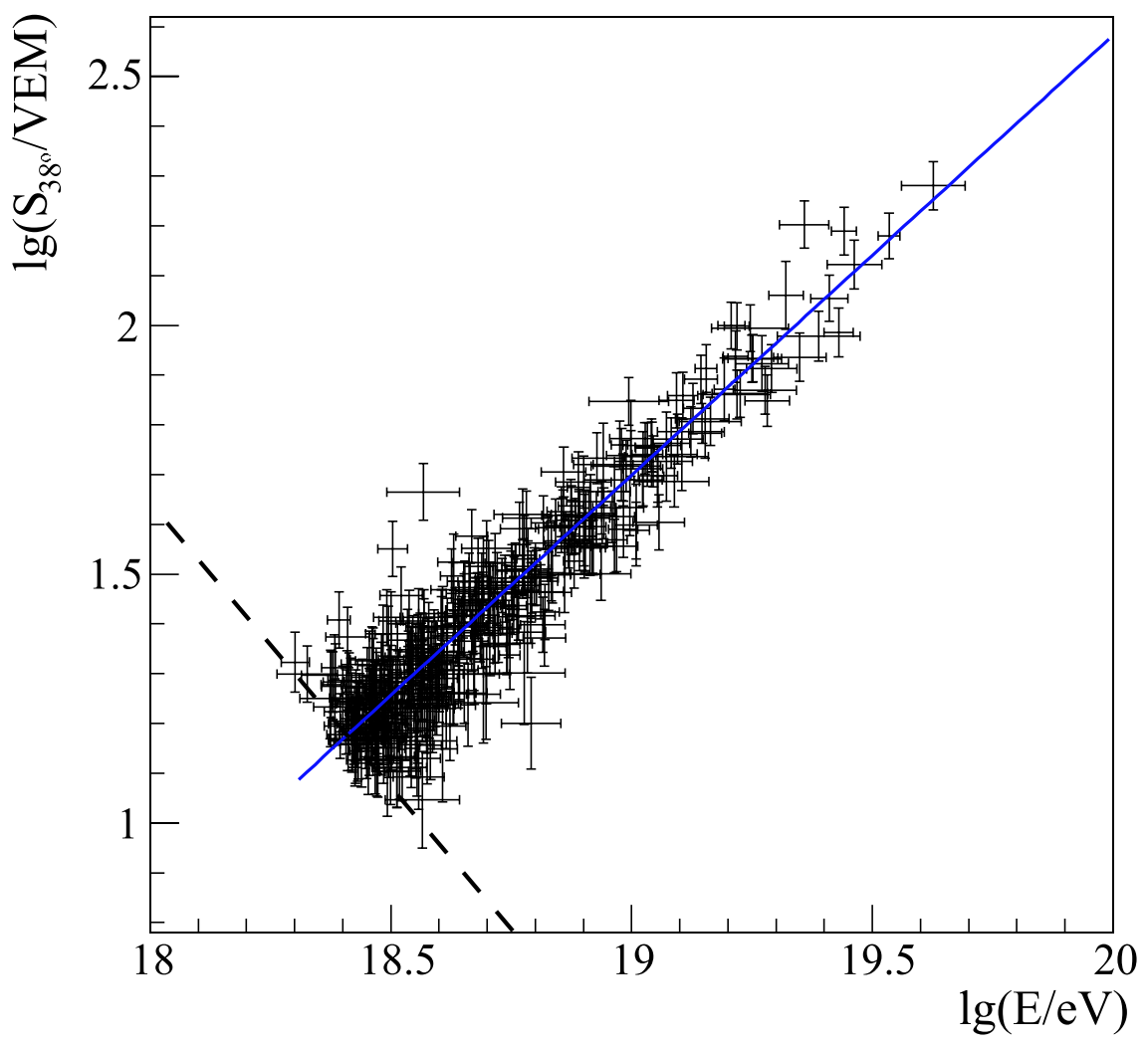

Figura 1.10: Correlação entre a energia estimada pelo FD $\left(E_{F D}\right)$ e o parâmetro $S_{38}$ do SD em 387 eventos híbridos. A linha cheia mostra o ajuste, a linha tracejada, o corte para inclusão no ajuste. Figura obtida da referência [30].

Considerando a LDF uma figura central no estudo de raios cósmicos em experimentos que utilizam SD e a falta de uma função que descreva a LDF como um todo, é importante que sejam realizados novos estudos que ampliem o conhecimento atual da LDF. Dentre a gama de possíveis tópicos, a influência que as primeiras interações podem ter na LDF, particularmente nas suas flutuações, é de grande interesse. As primeiras interações dos chuveiros atmosféricos ocorrem numa escala de energia algumas ordens de grandeza acima do que as colisões realizadas nos aceleradores de partículas atuais. A física atual especula, mas não sabe ainda quais os processos presentes nessa escala de energia. O estudo da flutuação da distribuição lateral das estações mais distantes do centro, presentes nos chuveiros com maiores energias, pode 
fornecer indícios dos mecanismos presentes nas primeiras interações.

Para elaboração desta seção, além das referências citadas, foram consultadas as referências [31] e [32], dentre outros trabalhos da colaboração ainda não publicados. 


\section{Capítulo 2}

\section{Reconstrução de eventos}

O ajuste da LDF aos dados de um evento é realizado num processo conhecido como reconstrução do evento. É nesse processo que os dados obtidos pelas estações são reduzidos aos parâmetros de interesse, como a estimativa de energia e a direção de chegada da partícula primária. Portanto, para o estudo das flutuações da LDF, esse processo é extremamente relevante e deve ser bem conhecido para que possíveis distorções induzidas na reconstrução sejam identificadas.

Dentro da colaboração existem dois principais softwares para análise dos dados, o CDAS [33] e o framework $\overline{\mathrm{Off}} \underline{\text { line }}$ [34]. O software do CDAS (Central Data Acquisition System) foi o primeiro a realizar reconstrução de eventos. Seu objetivo inicial era fornecer estimativas para calibração dos sistemas de trigger e depois acabou evoluindo para um sistema de reconstrução mais completo. Já o Offline foi idealizado como uma sistema completo para análise e simulação de eventos do SD, FD e híbridos e representa a ferramenta oficial da colaboração para a obtenção de resultados. Por ser um software mais complexo, demorou mais tempo que o CDAS para se tornar funcional. As reconstruções obtidas pelos dois sistemas são compatíveis dentro de suas incertezas.

Existem atualmente duas metodologias aceitas como padrão na reconstrução de eventos SD. O CDAS Herald [35], que faz a reconstrução baseado no software do CDAS, e o Auger Observer [36], que utiliza o Offline. Neste 
trabalho está sendo utilizado o modelo de reconstrução do Auger Observer

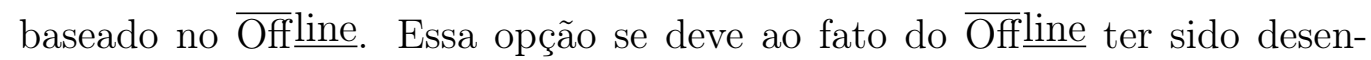
volvido para ser a infraestrutura de análise de dados da colaboração e por permitir uma maior flexibilidade na alteração do processo de reconstrução dos dados.

\subsection{Offline}

O Offline foi projetado para suportar simulações e reconstruções de eventos SD, FD e híbridos, além de simular as técnicas de calibração e outras tarefas auxiliares do processamento de dados. Como o Observatório Pierre Auger tem um ciclo de operação previsto de 20 anos, o software foi desenhado de maneira extensível para poder acomodar modificações na instrumentação do observatório. Além disso, o seu projeto modular permite aos usuários substituir, de maneira simplificada, os algoritmos padrão por outros adaptados

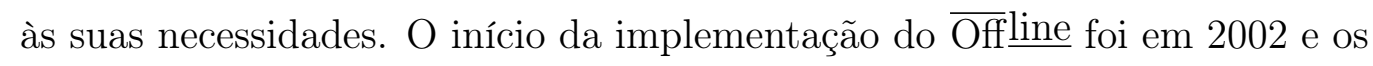
primeiros resultados obtidos com ele foram apresentados em 2005 [37].

A estrutura do $\overline{\mathrm{Off}}\lfloor$ line é dividida em três partes principais: um conjunto de módulos de processamentos, que podem ser ordenados e configurados por arquivos XML, um modelo de dados do evento que é utilizado para transmitir dados de um módulo para outro, modelo no qual são armazenados os dados de reconstrução e simulação, e uma descrição do detector, onde estão disponíveis informações sobre configuração e performance do observatório além das condições atmosféricas em função do tempo. Dentre essas partes, os módulos de processamento são mais relevantes dentro deste trabalho, pois são eles que realizam o processo de reconstrução. As outras partes servem de infraestrutura para o funcionamento consistente e coordenado dos módulos. Na próxima seção estão descritos, de forma resumida, os módulos utilizados na reconstrução, seguidos de uma descrição mais detalhada dos módulos mais relevantes ao trabalho. Os módulos e suas respectivas descrições são relativas a versão 2.6.2 do $\overline{\mathrm{Off}} \underline{\text { line, }}$, a qual foi utilizada neste trabalho. 


\subsection{Módulos utilizados na reconstrução}

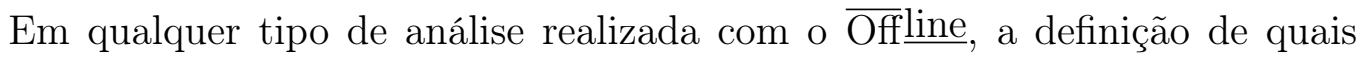
módulos são utilizados e qual a ordem de execução é feita num arquivo de configuração chamado ModuleSequence.xml. A seguir, se encontra a sequência de módulos que foi utilizada nas reconstruções de eventos reais do trabalho e uma breve descrição de cada um deles.

- EventFileReaderOG - Lê os eventos, reais ou simulados, de diferentes formatos e os armazena no modelo de dados do evento;

- EventCheckerOG - Verifica se existem erros nas definições do evento;

- SdCalibratorOG - Realiza a calibração e análise de sinal do evento SD;

- SdEventSelectorOG - Além de verificações de consistência, permite realizar cortes nos eventos. Por exemplo, excluir eventos em períodos ruins ou selecionar eventos que passaram por um determinado tipo de trigger;

- SdSignalRecoveryKLT - Recupera sinais saturados dos tanques. As saturações ocorrem normalmente pelo estouro de canais dos $\mathrm{FADCs}^{1}$ ou por não linearidade das $\mathrm{PMTs}^{2}$. A evidência mais comum de saturação são sinais menores que o esperado;

- SdPlaneFitOG - Estima os parâmetros do plano que descreve a frente do chuveiro;

- LDFFinderOG - Estima a LDF, a curvatura da frente do chuveiro e a energia da partícula primária. Será discutido em mais detalhes adiante;

- Risetime1000LLL - Calcula o tempo de subida do sinal do evento. Esse valor tipicamente é interpolado dos tempos de subida de cada estação no plano do chuveiro. O tempo de subida pode ser utilizado na identificação da partícula que atravessa o tanque, em particular, múons e elétrons;

\footnotetext{
${ }^{1}$ FADC - Fast Analog-to-Digital Converter, conversor rápido de analógico para digital. ${ }^{2} \mathrm{PMT}$ - PhotoMultiplier tube, tubo fotomultiplicador.
} 
- SdEventPosteriorSelectorOG - Realiza corte de eventos com objetivo de aumentar a estatística de eventos mas sem deteriorar a qualidade das reconstruções, conhecido como ICRC-posterior cut [38];

- RecDataWriter - Grava os eventos no formato do ADST (Advanced Data Summary Trees) [39];

- SdRecTree - Módulo criado nesse trabalho para facilitar uma análise rápida dos dados. Será discutido em mais detalhes posteriormente.

Como dito anteriormente, essa sequência de módulos é baseada na reconstrução utilizada pelo Auger Observer, com a adição dos módulos EventCheckerOG, RecDataWriter e SdRecTree. Os dois últimos são utilizados apenas para a extração dos dados das reconstruções.

Dentre os módulos citados, merecem destaque o LDFFinder, porque é o módulo que ajusta a LDF, e o SdRecTree, que foi criado durante este trabalho para facilitar a análise de dados. Nas duas seções seguintes, as partes mais relevantes destes módulos serão apresentadas.

\subsubsection{LDFFinder}

Essa seção descreve os algoritmos utilizados pelo LDFFinder para estimar a LDF. Detalhes sobre outras partes do módulo podem ser encontrados na referência [40].

\section{LDF}

A dependência do sinal medido no tanque em função da sua distância ao centro do chuveiro é descrita pela por:

$$
S(r)=S_{1000} \cdot f_{\mathrm{LDF}}(r)
$$

onde $f_{\mathrm{LDF}}(r)$ é uma parametrização normalizada da LDF, de maneira que $f_{\mathrm{LDF}}(1000 \mathrm{~m})=1$. 
Existem duas parametrizações da LDF implementadas nesse módulo. Uma delas é uma função modificada de Nishimura, Kamata [41] e Greisen [42] (NKG):

$$
f_{\mathrm{LDF}}(r)=\left[\frac{r}{1000}\right]^{\beta} \cdot\left[\frac{700+r}{700+1000}\right]^{(\beta+\gamma)}
$$

onde $\beta$ e $\gamma$ são parâmetros que podem ser ajustados ou fixos. No caso em que os parâmetros são fixos, por exemplo, quando o número de estações no evento não é suficiente para realizar o ajuste ou quando imposto pelo usuário, o valor deles é determinado pelas seguintes equações [43]:

$$
\begin{gathered}
\beta(\theta)=-3,35-0,125 \log S_{1000} \\
+\left(1,33-0,0324 \log S_{1000}\right) \sec \theta \\
+\left(-0,191-0,00573 \log S_{1000}\right) \sec ^{2} \theta \\
\gamma=0
\end{gathered}
$$

Quando $S_{1000}$ ainda não foi estimado são utilizadas [44]:

$$
\begin{aligned}
\beta_{\text {init }}(\theta) & =0,9 \cdot \sec \theta-3,3 \\
\gamma_{\text {init }} & =0
\end{aligned}
$$

onde $\theta$ é o ângulo entre o eixo de propagação do chuveiro e o eixo perpendicular à superfície terrestre. Quando $S_{1000}$ ainda não foi estimado, o valor máximo que $\beta$ pode assumir é $-0,5$.

A outra parametrização é do tipo lei de potência (PL):

$$
f_{\mathrm{LDF}}(r)= \begin{cases}{\left[\frac{r}{1000}\right]^{\left(\beta+\gamma \cdot \ln \left(\frac{r}{1000}\right)\right)}} & r>300 m \\ {\left[\frac{r}{1000}\right]^{\left(\beta+2 \cdot \gamma \cdot \ln \left(\frac{300}{1000}\right)\right)} \cdot\left[\frac{300}{1000}\right]^{\left(-\gamma \cdot \log \left(\frac{300}{1000}\right)\right)}} & r \leq 300 m\end{cases}
$$

Assim como no caso da NKG, quando necessário, os parâmetros $\beta$ e $\gamma$ são 
estimados por [40]:

$$
\begin{aligned}
\beta(\theta)= & -4.73-0.519 \log S_{1000} \\
& +\left(1.32+0.405 \log S_{1000}\right) \sec \theta \\
& +\left(-0.105-0.117 \log S_{1000}\right) \sec ^{2} \theta \\
\gamma= & 0.05 \sin (8(\cos \theta-0.6))-0.5
\end{aligned}
$$

e quando o $S_{1000}$ ainda não foi estimado:

$$
\beta(\theta)=0.7 \arctan (6(0.65-\cos \theta))-3
$$

\section{Incerteza do sinal}

A incerteza considerada para sinal é [40]:

$$
\sigma_{S}(\theta)=f_{s}(\theta) \sqrt{S}
$$

onde $f_{s}$ é:

$$
f_{s}(\theta)=(0,32+0,42 \sec \theta)
$$

Esta expressão foi obtida empiricamente com base no trabalho das referências [45, 46, 47].

O fator que multiplica a raiz do sinal é atribuído às diferentes contribuições ao sinal vindas das componentes eletromagnéticas (EM) e muônicas do chuveiro: uma flutuação menor e independente do ângulo zenital, proveniente das partículas EM, e uma flutuação maior e crescente com o ângulo zenital, devida aos múons. A parte EM do chuveiro é completamente absorvida em uma camada de aproximadamente $10 \mathrm{~cm}$ de água, o que implica que toda a energia da partícula é depositada no detector praticamente para qualquer ângulo de incidência, podendo então a distribuição do sinal proveniente deste processo ser considerada uma Poisson. No caso dos múons, o sinal é proporcional ao caminho percorrido pela partícula dentro do tanque, que depende 
do ângulo zenital. Simulações mostram que o sinal produzido por múons de mesma energia incidindo no tanque com ângulo zenital de $60^{\circ}$ é aproximadamente $40 \%$ maior quando comparado com o de múons verticais. Então, no caso de dois sinais iguais mas com ângulos zenitais diferentes, o que possui ângulo maior foi produzido por um número menor de partículas com maior influência relativa de flutuações do tipo Poisson. Além disso, existe um efeito chamado corner clipping muons [47] que também contribui para o aumento da flutuação em função do ângulo, pois ele também é proporcional ao caminho percorrido pelos múons no tanque. Ele corresponde a múons que não atravessaram o tanque em toda sua altura mas que saem ou entram pelos lados. Na figura 2.1 observa-se a dependência de $f_{s} \operatorname{com} \theta$.

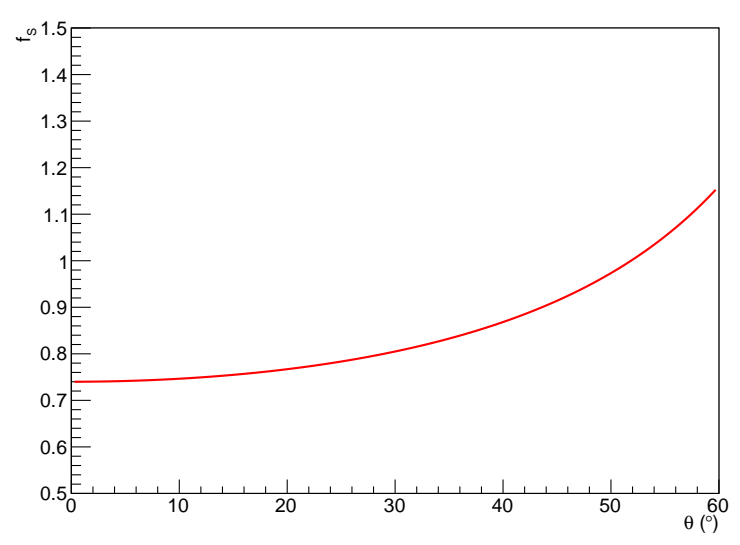

Figura 2.1: Gráfico da equação (2.12), fator multiplicativo da incerteza do sinal das estações SD.

Nos valores numéricos da expressão (2.11) estão embutidos efeitos causados pela unidade utilizada para medir o sinal dos tanques, o Vertical Muon Equivalent (VEM [48]) ou equivalente em múons verticais, em uma tradução livre, que equivale a aproximadamente 100 p.e. $/ \mathrm{PMT}^{1}$. São necessárias muitas partículas EM para produzir um sinal de 1 VEM, pois partículas EM, com energia na escala de $\mathrm{MeV}$, produzem aproximadamente 1 p.e./MeV. Portanto espera-se que, utilizando VEM como unidade, o sinal de partículas EM

\footnotetext{
${ }^{1}$ p.e. - photoelectron, fotoelétron.
} 
possua uma incerteza relativa menor que um sinal de múons, dado que o número de partículas na estação é descrito por uma distribuição de Poisson. Por exemplo, em chuveiros verticais a correção na incerteza do sinal será menor que 1, e nesse caso a razão do sinal de partículas EM sobre sinal de múons é maior.

Para o ajuste da LDF, o módulo permite utilizar dois estimadores, o Método dos Mínimos Quadrados (MMQ) e o Método da Máxima Verossimilhança (MMV). Neste trabalho foi utilizado o MMV porque este permite utilizar, num mesmo ajuste, sinais com diferentes distribuições.

\section{Método da Máxima Verossimilhança}

Como o sinal das estações do SD é obtido com PMTs, são medidos apenas fótons, nesse caso fótons Cherenkov emitidos por partículas carregadas que atravessam a estação, em sua maioria múons e elétrons. O número de fotoelétrons contados depende fortemente da partícula incidente, seu ponto de entrada no tanque e seu ângulo de incidência. Não existe uma maneira simplificada de fazer a conversão do sinal da PMT para o número de partículas detectadas e, além disso, o sinal é calibrado em unidades equivalentes em múons verticais (VEM). Entretanto, pode-se fazer uma aproximação como descrito adiante.

Ao aplicar o Método da Máxima Verossimilhança sobre o número efetivo de partículas, é possível incluir num mesmo ajuste: estações com sinal zero; estações com sinal pequeno, descrito pela distribuição de Poisson; estações com sinal grande, descrito pela distribuição Gaussiana; e estações que possuem sinais saturados, impondo um limite inferior ao sinal quando ele não é recuperado.

Considerando que $n$ partículas de um chuveiro atmosférico com energia primária $E$, massa $A$, ângulo zenital $\theta$ atingem uma estação a uma distância $r$ do centro do chuveiro, o número de partículas pode ser separado em:

$$
n=n_{\mu}+n_{e \gamma}
$$

onde $n_{\mu}$ é o número de múons e $n_{e \gamma}$ é a soma do número de elétrons e fótons, 
e ambos são funções dos parâmetros do chuveiro. O sinal $\left(S_{\mu}\right)$ produzido na estação por um múon é muito maior que o sinal de um elétron ou de um fóton. Então, neste caso é razoável a aproximação de que um fóton produz, em média, um sinal equivalente a um elétron $\left(S_{e \gamma}\right)$. Em uma abordagem simplificada, o sinal de uma partícula do tipo $i$ pode ser aproximado por:

$$
S_{i}=a_{i} \cdot n_{i}
$$

onde $a_{i}$ é um fator de conversão para cada tipo de partícula. O fator de conversão é aproximadamente igual para fótons e elétrons, e $a_{\mu}$ é aproximado por 1, quando se considera que um múon produz um sinal de 1 VEM independente dos parâmetros do chuveiro. Portanto, o sinal de uma estação é:

$$
S=S_{\mu}+S_{e \gamma}=n_{\mu}+a_{e \gamma} \cdot n_{e \gamma}
$$

O número de partículas pode ser reescrito em função da fração de múons presente no chuveiro $\left(k_{\mu}\right)$ :

$$
\begin{aligned}
n_{\mu} & =k_{\mu} \cdot n \\
n_{e \gamma} & =\left(1-k_{\mu}\right) \cdot n
\end{aligned}
$$

Substituindo as equações (2.16) e (2.17) em (2.15):

$$
S=\left[k_{\mu}+a_{e \gamma}\left(1-k_{\mu}\right)\right] n
$$

Invertento a equação é possível obter o número de partículas em função do sinal:

$$
n=\frac{1}{k_{\mu}+a_{e \gamma}\left(1-k_{\mu}\right)} \cdot S
$$

Esse parâmetro de proporcionalidade é definido como fator de Poisson $(p)$ : 


$$
n=p \cdot S
$$

O fator de Poisson pode ser aproximado por uma função que depende apenas do ângulo zenital [40]:

$$
p=p(\theta)= \begin{cases}1 & \text { se } f_{S}(\theta)<1 \\ \frac{1}{\left(f_{s}(\theta)\right)^{2}} & \text { se } f_{S}(\theta) \geq 1\end{cases}
$$

onde $f_{S}(\theta)$ é dado pela equação (2.1). Na figura 2.2 observa-se a dependência do fator de Poisson com o ângulo zenital.

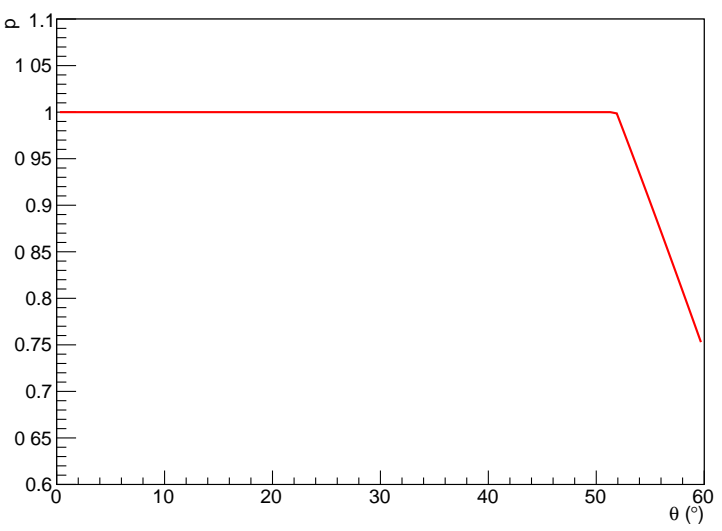

Figura 2.2: Gráfico do fator Poisson, equação (2.21), em função do ângulo zenital $\theta$.

A função de máxima verossimilhança pode ser escrita como o produtório das distribuições do número de partículas nas estações:

$$
\mathcal{L}=\prod_{i} f_{\mathrm{P}}\left(n_{i}, \mu_{i}\right) \prod_{j} f_{\mathrm{G}}\left(n_{j}, \mu_{j}\right) \prod_{k} F_{\text {sat }}\left(n_{k}, \mu_{k}\right) \prod_{l} F_{\text {zero }}\left(n_{l}, \mu_{l}\right)
$$

onde $f_{\mathrm{P}}, f_{\mathrm{G}}, F_{\text {sat }}$ e $F_{\text {zero }}$ são descritas abaixo. Aplicando o $\ln$ : 


$$
\begin{array}{r}
\ln \mathcal{L}=\sum_{i} \ln f_{\mathrm{P}}\left(n_{i}, \mu_{i}\right)+\sum_{j} \ln f_{\mathrm{G}}\left(n_{j}, \mu_{j}\right)+ \\
\sum_{k} \ln F_{\mathrm{sat}}\left(n_{k}, \mu_{k}\right)+\sum_{l} \ln F_{\text {zero }}\left(n_{l}, \mu_{l}\right)
\end{array}
$$

onde $n_{i}$ é o número efetivo de partículas na $i$-ésima estação e $\mu_{i}$ é o valor verdadeiro da LDF para a mesma estação, estimado pela parametrização da LDF utilizada.

Os quatro casos que correspondem às diferentes distribuições do número de partículas nas estações são:

Sinais pequenos - Nesse caso, o número de partículas é descrito por uma distribuição de Poisson:

$$
f_{\mathrm{P}}\left(n_{i}, \mu_{i}\right)=\frac{\mu_{i}^{n_{i}} \mathrm{e}^{-\mu_{i}}}{n_{i} !}
$$

e, aplicando o $\ln$ :

$$
\ln f_{\mathrm{P}}\left(n_{i}, \mu_{i}\right)=n_{i} \ln \mu_{i}-\mu_{i}-\sum_{j=1}^{n_{i}} \ln j
$$

Sinais grandes - O teorema do limite central permite aproximar a distribuição de Poisson por uma distribuição Gaussiana quando o número de partículas é grande $\left(S_{i}>S_{\lim }\right), n_{i}>30$ :

$$
f_{\mathrm{G}}\left(n_{i}, \mu_{i}\right)=\frac{1}{\sqrt{2 \pi} \sigma_{i}} \exp \left(-\frac{\left(n_{i}-\mu_{i}\right)^{2}}{2 \sigma_{i}^{2}}\right)
$$

Aplicando o ln:

$$
\ln f_{\mathrm{G}}\left(n_{i}, \mu_{i}\right)=-\frac{\left(n_{i}-\mu_{i}\right)^{2}}{2 \sigma_{i}^{2}}-\ln \sigma_{i}-\frac{1}{2} \ln 2 \pi
$$

onde o último termo pode ser omitido da somatória pelo fato de ser constante. 
Sinais saturados - Neste caso, $n_{i}$ representa um limite inferior para o sinal. Então para estimar a probabilidade de obter um valor maior que $n_{i}$, quando não é aplicado nenhum algoritmo de recuperação do sinal, integra-se a função $f_{\mathrm{G}}$ para todos os valores maiores que $n_{i}$ :

$$
F_{\text {sat }}\left(n_{i}, \mu_{i}\right)=\int_{n_{i}}^{\infty} f_{\mathrm{G}}\left(n, \mu_{i}\right) \mathrm{d} n=\frac{1}{2} \operatorname{erfc}\left(\frac{n_{i}-\mu_{i}}{\sqrt{2} \sigma_{i}}\right)
$$

onde $\operatorname{erfc}(x)=1-\operatorname{erf}(x)$ é a função complementar da função erro.

Em estações cujo sinal é recuperado, ele pode ser utilizado de duas maneiras: se a segunda derivada da LDF for muito grande (maior que 1), a estação está muito próxima do centro do chuveiro e a LDF cresce rapidamente nessa região. Então utiliza-se como limite inferior o sinal subtraído de sua incerteza; do contrário, utiliza-se uma distribuição de Poisson ou Gaussiana como descrito anteriormente.

Estações com sinal nulo - Considerando que existe um limiar mínimo $n_{\lim }$ para qual o trigger da estação é disparado, são necessários pelo menos $n_{\text {lim }} \equiv 3$ múons atingindo a estação. É necessário somar a probabilidade de uma Poisson, com valor verdadeiro $\mu_{i}$, obter $n=0,1, \ldots, n_{\text {lim }}$ :

$$
F_{\text {zero }}\left(n_{\lim }, \mu_{i}\right)=\sum_{n=0}^{n_{\lim }} f_{\mathrm{P}}\left(n, \mu_{i}\right)
$$

aplicando o ln:

$$
\ln F_{\text {zero }}\left(n_{\lim }, \mu_{i}\right)=-\mu_{i}+\ln \left(\sum_{n=0}^{n_{\lim }} \frac{\mu_{i}^{n}}{n !}\right)
$$

Definindo $n_{\lim } \equiv 3$ temos:

$$
\ln F_{\text {zero }}\left(3, \mu_{i}\right)=-\mu_{i}+\ln \left(1+\mu_{i}\left(1+\frac{\mu_{i}}{2}\left(1+\frac{\mu_{i}}{3}\right)\right)\right)
$$

Para $\mu_{i}$ pequeno, menor que 0,03 , a aproximação assintótica é válida [40]: 


$$
\ln F_{\text {zero }}\left(3, \mu_{i}\right)=-\frac{\mu_{i}^{4}}{24}
$$

\section{Estágios do ajuste}

O ajuste da LDF foi dividido em estágios, e a cada estágio o ajuste se torna mais complexo como descrito a seguir [40]:

Estágio 1 - Não é realizado nenhum cálculo pelo módulo, e os parâmetros foram obtidos da reconstrução geométrica realizada pelo módulo SdPlaneFit;

Estágio 2 - Utilizando uma estimativa da posição do centro do chuveiro baseada no baricentro "pesado" pelo sinal, os valores de iniciais $\beta_{\text {init }}$ e $\gamma_{\text {init }}$ descritos anteriormente e o sinal da estação cuja distância ao centro do chuveiro é mais próxima de $1000 \mathrm{~m}$, é realizada uma estimativa do $S_{1000}$

Estágio 3 - É realizado o ajuste da posição do centro do chuveiro e do $S_{1000}$;

Estágio 4 - É realizado o ajuste da posição do centro do chuveiro e do $S_{1000}$, incluindo no ajuste as estações ativas próximas cujo sinal é menor que o limiar do trigger, isto é, estações com sinal zero.

Os ajustes realizados normalmente são do estágio 3 ou 4. No entanto, existem eventos que possuem estágios com números não inteiros. Esses "adicionais" indicam que mais parâmetros foram ajustados. Os adicionais mais comuns são:

- 0,01 - O parâmetro $\gamma$ é ajustado;

- 0,1 - O ajuste inclui o parâmetro $\beta$;

- 0,5 - É ajustada a curvatura da frente do chuveiro.

A inclusão desses parâmetros no ajuste pode ser feita tanto no estágio 3, quanto o 4.

O LDFFinder utiliza o algoritmo do Minuit implementado no ROOT para o ajuste das funções. 


\subsubsection{SdRecTree}

Para a análise foi criado um módulo no Offline que extrai dos dados reconstruídos de cada evento as seguintes informações para cada uma das estações contidas no evento:

- identificação do evento, EventId;

- data e hora do evento, GPSTime;

- energia reconstruída e sua incerteza;

- ângulo zenital $\theta$ do chuveiro e sua incerteza;

- ângulo azimutal $\phi$ do chuveiro e sua incerteza;

- número de estações ativas no evento;

- identificação da estação, sId;

- status da estação, silenciosa, saturada, etc;

- distância da estação ao centro do chuveiro;

- S1000 obtido pelo ajuste;

- sinal da estação e sua incerteza;

- valor da LDF ajustada na posição da estação;

- o $\chi^{2}$ do ajuste;

- parâmetros utilizados para simulação, quando for o caso.

O módulo SdRecTree pode ser adicionado à sequência de módulos de reconstrução de eventos simulados ou reais e consome pouco tempo de máquina para sua execução. Por exemplo, na reconstrução de eventos reais, ele é responsável por apenas 0,3\% do tempo de processamento. Com pequenas modificações no código do programa, outras informações podem ser extraídas, e nesses casos, é necessário reconstruir os eventos novamente. As informações extraídas pelo módulo são arquivadas em um objeto do tipo TTree do ROOT [49] para facilitar e agilizar a análise posterior. 


\section{Capítulo 3}

\section{Eventos reais}

Este capítulo apresenta os resultados da reconstrução de eventos reais medidos pelo Observatório Pierre Auger. São descritos os cortes aplicados nos eventos, e discutidos seus resíduos, a incerteza do sinal das estações e as parametrizações da LDF.

\subsection{Cortes}

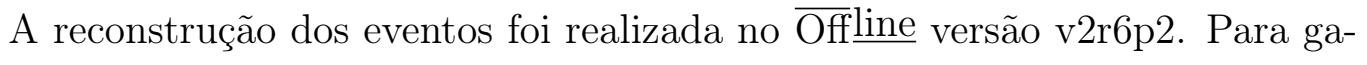
rantir um padrão de qualidade nos chuveiros analisados, foram utilizados apenas os eventos que satisfaçam o trigger T5 [50]. Este é o chamado trigger físico, e por ele são selecionados apenas os eventos que apresentam as melhores reconstruções de energia e direção. Uma das suas principais características é a exigência de cinco estações ativas ao redor da que possui maior sinal. Ativas significa que essas estações estavam em funcionamento normal e não que algum trigger foi disparados. Assim, são rejeitados eventos que estão nas bordas do array. Os eventos que ocorreram nos bad periods listados pelo grupo do Observer[36] também foram excluídos da análise. "Períodos ruins" são definidos como períodos em que pelo menos $30 \%$ das estações têm algum alarme de mau funcionamento acionado. Após a reconstrução, foi realizado mais um corte nos dados, incluindo apenas chuveiros com energia reconstruída maior ou igual a $10^{18} \mathrm{eV}$, como observado na figura 3.1a, e 
ângulo zenital menor ou igual a $60^{\circ}$, figura $3.1 \mathrm{~b}$. O corte de energia garante que os eventos estejam na faixa de energia em que o observatório está otimizado para operar. Não é observada uma correlação entre a energia e o ângulo zenital dos eventos, figura 3.2. Para todas energias o ângulo médio flutua em torno de $36.5^{\circ}$, o ângulo médio de uma distribuição uniforme em $\sin (\theta) \cos (\theta)$ de $0^{\circ}$ a $60^{\circ}$. Foram reconstruídos eventos desde o início de operação do observatório, em 2004, até 31 de dezembro de 2010. Estações com sinal saturado ou com sinal "zero", apesar de utilizadas nos ajustes, não são apresentados nos gráficos deste trabalho, a não ser quando especificado.

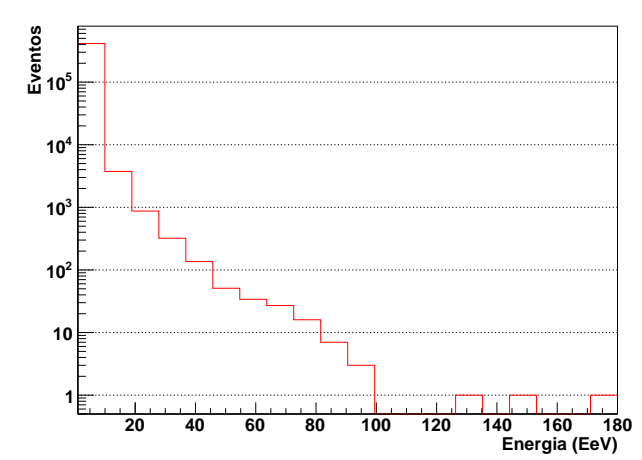

(a)

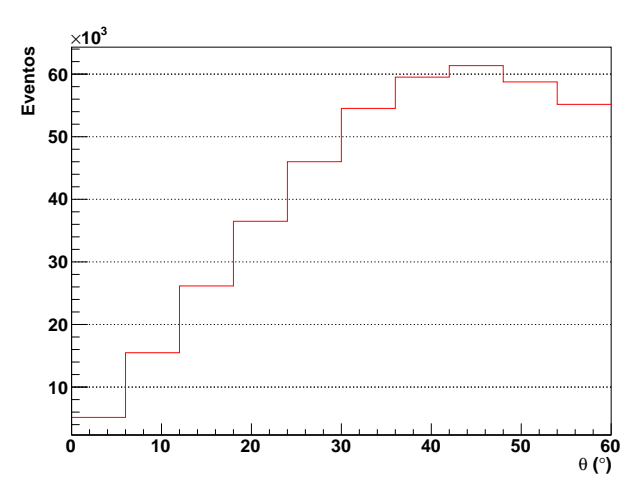

(b)

Figura 3.1: Distribuição da energia dos eventos na figura (a) e a distribuição de ângulo zenital $(\theta)$ na figura (b). Eventos T5 de 2004 a 2010. 


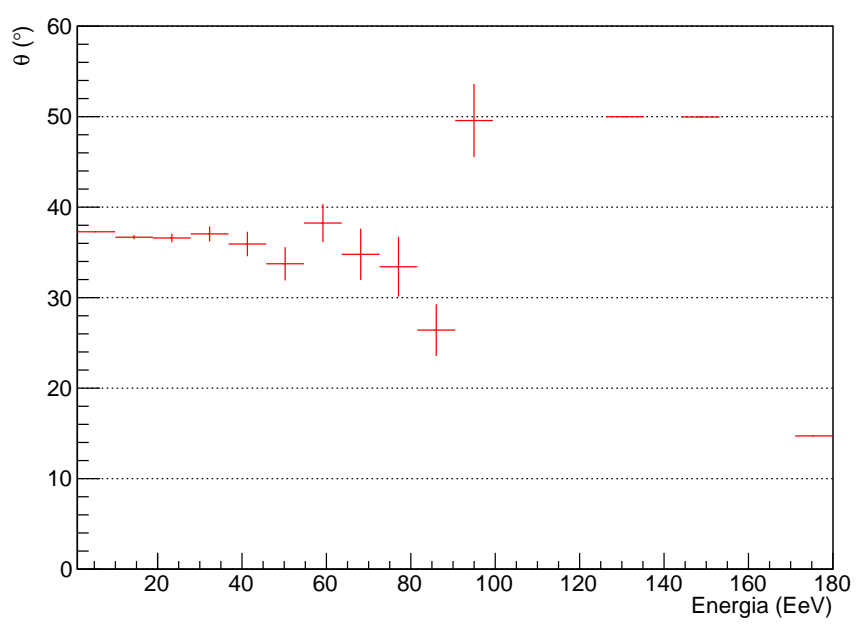

Figura 3.2: Perfil do ângulo zenital $(\theta)$ em função da energia, nesse caso a barra de incerteza corresponde ao desvio padrão da média. Eventos T5 de 2004 a 2010.

\subsection{Resíduos}

Uma das maneiras de observar as flutuações é através dos resíduos. Os resíduos podem ser absolutos, relativos ou reduzidos. O resíduo absoluto é definido como a diferença entre o valor experimental e o valor da função ajustada [51], o resíduo relativo é o resíduo absoluto dividido pelo valor experimental e o resíduo reduzido é o resíduo absoluto dividido pela incerteza do valor experimental. Nas figuras 3.3, 3.4 e 3.5 estão plotados os resíduos dos ajustes de LDFs de eventos T5 entre 2004 e 2010 com energia reconstruída maior que $1 \mathrm{EeV}$ e $\theta \leq 60^{\circ}$. A visualização dos dados é comprometida na região central dos gráficos devido à grande densidade de pontos. Para facilitar a visualização é plotado o perfil dos dados. O perfil é definido como a média dos dados em uma determinada extensão da abscissa e sua incerteza é o desvio padrão desses dados.

Os resíduos absolutos não são adequados para as análises realizadas neste trabalho pois a diferença absoluta entre o valor ajustado e os valores experimentais varia quase três ordens de grandeza, e em um mesmo gráfico fica 


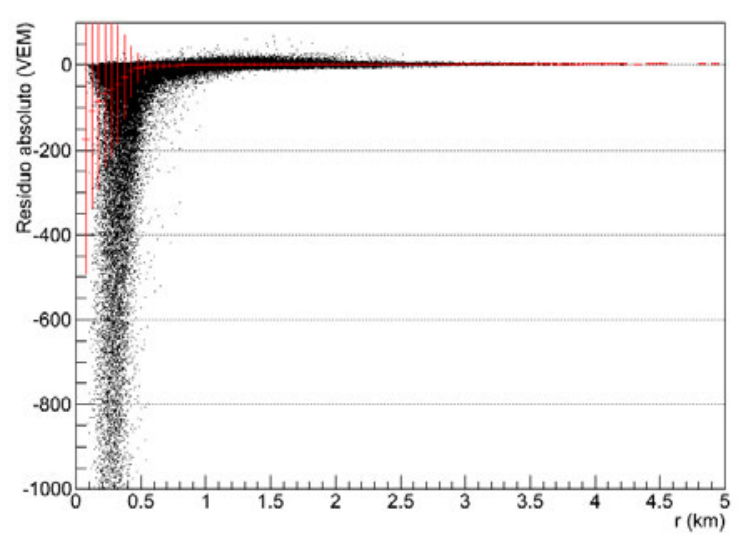

Figura 3.3: Gráfico dos resíduos absolutos, a diferença entre o valor experimental e o valor da função ajustada, dos ajustes de LDFs dos eventos T5 de 2004 à 2010. Os pontos vermelhos representam o perfil da distribuição.

impossível observar os resíduos próximos e distantes ao centro do chuveiro. Sabe-se que quanto maior o valor do sinal, maior sua flutuação, portanto este tipo de gráfico privilegia a observação das flutuações de estações com sinal maior (mais próximas ao centro do chuveiro) enquanto que a flutuação das estações com sinal menor (mais distantes do centro do chuveiro) é prejudicada e o interesse destre trabalho é estudar o comportamento dos resíduos longe do centro do chuveiro.

No gráfico de resíduos relativos, a variação de valores é de quatro unidades mas existe uma assimetria entre resíduos positivos e negativos. Nos casos em que o valor do sinal é maior que a função ajustada, o valor máximo do resíduo é um, isto é, quando o sinal é muito maior que o ajuste. No outro extremo, quando o sinal é muito menor que o ajuste, o valor do resíduo tende a menos infinito. Essa assimetria exagera os resíduos negativos, por exemplo, se a função ajustada for 3 vezes maior que o sinal, o resíduo é -2 e se a função for $1 / 3$ do sinal, o resíduo é $2 / 3$. Resíduos relativos são mais indicados nos casos em que a diferença entre o valor experimental e o ajustado é pequena.

No caso dos resíduos reduzidos, a unidade utilizada para medir a distância entre os dados e a função ajustada, é a incerteza. Dessa forma não existe a assimetria dos resíduos relativos. Utilizando a incerteza como unidade dos 


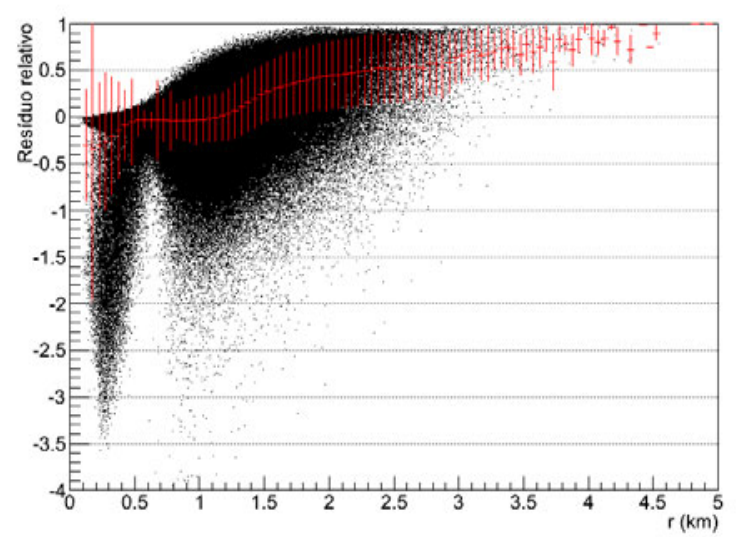

Figura 3.4: Gráfico dos resíduos relativos, resíduo absoluto divido pelo valor experimental, dos ajustes de LDFs dos eventos T5 de 2004 a 2010. Os pontos vermelhos representam o perfil da distribuição.

resíduos é possível verificar se a flutuação observada é compatível com a função de densidade de probabilidade esperada para o dados. Nesse caso, supõe-se que a flutuação dos dados é bem descrita por uma gaussiana com média igual à função ajustada e desvio padrão dado pela expressão 2.11, o valor do sinal utilizado nessa equação é dado pela função ajustada, a melhor estimativa do valor verdadeiro do sinal. Na figura 3.5 existe um conjunto grande de estações com sinal sistematicamente menor que o ajuste próximo ao centro do chuveiro. Possíveis causas desse efeito serão discutidas mais adiante. 


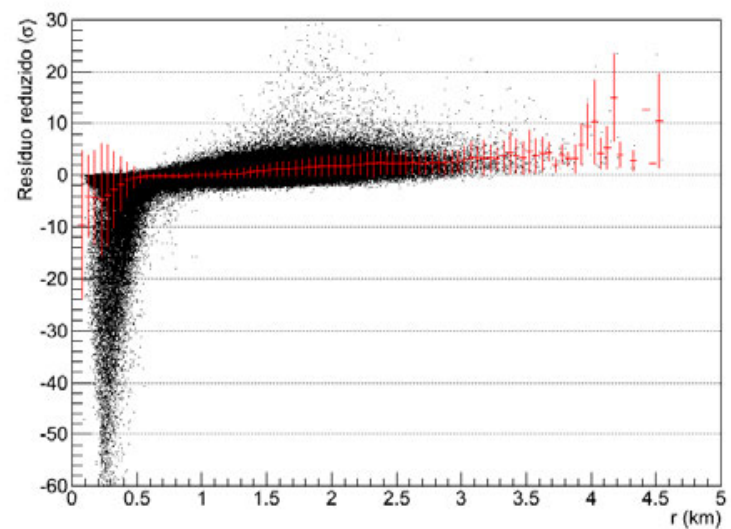

Figura 3.5: Gráfico dos resíduos reduzidos, resíduo absoluto dividido pela incerteza do valor experimental, dos ajustes de LDFs dos eventos T5 de 2004 a 2010. Os pontos vermelhos representam o perfil da distribuição.

\subsection{Incerteza do sinal das estações}

No gráfico de resíduos reduzidos da seção anterior, figura 3.5, supondo que a distribuição dos dados seja gaussiana, seria esperado que os pontos estivessem distribuídos simetricamente em torno de zero e com 99,7\% deles entre -3 e +3 , independente da distância ao centro do chuveiro. Diferenças deste comportamento são causadas por erro sistemático, por exemplo, uma função que não descreve bem a LDF, ou que a gaussiana não é a função de densidade de probabilidade que descreve os dados. Supondo que o sinal das estações, em VEM, é bem descrito por uma distribuição de Poisson, espera-se um gráfico de resíduo reduzido com média zero. Entretanto, ele só será simétrico em regiões nas quais o sinal tem valores elevados, isto é, quando a Poisson tende a uma gaussiana. Essa transição ocorre em torno de $1 \mathrm{~km}$ do centro do chuveiro, região na qual o sinal é, em média, aproximadamente $10 \mathrm{VEM}$, figura 3.6a. Para ilustrar esse comportamento, foi realizada uma simulação do gráfico de resíduos utilizando um toy model. Nesse modelo supõe-se que a distribuição verdadeira da LDF é dada pela média da LDF dos dados, figura 3.6a, e a distribuição verdadeira da posição das estações é dada pelo histograma das distância das estações ao centro do chuveiro, figura 3.6b. Essa 
simulação foi produzida utilizando os seguintes passos: sorteia-se a posição da estação conforme a distribuição do histograma da figura 3.6b; utiliza-se o perfil da LDF, figura 3.6a, para obter uma estimativa do valor médio do sinal de uma estação a esta distância do centro do chuveiro; então, é sorteado o sinal da estação de acordo com uma poisson com média igual ao valor obtido no passo anterior; finalmente é calculado o resíduo reduzido dessa estação simulada em relação ao perfil dos dados. Esse procedimento foi repetido $n$ vezes, onde $n$ é o número de estações com sinal em eventos T5 entre 2004 e 2010. O resultado desse toy model está plotado no gráfico da figura 3.7.

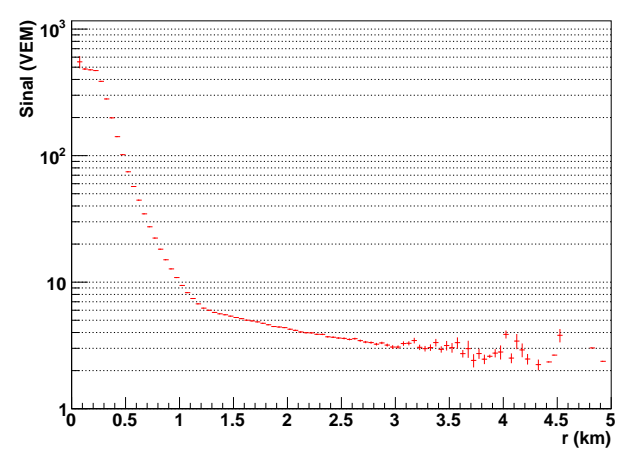

(a)

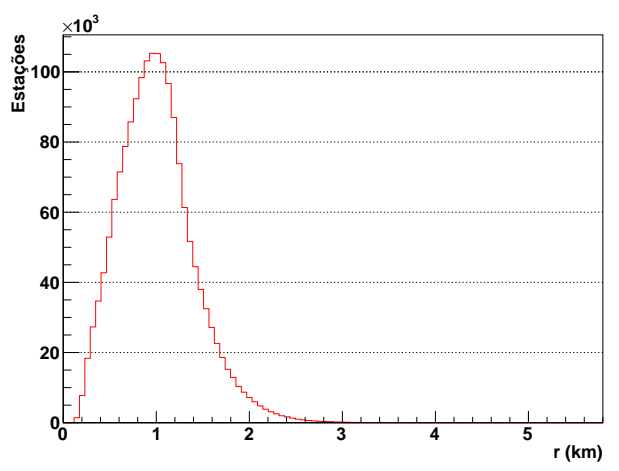

(b)

Figura 3.6: (a) Perfil do sinal das estações em função da distância ao centro do chuveiro. (b) Histograma das posições das estações. Eventos T5 de 2004 a 2010 .

Os resíduos possuem perfil compatível com zero, consequência de como sua distribuição foi construída. Os ponto mais distantes do centro do chuveiro estão agrupados em linhas, pois a poisson é uma distribuição discreta e o valor da média varia continuamente com r. Com a aproximação da estação ao centro do chuveiro, e consequentemente o aumento do sinal, os resíduos vão ficando simétricos e o comportamento discreto vai desaparecendo. Isso ocorre porque a Poisson vai tendendo a uma gaussiana.

Comparando os resíduos reduzidos do toy model com os dos ajustes dos eventos na mesma escala, figura 3.8, observa-se que a dispersão dos dados é menor que a do toy model, o que é um indicativo de que a incerteza pode estar 


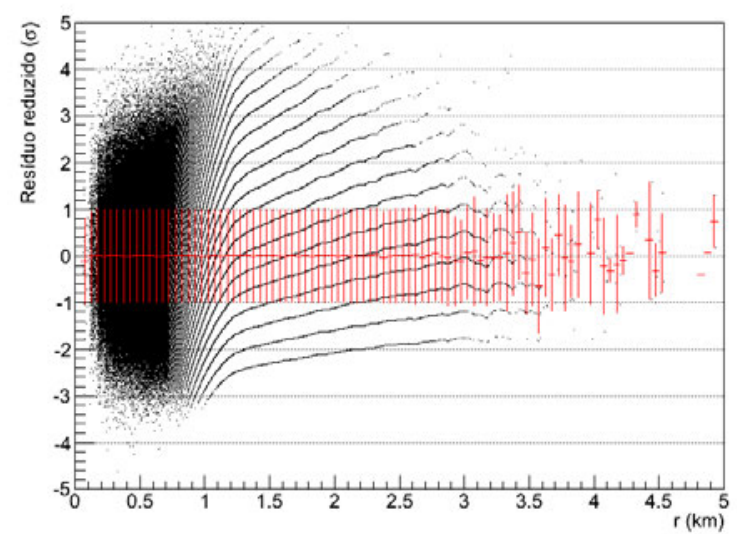

Figura 3.7: Gráfico dos resíduos reduzidos obtido por simulação. Os pontos vermelhos representam o perfil da distribuição.

superestimada. Além disso, as estações a mais de $1 \mathrm{~km}$ têm resíduo médio maior que zero, indicando um erro sistemático na função ajustada para a LDF. Um fator que contribui para isso é o nível de trigger das estações, em torno de 3 VEM. A LDF tende a zero quando se afasta do centro do chuveiro e o valor mínimo do sinal para as estações é 3 VEM, portanto é esperado um resíduo sistematicamente positivo para estações distantes do centro do chuveiro. Esta sistemática é discutida na seção 5.1 .

O toy model utilizado supõe que a função de probabilidade que descreve o sinal das estações, em VEM, é a Poisson. Esta hipótese pode não ser verdadeira. Uma descrição mais detalhada de como é obtido o sinal das estações mostra que não se erra tanto ao usar o modelo simplificado.

Supondo que fosse possível gerar M chuveiros idênticos (mesma partícula primária com mesma energia, mesma posição do centro do chuveiro e mesmos ângulos azimutal e zenital), a probabilidade de uma partícula cair em uma determinada área do array é a mesma, pois a LDF de todos os M chuveiros é a mesma. Portanto, como em um histograma, existe um número esperado $(\pi)$ de partículas que devem atingir essa estação e $\pi$ é o mesmo para todos os $\mathrm{M}$ chuveiros. Entretanto, o número de partículas observadas $(n)$ em uma determinada estação varia para cada um dos $M$ chuveiros. A função de 


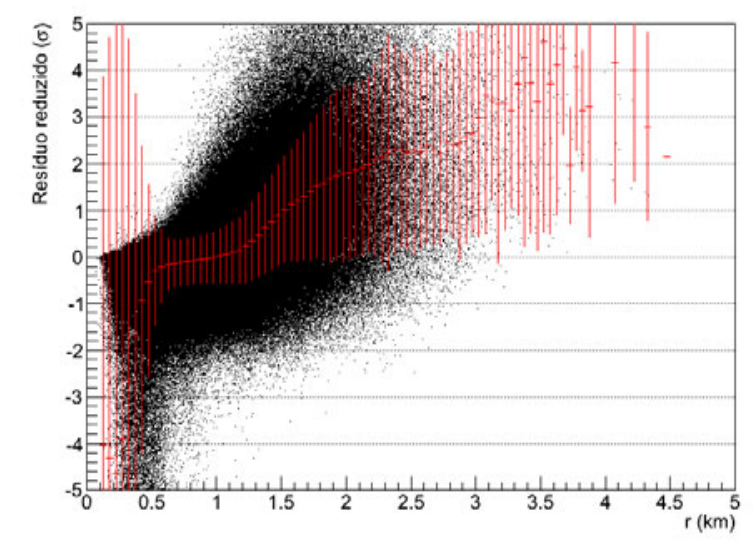

Figura 3.8: Gráfico dos resíduos reduzidos dos ajustes de LDFs dos eventos T5 de 2004 à 2010, zoom na região entre -5 e 5 desvios padrão. Os pontos vermelhos representam o perfil da distribuição.

probabilidade que descreve $n$ é uma Poisson com média $\pi$.

A produção de fótons Cherenkov por partículas carregadas é proporcional à distância percorrida no meio [52], portanto, em uma primeira aproximação, pode ser considerado um processo distribuído segundo uma Poisson com média $\gamma$. Cada partícula produz aproximadamente 250 fótons Cherenkov por centímetro percorrido [9], e considerando que um múon que atravessa o tanque percorre em média $125 \mathrm{~cm}[48]$ estima-se que $\gamma=31 \cdot 10^{3}$.

Os fótons dentro da estação podem ser absorvidos pelas paredes ou pela água, ou ser capturados pelas PMTs. Considerando que a taxa de refletividade do Tivec é 85 \% [9], o comprimento de absorção da água é 35 m [9] e que os fótons se deslocam em média 1,25 m [48] antes de refletirem nas paredes, em 30 colisões praticamente todos os fótons são absorvidos. A área somada das três PMTs de 9" corresponde a apenas 0,36\% da superfície interna da estação. Então estima-se que apenas 1,9\% dos fótons chegam às PMTs. Além disso, a taxa de transmissão da janela da PMT é de $90 \%$ e a eficiência quântica do foto-cátodo é de 15\%. Portanto a probabilidade de um fóton Cherenkov produzir um foto-elétron é $\epsilon=2,6 \cdot 10^{-3}$. Esse processo é descrito por uma binomial, e combinando a Poisson da produção dos fótons com a binomial da produção de foto-elétrons obtêm-se, como mostra o 
apêndice A.4, uma Poisson de média $\gamma \epsilon$.

Os foto-elétrons que deixam o foto-cátodo são atraídos para o primeiro dinodo, e são produzidos $\delta$ elétrons para cada foto-elétron incidente. Os elétrons secundários são atraídos para um segundo dinodo onde o processo se repete. Uma PMT possui vários estágios de multiplicação. Em um modelo simplificado [53] cada um desses estágios pode ser descrito por uma Poisson de média $\delta$. Em uma PMT com $K$ estágios de aceleração, e considerando $\delta$ é igual em todos os estágios, o número de elétrons após o último estágio é descrito por uma distribuição de Poisson composta, como deduzido no apêndice A.5.

A função de probabilidade que descreve o sinal das estações é a combinação dos processos Poissons descritos, o que está demonstrado no apêndice A.6. O resultado obtido para variância do sinal $(S)$ das estações SD é:

$$
\sigma^{2}=\pi \gamma \epsilon \delta^{K}\left[\gamma \epsilon \delta^{K}+\delta^{K}+\frac{\delta^{K}-1}{\delta-1}\right]
$$

Entretanto o sinal utilizado nos ajustes de LDF é $S_{V}=S / V E M$, então a variância desse sinal "verdadeiro" é:

$$
\sigma_{V}^{2}=\frac{\sigma^{2}}{V E M^{2}}
$$

Contudo a variância do sinal utilizada atualmente é:

$$
\sigma_{A}^{2}=\frac{\pi \gamma \epsilon \delta^{K}}{V E M}
$$

sendo então a relação da variância atual com a verdadeira:

$$
\sigma_{V}^{2}=\frac{\sigma_{A}^{2}}{V E M}\left[\gamma \epsilon \delta^{K}+\delta^{K}+\frac{\delta^{K}-1}{\delta-1}\right]
$$

Como o ganho da PMT, $\delta^{K}$, é muito maior que 1, pode-se aproximar:

$$
\sigma_{V}^{2}=\frac{\sigma_{A}^{2} \delta^{K}}{V E M}\left[\gamma \epsilon+1+\frac{1}{\delta-1}\right]
$$

Considerando que 1 VEM equivale aproximadamente a 100 foto-elétrons [47] e o ganho da PMT é $\delta^{K}$, tem-se: 


$$
\sigma_{V}^{2}=\frac{\sigma_{A}^{2} \delta^{K}}{100 \delta^{K}}\left[\gamma \epsilon+1+\frac{1}{\delta-1}\right]=\frac{\sigma_{A}^{2}}{100}\left[\gamma \epsilon+1+\frac{1}{\delta-1}\right]
$$

Substituindo os valores acima é possível desprezar o termo com $\delta$ por ser muito menor que os outros, então:

$$
\sigma_{V}^{2}=\sigma_{A}^{2} 0,82
$$

Finalmente, obtêm-se a relação entre a incerteza utilizada e a verdadeira:

$$
\sigma_{V}=0,90 \sigma_{A}
$$

\subsection{Resíduos ao longo dos anos}

Um efeito curioso é observado no gráfico de resíduos reduzidos em função do tempo dos eventos, figura 3.9. Existe uma crescente tendência de superestimação dos dados de 2004 a 2006, e no começo de 2007 há uma quebra e essa tendência desaparece. Na virada do ano de 2006 para 2007 houve uma alteração no trigger central e uma nova calibração do software das estações.

Definindo período 1 como o anterior à mudança de comportamento dos resíduos e período 2 como o posterior, e comparando os resíduos dos dois períodos na figura 3.10, constata-se que ocorre no período 1 a grande maioria dos eventos cujo ajuste da LDF tende a superestimar o valor do sinal das estações próximas ao centro do chuveiro.

Apesar das assimetrias, o sinal em torno de $1 \mathrm{~km}$ do centro não possui sistemática, indicando que as estimativas de energia das partículas primárias a partir do valor de S(1000) não são muito afetadas pela alteração ocorrida entre o primeiro e o segundo período. Para as estações a mais de $1 \mathrm{~km}$ do centro do chuveiro, também não é possível observar diferenças significativas entre os dois períodos. 


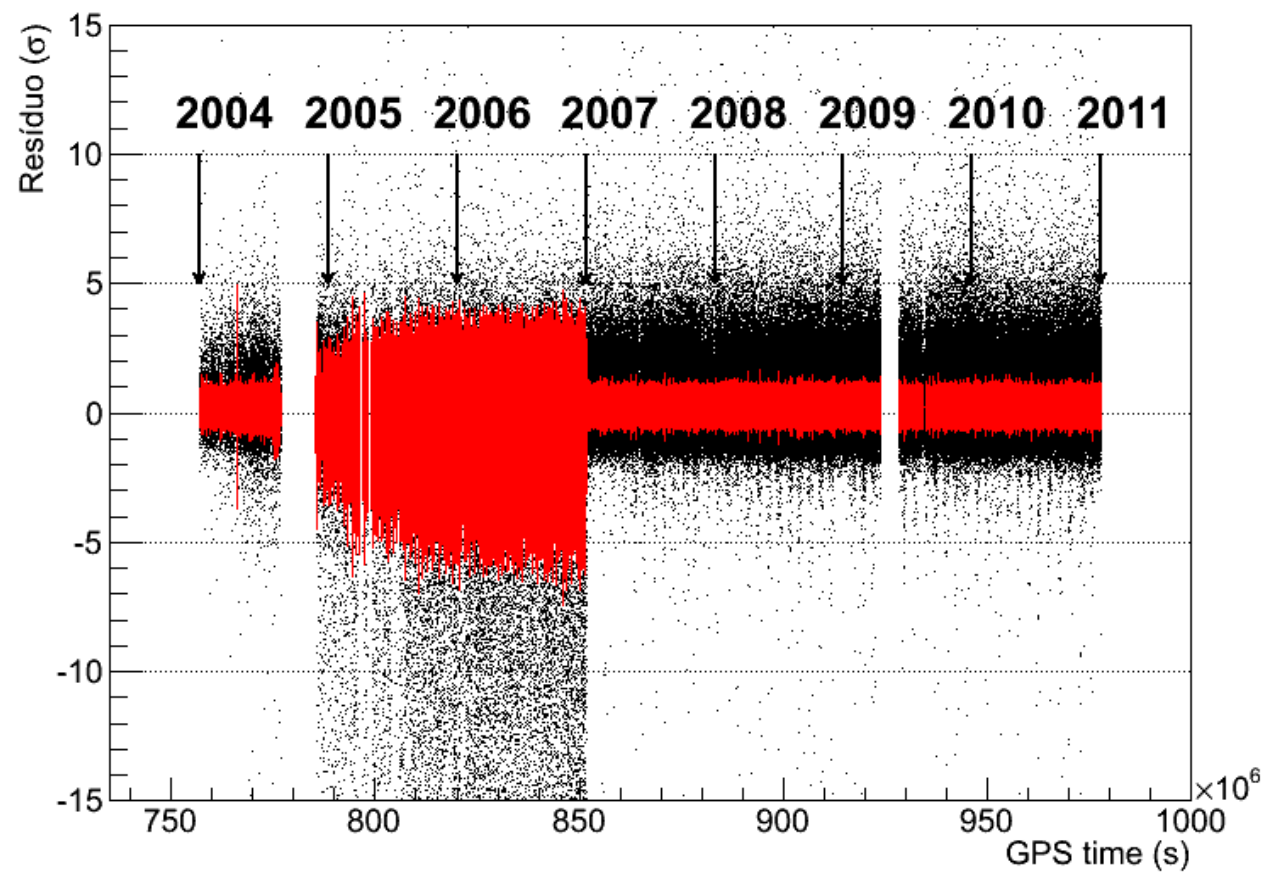

Figura 3.9: Gráfico de resíduos reduzidos de LDFs em função do tempo. As setas indicam o início dos anos e os pontos vermelhos representam o perfil da distribuição. 

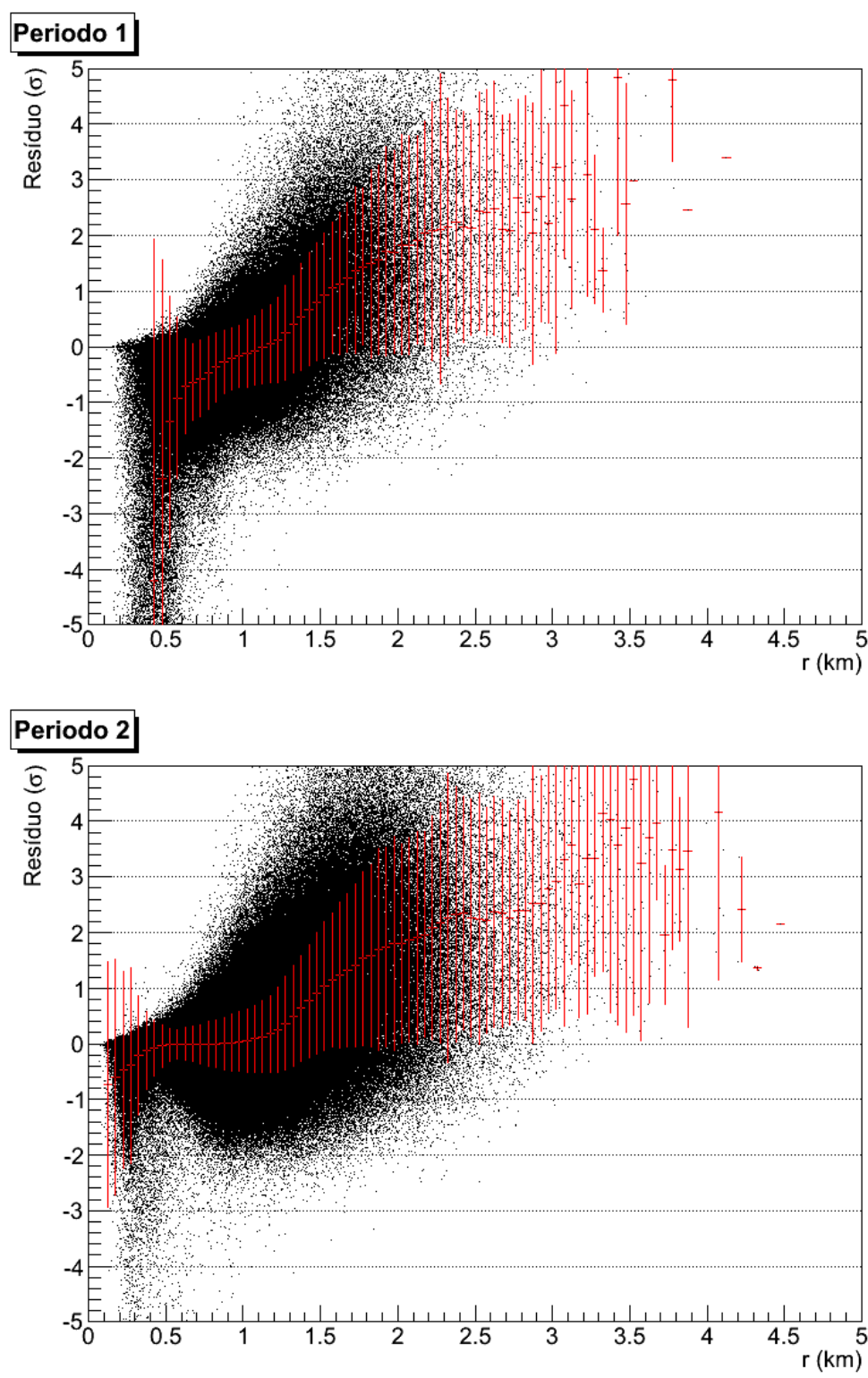

Figura 3.10: Gráfico de resíduos reduzidos de LDFs em função da distância ao centro do chuveiro. O gráfico superior contém apenas eventos anteriores a 1 de janeiro de 2007, e no gráfico inferior estão os eventos posteriores a esta data. 


\subsection{Parametrizações da LDF}

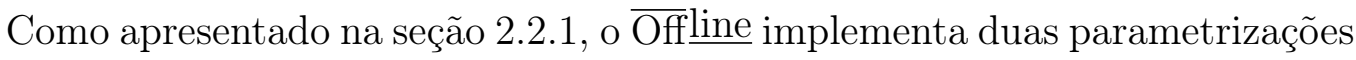
para a LDF, NKG e PL. Os eventos foram reconstruídos utilizando essas duas parametrizações e na figura 3.11 estão os perfis dos resíduos reduzidos em função da distância da estação ao centro do chuveiro.

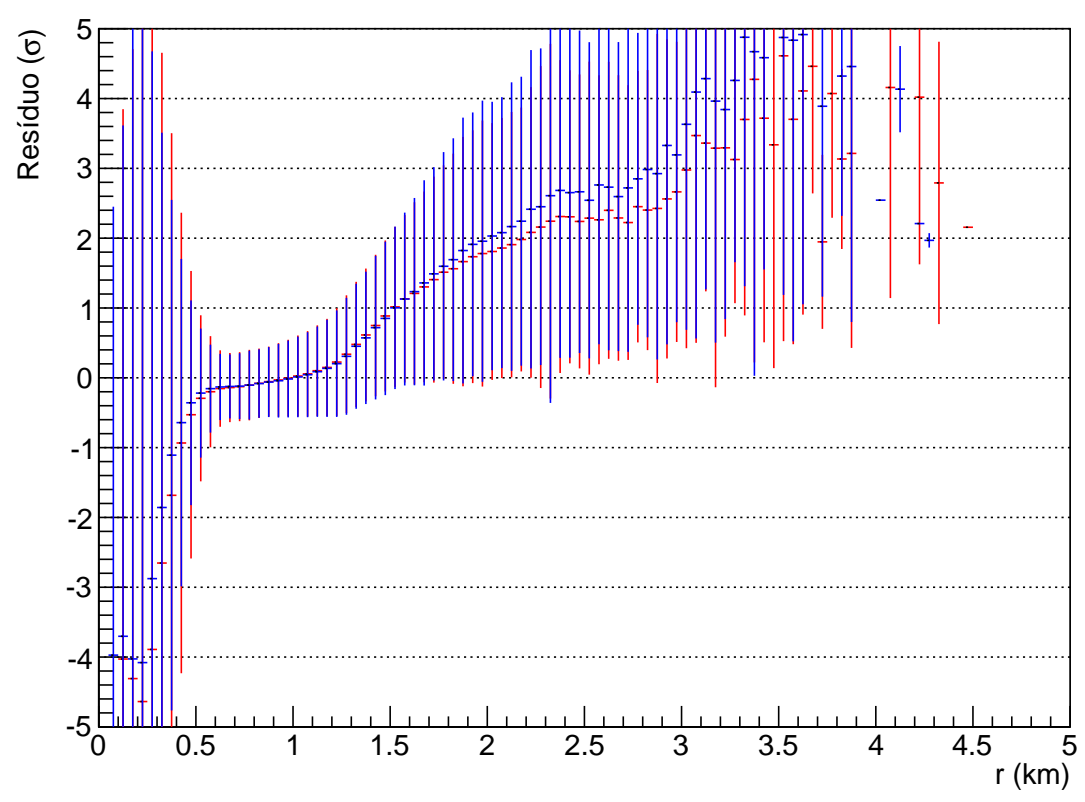

Figura 3.11: Gráfico dos perfis dos resíduos reduzidos de LDFs em função da distância ao centro do chuveiro. A curva vermelha é o perfil utilizado a equação (2.2) (NKG) como parametrização da LDF e a azul corresponde à equação (2.7) (PL).

As duas parametrizações apresentam resultados semelhantes, ou seja, superestimação do sinal para tanques a menos de $1 \mathrm{~km}$ do centro e subestimação de sinal para tanques mais distantes. Os resíduos da parametrização PL para estações mais distantes do centro do chuveiro são sistematicamente maiores que os da parametrização NKG mas a forma geral do resíduo é a mesma. Considerada essa pequena diferença entre as parametrizações, adota-se, assim como é feito pela reconstrução padrão do Observer, a NKG como para- 
metrização da LDF nos ajustes neste trabalho.

Após a familiarização com o processo de reconstrução de eventos e com a flutuação resultante dos mesmos nos eventos reais do Observatório Pierre Auger, é possível prosseguir para o próximo capítulo, onde são discutidas a metodologia utilizada nas simulações de chuveiros atmosféricos extensos e as diferenças entre os dois modelos de interação hadrônica utilizados neste trabalho. 


\section{Capítulo 4}

\section{Eventos simulados}

Esse capítulo é dedicado às simulações dos chuveiros atmosféricos. Nas próximas seções é descrita uma simplificação do algoritmo utilizado nos programas que simulam chuveiros e os diferentes modelos de interações hadrônicas utilizados por eles. Na última seção do capítulo são apresentados os resultados da reconstrução dos eventos simulados, de maneira semelhante ao realizado com os eventos reais.

O dicionário Houaiss define simular como o ato de reproduzir, da forma mais exata possível, as características e a evolução de um fenômeno, situação ou processo. As simulações são uma forma de compreender um determinado fenômeno, pois a cada iteração do aperfeiçoamento da simulação, para que ela reproduza melhor o fenômeno em questão, são impostos vínculos aos parâmetros dos modelos utilizados para descrever a evolução do fenômeno, alguns desses modelos são descartados e novos são propostos. No fim, quando o fenômeno está bem descrito pela simulação, tem-se um panorama geral do mesmo, sendo identificadas quais as partes da evolução que possuem mais impacto no fenômeno e quais são menos relevantes.

Como apresentado no capítulo 3, as parametrizações atuais da LDF não descrevem bem os eventos observados. Então, se um simulador de eventos estiver correto, isto é, a física envolvida na evolução desses eventos é conhecida e, consequentemente, ele reproduz de maneira satisfatória os eventos observados, as parametrizações atuais da LDF apresentarão a mesma dificuldade 
para descrever os eventos simulados que é encontrada com os eventos observados. Assim, este trabalho se propõe a estudar uma forma para comparar eventos observados e simulados de maneira independente das parametrizações da LDF.

A simulação de eventos do Observatório Pierre Auger é realizada em duas etapas. Na primeira são simulados os chuveiros atmosféricos extensos, em que é simulada a evolução do chuveiro e se obtém quais as partículas no nível do solo, suas posições e momentos. As únicas informações utilizadas do Observatório são relacionadas à posição geográfica: altitude, intensidade e direção do campo magnético e perfil da atmosfera. Essa etapa é a que demanda maior tempo de processamento. Na segunda etapa é simulado como esse chuveiro seria medido pelo Observatório (evento Auger). É nessa etapa que são considerados todos os detalhes das estações: geometrias, respostas da eletrônica, triggers, etc.

\subsection{Simulação de EAS}

Os programas de simulação de chuveiros atmosféricos extensos são, de maneira simplificada, propagadores de partículas. A partícula primária é colocada em uma fila de processamento e cada partícula dessa fila passa por um loop até a fila ser esvaziada.

No início do loop, retira-se a primeira partícula da fila. Essa partícula é propagada até sofrer algum tipo de interação ou decaimento possível, durante a propagação é calculada a perda de energia devido a ionização do ar e/ou ao espalhamento Coulombiano, quando se aplica. Para definir qual interação ocorreu, é utilizado um simulador de interações externo, normalmente um para interações hadrônicas de alta energia, outro para interações hadrônicas de baixa energia e um para interações eletromagnéticas. As partículas resultantes da interação ocorrida são colocadas no fim da fila de processamento, a não ser que a partícula tenha chegado ao nível do solo ou tenha energia menor que o corte estabelecido previamente.

Com o aumento da energia da partícula primária, esse algoritmo apresenta

uma limitação computacional. Um primário de $10^{20} \mathrm{eV}$ produz um chuveiro 
com aproximadamente $10^{11}$ partículas. Considerando que se armazena para cada partícula, sua posição (3 doubles $\left.{ }^{1}\right)$, o tempo (1 double), o momento (3 doubles) e o tipo de partícula $\left(1 c^{c h a r^{2}}\right.$ ), e que, em um sistema linux de 64 bits, um double ocupa 8 bytes e um char 1 byte, para representar um chuveiro seriam necessários, aproximadamente, $5 \mathrm{~TB}^{3}$. Além disso, com os computadores disponíveis atualmente, seria muito difícil produzir uma biblioteca com milhares de chuveiros em um tempo finito.

Para resolver esse problema, foi proposto por Hillas [54] um algoritmo chamado de thin sampling. A implementação desse algoritmo varia entre os programas de simulação existentes, e uma descrição geral se encontra nos próximos parágrafos.

Define-se a fração da energia da partícula primária $\left(E_{0}\right)$, conhecida como thinning level $\left(\epsilon_{t h}\right)$, que será o limite para a atuação do algoritmo. Em cada interação do loop da simulação, tem-se uma reação do tipo:

$$
A \rightarrow \sum_{i=1}^{N} B_{i}
$$

onde $N>0$. Seja $E_{A}$ e $E_{i}$ as energias das partículas $A$ e $B_{i}$ resultantes da interação, respectivamente.

Quando $\sum_{i} E_{i}<\epsilon_{t h} E_{0}$, apenas uma das partículas secundárias é propagada, sendo todas as outras descartadas. A probabilidade de cada partícula ser propagada é $p_{i}=E_{i} / \sum_{j} E_{j}$. A partícula "sobrevivente" é adicionada ao início da fila do loop com um peso $w_{i}=w_{A} / p_{i}$, onde $w_{A}$ é o peso da partícula $A$.

Quando $\sum_{i} E_{i} \geq \epsilon_{t h} E_{0}$, cada partícula $B_{i}$ é tratada individualmente. Partículas com $E_{i} \geq \epsilon_{t h} E_{0}$ são propagadas com $w_{i}=1$. Quando $E_{i}<\epsilon_{t h} E_{0}$, a partícula tem uma probabilidade $p_{i}=E_{i} /\left(\epsilon_{t h} E_{0}\right)$ de ser propagada. Se isso ocorrer ela adquire peso $w_{i}=w_{A} / p_{i}$.

Isso significa que todas as partículas com energia maior que $\epsilon_{t h} E_{0}$ são propagadas, isto é, o número de partículas no chuveiro cresce exponencial-

\footnotetext{
${ }^{1}$ double: tipo de variável de $\mathrm{C} / \mathrm{C}++$ utilizado para representar um número de ponto flutuante com dupla precisão.

${ }^{2}$ char: tipo de variável de $\mathrm{C} / \mathrm{C}++$ utilizado para representar um caractere.

${ }^{3} 1 \mathrm{~TB}=1024^{4}$ bytes
} 
mente com o desenvolvimento do mesmo. Quando as energias das partículas são menores que $\epsilon_{t h} E_{0}$, apenas uma partícula é propagada de cada interação, e consequentemente o número de partículas permanece aproximadamente constante.

Neste trabalho foram utilizados dois programas para simulação dos chuveiros atmosféricos extensos: o AIRES e o CORSIKA.

O AIRES [55, 56] (AIR-shower Extended Simulations) foi desenvolvido por Sergio J. Sciutto, da Universidad Nacional de La Plata, Argentina. Escrito em Fortran e baseado no MOCCA [54], permite utilizar como modelo para as interações hadrônicas de alta energia os programas SIBYLL [57], QGSJET01 [58] e QGSJET-II [59]. Neste trabalho foi utilizada a versão mais recente do software 2.8.4a, de 12 de dezembro de 2006, e o SIBYLL 2.1 como modelo para as interações hadrônicas.

O CORSIKA [60] (COsmic Ray SImulations for KAscade) foi inicialmente desenvolvido para simular eventos para o experimento KASCADE [61] em Karlsruhe, Alemanha, em 1989 por D. Heck and T. Pierog. Também escrito em Fortran, foi refinado ao longo dos anos e evoluiu para uma ferramenta utilizada por diversos grupos. Atualmente é utilizado em experimentos com telescópios Cherenkov ( $\mathrm{E} \sim 10^{12} \mathrm{eV}$ ) até experimentos como o Observatório Pierre Auger $\left(\mathrm{E} \sim 10^{20} \mathrm{eV}\right)$. Possibilita o uso de diversos modelos para as interações hadrônicas de alta energia, SIBYLL [57], QGSJET01 [58], QGSJETII [59], DPMJET [62], neXus [63], EPOS [64] e VENUS [65]. Neste trabalho foi utilizado o CORSIKA versão 6735, de junho de 2008, e o EPOS 1.60 como modelo de interações hadrônicas.

\subsubsection{SIBYLL vs EPOS}

Trabalhos que utilizam modelos mais tradicionais de interações hadrônicas, como o SIBYLL e QGSJET01(-II), constataram que as simulações possuem menos múons que os eventos reais [66], [67] e [68]. Seus autores sugerem que o uso do EPOS como modelo hadrônico pode minimizar essa deficiência.

Sabe-se que $90 \%$ da energia dos chuveiros atmosféricos extensos termina na sua componente eletromagnética, e os outros $10 \%$ nos múons produzidos 
em decaimentos hadrônicos. Essa componente muônica depende fortemente dos modelos hadrônicos (chegando a um fator dois para diferentes modelos), enquanto o desenvolvimento da parte eletromagnética (em particular seu máximo $X_{\max }$ ) é relativamente robusto e bem conhecido (variando menos de $10 \%$ entre diferentes modelos). O uso de diferentes modelos de interações hadrônicas pode produzir diferentes flutuações nas LDF de chuveiros simulados.

Na figura 4.1 é possível observar o quanto são extrapolados os modelos hadrônicos em relação a dados obtidos dos aceleradores de partículas. A área hachurada é uma estimativa da incerteza desses modelos. Verifica-se também a grande diferença entre as seções de choque de interação para os diversos modelos nas energias maiores que $10^{19} \mathrm{eV}$.

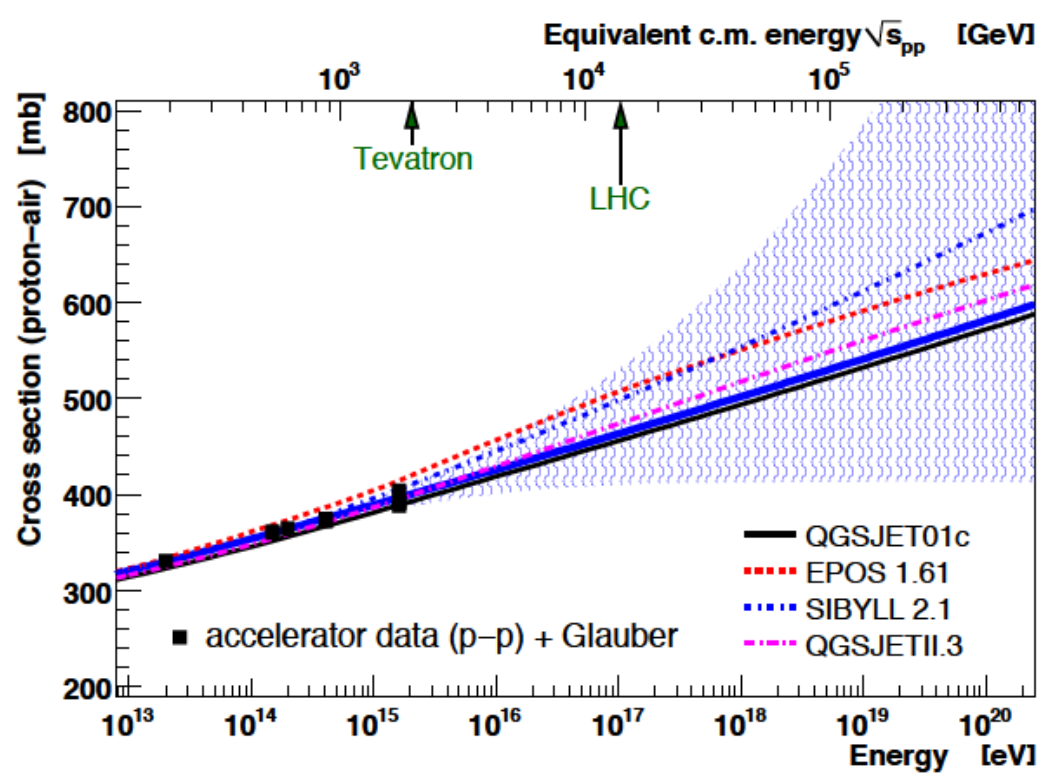

Figura 4.1: Gráfico da seção de choque próton-ar em função da energia para diferentes modelos de interação hadrônica comparados com dados de aceleradores. A área hachurada é uma estimativa da incerteza desse modelos [69].

A referência [70], utilizando o EPOS, observa pela primeira vez uma compatibilidade dos dados de $X_{\max }$ (provenientes do HiRes) e dos dados de múons (provenientes do HiRes-MIA) com a transição da composição dos RC primá- 
rios de pesado para leve nas energias entre $10^{17}$ e $10^{18} \mathrm{eV}$.

Entretanto, quando simulações do EPOS são comparadas com eventos do Observatório Pierre Auger [71], o EPOS se aproxima mais dos dados do SD do que o SIBYLL e o QGSJET-II, mas os dados de $X_{\max }$ obtidos com o FD não são compatíveis com o EPOS.

\subsubsection{Biblioteca de EAS}

Para este trabalho foi produzida uma biblioteca de chuveiros atmosféricos extensos simulados. Esta biblioteca tenta reproduzir o que é observado pelo Observatório Pierre Auger, a energia das partículas das primárias esta entre $10^{18}$ e $2 \cdot 10^{20} \mathrm{eV}$, distribuídas segundo uma lei de potência, $E^{-2,7}$, que corresponde aproximadamente ao espectro de raios cósmicos nesta faixa de energia. O ângulo zenital está distribuído uniformemente entre $0^{\circ}$ e $65^{\circ}$ e o ângulo azimutal, entre $0^{\circ}$ e $360^{\circ}$. Foi utilizado um thinning relativo de $10^{-7}$ e considerada a localização de Malargüe, para efeitos de campo magnético e altitude.

A biblioteca é constituída de eventos simulados com AIRES e com CORSIKA. Utiliza como partícula primária próton e núcleo de ferro, como mostra a tabela 4.1. Considerada a limitação de tempo para realizar este trabalho optou-se por realizar o maior número de simulações possível para cada um dos programas utilizados, sendo o tempo total de uso de máquina aproximadamente o mesmo para cada programa. Como as simulações do CORSIKA foram cinco vezes mais lentas que as do AIRES, foram produzidos cinco vezes menos chuveiros com CORSIKA em relação ao AIRES. 


\begin{tabular}{lcccc}
\hline & \multicolumn{2}{c}{ AIRES } & \multicolumn{2}{c}{ CORSIKA } \\
\cline { 2 - 5 } & chuveiros & tempo* & chuveiros & tempo* \\
\cline { 2 - 5 } próton & 50000 & 1307 & 9986 & 1308 \\
ferro & 50000 & 1242 & 9984 & 1675 \\
\hline
\end{tabular}

Tabela 4.1: Número de chuveiros simulados com o AIRES e CORSIKA utilizando próton e ferro como partículas primárias. ${ }^{*} \mathrm{O}$ tempo é expresso em número de dias que seriam necessários para simular todos os chuveiros em 1 núcleo de processamento (equivalente a um core 2 duo de $3 \mathrm{GHz}$ ).

Tanto o CORSIKA, quanto o AIRES foram compilados com o Intel Fortran Compiler Professional Edition 11.1. Este compilador foi escolhido porque, em testes preliminares, produziu binários que rodam aproximadamente na metade do tempo que binários gerados pelo gcc 4.3.4. Isto é, se fossem utilizados binários produzidos com o gcc, em vez dos 5532 CPU-dia ${ }^{1}$ seriam necessários 11 mil CPU-dia. O uso de compiladores otimizados como esse é a maneira mais barata e simples de dobrar a capacidade de processamento disponível. Entretanto não são todos os programas que são facilmente compilados com esse compilador. Por exemplo, não foi possível compilar o $\overline{\mathrm{Off}} \underline{\text { line }}$ com o compilador equivalente para $\mathrm{C}++$.

\subsection{Simulação de eventos}

Para simulação de eventos Auger foi utilizado o Offlline, versão v2r6p2, com a sequência padrão de módulos sugerida na documentação do programa. Para cada chuveiro simulado pelo AIRES e pelo CORSIKA foram simulados 10 eventos, sendo que o centro dos chuveiros foi escolhido aleatoriamente dentro da área ocupada pelo SD. Entretanto, não foram obtidos 10 vezes mais eventos do que chuveiros, pois cada evento precisa passar por um trigger igual ao utilizado no Observatório. No pior caso, apenas $60 \%$ dos eventos geraram trigger, para chuveiros iniciados por prótons simulados com o AIRES, e no

\footnotetext{
${ }^{1} \mathrm{CPU}$-dia: número de núcleos que seriam necessários para realizar o processamento em apenas um dia.
} 
melhor caso $88 \%$, para chuveiros iniciados por núcleos de ferro simulados com o CORSIKA, vide tabela 4.2. Chuveiros simulados com o CORSIKA geram entre 16 e $19 \%$ mais eventos que os chuveiros provenientes do AIRES.

\begin{tabular}{lcccc}
\hline & \multicolumn{2}{c}{ AIRES } & \multicolumn{2}{c}{ CORSIKA } \\
\cline { 2 - 5 } & eventos & tempo* & eventos & tempo* \\
\cline { 2 - 5 } próton & 296863 & 978 & 78506 & 328 \\
ferro & 361471 & 908 & 88240 & 297 \\
\hline
\end{tabular}

Tabela 4.2: Número de eventos simulados utilizando chuveiros provenientes do AIRES e do CORSIKA utilizando prótons e núcleos de ferro como partículas primárias. ${ }^{*} \mathrm{O}$ tempo é expresso em número de dias que seriam necessários para simular todos os chuveiros em 1 núcleo de processamento.

A simulação dos eventos com o CORSIKA foi realizada no cluster do Instituto de Física da USP de São Carlos. Já a simulação dos eventos com AIRES foi realizada no cluster montado para a realização deste trabalho. Montado, configurado e administrado pelo estudante especialmente para este trabalho. Ele é composto por 3 máquinas, contando com 20 núcleos de processamento, rodando entre 2,4 e 2,7 GHz, e 16 TB para armazenamento.

\subsection{Reconstrução dos eventos simulados}

A reconstrução dos eventos simulados também foi feita no $\overline{\text { Offlline, versão }}$ v2r6p2, com a sequência padrão de módulos sugerida na documentação do programa com a adição do módulo SdRecTree, seção 2.2.2. Os cortes utilizados foram os mesmos utilizados para os eventos reais, descritos na seção 3.1, descartando o corte dos bad periods, pois não se aplica a eventos simulados. Todas as reconstruções foram realizadas no cluster de São Paulo.

A estimativa de energia em um evento SD é obtida do S(38), que depende do ângulo zenital do chuveiro e do S(1000). O S(1000) depende da intensidade do sinal das estações e boa parte do sinal das estações é proveniente de múons. Portanto a falta de múons influencia na estimativa de energia 
em eventos simulados, pois a relação entre $\mathrm{S}(38)$ e a energia do chuveiro é obtida de eventos híbridos reais, como apresentado na seção 1.7. Isso é observado na figura 4.2 , onde é mostrado que os eventos simulados têm energia reconstruída sistematicamente menor que a energia simulada para a partícula primária. Eventos com núcleos de ferro como partículas primárias simulados pelo CORSIKA/EPOS são os únicos eventos que têm a energia reconstruída compatível com a energia simulada. Nos eventos cuja partícula primária é próton, o erro sistemático é maior que nos eventos simulados com núcleo de ferro, independentemente do modelo de interação hadrônica utilizado. Os eventos provenientes de chuveiros simulados com CORSIKA/EPOS possuem erro sistemático menor que os provenientes do AIRES/SIBYLL. Esse é um indício de que o CORSIKA/EPOS pode descrever melhor os eventos reais do que o AIRES/SIBYLL.

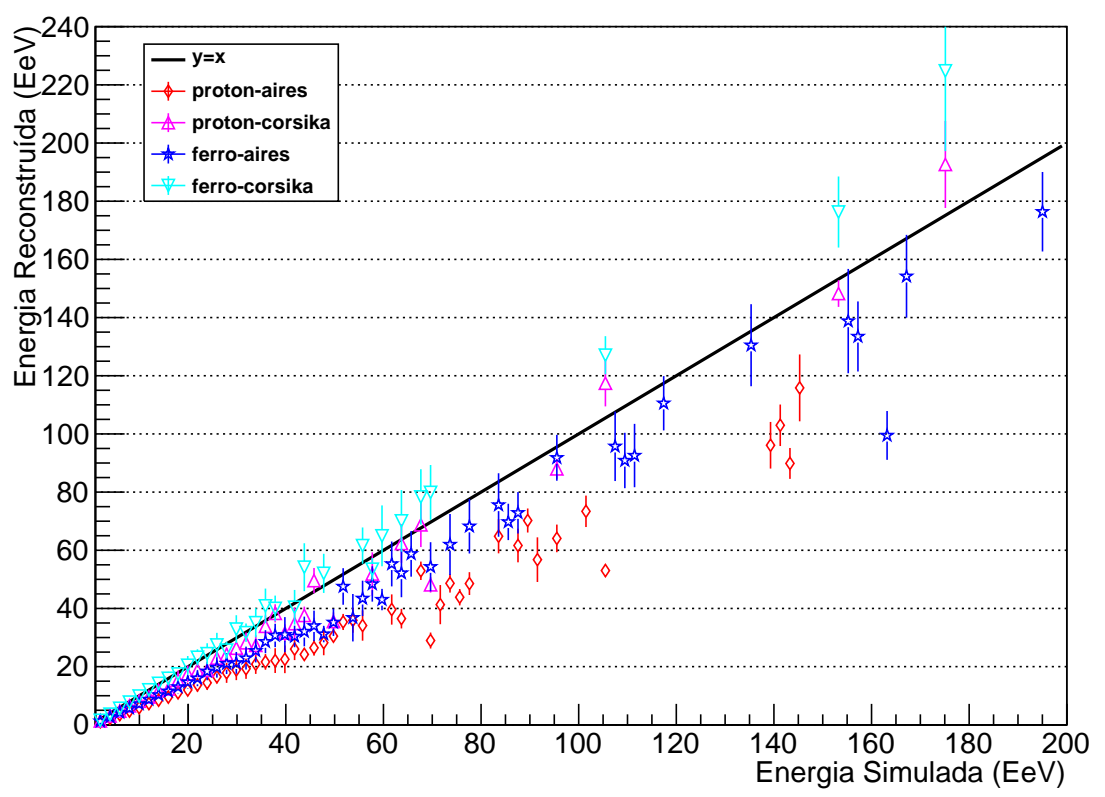

Figura 4.2: Gráfico do perfil da energia reconstruída em função da energia simulada para os eventos simulados com o AIRES/SIBYLL e CORSIKA/EPOS; as barras de incerteza são o desvio padrão da média. Os valores abaixo da reta possuem energia reconstruída menor que a energia simulada. 
As LDFs das simulações são qualitativamente semelhantes entre si, mas possuem uma diferença sistemática no sinal devido à deficiência de múons nas simulações. A média das LDFs das simulações se ordenam do maior para o menor em Fe/CORSIKA, p/CORSIKA, Fe/AIRES e p/AIRES, respectivamente, figura 4.3a. A distribuição das posições das estações nos eventos simulados também possuem comportamento semelhante entre si e em relação aos eventos reais, como observado na figura 4.3b. A aparente incompatibilidade é devida aos diferentes números de eventos em cada conjunto. A LDF e a distribuição de posições podem ser comparadas com as dos eventos reais que estão na figura 3.6.

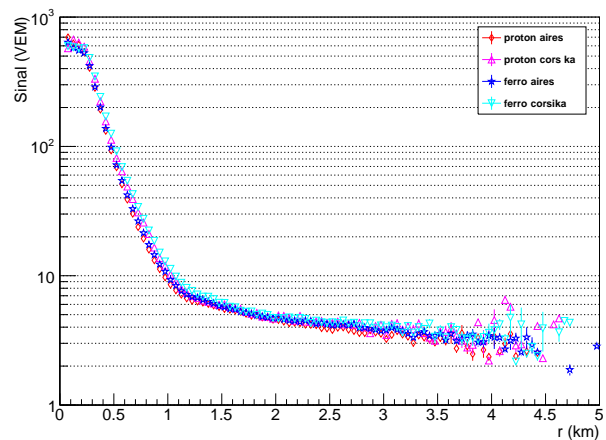

(a)

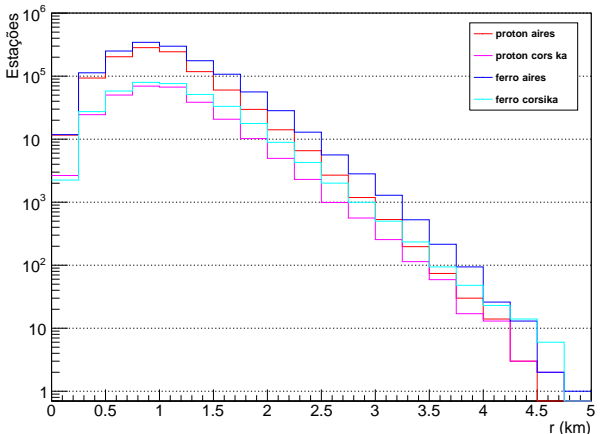

(b)

Figura 4.3: (a) Perfil do sinal das estações em função da distância ao centro do chuveiro; as barras de incerteza são os desvios padrão das médias. (b) Histograma das posições das estações. Eventos simulados.

As distribuições de energia da partícula primária (figura 4.4a) e do ângulo zenital (figura 4.4b) dos eventos simulados também possuem um comportamento semelhante salvo as diferenças nos números de eventos dos conjuntos. E, como esperado, não é observada uma correlação entre a energia da partícula primária e o ângulo zenital dos eventos simulados, como mostram os perfis na figura 4.5. Sabe-se que, nesse caso, as barras de incerteza estão subestimadas, pois para cada chuveiro simulado, são gerados 10 eventos, e por isso tem-se 10 eventos com a mesma energia e mesmo ângulo zenital. Conse- 
quentemente a incerteza deve ser $\sqrt{10} \sim 3.16$ vezes maior. Por essa mesma razão, o número mínimo de eventos num canal no histograma da figura 4.4a é $10^{1}$.

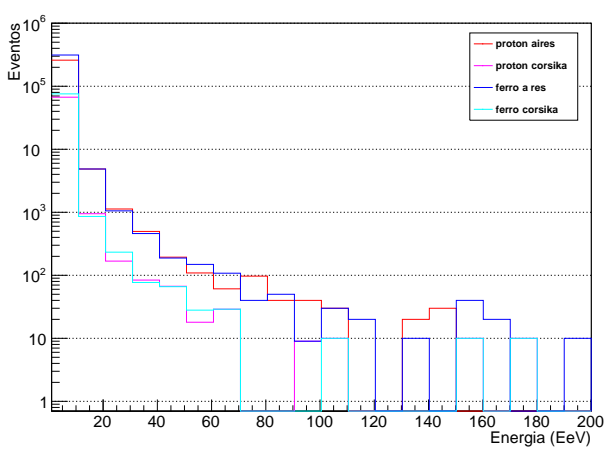

(a)

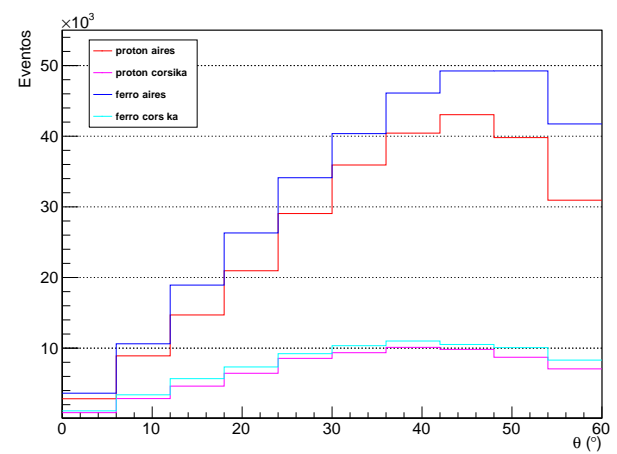

(b)

Figura 4.4: Distribuição da energia dos eventos simulados na figura (a) e a distribuição de ângulo zenital $(\theta)$ na figura (b)

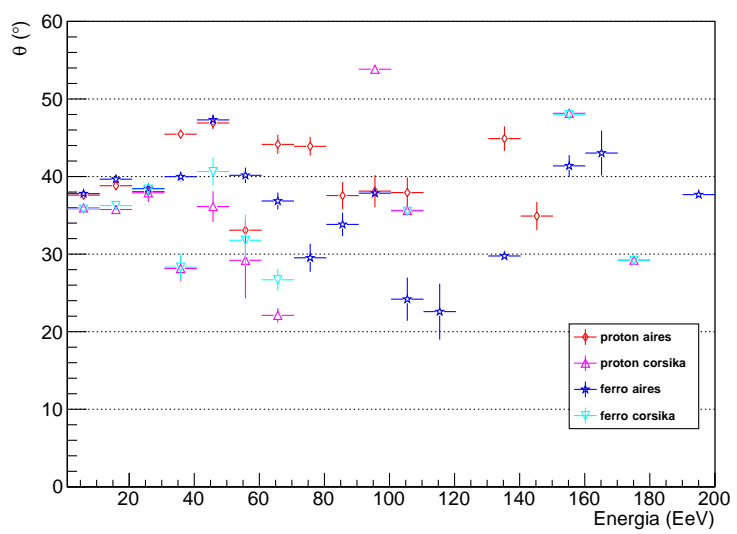

Figura 4.5: Perfil do ângulo zenital $(\theta)$ em função da energia da partícula primária; as barras de incerteza correspondem ao desvio padrão da média, entretanto sabe-se que este está subestimado, para detalhes vide texto.

\footnotetext{
${ }^{1} \mathrm{Na}$ verdade é $\sim 10$, pois nem todo o evento simulado passa pelo trigger do Observatório.
} 
Na figura 4.6 estão plotados os resíduos reduzidos dos ajustes das LDFs dos eventos simulados. O comportamento dos resíduos é semelhante entre os diferentes programas de simulação e partículas primárias. A maior amplitude do eventos provenientes do AIRES vem do fato do mesmo ter 5 vezes mais eventos que o CORSIKA. Também não se observa a média negativa para os resíduos a menos de $0,5 \mathrm{~km}$ como ocorre nos eventos reais, o que indica que ou a saturação não é bem simulada ou estações saturadas em eventos reais não são identificadas corretamente.

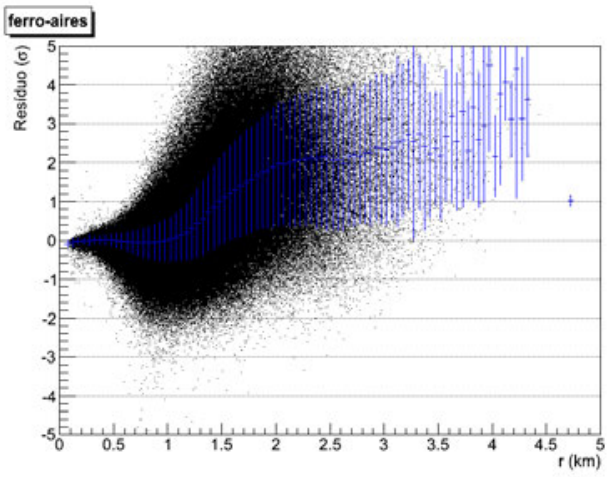

(a)

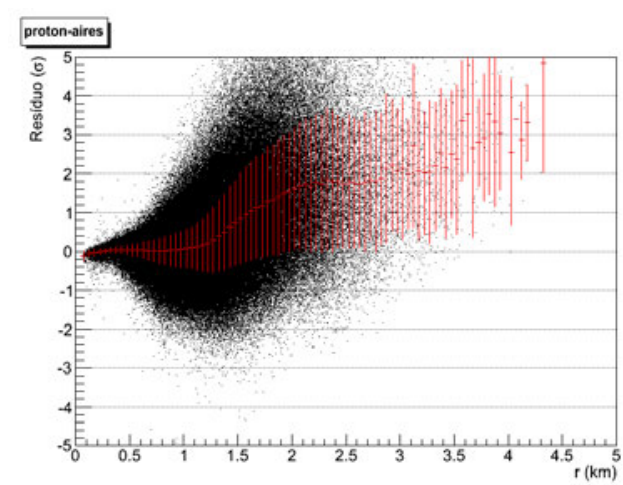

(c)

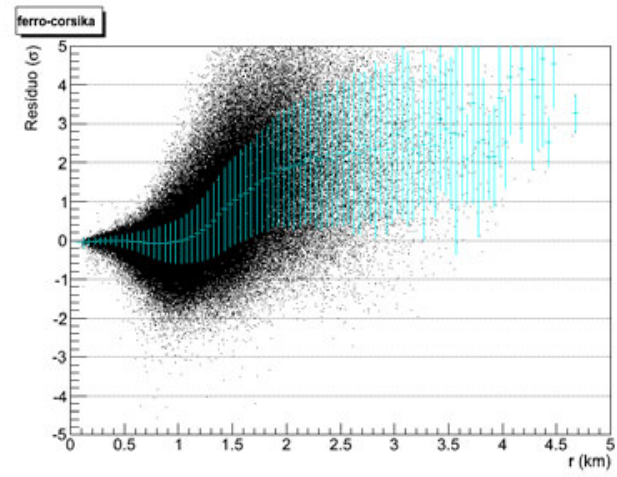

(b)

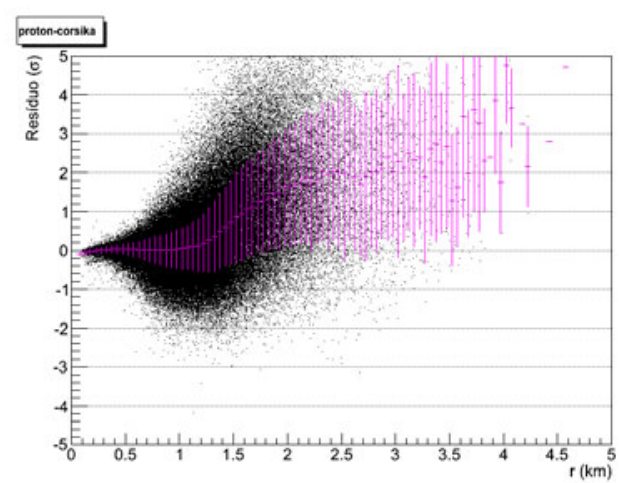

(d)

Figura 4.6: Gráfico de resíduos reduzidos da LDFs em função da distância ao centro do chuveiro. As marcas coloridas representam os perfis das distribuições. Os gráficos da esquerda são de chuveiros simulados pelo AIRES/SIBYLL e os da direita pelo CORSIKA/EPOS. 
Na sobreposição dos perfis dos resíduos, figura 4.7, se observa que os resíduos dos eventos originados por núcleos de ferro são diferentes dos originados por prótons tanto para o CORSIKA/EPOS quanto para o AIRES/SIBYLL, particularmente entre 0,5 e 2,2 km com uma intersecção em $1 \mathrm{~km}$. Além disso as dispersões são compatíveis entre todos os conjuntos de eventos simulados.

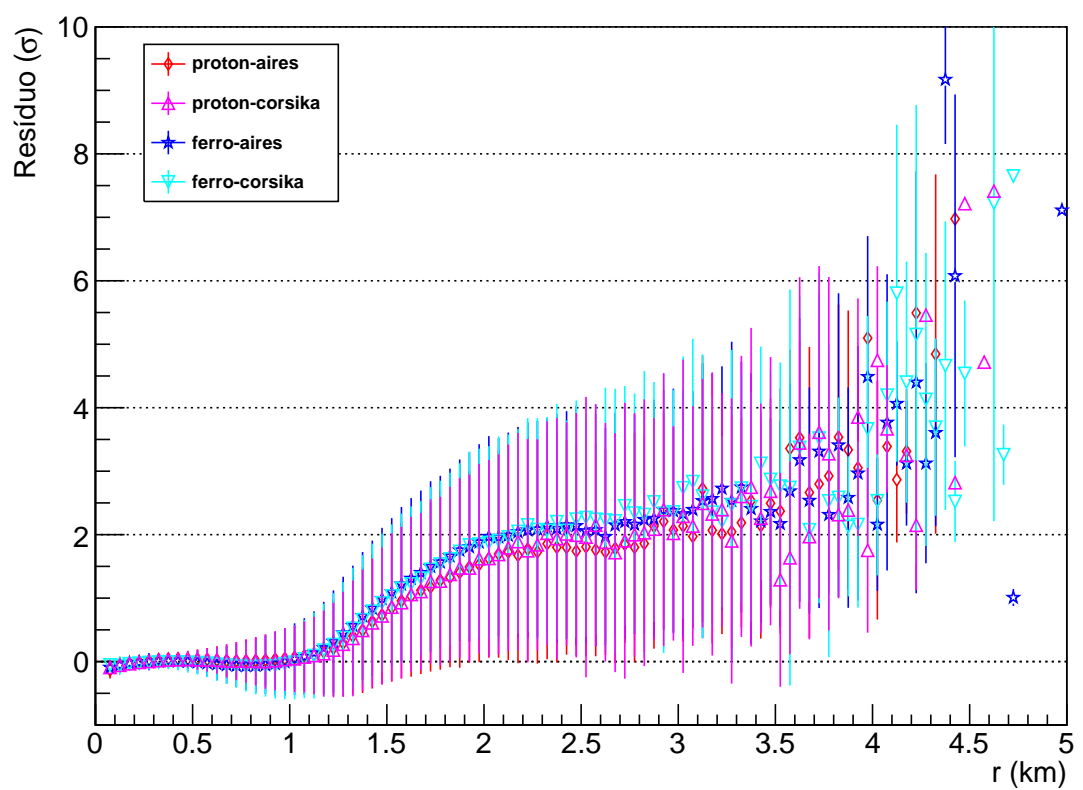

Figura 4.7: Sobreposição dos perfis dos resíduos contidos na figura 4.6. 


\section{Capítulo 5}

\section{Análise}

Nos capítulos anteriores foi exposto um panorama geral sobre os eventos reais e simulados, assim como suas reconstruções e resíduos. Neste capítulo o estudo das reconstruções é aprofundado e são estudadas as diferenças entre reconstruções que consideram as estações silenciosas ou não e as reconstruções que utilizam as variáveis $\beta$ e $\gamma$ da NKG parametrizadas ou ajustadas. Depois são apresentadas metodologias para comparar os eventos reais e simulados com o objetivo de obter uma estimativa da composição das partículas primárias dos chuveiros medidos pelo Observatório Pierre Auger. E por último é apresentado um erro sistemático nos ajustes da LDF em estações com sinal próximo ao trigger, proposta uma correção e apresentadas as principais consequências dessa correção.

O número total de eventos reconstruídos utilizados neste capítulo, separados para cada conjunto de eventos, é apresentado na tabela 5.1. Nem todos os eventos reconstruídos são utilizados na análise, pois esses números foram contabilizados antes de aplicados os cortes de energia e ângulo zenital. Os eventos reais do período I não são utilizados nas análises deste capítulo, apesar deles representarem quase $25 \%$ do total de eventos. As figuras 3.9 e 3.10 mostram uma diferença muito grande na qualidade dos eventos dos dois períodos e o uso dos dados do período I comprometeria os resultados das análises aqui apresentadas. 


\begin{tabular}{lcc}
\hline & \multicolumn{2}{c}{ eventos } \\
\hline Período I & \multicolumn{2}{c}{440821} \\
Período II & \multicolumn{2}{c}{1544102} \\
\cline { 2 - 3 } & próton & ferro \\
\cline { 2 - 3 } AIRES & 284416 & 348387 \\
CORSIKA & 72400 & 82209 \\
\hline
\end{tabular}

Tabela 5.1: Número de eventos reconstruídos utilizados neste trabalho, sejam eles provenientes de simulações do AIRES e do CORSIKA ou de eventos reais. Entretanto nem todos os eventos reconstruídos satisfazem os cortes de energia e ângulo zenital utilizados neste trabalho.

\subsection{Influência das estações silenciosas}

Na referência [72] é levantada a hipótese de que o uso das estações silenciosas ${ }^{1}$ nos ajustes tem grande influência nos resíduos sistematicamente positivos das estações mais distantes do centro do chuveiro, como ilustrado nas figuras 3.11 e 4.7 .

Na região onde existem estações silenciosas (SS) o valor da LDF deve estar próximo de $3 \mathrm{VEM}^{2}$. Supondo que o sinal das estações seja distribuído simetricamente em torno da LDF, parte das estações consideradas no ajuste não são plotadas no gráfico de resíduos, pois o resíduo não está definido para estações com sinal zero, as SS. Esse "corte" assimétrico nos resíduos plotados implicaria em um gráfico com médias sistematicamente positivas. Seguindo essa linha de raciocínio, um ajuste em que não são consideradas as SS os resíduos devem ser compatíveis com zero nas regiões distantes ao centro do chuveiro, pois nesse caso todas as estações do ajuste estão no gráfico de resíduos. Esse fenômeno acontece, mas sua amplitude não é suficiente para explicar os resíduos sistematicamente positivos das estações mais distantes ao centro do chuveiro. Na figura 5.1 está plotada a diferença dos perfis dos

\footnotetext{
${ }^{1}$ Estações que operam sem problemas na região em que o chuveiro é detectado mas não registram sinal acima do trigger.

${ }^{2}$ Valor do trigger de uma estação.
} 
resíduos em ajustes com SS e sem SS. A diferença é da ordem de 1 incerteza apenas a mais de $3 \mathrm{~km}$ do centro do chuveiro mas, nesse caso é compatível com zero. Estações mais próximas ao centro do chuveiro, a menos de $2 \mathrm{~km}$, possuem resíduos da ordem de 0,1 incertezas maior nos ajustes com SS. Apesar de ser incompatível com zero ${ }^{1}$, essa diferença é muito pequena frente a outros efeitos presentes no ajuste, e, no contexto deste trabalho pode ser desprezada. Ou seja, todos os ajustes utilizados neste trabalho contêm as estações silenciosas.

\footnotetext{
${ }^{1}$ Devido a incerteza da incerteza.
} 


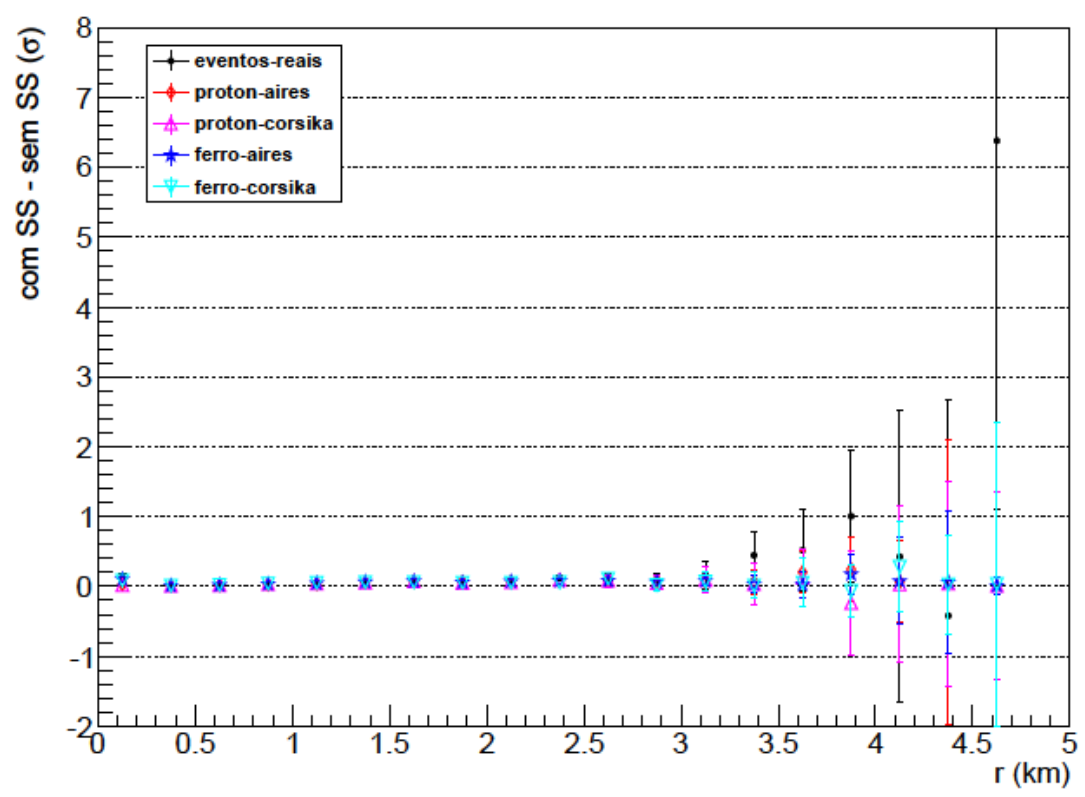

(a)

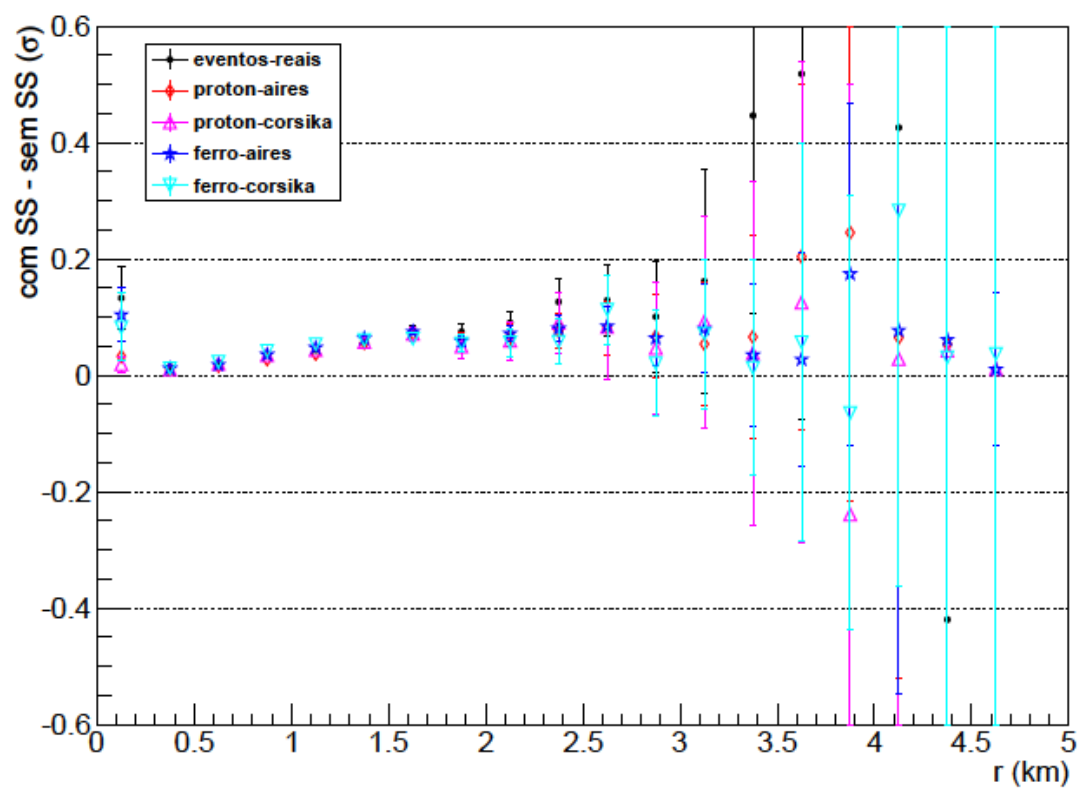

(b)

Figura 5.1: Diferença entre os perfis dos resíduos de ajustes com estações silenciosas e sem estações silenciosas (SS). O gráfico inferior é um zoom na escala do gráfico superior para facilitar a visualização das diferenças das estações mais próximas ao centro do chuveiro. 


\subsection{A função NKG com variáveis parametriza- das}

A reconstrução padrão do Auger Observer [36] utiliza a função NKG modificada (2.2) em seus ajustes. São ajustados 3 parâmetros: a posição do centro do chuveiro (um ponto no plano do array) e o $S_{1000}$. As variáveis $\beta$ e $\gamma$ são obtidas de suas parametrizações (equações (2.3) e (2.4)), independentemente do número de estações no ajuste. Misturar ajustes com número de parâmetros ajustados diferentes em uma mesma análise pode causar uma tendenciosidade. Como não é possível ajustar $\beta$ e $\gamma$ para todos os eventos, pois a maioria dos eventos possui apenas 3 ou 4 estações, opta-se pelo ajustes de 3 variáveis (coordenadas x e y do centro do chuveiro e $S_{1000}$ ) e a parametrização das outras duas $(\beta$ e $\gamma)$. Entretanto forçar parâmetros também pode causar uma tendenciosidade. Nesta seção estuda-se qual a fração dos eventos cujas variáveis $\beta$ e $\gamma$ são ajustadas e, nesses casos, quão diferentes elas são de suas respectivas parametrizações. Também são discutidas as implicações deste tipo de ajuste.

Considerando ajustes do tipo A quando as variáveis $\beta$ e $\gamma$ são parametrizadas e tipo B quando as variáveis $\beta$ e $\gamma$ são ajustadas, a fração de eventos tipo B cresce com o aumento da energia da partícula primária e com o ângulo zenital $(\theta)$, como apresentado nos gráficos da figura 5.2. No caso da dependência com a energia, isso acontece porque o chuveiro fica mais "largo" com o aumento da energia. Nota-se que mais de $80 \%$ dos ajustes com energia reconstruída maior que $10 \mathrm{EeV}$ são do tipo B. Em relação a $\theta$, a dependência possui uma amplitude menor, crescente entre 5 e $25 \%$. Isso também é esperado pois o chuveiro possui uma simetria cilíndrica em torno do eixo. Um chuveiro vertical, $\theta=0^{\circ}$, é observado aproximadamente como um círculo pelo SD. Com a inclinação, o círculo se deforma em uma elipse, com o eixo maior paralelo à projeção do eixo do chuveiro no solo. Quanto mais inclinado o chuveiro, maior é o eixo maior da elipse enquanto o eixo menor se mantém aproximadamente constante. Portanto espera-se que eventos mais inclinados possuam mais estações do que eventos de mesma energia menos inclinados e, consequentemente, têm maior probabilidade de um ajuste de tipo B. A 
dependência do número de ajustes tipo $\mathrm{B}$ com a energia e o ângulo zenital nos diferentes conjuntos de eventos (reais e simulados) é semelhante, mas estatisticamente incompatível.

Para os ajustes do tipo $\mathrm{B}$, foram calculadas duas grandezas: $\Delta \beta$, definido como diferença entre $\beta$ ajustado e $\beta$ parametrizado, e $\Delta \gamma$, dado pela diferença entre $\gamma$ ajustado e $\gamma$ parametrizado. O valor típico de $\beta$ parametrizado é -2 e de $\gamma$ é 0 . Na figura 5.3 observa-se a dependência dessas grandezas com a energia reconstruída do chuveiro. Existe uma correlação negativa entre $\beta$ e $\gamma$, mas a amplitude em $\Delta \gamma$ é aproximadamente 3 vezes maior que em $\Delta \beta$. Nos eventos simulados, as diferenças possuem a mesma forma funcional mas é possível diferenciar os chuveiros de ferro dos de próton, pelo menos até $20 \mathrm{EeV}$. Acima dessa energia, o número menor de eventos pode ter ocultado essa separação. Já nos eventos reais, as diferenças seguem um comportamento distinto das simulações, sendo difícil de fazer uma correlação indicativa de composição.

Também é observada uma correlação negativa entre $\Delta \beta$ e $\Delta \gamma$ quando essas grandezas são plotadas em função do ângulo zenital, figura 5.4. As amplitudes são bem menores que as da figura 5.3, e as incertezas relativamente maiores, mas a relação de amplitudes $\Delta \gamma / \Delta \beta$ continua em torno de 3. A separação dos diferentes conjuntos de eventos é bem mais difícil, e o máximo que se pode notar é uma possível tendência de separação dos conjuntos para ângulos maiores que $40^{\circ}$, mas nada mais do que isso.

A NKG modificada que é utilizada para descrever a LDF atualmente possui apenas um parâmetro de forma, $S_{1000}$, e uma dependência implícita do ângulo zenital $\theta$. Essa dependência é ilustrada na figura 5.5, onde estão plotadas a NKG para vários valores de $S_{1000}$ nos dois extremos do ângulo zenital. A extensão dos chuveiros cresce com o ângulo zenital e com $S_{1000}$, e a dependência com essas duas variáveis é condizente com o esperado e demonstra uma possível ambiguidade na NKG. Um mesmo chuveiro pode ser compatível com dois pares diferentes dos parâmetros $S_{1000}$ e $\theta$, isto é, um $S_{1000}$ menor com um $\theta$ maior ou um $S_{1000}$ maior com um $\theta$ menor. Por isso é importante que a estimativa de $\theta$ venha de uma análise independente, como a utilizada no módulo SdPlaneFit [40]. 
Acredita-se que partículas primárias diferentes, mas com mesma energia, produzem chuveiros levemente diferentes. Essa diferença deveria ser quantificada em algum dos parâmetros da LDF ajustada. Pode ser que não seja possível fazer a identificação evento a evento devido a limitações estatísticas, mas comportamentos médios devem ser observados. Ao ajustar a LDF somente com um parâmetro de forma, $S_{1000}$, a informação de composição é misturada com a informação de energia. Consequentemente, podem ocorrer distorções como, por exemplo, chuveiros gerados por núcleos ferro com uma dada energia possuírem $S_{1000}$ em média maior que o de chuveiros gerados por prótons com mesma energia. A parametrização utilizada para a LDF não prevê um termo de forma para diferentes partículas primárias e vários fatores contribuem para isso, como: insuficiência de graus de liberdade em eventos com energia mais baixa; dificuldade de modelar a forma da LDF de maneira geral; limitações dos geradores de chuveiros atuais, devido às extrapolações dos modelos hadrônicos, que produzem eventos com sinal sistematicamente menor que eventos reais; e, talvez, a necessidade em obter prioritariamente uma estimativa de energia da partícula primária. Portanto se existe alguma diferença na LDF de partículas primárias com composição diferente, dada que a forma da LDF é fixa, essa diferença tem que ser observada nos resíduos.

Enfim, em uma análise na qual o objetivo é obter uma estimativa da energia da partícula primária é aceitável o uso da NKG com $\beta$ e $\gamma$ parametrizados, apesar da flutuação de $S_{1000}$ ser provavelmente maior. O fato de não misturar duas metodologias de ajuste diferentes evita uma mudança de um eventual viés nos eventos, pois em eventos menos energéticos é menos provável um ajuste do tipo B. Seria interessante um estudo sobre a influência do tipo do ajuste na flutuação do $S_{1000}$. Também seria de grande importância um estudo da dependência das variáveis $\beta$ e $\gamma$ com o tipo da partícula primária. As simulações mostram LDFs com formas levemente diferentes indicando que pode ser possível obter uma estimativa da composição com este tipo de análise. Não se espera que seja possível identificar a composição para cada evento individualmente, mas é provável que um comportamento médio seja observado. 


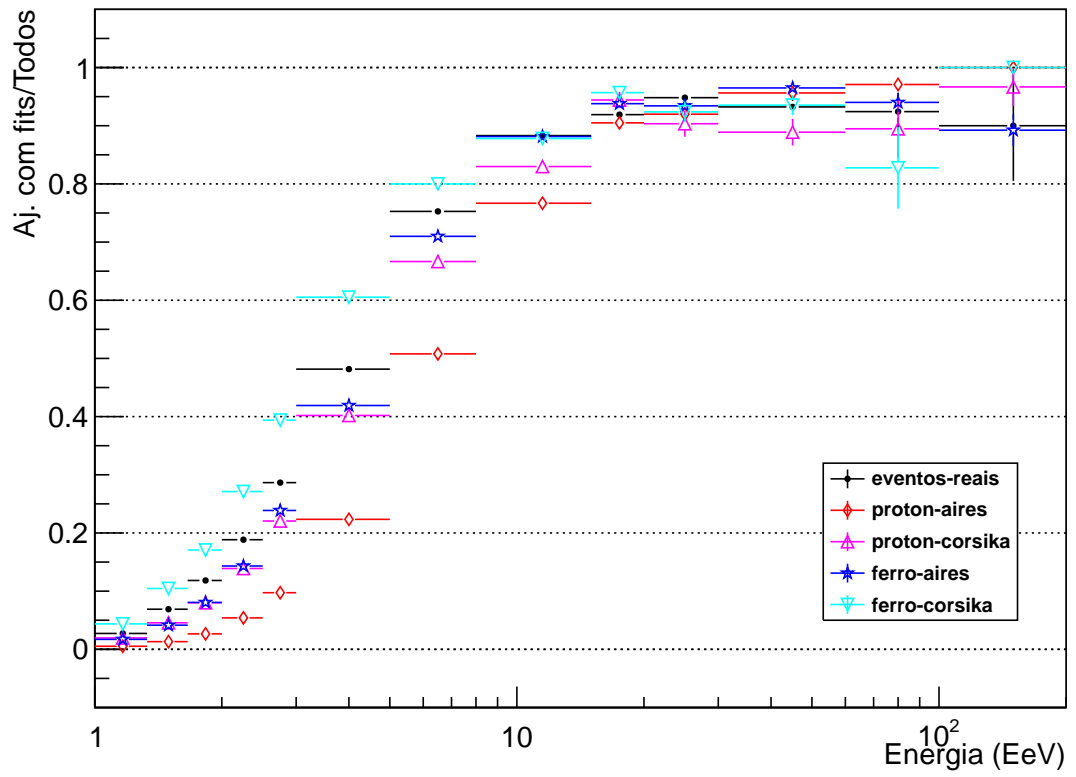

(a)

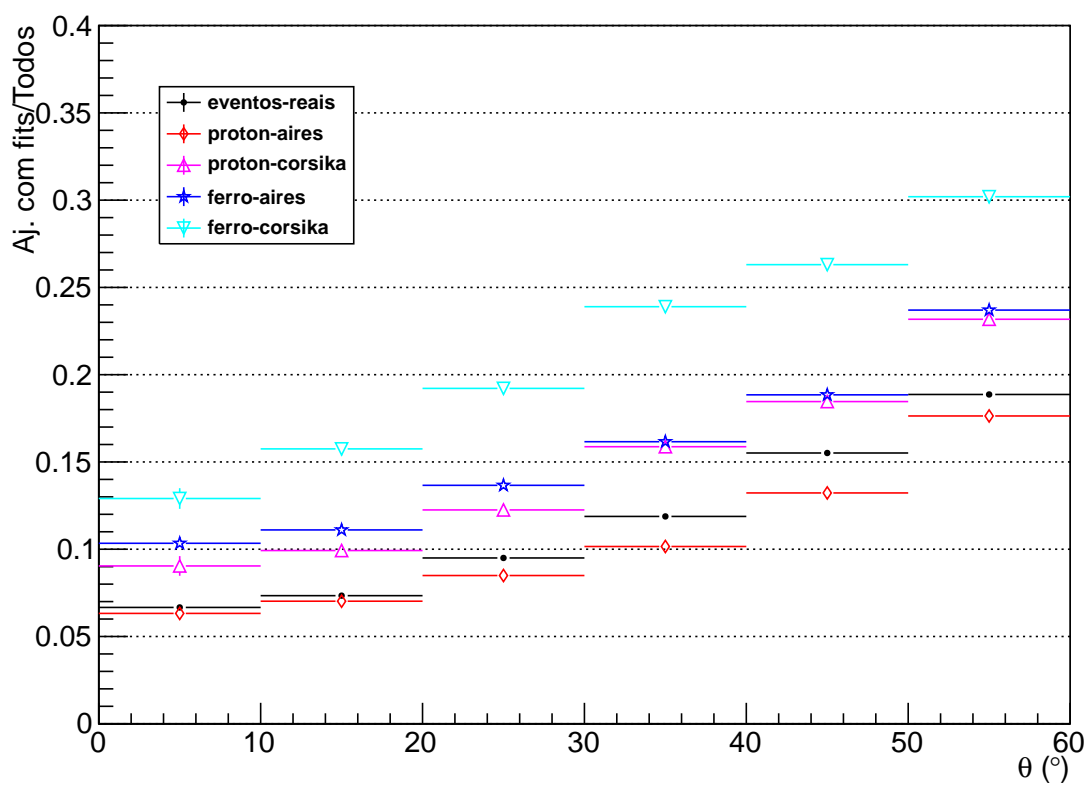

(b)

Figura 5.2: Gráfico com a fração dos eventos que têm $\beta$ ou $\gamma$ ajustados em função da energia e $\theta$. 


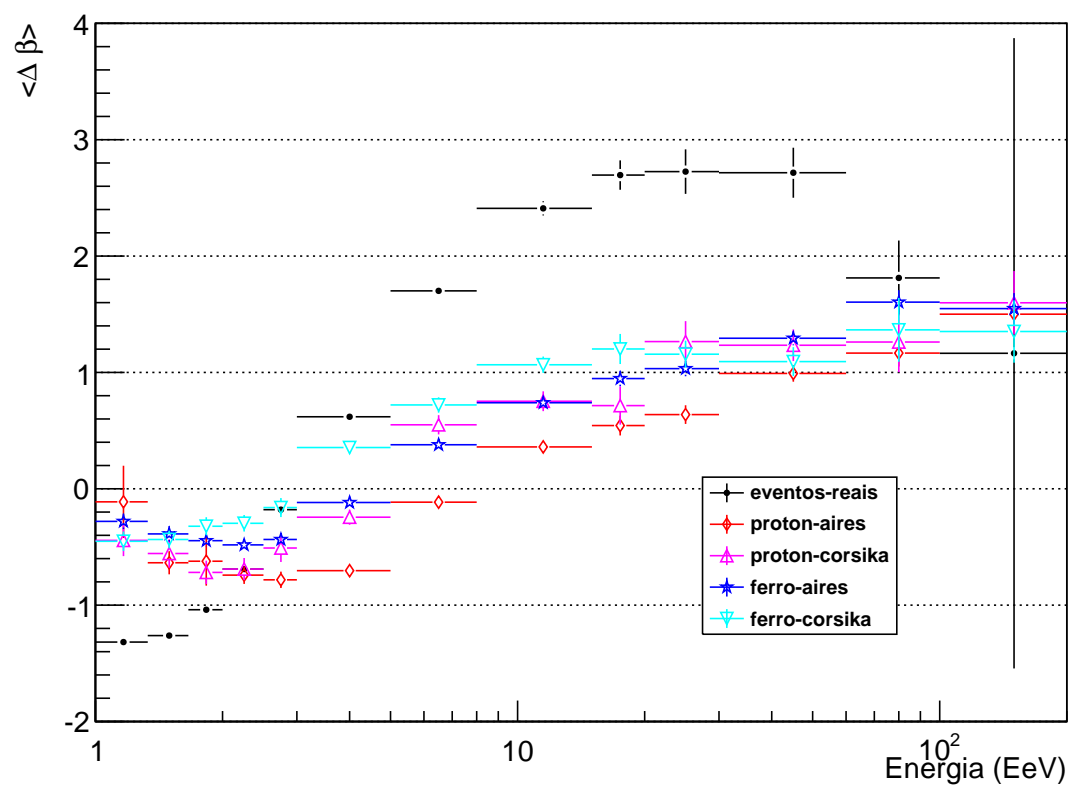

(a)

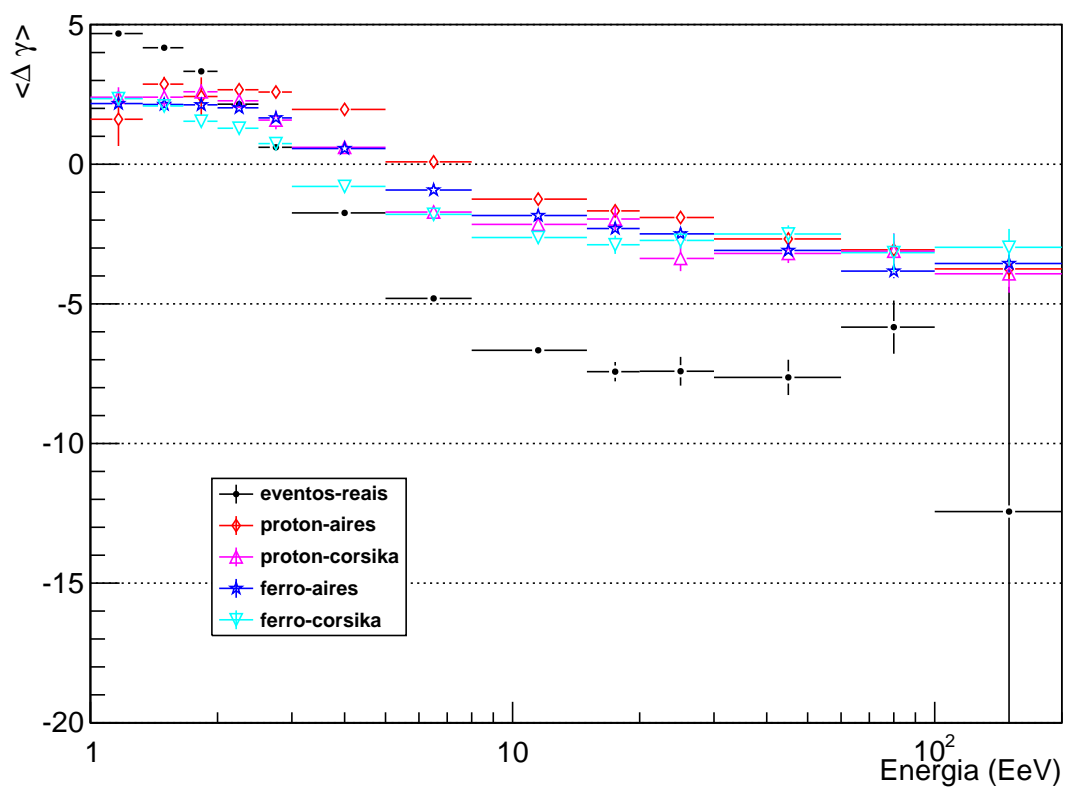

(b)

Figura 5.3: Gráficos de $\Delta \beta$ e $\Delta \gamma$ médios, em função da energia reconstruída da partícula primária. 


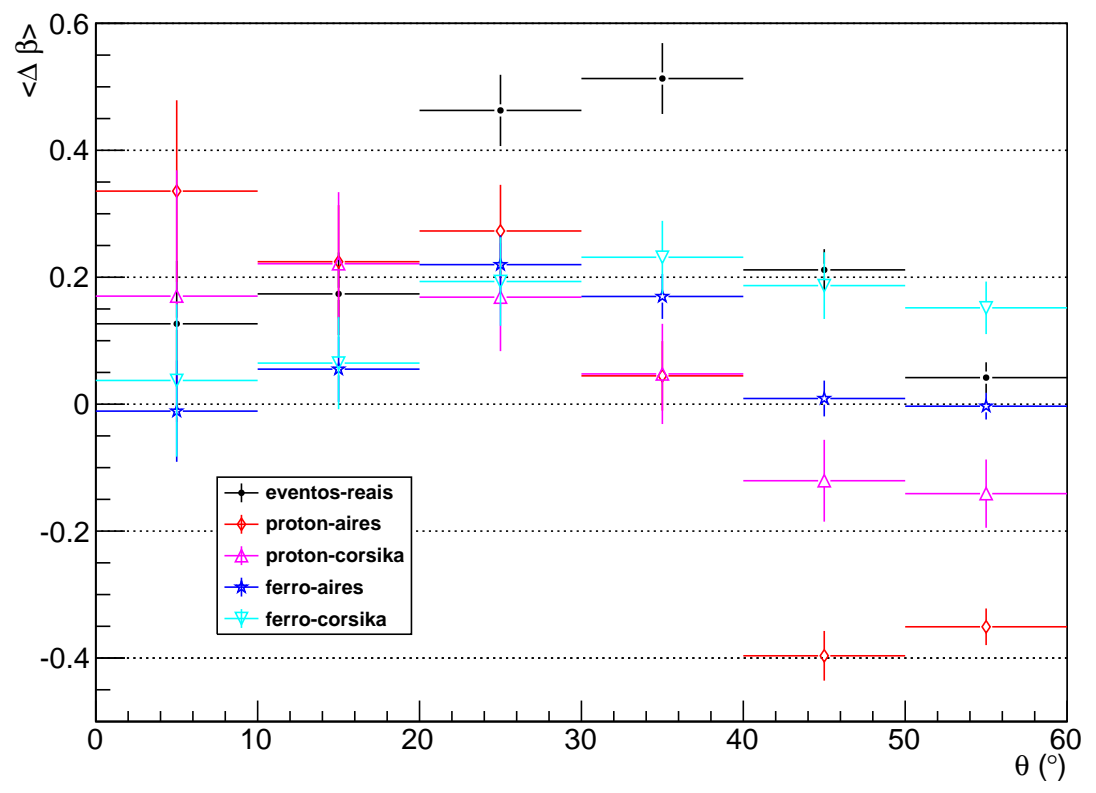

(a)

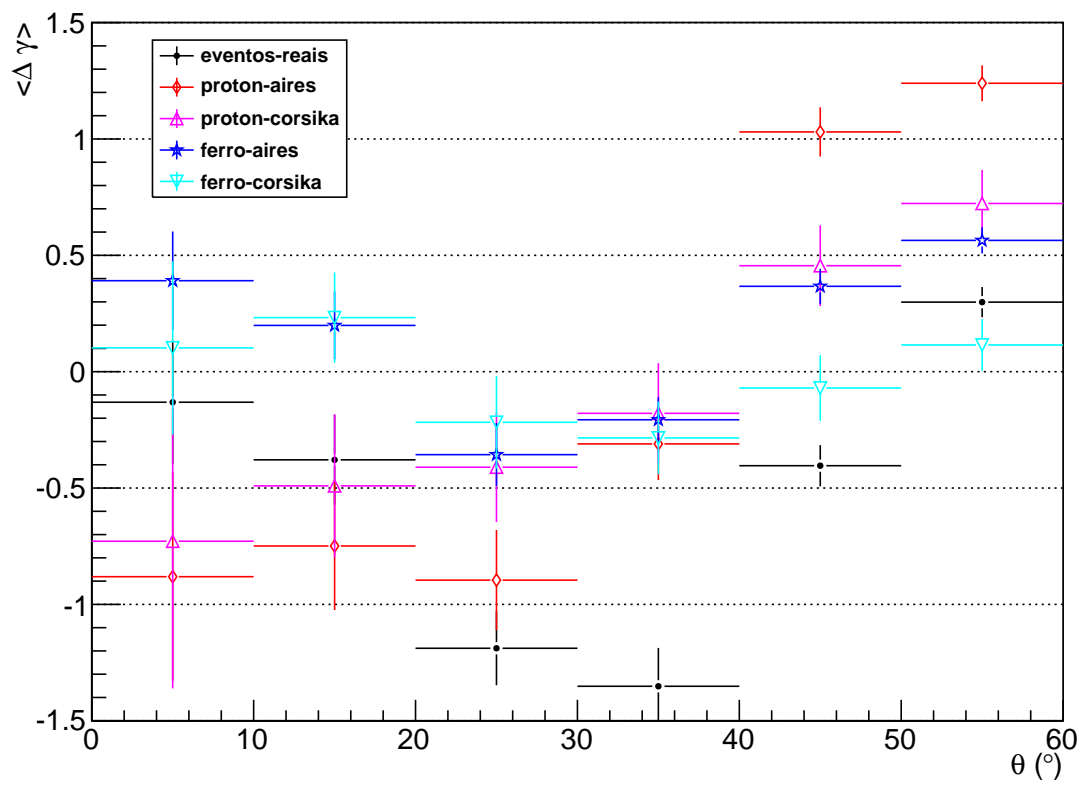

(b)

Figura 5.4: Gráficos de $\Delta \beta$ e $\Delta \gamma$ médios, em função do ângulo zenital $\theta$. 


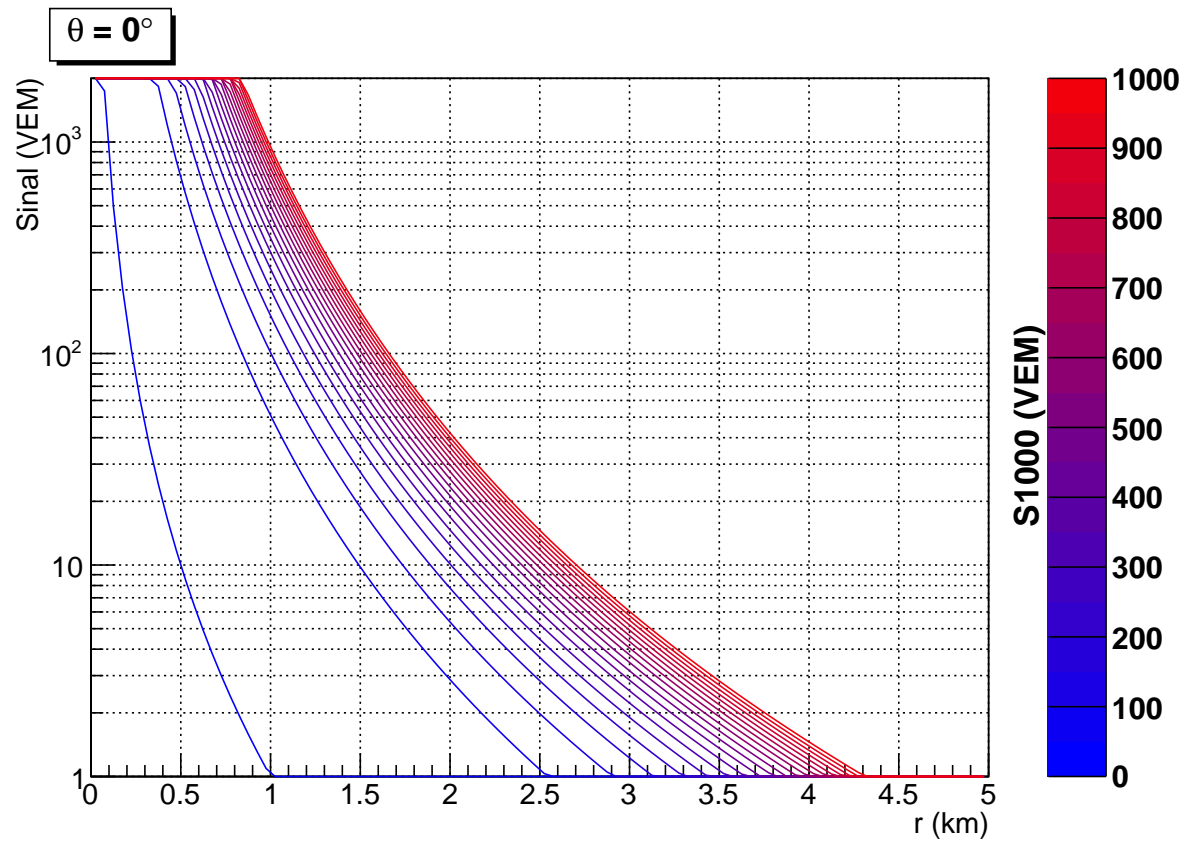

(a)

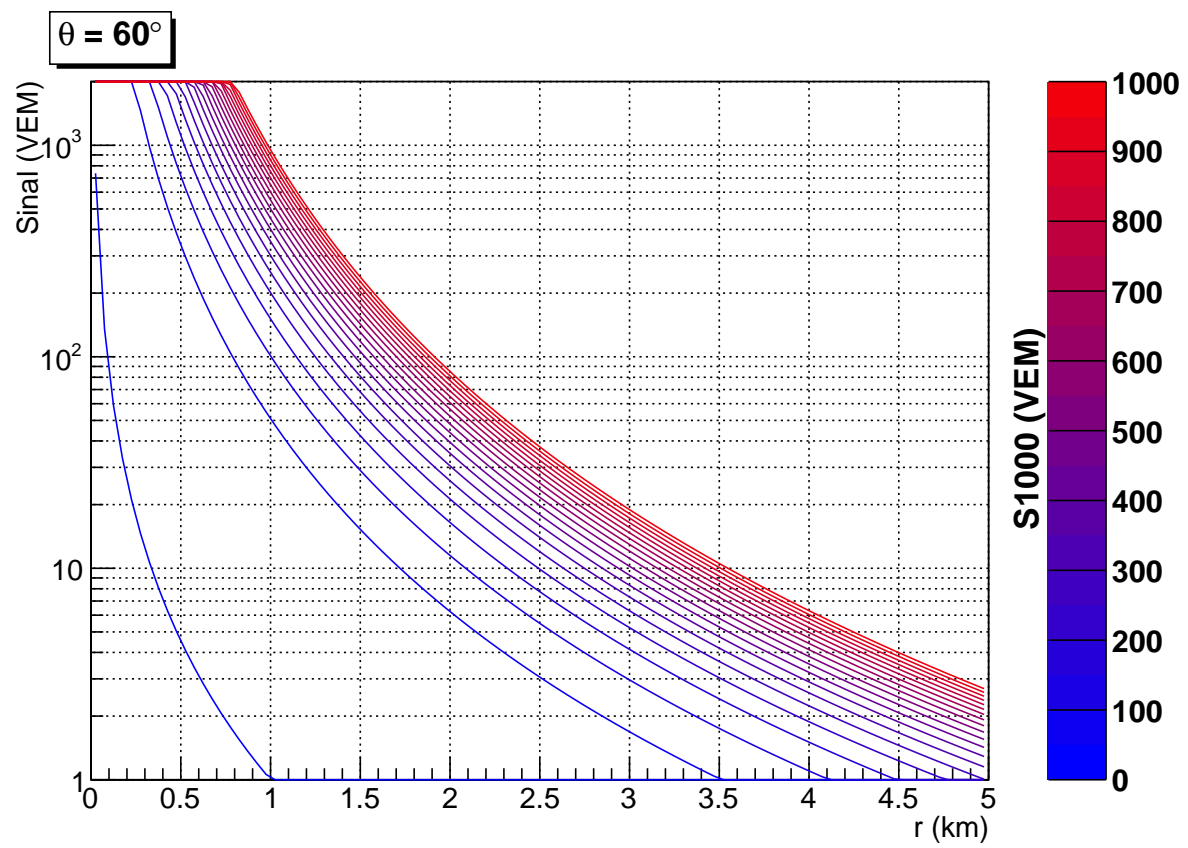

(b)

Figura 5.5: Várias LDFs com S1000 diferentes, para $\theta=0^{\circ}$ e $60^{\circ}$. A função é a NKG, (2.2), e foi utilizada a parametrização de $\beta$ da (2.3) e $\gamma=0$. Um evento com $S_{1000}=1900 \mathrm{VEM}$ e $\theta=0^{\circ}$ tem energia de $430 \mathrm{EeV}$. Um evento que tem $S_{1000}=10 \mathrm{VEM} \operatorname{com} \theta=0^{\circ}$ possui $1,5 \mathrm{EeV}$ e $\operatorname{com} \theta=60^{\circ}, 3,8 \mathrm{EeV}$. 


\subsection{Modelagem das diferenças de sinal entre conjuntos de dados diferentes}

O capítulo 4 apresenta diferenças entre o sinal das simulações. Desta seção em diante é discutida também a diferença entre os eventos simulados e os eventos reais. Tais diferenças, sejam elas entre simulações ou eventos reais versus simulados, possuem basicamente a mesma origem. Em um contexto mais amplo, a diferença se origina na física que descreve as interações entre as partículas, seja pelos modelos hadrônicos mal definidos em ultra alta energia ou nas partículas secundárias diferentes que são produzidas nas interações de partículas primárias distintas.

Supondo que as simulações estejam corretas, seria possível, comparando eventos reais e simulados em condições semelhantes, estimar uma composição média dos eventos reais. Como NKG não prevê uma distinção da LDF de chuveiros com composições diferentes, vide seção 5.2, uma análise independente do ajuste da LDF é potencialmente relevante. Além disso, no capítulo 3 e na seção 4.3, ficou aparente a descrição incompleta dos dados pela NKG parametrizada. Entretanto isso não implica que a diferença entre dois conjuntos de eventos não possa ser explicada por ela.

Nesta seção são comparados os sinais dos diferentes conjuntos de eventos utilizando dois modelos para a diferença: um é independente de parametrização da LDF, em que o sinal de um conjunto é relacionado diretamente ao sinal do outro; o outro modelo supõe que a diferença entre os dois conjuntos é descrita pela relação de duas NKGs parametrizadas distintas apenas pelo $S_{1000}$.

\subsubsection{Modelo baseado apenas no sinal}

A diferença mais relevante entre as simulações deste trabalho são os modelos de interação hadrônicas, especificamente na produção de múons resultantes dessas interações, vide capítulo 4. Esta seção se propõe a quantificar essa diferença de uma maneira simplificada, considerando apenas o sinal das estações. Em um segundo momento, aplica-se essa metodologia para quantificar 
a diferença entre eventos simulados e eventos reais.

Para cada conjunto de eventos, reais ou simulados, as estações de cada evento foram agrupadas em conjuntos com energia $(E)$, ângulo zenital $(\theta)$ e distância ao centro do chuveiro $(r)$ semelhantes. São 28 intervalos em $r$, de tamanhos que variam de acordo com a concentração das estações na região ${ }^{1}$, entre 0 e $5 \mathrm{~km}$. Para a energia, são 13 intervalos que crescem logaritmamente entre 1 e $200 \mathrm{EeV}$. Em $\theta$ são 6 intervalos uniformemente distribuídos entre $0^{\circ} \mathrm{e}$ $60^{\circ}$. Considerando cada grandeza como um eixo de um gráfico tridimensional existem 2184 células onde cada estação pode estar contida. Supondo que todas as estações dentro de uma célula possuem $r, E$ e $\theta$ compatíveis e, portanto, seus sinais são medidas de uma mesma grandeza, a informação do sinal das estações contidas em uma célula pode ser representada pela média e desvio padrão da média. A estimativa de $r$ é sempre obtida da reconstrução padrão, já as grandezas $E$ e $\theta$ são obtidas da reconstrução padrão no caso dos eventos reais e dos parâmetros de entrada em eventos simulados. As células que contêm menos de duas estações são excluídas da análise.

Os chuveiros atmosféricos possuem três componentes, que são uma parte hadrônica, uma eletromagnética e uma muônica. A componente hadrônica alimenta as outras duas partes, sendo os fótons resultantes do decaimento de píons neutros e os múons, de decaimentos de píons carregados e káons. Os fótons iniciam os sub-chuveiros que formam a parte eletromagnética, composta elétrons, pósitrons e fótons. Já os múons interagem pouco com a atmosfera perdendo energia basicamente por ionização do meio.

A componente hadrônica se limita a uma ou duas centenas de metros do centro do chuveiro, região onde o sinal das estações do SD é normalmente saturado. Então é razoável considerar que o sinal de uma estação possui duas componentes aproximadamente independentes, uma eletromagnética $\left(S_{e m}\right)$ e uma muônica $\left(S_{\mu}\right)$ :

$$
S=S_{e m}+S_{\mu}
$$

\footnotetext{
${ }^{1}$ A largura varia de maneira que a diferença no número de estações em cada intervalo seja a menor possível. Segundo a figura 3.6b, os intervalos próximos a $1 \mathrm{~km}$ devem ser menores que os intervalos a $2 \mathrm{~km}$, pois a densidade de estações é maior próximo a $1 \mathrm{~km}$.
} 
Essa característica é ilustrada na figura 5.6, onde se verifica, através de simulação, que, independente da partícula primária, mais próximo ao centro do chuveiro o sinal é dominado pela componente eletromagnética e mais distante é dominado pela componente muônica.

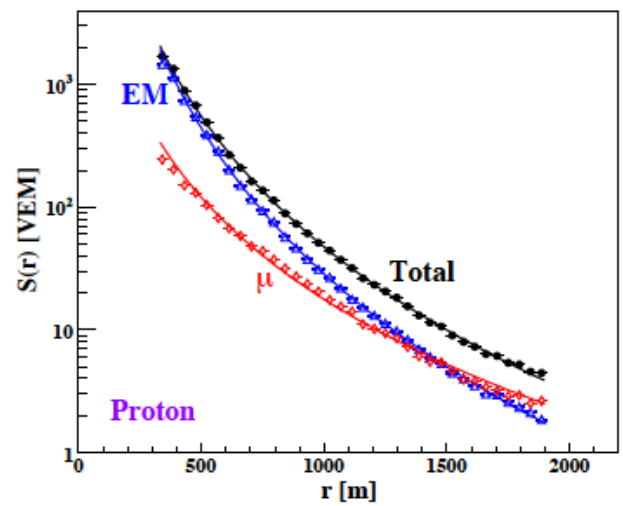

(a) Próton

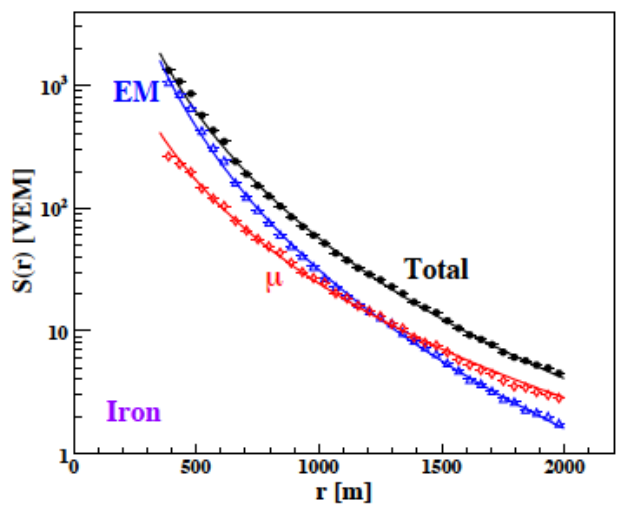

(b) Ferro

Figura 5.6: Gráfico do sinal de uma estação SD em função da distância ao centro do chuveiro, destacados os sinais das componentes eletromagnética e muônica do chuveiro. Simulações realizadas com AIRES/QGSJET-II com $10 \leq E \leq 12 \mathrm{EeV}$ e $0^{\circ} \leq \theta \leq 33^{\circ}$. Gráficos obtidos da referência [73].

Esse comportamento se relaciona ao modo como são produzidos os iniciadores dessas componentes e como eles interagem com a atmosfera. Iniciadores são os primeiros fótons ou múons resultantes das interações hadrônicas.

Os iniciadores dos sub-chuveiros eletromagnéticos interagem rapidamente com a atmosfera dissipando grande parte de sua energia, assim como as partículas secundárias resultantes de suas interações, então os sub-chuveiros iniciados em grandes altitudes só vão chegar ao solo se seus iniciadores forem muito energéticos, enquanto sub-chuveiros de iniciadores menos energéticos só chegam ao solo se iniciarem em altitudes menores.

$\mathrm{O}$ iniciador da componente muônica, devido à sua massa elevada, perde muito menos energia por Bremsstrahlung, e sua alta energia implica em um grande fator de Lorentz que faz com que seu decaimento na atmosfera seja improvável. Por isso dificilmente são gerados sub-chuveiros a partir de múons. 
Os múons iniciadores são produzidos no decaimento de píons carregados produzidos nas interações hadrônicas. Esses píons, quando possuem alta energia, raramente decaem na atmosfera, também devido ao grande fator de Lorentz. Então os múons do chuveiro provêm do decaimento de píons com menor energia e o mesmo fator de Lorentz que permite o decaimento dos píons faz com que o ângulo da trajetória das partículas em relação ao eixo do chuveiro seja maior, enfim, contribuindo para uma maior densidade de múons a distâncias maiores do centro do chuveiro. Mais detalhes sobre a influência da energia e altitude de produção de um iniciador em um chuveiro atmosférico podem ser encontrados na referência [74].

Os eventos simulados obtidos com CORSIKA/EPOS possuem mais múons que os obtidos com AIRES/SIBYLL mas, em princípio, não devem diferir na parte eletromagnética. Supondo que a simulação com CORSIKA/EPOS esteja correta, o sinal dos eventos neste caso pode ser definido pela expressão (5.1). O sinal dos múons em eventos simulados com AIRES/SIBYLL estaria sujeito a um fator de redução $f_{\mu}$, e então, nesse caso, o sinal $\left(S_{d}\right)$ de uma estação em um evento com deficiência de múons seria:

$$
S_{d}=S_{e m}+f_{\mu} \cdot S_{\mu}
$$

Uma maneira de obter uma estimativa do parâmetro $f_{\mu}$ é ajustando a equação:

$$
S_{d}=a_{0}+a_{1} \cdot S
$$

onde se obtêm de $a_{0}$ e $a_{1}$ :

$$
\begin{aligned}
f_{\mu} & =a_{1} \\
S_{e m} & =-\frac{a_{0}}{a_{1}-1}
\end{aligned}
$$

Ao utilizar a equação (5.3), supõe-se que os parâmetros não dependam de $E, r$ ou $\theta$. Em princípio, $f_{\mu}$ não deve depender desses parâmetros. A dependência com a energia da partícula primária é mais complexa do que 
com as outras variáveis e está relacionada às diferenças nas seções de choque de produção de píons carregados. Seria necessário um estudo detalhado para verificar essas diferenças caso a caso e como cada uma delas impacta no número global de múons produzidos. Entretanto a intenção é obter uma estimativa da ordem de grandeza de $f_{\mu}$ e, portanto, um estudo detalhado das seções de choque foge do escopo do trabalho. Uma hipótese razoável é que as seções de choque não tenham uma mudança de comportamento na dependência com a energia mas que difiram de um fator multiplicativo. Logo são produzidos proporcionalmente mais píons e, consequentemente, mais múons. Enfim, não se espera que $f_{\mu}$ dependa da energia da partícula primária. A dependência com $r$ e $\theta$ também deve ser desprezível, porque os múons interagem pouco com a atmosfera. Por isso um número maior de múons vai produzir um sinal proporcionalmente maior nas estações, independente da inclinação do chuveiro ou da distância da estação ao centro do mesmo.

Entretanto, $S_{e m}$ depende de $E, r$ e $\theta$ e essa é uma limitação desse ajuste. Os parâmetros do ajuste, $a_{0}$ e $a_{1}$, devem se adaptar a essa dependência, já que $S_{e m}$ está relacionado a ambos. O parâmetro $a_{0}$ deveria depender de $E, r$ e $\theta$, mas nesse caso esse parâmetro está sendo aproximado por uma constante. De uma maneira simplificada, seria equivalente a ajustar uma constante a dados descritos por uma reta. Devido a essa aproximação, é esperado $\chi^{2}$ reduzido sistematicamente maior que 1 e resíduos que indicam subestimação das incertezas. De forma a minimizar, pelo menos em parte, essa limitação, se estipulou um corte em $r$. São utilizadas apenas as estações que estão entre 1,5 e $5 \mathrm{~km}$. Isso porque a partir de $1,5 \mathrm{~km}$ do centro do chuveiro, a intensidade de $S_{e m}$ é menor que $S_{\mu}$, como mostra a figura 5.6.

As figuras 5.7 e 5.8 mostram a comparação entre as simulações de chuveiros iniciados por prótons e ferro, respectivamente. As grandezas relevantes obtidas desses ajustes estão nas duas primeiras linhas da tabela 5.2. Como esperado, o $\chi^{2}$ é elevado, sendo menor no caso do ferro, pois nesse tipo de chuveiro a parte muônica é proporcionalmente maior e, portanto, a flutuação causada por se ajustar uma constante à $S_{e m}$ é menor. Os resíduos dos sinais utilizados nos ajustes não apresentam sistemática aparente, mas indicam uma subestimação das incertezas, como esperado. Já os resíduos dos sinais 
fora do corte são sistematicamente positivos acima de 10 VEM e sistematicamente negativos abaixo desse valor. Isso ocorre porque $S_{e m}$ é maior que $S_{\mu}$ nas regiões mais próximas ao centro do chuveiro, onde a aproximação válida considerando as hipóteses desse modelo seria $S_{d} \approx S$, e portanto $a_{0} \approx 0$ e $a_{1} \approx 1$.

Os valores de $S_{e m}$ ajustados são compatíveis entre si e estão em torno de 2,7 VEM. Esse valor deve ser comparado com o das simulações na figura 5.6, em que $S_{e m}$ varia entre 2 e 10 VEM, e tem uma média de 6 VEM. Entretanto, os gráficos das simulações apresentam valores até $2 \mathrm{~km}$ do centro do chuveiro. $\mathrm{Na}$ análise apresentada neste trabalho, são consideradas estações até $5 \mathrm{~km}$ e o sinal é monotonicamente decrescente com a distância. Além disso, na figura 5.6 são considerados apenas eventos com energias entre 10 e $12 \mathrm{EeV}$, ou seja, apenas eventos com altas energias, para os quais o sinal das estações é maior. Os eventos mais abundantes são os de baixa energia, para os quais os valores de $S_{e m}$ são menores, e a variação do mesmo, na faixa de distância observada, também é menor. Enfim, o valor baixo do $S_{\text {em }}$ nos ajustes é esperado.

As simulações com AIRES/SIBYLL possuem, em média, 71\% dos múons presentes nas simulações com CORSIKA/EPOS. Entretanto, o $f_{\mu}$ das simulações que têm ferro como partícula primária não é compatível com o estimado nas que usam próton. Os valores estão a 7,8 incertezas e, mesmo considerando que as incertezas estão subestimadas, o cenário de incompatibilidade persiste $^{1}$. Para interpretar esse resultado, é necessário compreender porque os chuveiros gerados por ferro têm mais múons que os gerados por próton, e qual a diferença entre o SIBYLL e o EPOS que implica em números tão diferentes de múons no chuveiro.

Considerando as duas partículas primárias, ferro e próton, com mesma energia total, a energia por núcleon do ferro é significativamente menor que do próton. Com energias menores, os píons produzidos nas interações hadrônicas terão uma energia em média menor, ou seja, fator de Lorentz menor, consequentemente, terão maior probabilidade de decair em múons na atmos-

\footnotetext{
${ }^{1}$ Uma estimativa de ordem de grandeza da subestimação da incerteza é a raiz do $\chi^{2}$ reduzido, nesse caso algo em torno de 1,4 , o que resulta em uma diferença de 5,5 incertezas.
} 
fera como ilustrado na figura 5.9, onde estão representações hipotéticas das distribuições de energia dos píons em chuveiros simulados iniciados por ferro e por prótons e o limite máximo de energia para um píon decair em múon na atmosfera. De maneira simplificada, pode-se dizer que os píons que estão abaixo do limite de energia decairão em múons que podem ser detectados. Portanto os chuveiros inciados por ferro terão mais múons que os chuveiros iniciados por prótons, independente do modelo de interações hadrônicas utilizado.

Uma das características do EPOS é o aumento da produção de bárions nas interações hadrônicas. Sabe-se também que sub-chuveiros induzidos por píons produzem $30 \%$ menos múons que sub-chuveiros induzidos por prótons [75]. Portanto atribui-se o aumento no número de múons em chuveiros simulados com o EPOS à maior produção de bárions.

Como EPOS aumenta a produção de bárions, a distribuição de energia dos bárions em simulações com EPOS tende a ter uma média menor que em simulações com SIBYLL. A média da distribuição de energia dos píons carregados se reduz com a diminuição da média da distribuição de energia dos bárions e o número de píons cresce com o aumento do número de bárions. Então a distribuição de energia de píons em chuveiros simulados pelo CORSIKA/EPOS possui maior área, mais píons, e média de energia menor que em chuveiros simulados pelo AIRES/SIBYLL, como é ilustrado na figura [75]. O número de múons no chuveiro é proporcional a áreas das curvas à esquerda do limite, e a grandeza $f_{\mu}$ é a razão entre as áreas sob as curvas correspondentes ao resultados com AIRES e CORSIKA. Portanto, apesar do aumento de áreas sob as curvas do CORSIKA serem a iguais para ferro e próton, o aumento da áreas à esquerda do limite é maior para as simulações de próton e portanto a razão $f_{\mu}$ deve ser menor na comparação das simulações de chuveiros induzidos por prótons.

Estimada uma falta nos sinais de múons de aproximadamente $30 \%$ nas simulações do AIRES/SIBYLL em relação as simulações do CORSIKA/EPOS, se aplicou a mesma metodologia de análise para comparar eventos reais com eventos simulados pelo CORSIKA/EPOS, nas figuras 5.10 e 5.11 e os resultados dos ajustes estão nas duas últimas linhas da tabela 5.2. Pelo $f_{\mu}$ pode-se 
dizer que os eventos reais têm uma composição das partículas primárias entre próton e ferro e analisando os valores de $\chi^{2}$ o eventos reais estão mais semelhantes com os eventos simulados cujas partículas primárias são próton. Mas como essa análise não considera a dependência da composição com a energia, o que se pode afirmar é que na faixa de energia estudada ${ }^{1}$ existe uma composição que tende a ser contribuída predominantemente por próton.

\begin{tabular}{ccccc}
\hline & $f_{\mu}$ & $S_{e m}(\mathrm{VEM})$ & $\rho\left(f_{\mu}, S_{e m}\right)$ & $\chi^{2} / N D F$ \\
\cline { 2 - 5 } $\mathrm{p}$ - SIBYLL vs EPOS & $0,689(5)$ & $2,693(25)$ & $-0,678$ & 2,26 \\
Fe - SIBYLL vs EPOS & $0,739(4)$ & $2,741(24)$ & $-0,688$ & 2,09 \\
p EPOS vs reais & $0,845(6)$ & $2,63(6)$ & $-0,716$ & 1,85 \\
Fe EPOS vs reais & $1,137(6)$ & $2,88(6)$ & 0,649 & 2,29 \\
\hline
\end{tabular}

Tabela 5.2: Compilação das grandezas físicas estimadas com ajustes das figuras 5.7, 5.8, 5.10 e 5.11. As duas primeiras linhas são comparações entre eventos simulados e as duas últimas entre eventos simulados e reais. A variável $\rho\left(f_{\mu}, S_{e m}\right)$ é a correlação entre as grandezas $f_{\mu}$ e $S_{e m}$.

\footnotetext{
${ }^{1}$ Eventos com mais de $1 \mathrm{EeV}$.
} 


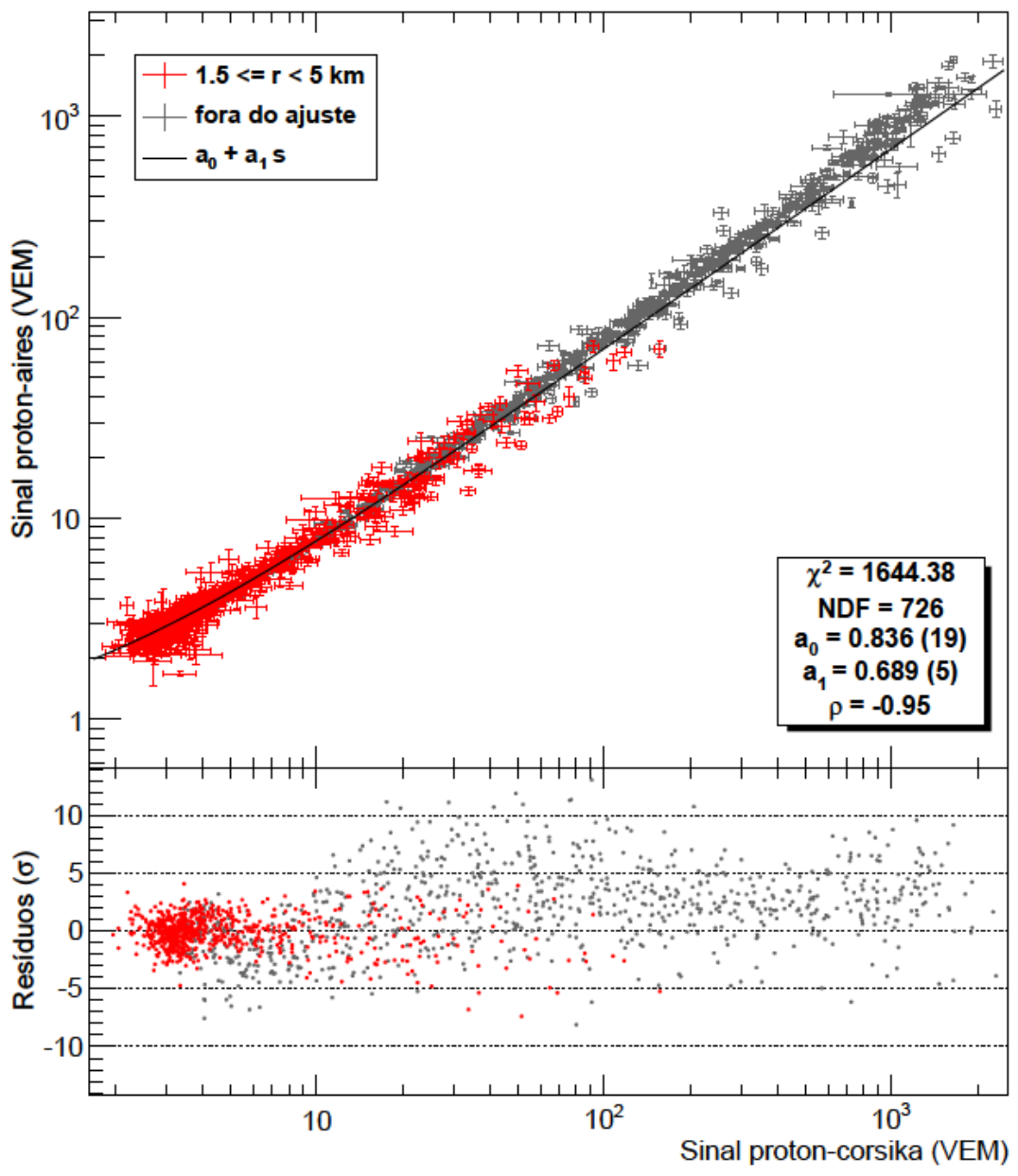

Figura 5.7: Gráfico do sinal médio das simulações do AIRES/SIBYLL em função do sinal médio das simulações do EPOS/CORSIKA para chuveiros iniciados por próton. Os pontos coloridos correspondem a estações utilizadas no ajuste; no gráfico inferior estão os resíduos reduzidos. 


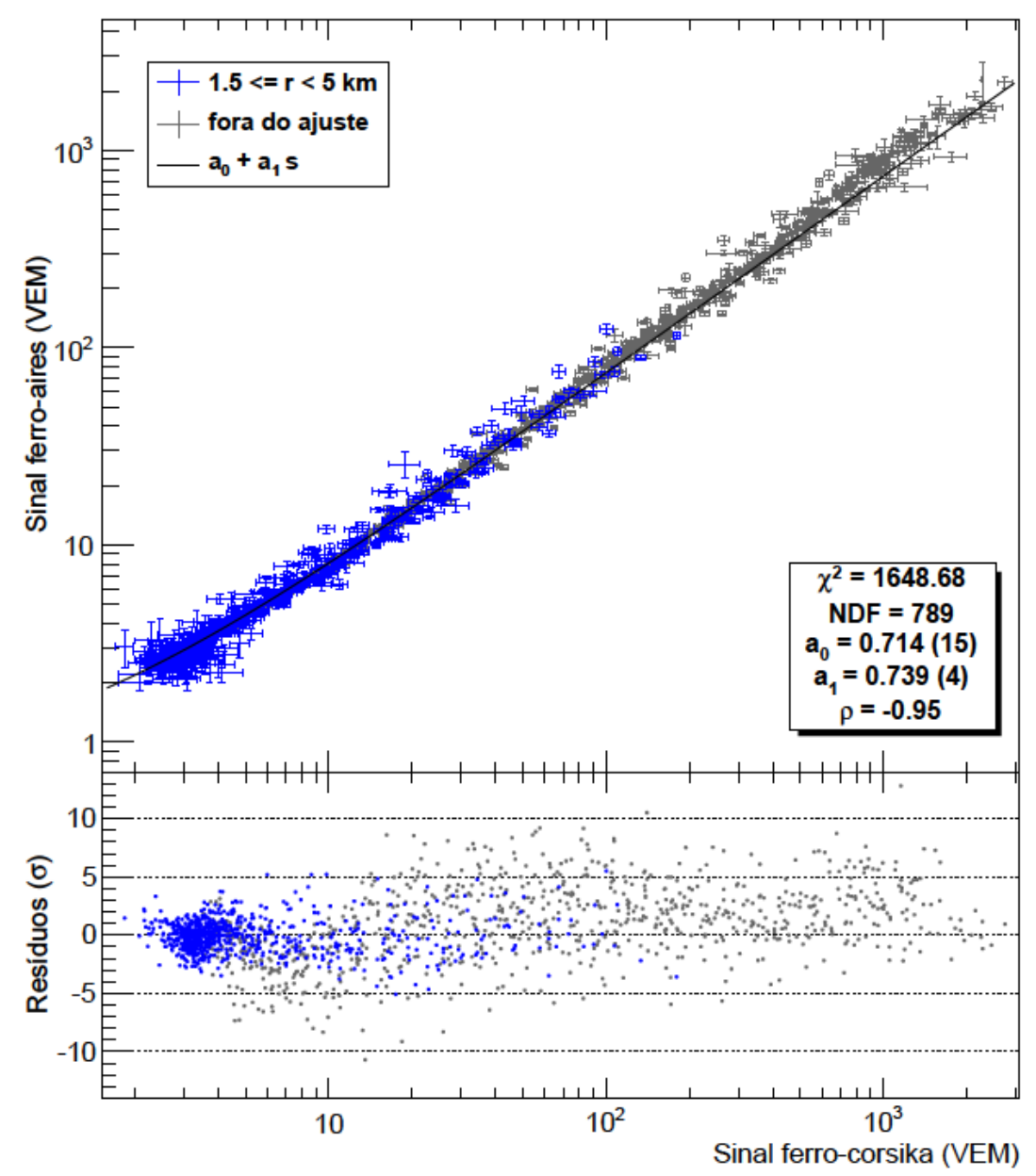

Figura 5.8: Gráfico do sinal médio das simulações do AIRES/SIBYLL em função do sinal médio das simulações do EPOS/CORSIKA para chuveiros iniciados por ferro. Os pontos coloridos correspondem a estações utilizadas no ajuste; no gráfico inferior estão os resíduos reduzidos. 
Assim como na comparação entre as simulações, o $\chi^{2}$ reduzido também é elevado pelos motivos já discutidos. Já os resíduos possuem um padrão diferente.

Os resíduos dos sinais utilizados no ajuste com a simulação de próton são bem semelhantes aos da comparação das simulações, sem dependência do sinal e com indicativos de incerteza subestimada.

Já os resíduos dos eventos de ferro têm uma tendência de serem positivos para sinais menores, além de apresentar o indicativo de subestimação de incertezas. Essa tendência pode ser causada por algum efeito de trigger, já que esse limite é em torno de $3 \mathrm{VEM}$. Os resíduos dos sinais fora do corte são significativamente diferentes dos obtidos na comparação das simulações. Eles são sistematicamente negativos tendo uma amplitude bem maior na comparação com ferro. Isso indica uma deficiência no sinal simulado, e uma hipótese plausível poderia ser que o sinal dos múons está correto, mas o sinal da parte eletromagnética do chuveiro ainda está deficiente. Entretanto, isso é apenas especulação e outros estudos são necessários para afirmar algo mais preciso.

Os valores obtidos para $f_{\mu}$ são incompatíveis com 34 incertezas, isto é, mesmo considerando incertezas subestimadas, os valores serão incompatíveis. Ambos os valores de $f_{\mu}$ são incompatíveis com 1, indicando que nenhuma das simulações descreve bem os eventos reais. No caso de $S_{e m}$, os ajustes estão no limite da compatibilidade de 2,9 incertezas. Nesse caso a subestimação das incertezas pode fazer diferença, sendo difícil de afirmar se as grandezas estimadas são compatíveis ou não.

A utilização de um modelo simples como esse, que num primeiro momento se mostra ingênuo, pode proporcionar uma boa compreensão do fenômeno estudado. Nesse caso, foi possível entender melhor como se dividem as partes muônicas e eletromagnéticas do chuveiro e quais são os principais processos envolvidos nos chuveiros. Essa metodologia tem potencial para ser aperfeiçoada de forma a obter a dependência de $f_{\mu}$ em relação à energia. 


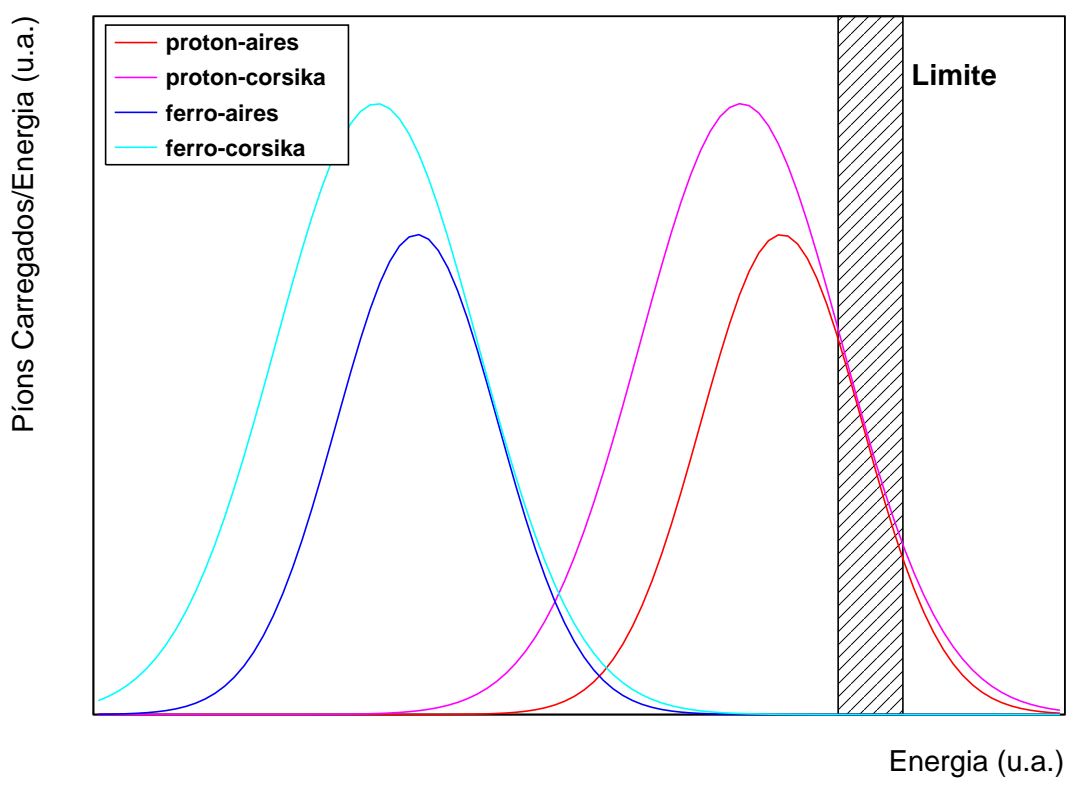

Figura 5.9: Ilustração hipotética das distribuições de energia de píons carregados em chuveiros simulados. A área indicada por "Limite" representa a região de transição entre os píons que decaem na atmosfera (energia mais baixa) e a região dos píons que não decaem na atmosfera (energia mais alta). 


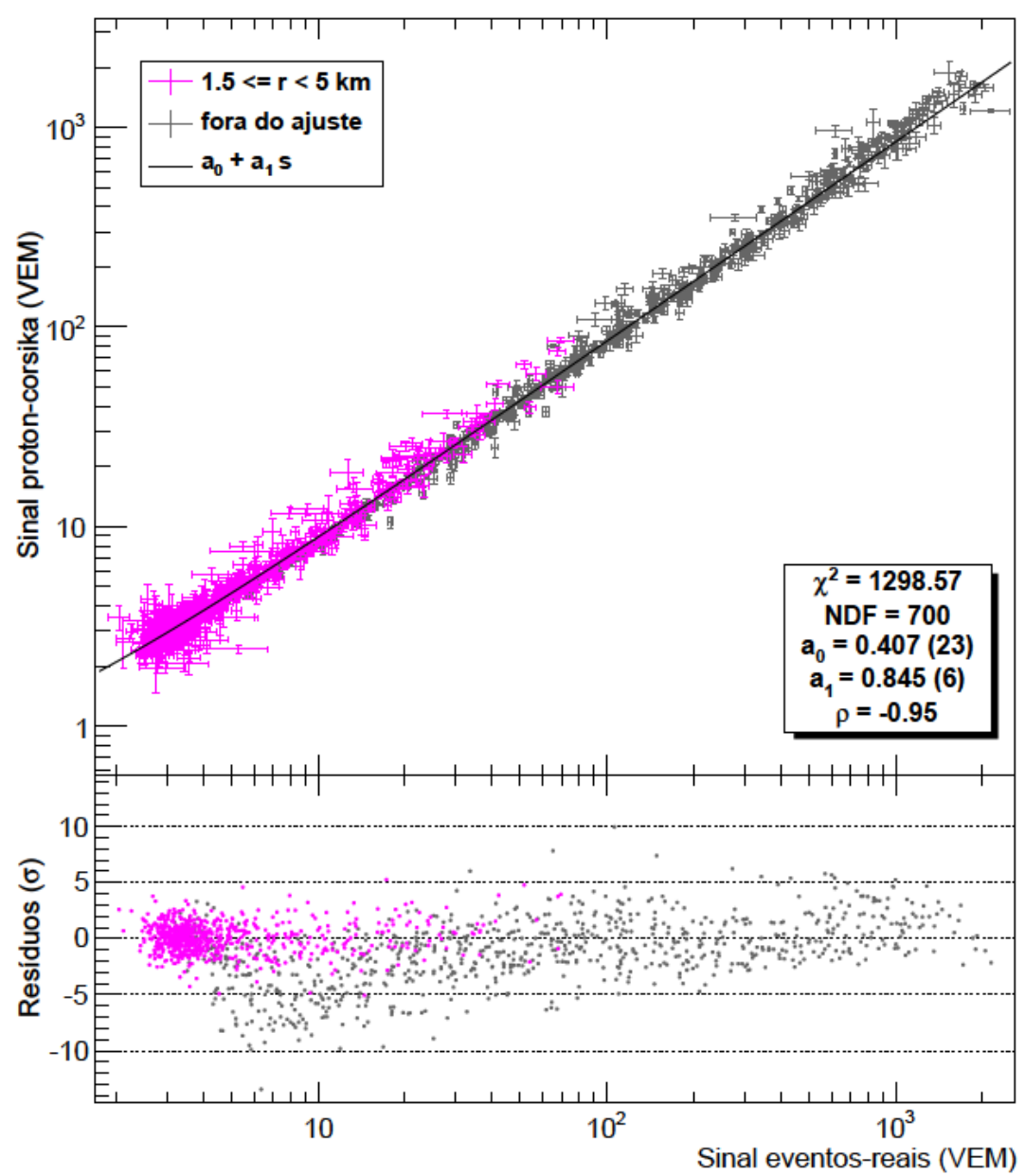

Figura 5.10: Gráfico do sinal médio das simulações com EPOS/CORSIKA para chuveiros iniciados por prótons em função do sinal médio de eventos reais. Os pontos coloridos correspondem à estações utilizadas no ajuste; no gráfico inferior são apresentados os resíduos reduzidos. 


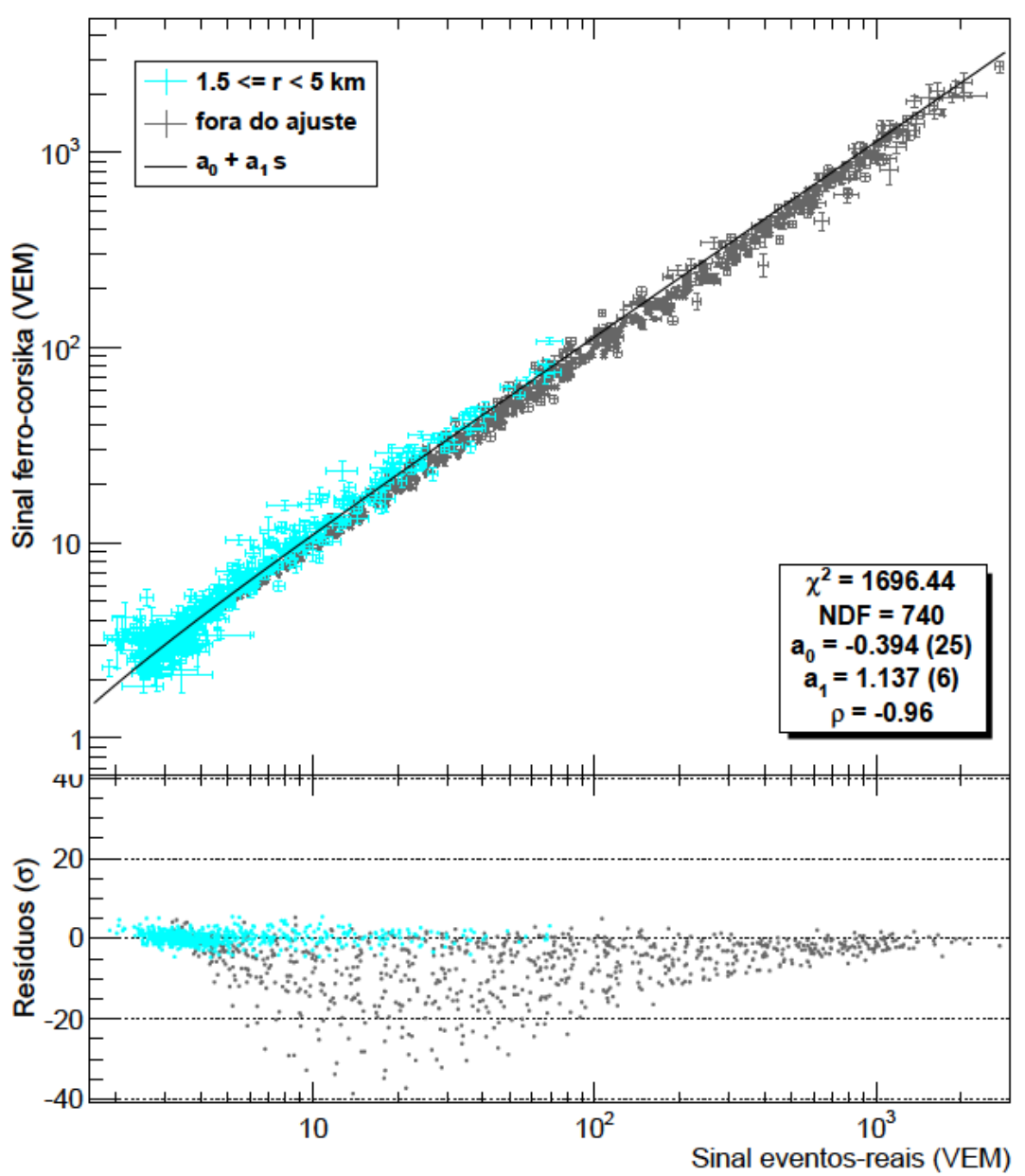

Figura 5.11: Gráfico do sinal médio das simulações com EPOS/CORSIKA para chuveiros iniciados por ferro em função do sinal médio de eventos reais. Os pontos coloridos correspondem à estações utilizadas no ajuste; no gráfico inferior são apresentados os resíduos reduzidos. 


\subsubsection{Modelo baseado na função NKG}

A proposta desta seção é quantificar a diferença entre dois conjuntos de eventos de maneira semelhante ao realizado na seção anterior, só que neste caso o modelo que descreve a relação entre os sinais é baseado na NKG modificada. Inicialmente, são comparados eventos simulados com o AIRES/SIBYLL e com o CORSIKA/EPOS e depois os eventos reais com os simulados com CORSIKA/EPOS.

A NKG modificada, equação (2.2), utilizada na reconstrução do Observer como função padrão para ajustar da LDF, possui apenas uma variável de forma ajustada, já que adota $\beta$ parametrizado, segundo a equação (2.3), e $\gamma=0$. Logo as diferenças entre os conjuntos serão observadas em desvios no $S_{1000}$. Tais diferenças podem ser quantificadas por uma grandeza $K$ definida como a razão dos valores de $S_{1000}$ dos dois conjuntos de eventos comparados:

$$
K=\frac{S_{1}}{S_{2}}
$$

onde $S_{i}$ é o $S_{1000}$ do $i$-ésimo conjunto de eventos.

Essa grandeza $K$ pode ser estimada da comparação do sinal de dois eventos. A dedução dessa relação é facilitada por uma notação mais compacta. Para tanto, a equação (2.2) é substituída na equação (2.1) e reescrita da seguinte forma:

$$
S\left(r, \theta, S_{i}\right)=S_{i} \cdot f_{L D F}\left(r, \theta, S_{i}\right)=S_{i}[X(r)]^{\beta\left(S_{i}, \theta\right)}
$$

com:

$$
\begin{aligned}
X(r) & =\left(\frac{r^{2}+r_{0} r}{r_{1}^{2}+r_{0} r_{1}}\right) \\
\beta\left(S_{i}, \theta\right) & =a(\theta)+b(\theta) \log \left(S_{i}\right) \\
a(\theta) & =a_{0}+a_{1} \sec (\theta)+a_{2} \sec ^{2}(\theta) \\
b(\theta) & =b_{0}+b_{1} \sec (\theta)+b_{2} \sec ^{2}(\theta)
\end{aligned}
$$

e os parâmetros $a_{i}, b_{i}$ e $r_{i}$ são: 


$$
\begin{aligned}
a_{0}=-3,35 & b_{0}=-0,0125 \\
a_{1}=+1,33 & b_{1}=-0,0324 \\
a_{2}=-0,191 & b_{2}=-0,00573 \\
r_{0}=0,7 \mathrm{~km} & r_{1}=1 \mathrm{~km}
\end{aligned}
$$

De maneira compacta:

$$
S\left(X, \theta, S_{1}\right)=S_{1} X^{a+b \log \left(S_{1}\right)}
$$

que, ao substituir a identidade $S_{1}=K S_{2}$ no lado direito da equação, resulta em:

$$
\begin{aligned}
S\left(X, \theta, S_{1}\right) & =K S_{2} X^{a+b \log \left(K S_{2}\right)}=S_{2} X^{a+b \log \left(S_{2}\right)} K X^{b \log K}= \\
& =S\left(X, \theta, S_{2}\right) K X^{b \log K}
\end{aligned}
$$

Ao aplicar o logaritmo em $K X^{b \log K}$ :

$$
\begin{aligned}
\log \left(K X^{b \log K}\right) & =\log (K)+\log \left(X^{b \log K}\right)=(1+b \log (X)) \log (K) \\
& =\log \left(K^{1+b \log (X)}\right)
\end{aligned}
$$

verifica-se que $K X^{b \log K}=K^{1+b \log (X)}$, logo a relação entre o sinal de duas LDFs, cujo $K$ é razão de seus $S_{1000}$, é:

$$
S\left(X, \theta, S_{1}\right)=S\left(X, \theta, S_{2}\right) K^{1+b(\theta) \log (X)}
$$

Dois eventos simulados com mesmos parâmetros iniciais, energia, direção e composição da partícula primária mas gerados com diferentes modelos de interação hadrônica, no caso AIRES/SIBYLL e CORSIKA/EPOS, possuem sinais diferentes na mesma distância ao centro do chuveiro devido a uma diferença no número de múons. Ao ajustar uma NKG modificada a esses eventos, 
espera-se que o $S_{1000}$ seja diferente e, portanto, ajustando a função (5.9), é possível quantificar essa diferença.

Foi apresentado nesse trabalho o erro sistemático na energia reconstruída dos eventos simulados, figura 4.2. Esse erro indica que a calibração entre a energia reconstruída e de $S_{1000}$ é diferente dos eventos reais, porque o valor da energia reconstruída depende de $\theta$, obtido por ajuste independente da LDF, e de $S_{1000}$, obtido diretamente da LDF que depende do sinal de múons. Portanto, essa metodologia de análise também pode quantificar quão diferente é o $S_{1000}$ entre eventos simulados e eventos reais.

Note que, neste modelo, $K$ é constante e não depende da distância ao centro do chuveiro $(r)$, da energia da partícula primária $(E)$ ou do ângulo zenital $(\theta)$. Assim, é possível ajustar um mesmo $K$ para quantificar as diferenças em $S_{1000}$ independentemente das grandezas citadas. Isto é, agrupando os eventos da mesma maneira que na seção 5.3.1 e fazendo um ajuste global, é possível estimar um único valor de $K$ que caracteriza dois conjuntos de eventos.

Um detalhe relevante é que os eventos da seção 5.3.1 foram agrupados em $r, \theta$ e $E$, não em $r, \theta$ e $S_{1000}$, como prevê este modelo. Entretanto, na equação (5.9) a dependência de $S_{1000}$ é implícita nos valores dos sinais. Como para um $\theta$ fixo existe uma relação unívoca entre $S_{1000}$ e $E$, é equivalente fazer a comparação de eventos no mesmo intervalo de $E$ ou de $S_{1000}$.

Essa metodologia de análise apresenta uma complicação técnica adicional em relação às outras análises dessa tese. Apesar de se ajustar apenas um parâmetro, o ajuste possui três variáveis independentes $S\left(X, \theta, S_{2}\right), \theta$ e $r$. Sendo assim, é praticamente impossível de plotar um gráfico de uma maneira visualizável e, muito por isso, não é possível utilizar as funções de ajustes usuais do ROOT. Para realizar os ajustes utilizando o método dos mínimos quadrados foi utilizado o minimizador de funções MINUIT, que também é implementado no ROOT. Para isso foi necessário escrever uma função que calcula o $\chi^{2}$ do ajuste em função do valor de $K$. Esta função está descrita no Apêndice C.

Diferente do utilizado na seção 5.3.1, o modelo baseado na NKG não prevê uma distinção na origem do sinal, isto é, não há distinção entre $S_{\mu}$ e $S_{e m}$. 
Portanto, esse modelo, observado de maneira isolada, não possui justificativa física para desconsiderar as estações a menos de 1,5 km do centro do chuveiro, mas sim um corte a $0,5 \mathrm{~km}$ para evitar que os efeitos de saturação nas PMTs influenciem os resultados dos ajustes.

Os resultados dos ajustes entre CORSIKA/EPOS e AIRES/SIBYLL para próton e ferro como partículas primárias se encontram nas duas primeiras linhas da tabela 5.3. Observa-se que o $S_{1000}$ das simulações com o AIRES/SIBYLL é aproximadamente $80 \%$ do medido em simulações com CORSIKA/EPOS, sendo a diferença menor nas simulações iniciadas por núcleos de ferro. Esse resultado corrobora as conclusões em relação à produção dos múons obtidas na seção passada, onde a energia por núcleon significativamente mais alta no próton produz píons carregados mais energéticos que não decaem na atmosfera e, portanto, não são detectados. Com o aumento da produção de hádrons nas simulações com o EPOS, mais píons são produzidos, diminuindo a energia média deles e, portanto, proporcionalmente mais píons decairão em múons, como mostra a figura 5.9. Mesmo com $\chi^{2}$ reduzido tão elevado, os valores de $K$ não são compatíveis.

\begin{tabular}{cccc}
\hline & $K$ & $\chi^{2} / N D F$ & $N D F$ \\
\cline { 2 - 4 } $\mathrm{p}$ - SIBYLL vs EPOS & $0,8054(6)$ & 8,323 & 1413 \\
Fe - SIBYLL vs EPOS & $0,8231(5)$ & 8,935 & 1470 \\
$\mathrm{p}$ EPOS vs reais & $0,8604(6)$ & 5,879 & 1361 \\
Fe EPOS vs reais & $0,9763(5)$ & 9,583 & 1394 \\
\hline
\end{tabular}

Tabela 5.3: Compilação dos valores de $K$ estimados com ajustes entre simulações, primeira e segunda linhas, e eventos reais e simulados, duas últimas linhas.

Como não é possível visualizar graficamente estes ajustes, a análise de resíduos é imprescindível para a compreensão dos valores elevados do $\chi^{2}$ e, por isso mesmo, foi adotada uma abordagem diferente nos gráficos de resíduos desta seção. O perfil dos resíduos foi plotado em função de duas variáveis independentes de cada vez, com o resíduo médio em uma escala de cores. Os três planos dos perfis são plotados em um mesmo gráfico com três 
eixos, facilitando a visualização de possíveis correlações entre as variáveis. Nas figuras 5.12 e 5.13 são apresentados os perfis dos resíduos dos ajustes entre as simulações. Os resíduos médios apresentam um comportamento característico, independente da partícula geradora do chuveiro.

É observada uma dependência sutil dos resíduos em relação a $\theta$. O perfil do plano $\theta$-Energia não apresenta uma sistemática aparente. No plano $\theta-r$ são observados resíduos negativos em torno de $750 \mathrm{~m}$, resíduos positivos em torno de $2 \mathrm{~km}$ e resíduos em torno de zero para distâncias maiores. Essas distâncias tendem a crescer com o aumento de $\theta$. Dado que os chuveiros ficam extensos com o aumento de $\theta$, é natural que os resíduos que possuam uma dependência com $r$ se comportem da mesma maneira.

O plano r-Energia contém os resultados mais interessantes e, por isso, os resíduos desse plano são apresentados em gráficos separados e com escala logarítmica no eixo da energia, 5.12b e 5.13b. Os resíduos apresentam uma dependência com $r$ semelhante ao observado no plano $\theta-r$, mas agora neste plano esse comportamento é mais evidente. Observam-se resíduos sistematicamente negativos próximos ao centro do chuveiro e sistematicamente positivos mais distantes do centro do chuveiro. A transição entre resíduos negativos para positivos começa em $1 \mathrm{~km}$ para chuveiros de $1 \mathrm{EeV}$ e vai se distanciando com o aumento da energia. Ao comparar o perfil dos resíduos com o perfil do sinal das estações, por exemplo, o na figura 5.14, observa-se que a transição ocorre sempre próxima às estações com sinal em torno de 5 VEM. Isso indica que todas as estações que têm sinal menor que esse valor possuem resíduo positivo, independentemente da energia, composição ou ângulo zenital da partícula primária. Esse efeito é causado pelo trigger das estações, que é de 3 VEM. Em princípio, não deveria ser observado sinal em nenhuma estação a partir da distância ao centro do chuveiro na qual a LDF vale menos que 3 VEM. Entretanto são observadas estações com sinal centenas de metros mais distantes. Isso acontece por causa da flutuação natural do sinal nas estações e não está previsto na NKG modificada. Esse efeito de trigger também causa a mudança significativa da inclinação da LDF em torno de 1,1 km nas figuras 3.6a e 4.3, resultando em resíduos sistematicamente positivos distantes do centro do chuveiro nos ajustes da LDF, já que é 
a parametrização utilizada. Tal efeito é descrito e discutido em detalhes na seção 5.5. 


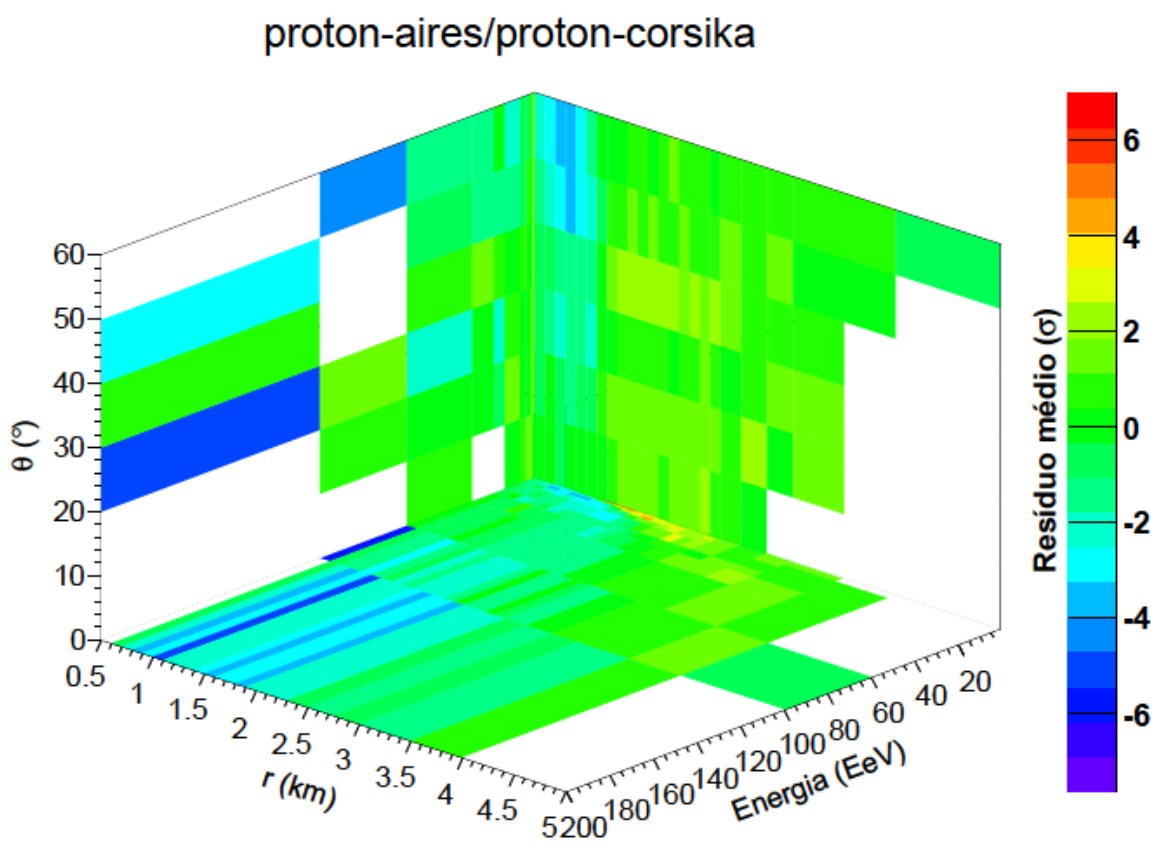

(a)

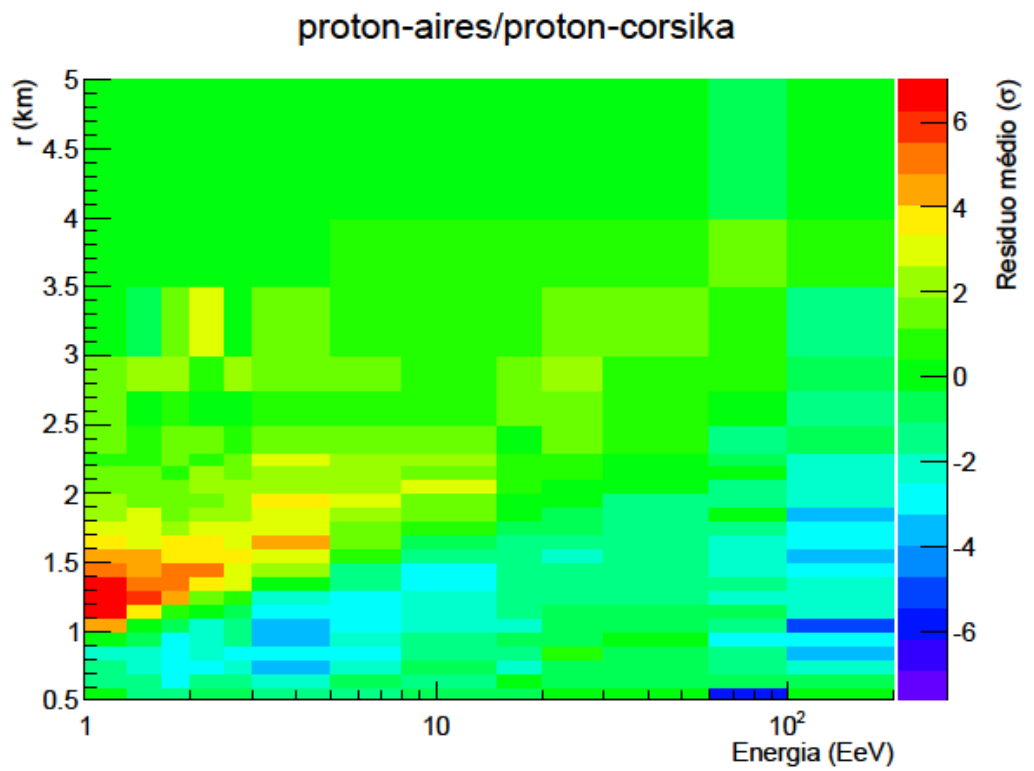

(b)

Figura 5.12: (a) Gráfico com os perfis em duas dimensões do ajuste de $K$ para simulações com próton como partícula primária. O resíduo reduzido médio está indicado pela escala de cor. (b) Zoom no perfil dos resíduos em função da energia e da distância ao centro do chuveiro; a energia está em escala logarítmica. 


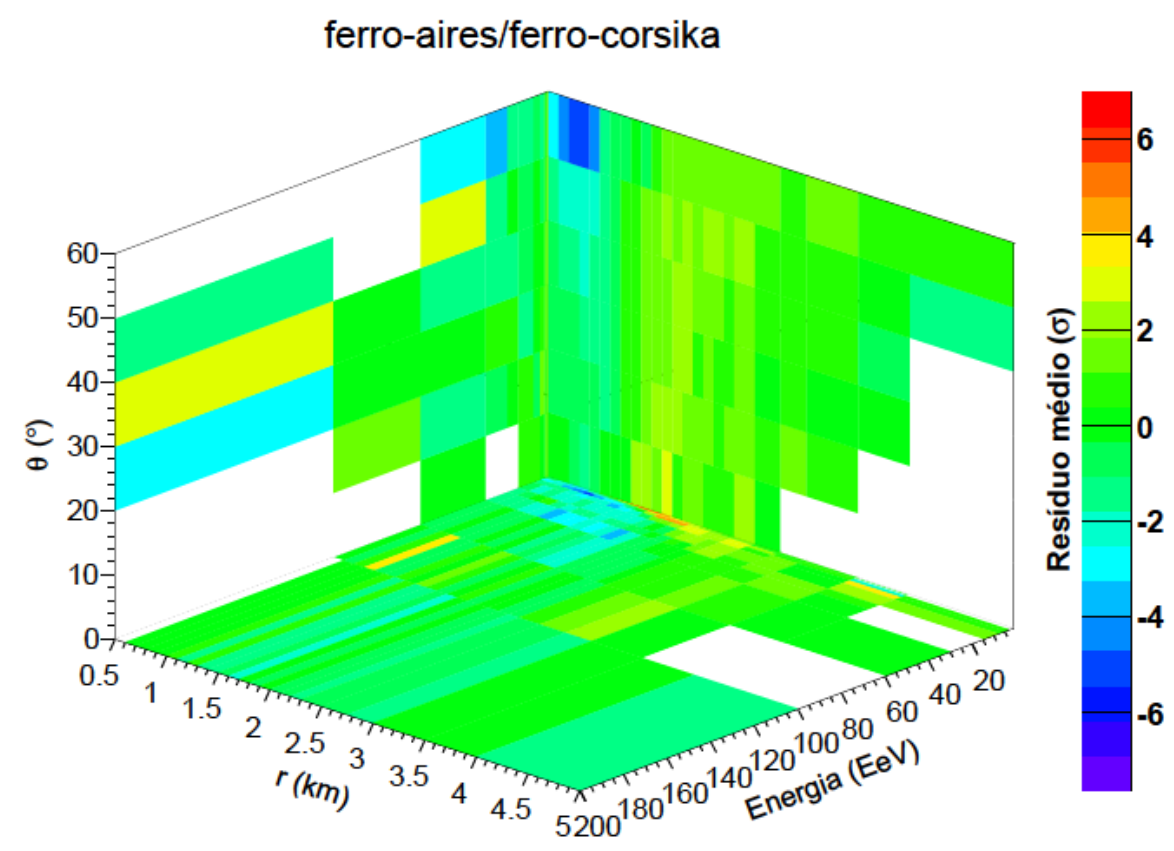

(a)

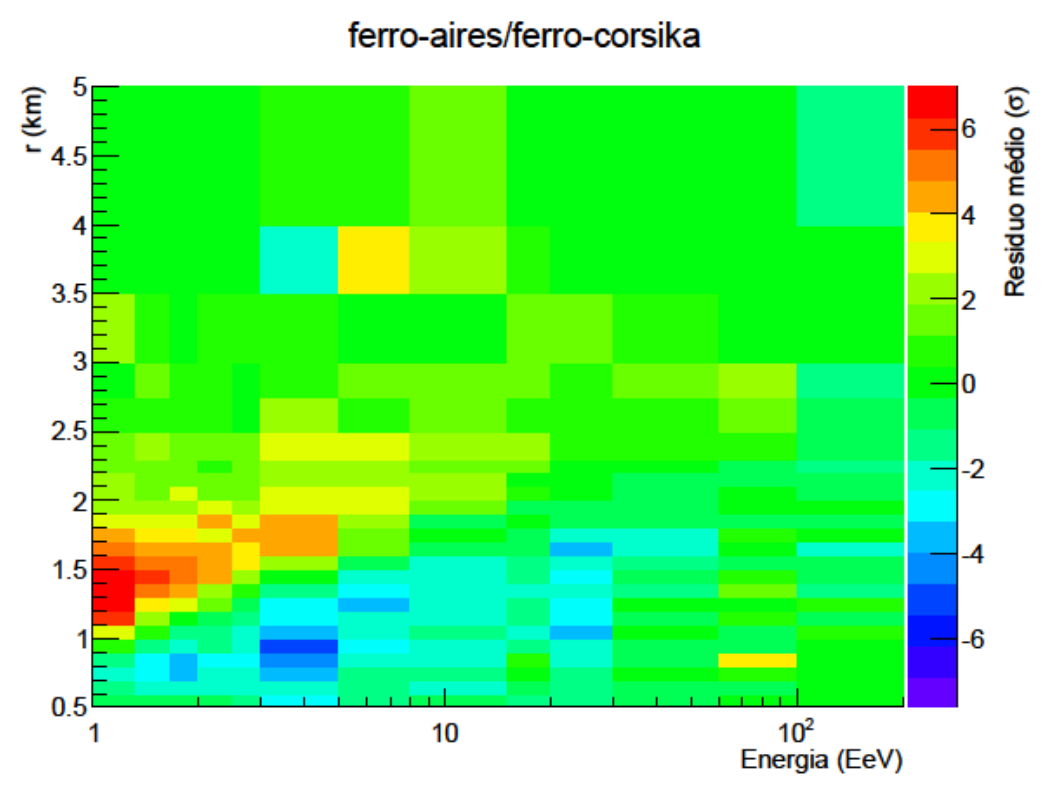

(b)

Figura 5.13: (a) Gráfico com os perfis em duas dimensões do ajuste de $K$ para simulações com ferro como partícula primária. O resíduo reduzido médio está indicado pela escala de cor. (b) Zoom no perfil dos resíduos em função da energia e da distância ao centro do chuveiro; a energia está em escala logarítmica. 
Na comparação dos eventos reais com simulações obtidas pelo CORSIKA/EPOS foram obtidos os parâmetros que são apresentados nas duas últimas linhas da tabela 5.3. O ajuste que confronta os eventos reais com as simulações que têm núcleos de ferro como partícula primária possue $K$ mais próximos de 1. Entretanto esse mesmo ajuste apresenta o maior $\chi^{2}$, mesmo quando comparado com os ajustes entre simulações.

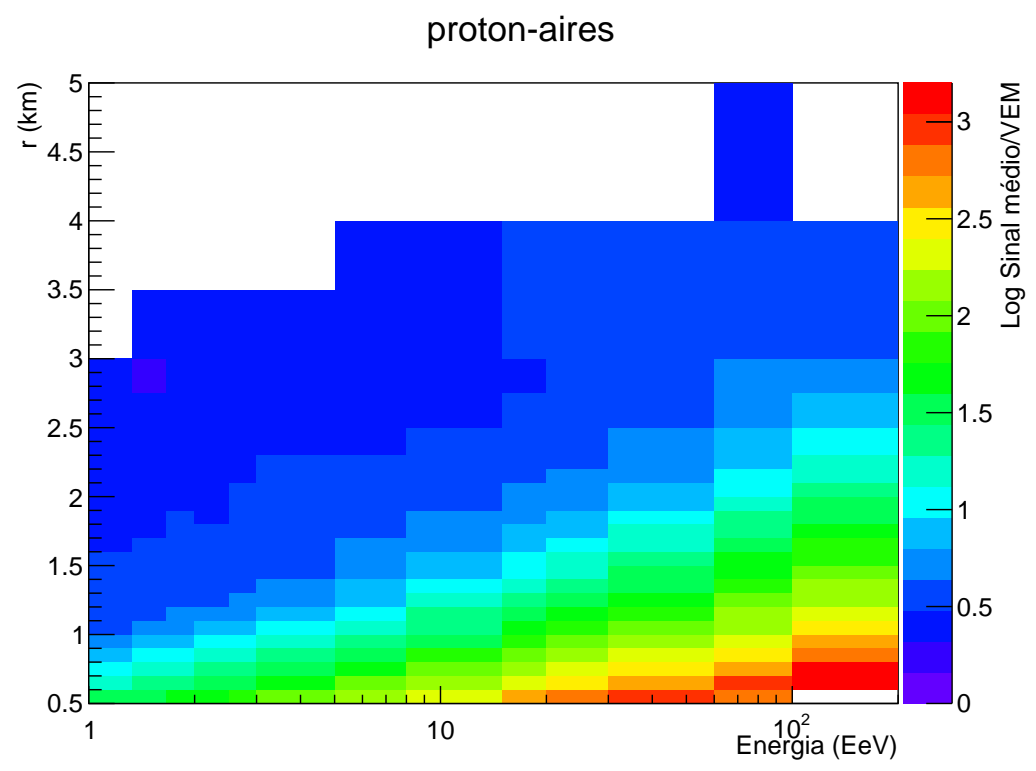

Figura 5.14: Perfil do logaritmo do sinal das estações em função da distância ao centro do chuveiro e da energia da partícula primária. Eventos gerados com simulações do AIRES para chuveiros iniciados por prótons.

Assim como feito com os ajustes entre as simulações, nas figuras 5.15 e 5.16 se encontram os gráficos de resíduos que permitem uma melhor compreensão dos resultados obtidos. Os resíduos do ajuste das simulações com prótons, figura 5.15a, são semelhantes aos dos ajustes entre as simulações, com exceção de um evento real de alta energia ${ }^{1}$ que aparenta estar fora do comportamento médio. Mas, de maneira geral, os resíduos médios são menores, o que reflete o $\chi^{2}$ menor. Também é observado que a transição entre resíduos positivos e negativos se afasta do centro do chuveiro com o aumento

\footnotetext{
${ }^{1}$ Observe que os resíduos com média elevada para energia maior que $100 \mathrm{EeV}$ também aparecem nos ajustes com ferro, figura 5.16a
} 
da energia que, da mesma forma, é atribuído ao efeito do trigger descrito na seção 5.5 .

O ajuste que compara os eventos reais com simulações do CORSIKA/EPOS que utilizam ferro como partícula primária possuem resíduos médios diferentes dos outros ajustes, como pode ser visto na figura 5.16a. Os resíduos no plano $\theta-r$ possuem uma maior amplitude, mas é no plano $r$-Energia que se observa um comportamento diferente, figura 5.16b. A transição entre resíduos sistematicamente negativos (próximos ao centro do chuveiro) para resíduos positivos (distantes ao centro do chuveiro) não depende da energia, tal transição ocorre sempre em torno de $1 \mathrm{~km}$. Nesse caso não foi possível formular uma hipótese razoável que explique este comportamento, mas especula-se que pode ser uma combinação de uma forma diferente da LDF (provavelmente relacionada a distribuição de múons) juntamente com o efeito do trigger. Isso porque as indicações de composição atualmente apontam para uma predominância de próton em baixas energias. Como essa análise não faz uma separação por energia, se realmente houver essa predominância, seria esperado observar uma maior compatibilidade com simulações de chuveiros iniciados por prótons do que os iniciados por núcleos de ferro. 


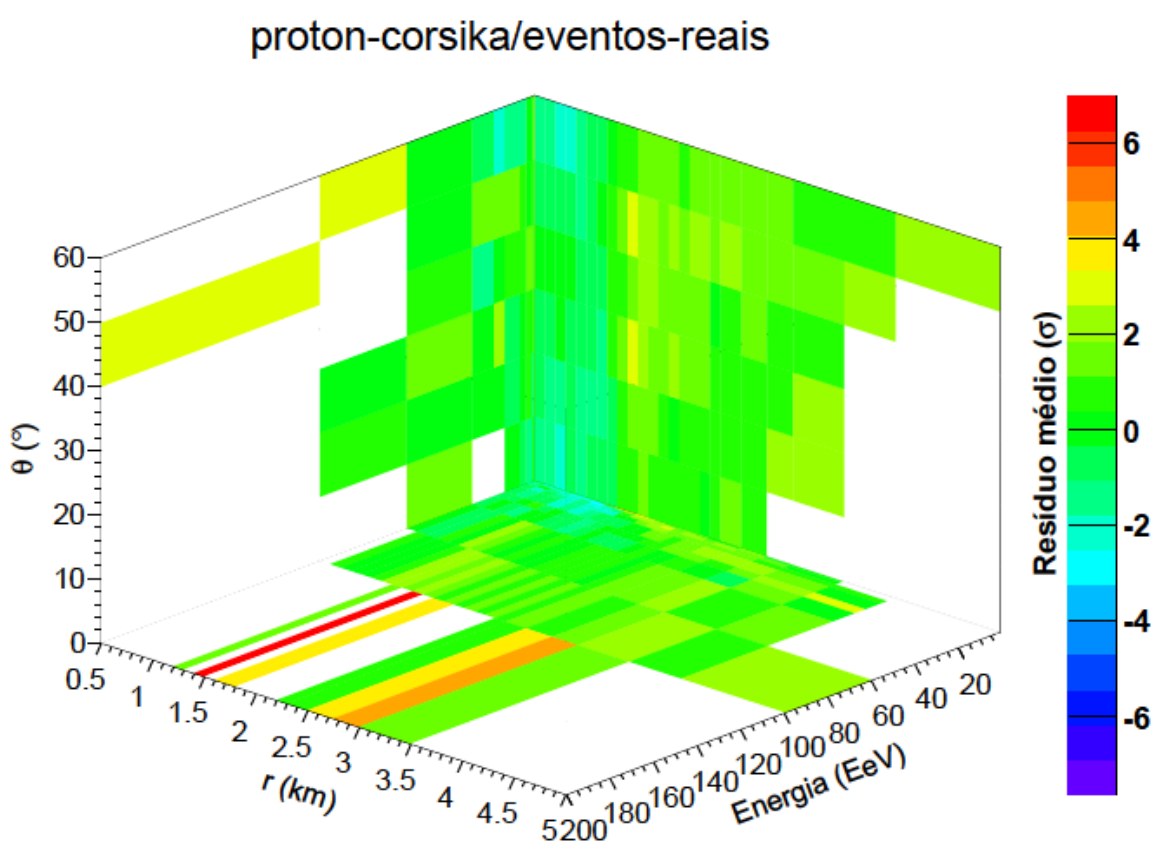

(a)

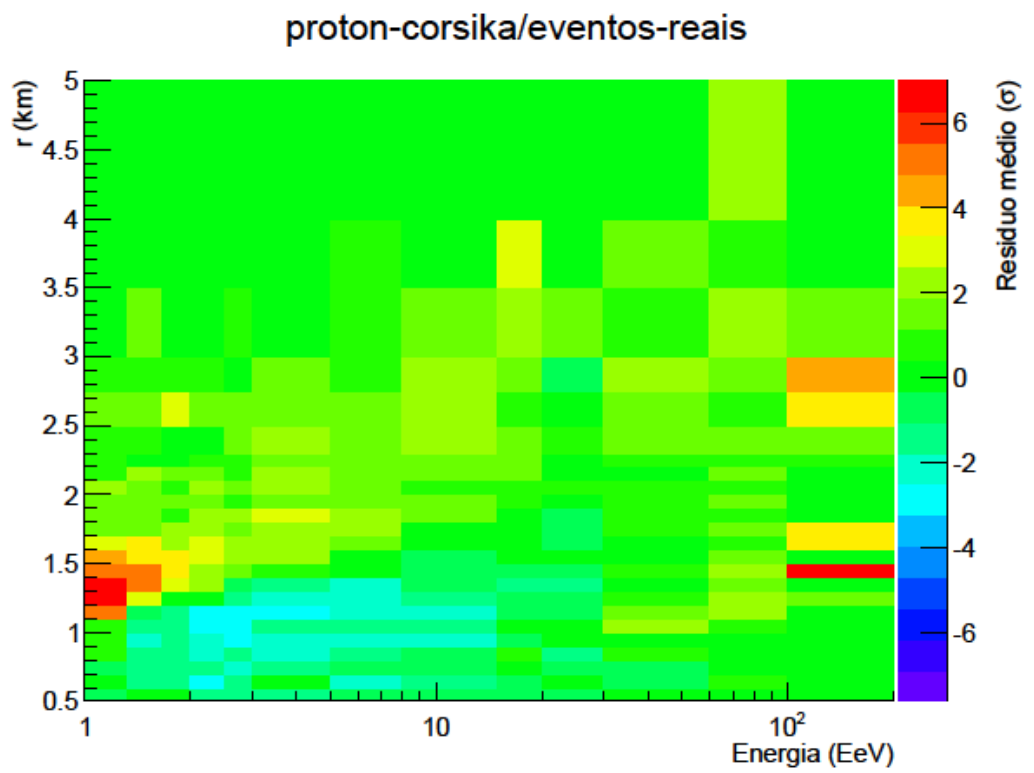

(b)

Figura 5.15: (a) Gráfico com os perfis em duas dimensões do ajuste de $K$ para simulações do CORSIKA/EPOS com próton como partícula primária e eventos reais. O resíduo reduzido médio está indicado pela escala de cor. (b) Zoom no perfil dos resíduos em função da energia e da distância ao centro do chuveiro; a energia está em escala logarítmica. 


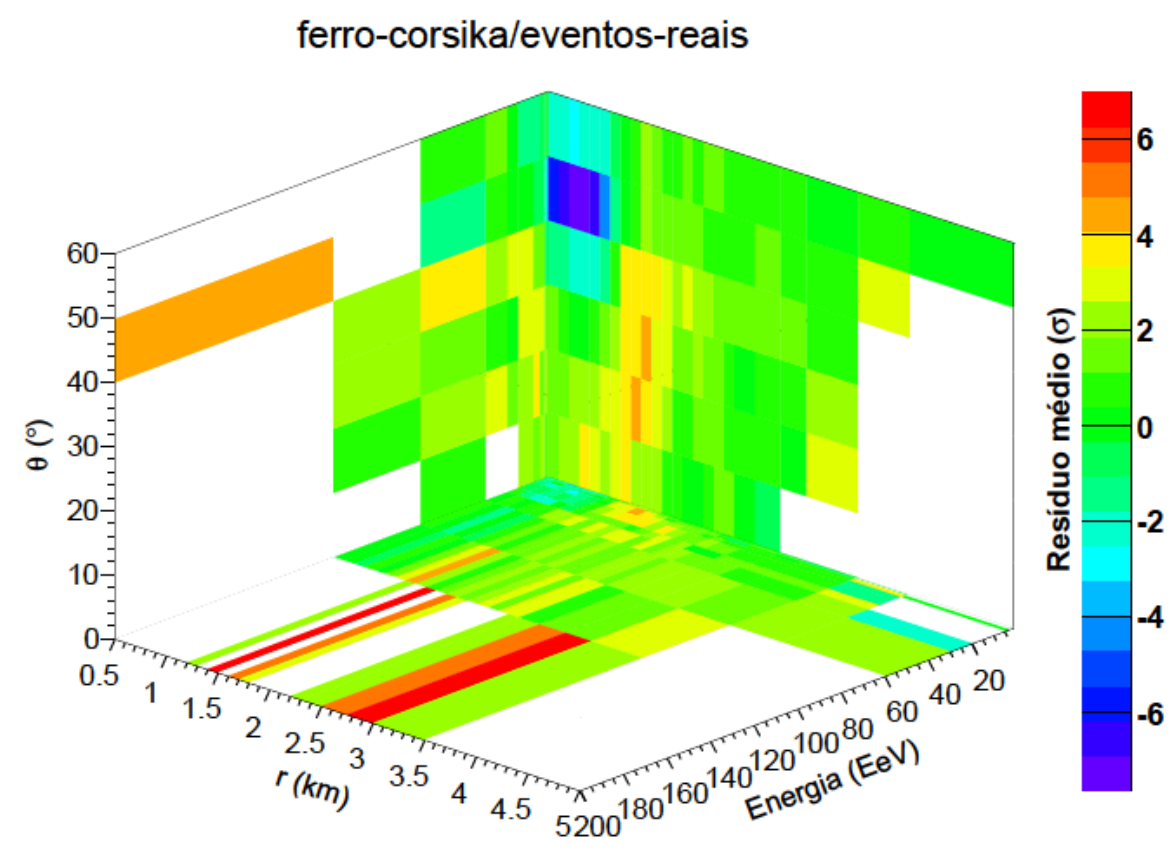

(a)

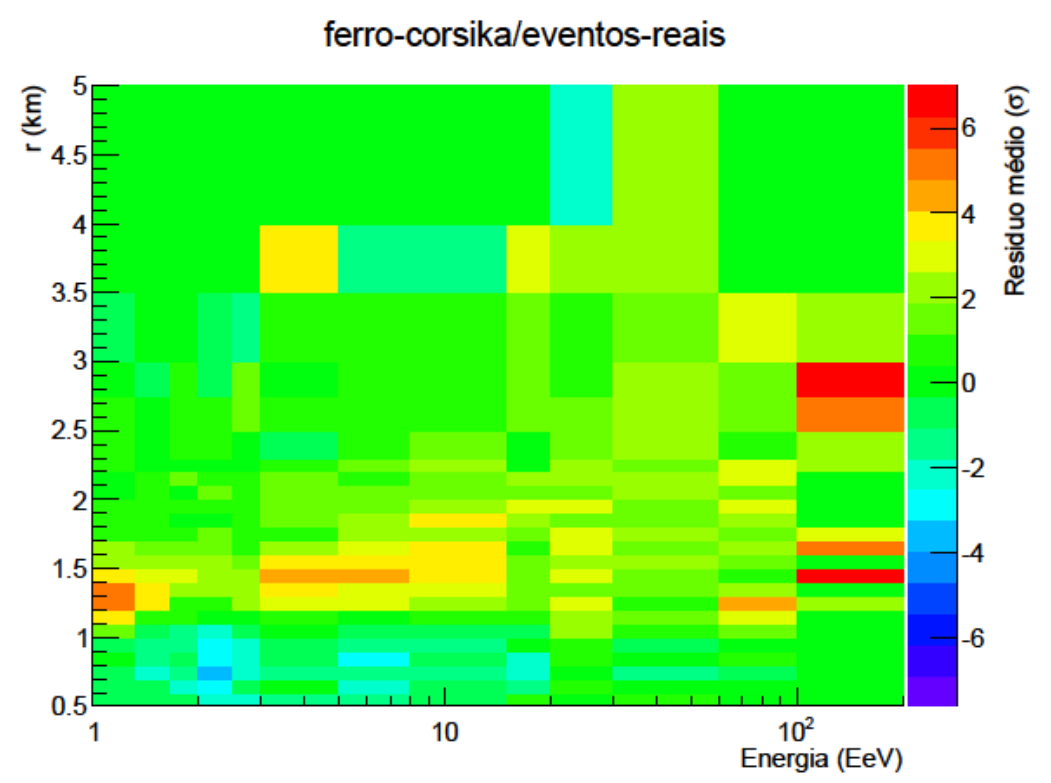

(b)

Figura 5.16: (a) Gráfico com os perfis em duas dimensões do ajuste de $K$ para simulações do CORSIKA/EPOS com ferro como partícula primária e eventos reais. O resíduo reduzido médio está indicado pela escala de cor. (b) Zoom no perfil dos resíduos em função da energia e da distância ao centro do chuveiro; a energia está em escala logarítmica. 
Os dois modelos utilizados para comparação do sinal entre os conjuntos de eventos forneceram conclusões semelhantes, apesar da diferente perspectiva de análise. Ao comparar os modelos de interações hadrônicas SIBYLL e EPOS, é observado um sinal sistematicamente menor nas simulações obtidas com o SIBYLL, independente da partícula que induz o chuveiro. Quando são comparados os eventos reais com eventos simulados pelo CORSIKA/EPOS, as simulações iniciadas por prótons são sempre mais próximas dos eventos reais, tanto nos valores de $\chi^{2}$, quanto na forma geral dos resíduos nos dois métodos de análise, o que permite concluir que no espectro analisado de eventos reais uma composição de próton é mais presente do que uma de ferro, mas não é possível apontar se essa composição possui uma dependência com a energia da partícula primária. Porém, como são medidos muito mais eventos com energia menor, as análises indicam que a composição mais provável, pelo menos em baixa energia, é predominantemente de prótons, o que corrobora os resultados observados pelo detector de fluorescência [76]. A análise que utiliza apenas o sinal das estações pode ser aprimorada para se obter uma diferenciação da composição em função da energia da partícula primária. Já a análise que utiliza a NKG modificada não é viável, devido ao grande efeito que o trigger tem nas estações com sinal baixo.

Os maiores $\chi^{2}$ são obtidos quando comparados os eventos reais com as simulações iniciadas por núcleos de ferro. Isso indica uma inconsistência entre esses conjuntos de dados, que pode ser de origem física, como os eventos não sendo originados por núcleos de ferro, ou as simulações de ferro ainda estarem incompletas, ou algum efeito na detecção dos eventos.

\subsection{Perfil dos resíduos}

Nas seções anteriores foram apresentadas algumas das limitações da NKG modificada como representação da LDF. Dentro dessas limitações, destacamse a apresentação de resíduos sistemáticos e a indiscriminação de composição da partícula que induz o chuveiro atmosférico. Foi mostrado que as simulações de chuveiros iniciados por prótons possuem uma forma diferente dos chuveiros iniciados por ferro, principalmente para distâncias maiores ao cen- 
tro do chuveiro, onde existem diferenças na componente muônica do chuveiro.

Considerando os fatos acima se formula a hipótese: A NKG modificada não consegue diferenciar o tipo de partícula que iniciou um chuveiro específico, mas, ao olhar um conjunto suficiente grande de eventos, é possível observar um comportamento médio distinto de outro conjunto de eventos que possui uma partícula primária diferente. Esse comportamento é apresentado nos resíduos médios dos ajustes.

O objetivo dessa seção é verificar se as reconstruções realizadas são compatíveis com a hipótese formulada e se é possível obter, apenas com os resíduos dos ajustes, um indicativo da composição da partícula primária em função de sua energia. Para tanto, é estudado o comportamento dos resíduos em função da distância ao centro do chuveiro e do ângulo zenital para encontrar uma região nesse espaço de parâmetros em que se possa observar a dependência dos resíduos com a energia, ou que pelo menos se conheça as limitações desse tipo de análise.

\subsubsection{Perfil em função da distância ao centro do chu- veiro}

O parâmetro mais óbvio na análise de resíduos em ajustes da LDF é a distância ao centro do chuveiro $(r)$, pois o ajuste é feito sobre o sinal em função do mesmo. A intenção é identificar as regiões de $r$ que possuem resíduos com comportamentos semelhantes e bem definidos, independentemente da energia da partícula primária.

A figura 5.17 apresenta um gráfico do perfil dos resíduos dos eventos reais e simulados, para todos eventos reconstruídos com energia da partícula primária maior que $1 \mathrm{EeV}$ e ângulo zenital entre $0^{\circ}$ e $60^{\circ}$. Nesse gráfico identificam-se 3 regiões de comportamentos distintos: entre 0 e $1 \mathrm{~km}$, com resíduo médio próximo de 0 ; entre 1 e $2 \mathrm{~km}$, onde há uma transição dos resíduos médio de 0 para 2 incertezas; e mais de $2 \mathrm{~km}$, com resíduo médio em torno de 2 incertezas. Uma questão pertinente com relação à última região seria porque incluir as estações a mais de $3 \mathrm{~km}$ na mesma classificação, se elas apresentam resíduos maiores? Deve-se levar em conta que o número de 
estações nessa região é muito pequeno quando comparada a posições mais próximas ao centro do chuveiro (vide figura 3.6b) e, portanto, a flutuação dos valores é muito maior. Além disso, esse pequeno número de estações não deve alterar muito a média dessa região. Considerando o perfil da LDF dos eventos reais e simulados, figuras 3.6a e 4.3a respectivamente, a primeira região é dividida em duas: entre 0 e $0,5 \mathrm{~km}$, onde ocorre uma aparente "saturação" do sinal das estações, e entre 0,5 e $1 \mathrm{~km}$. Resumidamente, são identificadas 4 regiões:

- Região 1 , de 0 a $0,5 \mathrm{~km}$ : sinal médio com indícios de saturação e resíduos médios próximos de 0 ;

- região 2, de 0,5 a $1 \mathrm{~km}$ : sinal médio sem indício de saturação e resíduos médios próximos de 0 ;

- região 3, de 1 a 2 km: sinal médio com inclinação diferente da região 2 e uma transição dos resíduos médios de 0 para 2 incertezas; e

- região 4, mais de $2 \mathrm{~km}$ : sinal médio com o comportamento semelhante ao da região 3, resíduos médios em torno de 2 incertezas e diminuição significativa do número de estações em relação às outras regiões.

No apêndice B são apresentados os perfis dos resíduos para diferentes intervalos de energia e, apesar de alterações no comportamento dos resíduos nos intervalos diferentes, as regiões definidas acima delimitam comportamentos diferentes. As análises de resíduos realizadas no transcorrer desta seção serão realizadas em cada uma das 4 regiões, independentemente. 


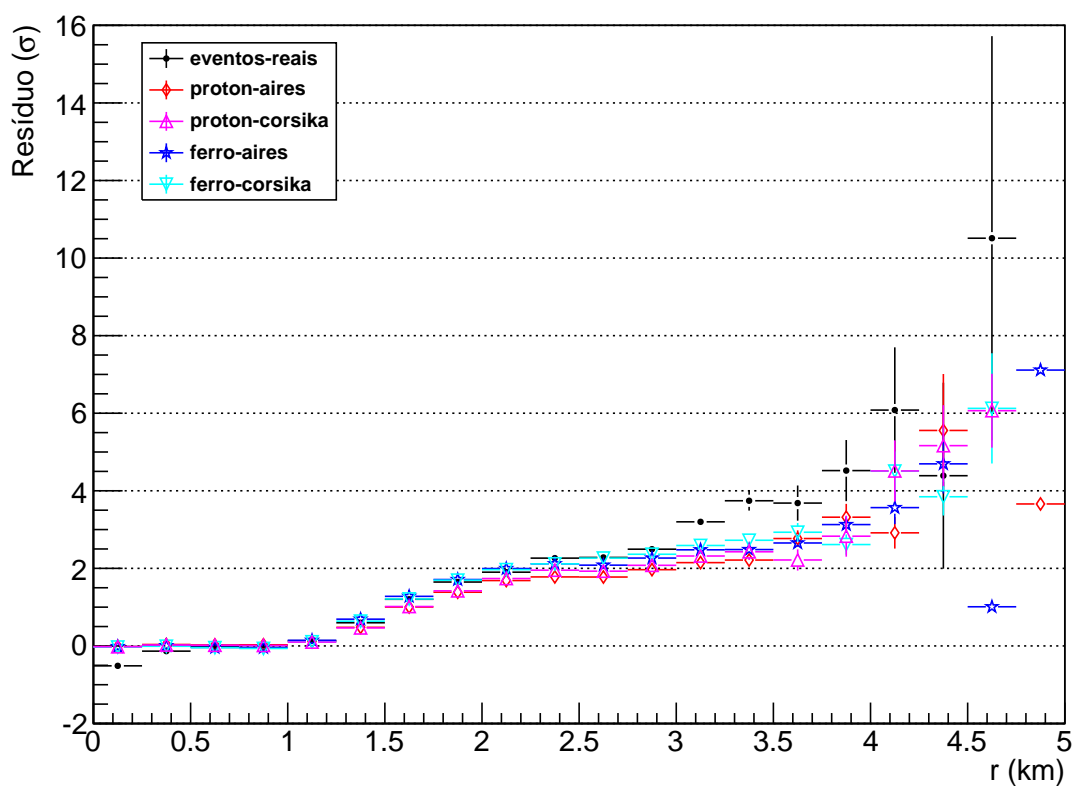

Figura 5.17: Perfil dos resíduos dos ajuste de LDF com a NKG em eventos reais e simulados em função da distância da estação ao centro do chuveiro.

\subsubsection{Perfil em função do ângulo zenital}

O objetivo desta subseção é observar como os resíduos variam com o ângulo zenital, compreender quais motivos causariam essa dependência e então avaliar se alguma das regiões não deve ser utilizadas para um estudo de composição em função da energia.

Na figura 5.18 se encontram os perfis dos resíduos em função do ângulo zenital nas 4 regiões de $r$ definidas na subseção anterior. Na região 1, figura 5.18a, as estações estão próximas ao centro do chuveiro, onde há maior densidade de partículas, portanto com maior probabilidade de saturação das PMTs. Se, por algum motivo, as estações "saturadas" não forem identificadas como tal e forem incluídas nos gráficos de resíduos, elas causariam uma diminuição sistemática das médias. Como a intensidade do sinal em uma estação a uma distância fixa do centro do chuveiro diminui com o aumento de $\theta$, devido à maior camada de atmosfera atravessada, o número de estações 
"saturadas" diminuiria e, consequentemente, o resíduo tenderia a zero. Esse comportamento é observado nos eventos reais, mas não nos simulados, o que indica que pode haver um problema no sistema de identificação de saturação utilizado pelas estações. Devido a essa diferença no comportamento entre os resíduos de eventos reais e simulados, a região 1 não é recomendada para um estudo de composição em função da energia.

A região 2, figura 5.18b, possui uma amplitude de variação de resíduos muito menor que em outras regiões, variando menos de 0,1 incertezas. Como a intenção é observar diferenças maiores que esse valor, se considera que os resíduos dessa região não dependem do ângulo zenital e a região 2 pode ser interessante para uma comparação entre eventos reais e simulados.

No caso da região 3, figura 5.18c, os resíduos médios começam em torno de 0,3 incertezas e aumentam $\operatorname{com} \theta$. Como já foi dito, o sinal das estações em uma determinada posição em relação ao centro do chuveiro tende a diminuir com o aumento do ângulo zenital. O que provavelmente acontece neste caso é que em torno de $25^{\circ}$ o sinal começa a se aproximar do trigger e o efeito descrito na seção 5.5 causa um aumento dos resíduos médios. Se essa for a causa do aumento dos resíduos, a região 3 pode ser utilizada para comparação de eventos reais com simulados, pois a dependência dos resíduos com o ângulo aparenta ser mesmo independente do conjunto de dados em questão. Mas deve-se ficar atento, pois os dados podem apresentar algum viés.

Na figura 5.18d são apresentados os resíduos em função do ângulo zenital para a região 4. A amplitude da variação dos resíduos é a maior dentre as quatro regiões. As incertezas também e, além disso, os resíduos não apresentam uma dependência definida $\operatorname{com} \theta$. Esse efeitos devem ser causados pela pequena quantidade de estações nessa região. Devido a todos esses fatores, a região 4 não deve ser utilizada na comparação de eventos reais com simulados. Entretanto, esta seria a região mais interessante, pois apenas os eventos com energias maiores são tão extensos e é também a região onde ocorre a predominância da parte muônica dos chuveiros. 


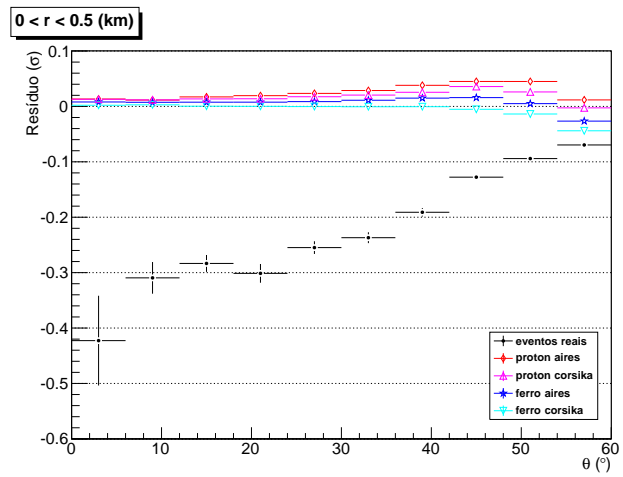

(a) região 1

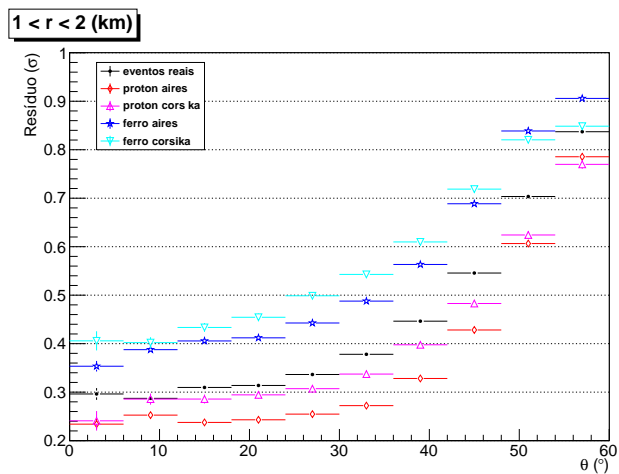

(c) região 3

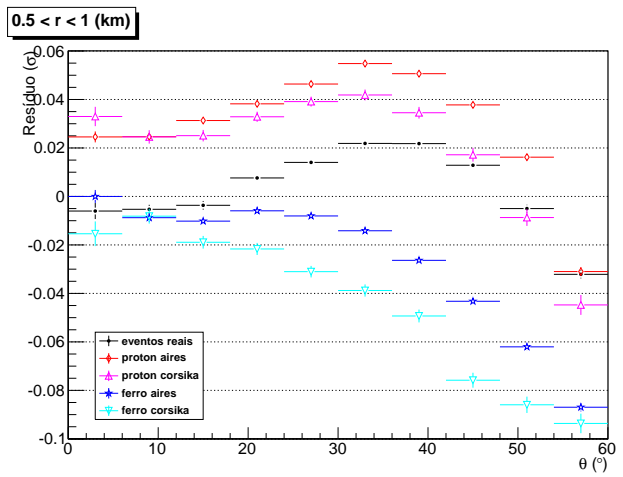

(b) região 2

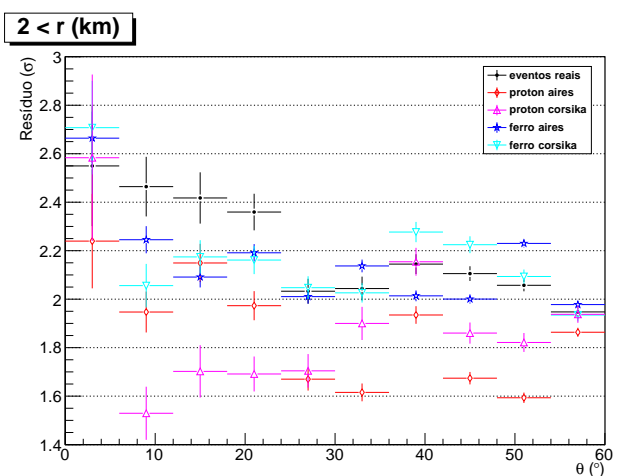

(d) região 4

Figura 5.18: Gráficos do perfil dos resíduos reduzidos para as diferentes regiões de distâncias entre as estações e o centro do chuveiro $(r)$, em função do ângulo zenital $(\theta)$. Contêm eventos reais e simulados com o AIRES/SIBYLL e o CORSIKA/EPOS utilizando como partículas primárias núcleos de ferro e prótons.

\subsubsection{Perfil em função da energia da partícula primária}

Nesta subseção são comparados os resíduos médios dos eventos reais e simulados nos intervalos de distância ao centro do chuveiro definidos anteriormente. O objetivo é obter uma estimativa qualitativa da composição das partículas primárias em função da sua energia. Tal estimativa é comparada com as estimativas obtidas pela metodologia padrão utilizada pela colaboração Pierre Auger, que utiliza a profundidade atmosférica em que o número de partículas 
do chuveiro é máximo $\left(X_{\max }\right)$ medida pelo detector de fluorescência (FD).

Na subseção anterior, as regiões foram avaliadas como adequadas e não adequadas para a análise de composição. As não adequadas, regiões 1 e 4, apresentam complicações relacionadas a características do Observatório Pierre Auger, e os resíduos em função da energia para essas regiões estão na figura 5.19. No gráfico da região 1, 5.19a, é evidente nos eventos reais a influência de estações "saturadas" classificadas erroneamente como "não saturadas". Pois, com o aumento de energia, a intensidade do sinal aumenta e, consequentemente, a probabilidade das estações próximas ao centro do chuveiro terem suas PMTs saturadas. O sinal "saturado" é sistematicamente menor que a função ajustada, causando resíduos em média negativos. Esse efeito pode ser a causa da tendência de diminuição dos resíduos dos eventos simulados com o aumento da energia, mas não é possível afirmar com certeza pois essa diminuição não é observada no gráfico de resíduos em função de $\theta$, figura 5.18a.

No gráfico de resíduos da região 4, figura $5.19 \mathrm{~b}$, predomina a influência do efeito do trigger que é discutido na seção 5.5. Esse efeito está presente nas estações com sinal próximo ao trigger e causa resíduos sistematicamente positivos. Em baixas energias, a maioria da estações dessa região tem sinal baixo e por isso resíduos elevados. Com o aumento da energia, o sinal médio das estações também aumenta e muitas delas passam a não sofrer a influência do efeito citado, contribuindo para um resíduo menor. Como os eventos reais possuem sinal maior, o efeito do trigger os afeta menos que aos eventos simulados. 


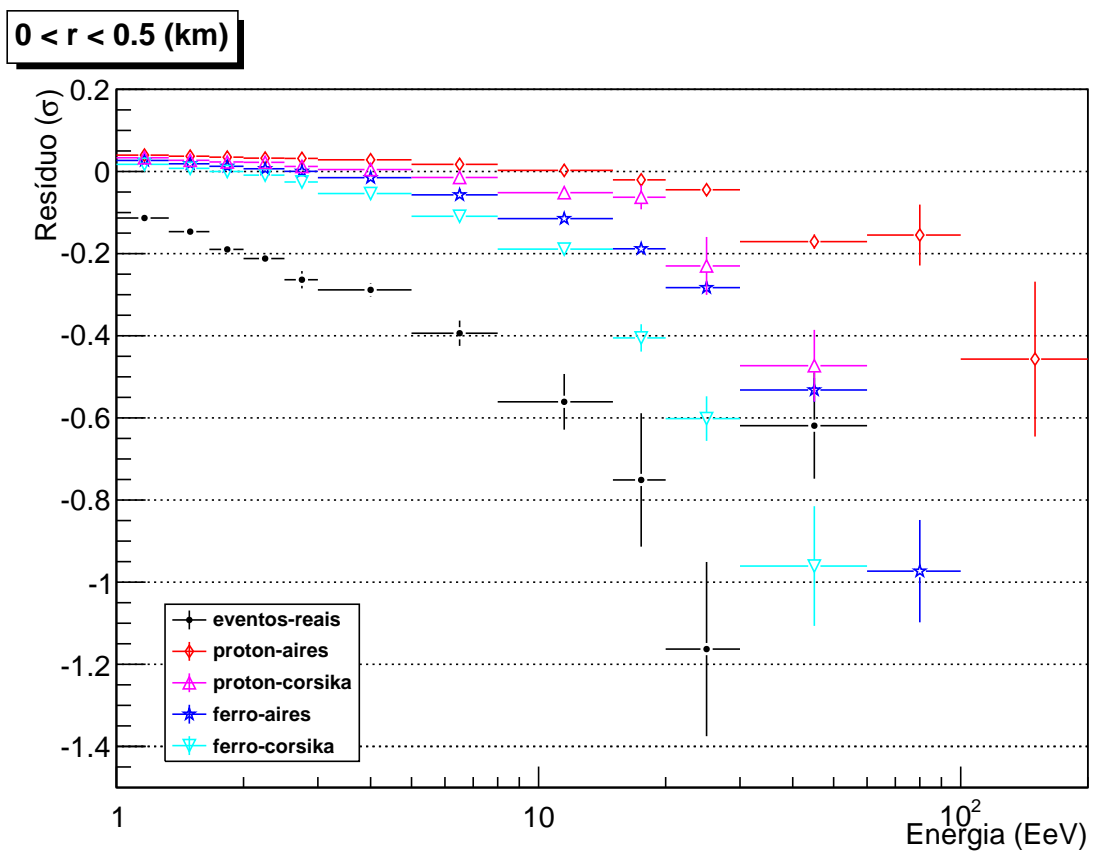

(a) região 1

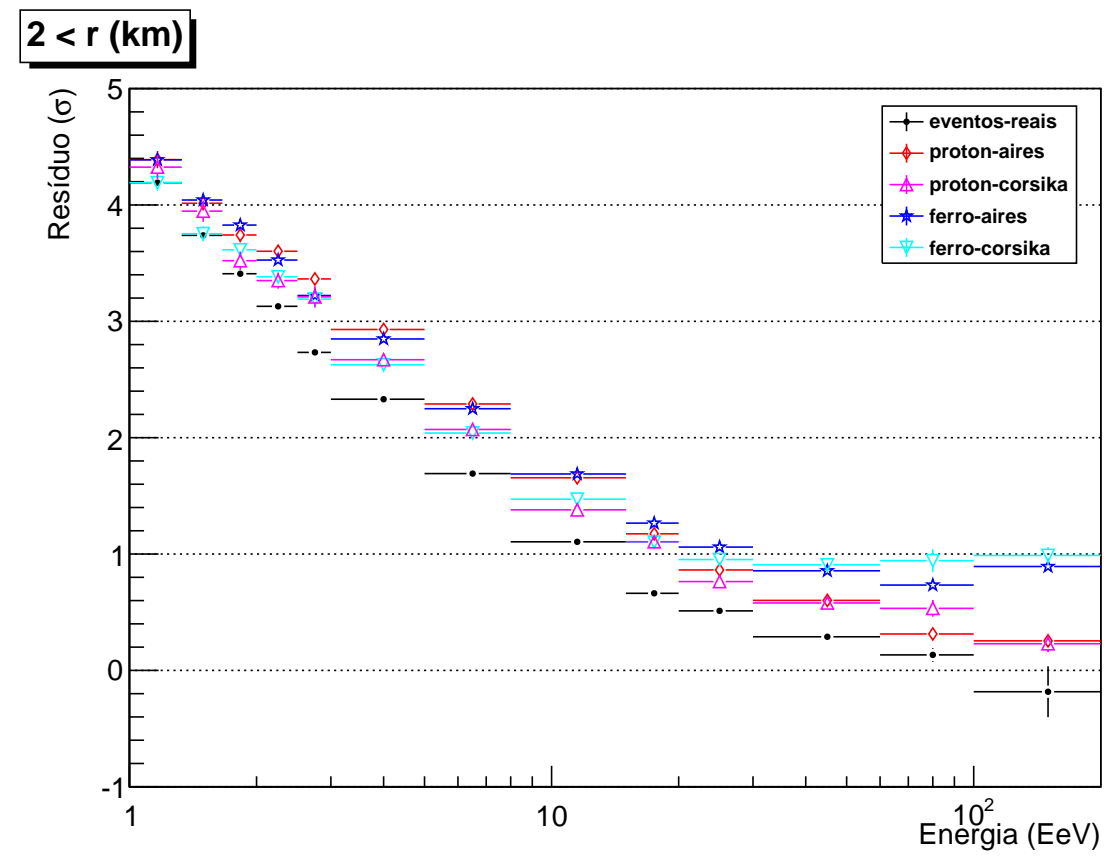

(b) região 4

Figura 5.19: Gráficos do perfil dos resíduos reduzidos em função da energia reconstruída para os eventos reais e energia simulada para eventos simulados nas regiões 1 e 4 . As barras de incerteza representam o desvio padrão da média. 
Os resíduos das regiões 2 e 3 foram avaliados como adequados para uma análise de composição, pois os efeitos de detecção conhecidos podem ser desprezados nessas regiões. Os resíduos da região 2 estão plotados na figura 5.20a. Os eventos reais têm resíduos compatíveis com os das simulações que usam próton como partícula primária em chuveiros com até $6 \mathrm{EeV}$, quando há uma mudança no comportamento e começam a tender para as simulações de chuveiros iniciados por ferro. Nas energias mais altas os eventos reais são compatíveis com as simulações de ferro, mas o número menor de eventos implica em incertezas maiores.

As estações da região 3, figura 5.20b, possuem resíduos com formas distintas das presentes na região 2. Entretanto, o comportamento relativo dos eventos reais em relação aos simulados é semelhante. Em $1 \mathrm{EeV}$, os resíduos dos eventos reais estão entre os dos eventos simulados com ferro e próton, e em 1,5 EeV se tornam compatíveis com as simulações de próton. Este comportamento permanece até $10 \mathrm{EeV}$, quando começa a tender para ferro. Esta mudança de tendência ocorre apenas 1 canal mais energético do que na região 2 .

Atualmente, a informação sobre a composição das partículas primárias do chuveiros atmosféricos usualmente é obtida através do detector de fluorescência $(\mathrm{FD})$, através da profundidade atmosférica em que o número de partículas do chuveiro é máximo $\left(X_{\max }\right)$. Com esse parâmetro não é possível identificar evento a evento, mas observar um comportamento médio em um determinado conjunto de dados e para tanto são calculadas duas grandezas, seu valor médio $\left\langle X_{\max }\right\rangle$ e a raiz quadrada de sua média quadrática $R M S\left(X_{\max }\right)$. Na figura 5.21 são plotadas essas grandezas para dados do FD apresentados na ICRC 2011 [76], juntamente com as estimativas de simulações que utilizam diferentes modelos de interação hadrônica. Note que esses gráficos apresentam eventos até $30 \mathrm{EeV}$, quanto os gráficos obtidos neste trabalho apresentam eventos até $200 \mathrm{EeV}$. No gráfico de $\left\langle X_{\max }\right\rangle$ em função da energia do chuveiro, 5.21a, os eventos reais estão mais próximos das simulações de próton em $1 \mathrm{EeV}$, com uma mudança de tendência em torno de $5 \mathrm{EeV}$, onde começam a se aproximar das simulações de chuveiros de ferro. No gráfico do $R M S\left(X_{\max }\right), 5.21 \mathrm{~b}$, o comportamento dos eventos reais é bem 
semelhante, compatível com as simulações de próton entre $1 \mathrm{EeV}$ e $4 \mathrm{EeV}$. Para energias maiores, há uma aproximação gradativa com as simulações de eventos de ferro e em $12 \mathrm{EeV}$, é compatível com os resultados para uma composição de ferro. 


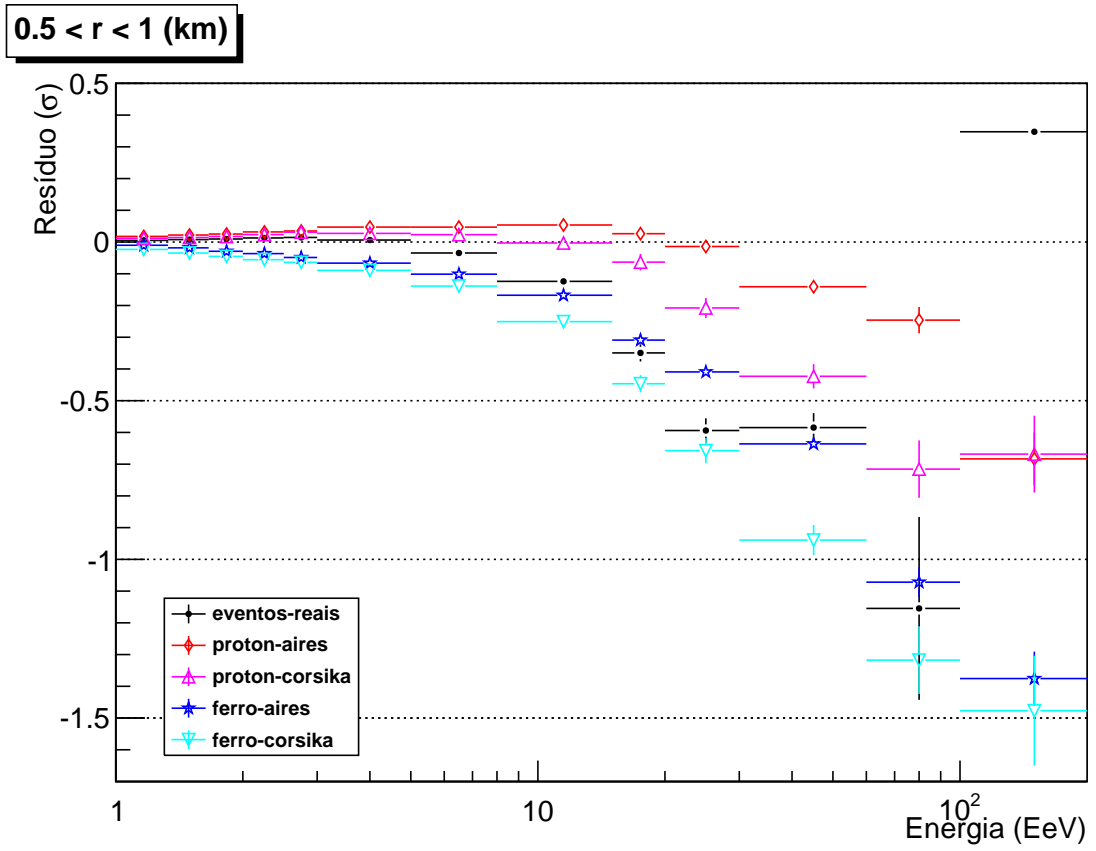

(a) região 2

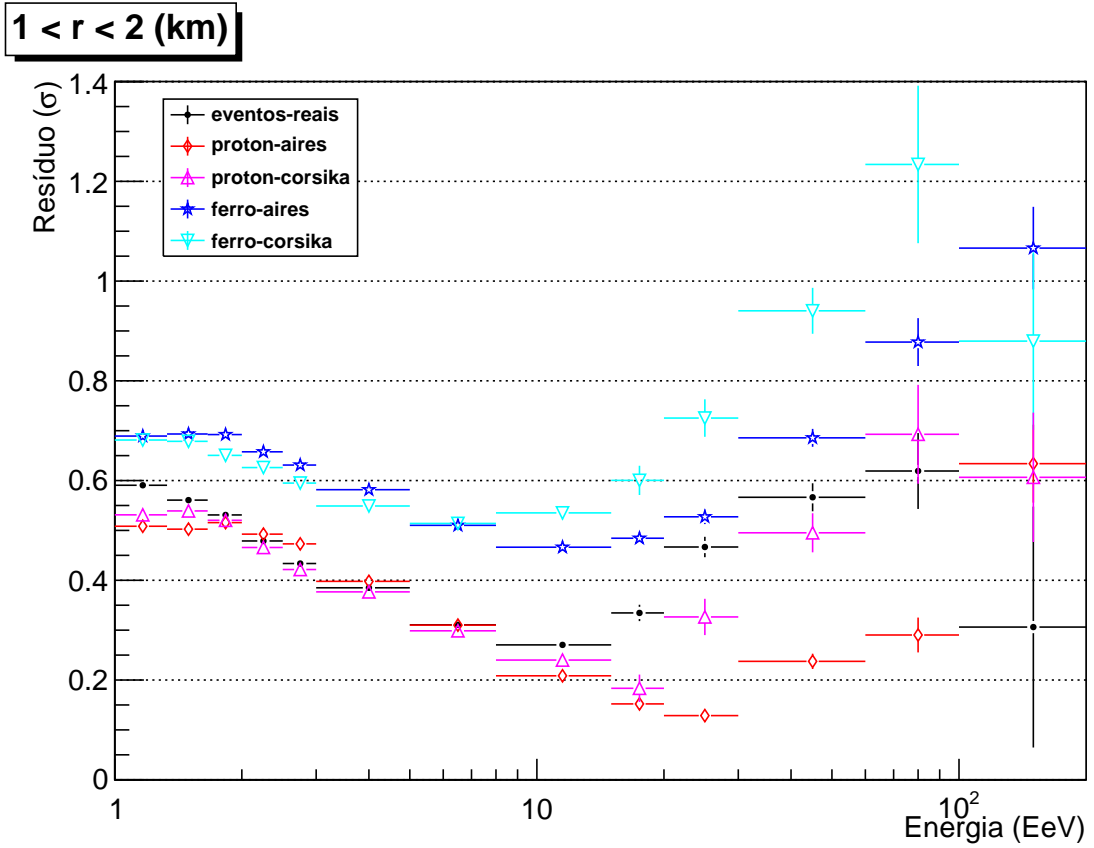

(b) região 3

Figura 5.20: Gráficos do perfil dos resíduos reduzidos em função da energia reconstruída para os eventos reais e energia simulada para eventos simulados nas regiões 2 e 3 . As barras de incerteza representam o desvio padrão da média. 

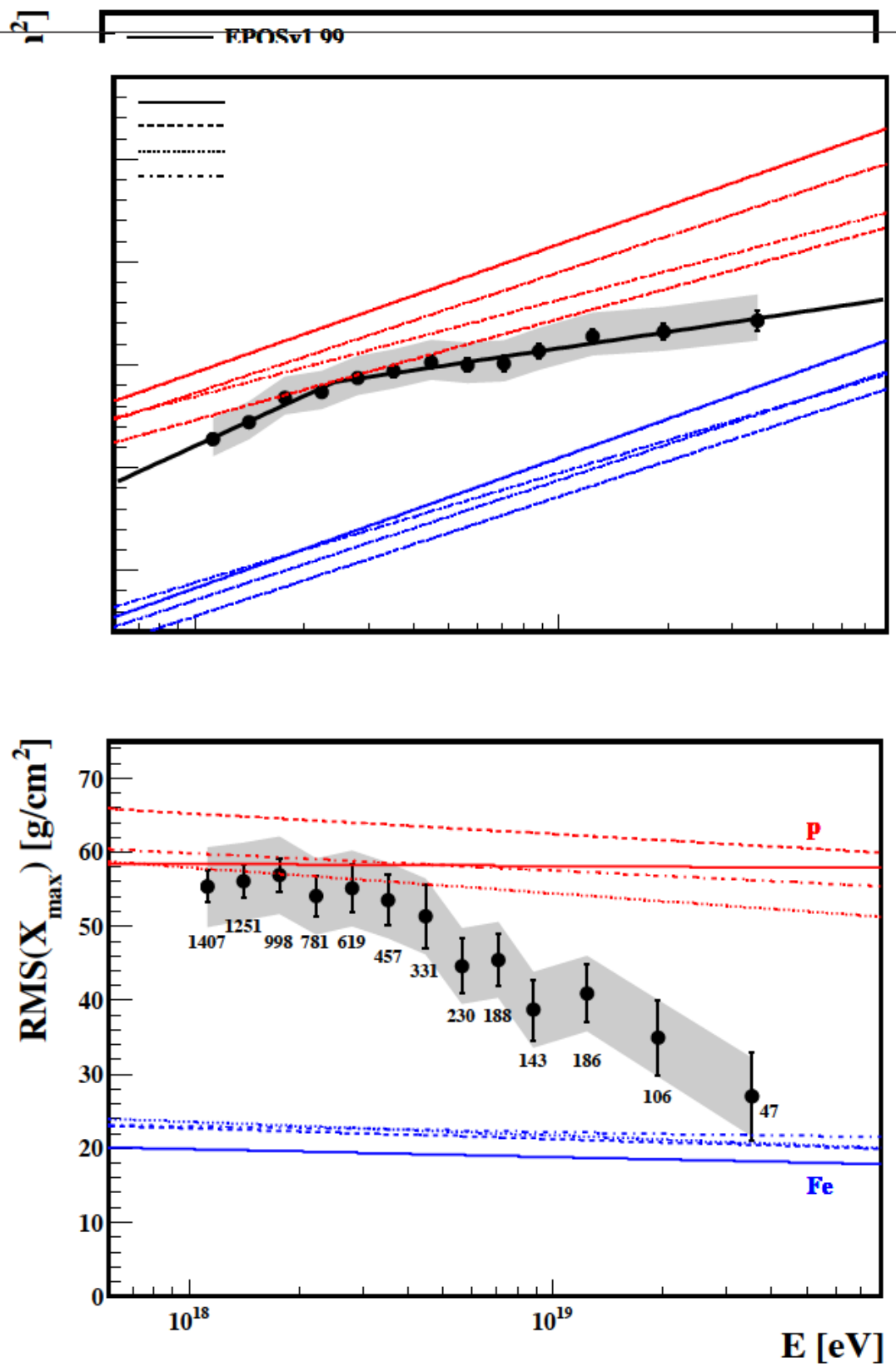

(b)

Figura 5.21: $\left\langle X_{\max }\right\rangle$ (a) e $R M S\left(X_{\max }\right)$ (b) em função da energia reconstruída. Os pontos são eventos reais medidos pelo Observatório Pierre Auger, e as linhas são simulações com diferentes modelos de interação hadrônica. Os números representam a quantidade de eventos utilizados no canal. Estes gráficos foram apresentados no ICRC de 2011 [76]. 
Apesar da análise de composição que utiliza $X_{\max }$ ser completamente independente da análise de resíduos apresentada nesse trabalho, seus resultados são compatíveis entre si, isto é, os resíduos das regiões 2 e 3 corroboram a estimativa de composição em função da energia apresentada pela colaboração Pierre Auger. Além disso, essa análise observa um problema na identificação das estações "saturadas", que são registradas como estações "não saturadas". Também é observada uma sistemática nos resíduos devido ao efeito de trigger que não é considerado. Esse efeito é discutido em detalhes na próxima seção.

\subsection{Possível viés em estações com sinal médio próximo ao trigger}

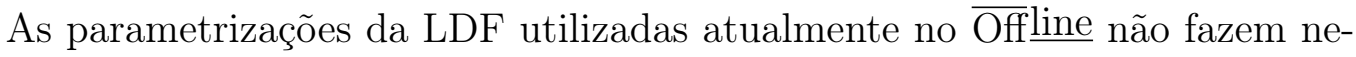
nhuma suposição sobre como características do Observatório influenciam a forma da LDF observada, ou seja, elas prevêem a LDF real, não a LDF que seria observada pelo Observatório Pierre Auger. Entretanto, quando essas parametrizações são utilizadas, se observam resíduos sistematicamente positivos a grandes distâncias do centro do chuveiro. Na seção 5.3.2, em um ajuste que utiliza uma derivação da NKG modificada, foram observados resíduos com sistemáticas que indicam problemas nas estações com sinais próximos ao trigger. Nesta seção é apontado um viés no sinal das estações próximos ao

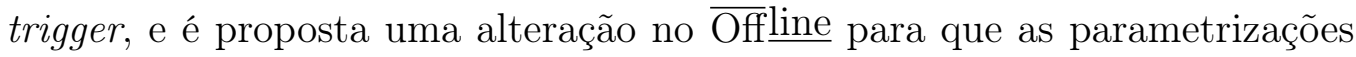
da LDF descrevam o evento medido pelo Observatório e são apresentados os resíduos das reconstruções que utilizam a NKG com a correção proposta.

Sabe-se que a parametrização da LDF em uma posição $r$ estima o valor médio $\langle S\rangle$ da distribuição do sinal para essa posição. A função de densidade de probabilidade (f.d.p.) utilizada para descrever o sinal é uma gaussiana com média $\langle S\rangle$ e desvio padrão $f_{s} \cdot \sqrt{\langle S\rangle}$, onde $f_{s}$ foi definido na equação (2.12). A gaussiana é uma boa aproximação para uma Poisson com média maior que 20, só que nesse caso a média, em geral, é da ordem do valor do trigger (3 VEM). Além disso, quando a Poisson é aproximada por uma gaussiana, seu desvio padrão deve ser a raiz da média. O sinal que, em princípio, seria 
bem descrito por uma Poisson, é o número de elétrons medidos pela PMT e este número é grande o suficiente para a aproximação ser válida. Além disso, a mudança de unidades de número de elétrons para VEM não altera a função de densidade de probabilidade (f.d.p). Por outro lado, como visto na seção 3.3, o sinal não é exatamente uma Poisson, e por isso seu desvio padrão deve ser corrigido.

Na figura 5.22a está plotada a f.d.p. do sinal para duas posições de uma LDF e o trigger das estações. As linhas verticais contínuas com as cores das f.d.p.s representam as médias dessas distribuições, as áreas hachuradas (acima do trigger) são as regiões em que o sinal pode ser registrado. As linhas verticais tracejadas são as médias dos sinais das regiões hachuradas, ou seja, as médias dos sinais observáveis. Então existe uma diferença entre o sinal real (média da f.d.p.) e o sinal observável (média da f.d.p. acima do trigger), e essa diferença fica maior para sinais menores. Se esse cálculo for feito para todas os sinais, é possível corrigir a LDF, como na figura 5.22b. Observe que a LDF padrão diminui muito mais rápidamente que a LDF corrigida, que tem seu valor tendendo assintoticamente ao valor do trigger. 


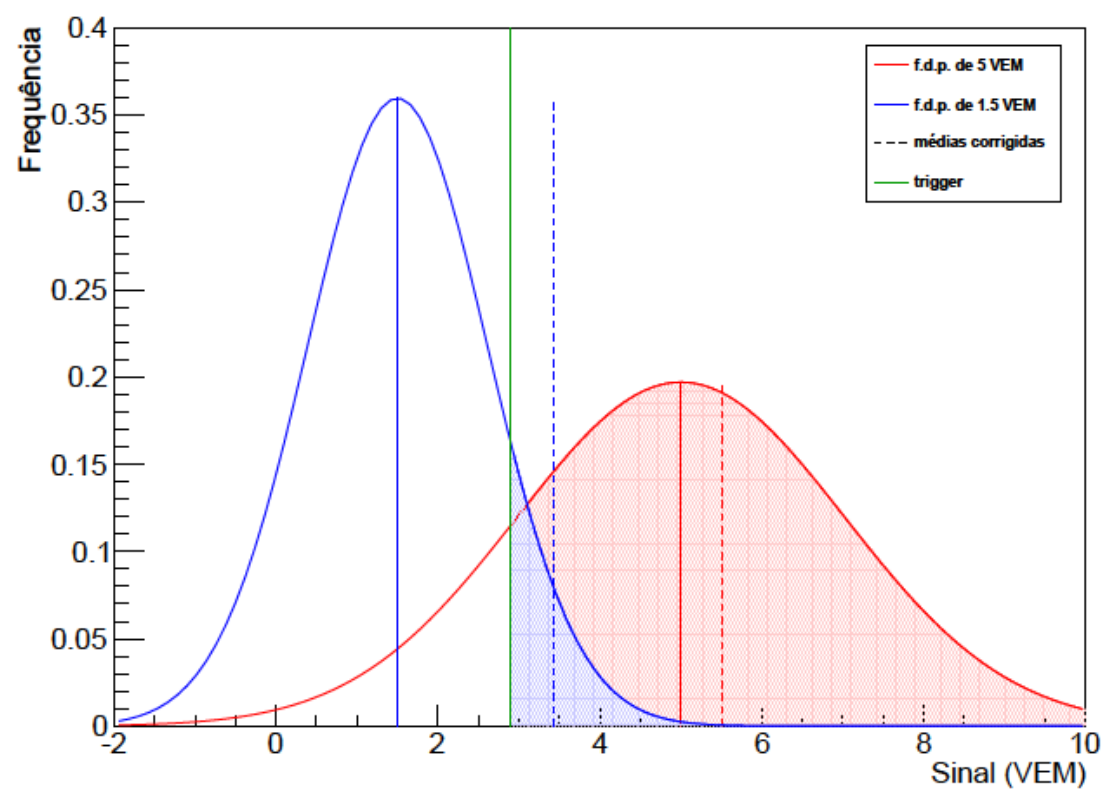

(a)

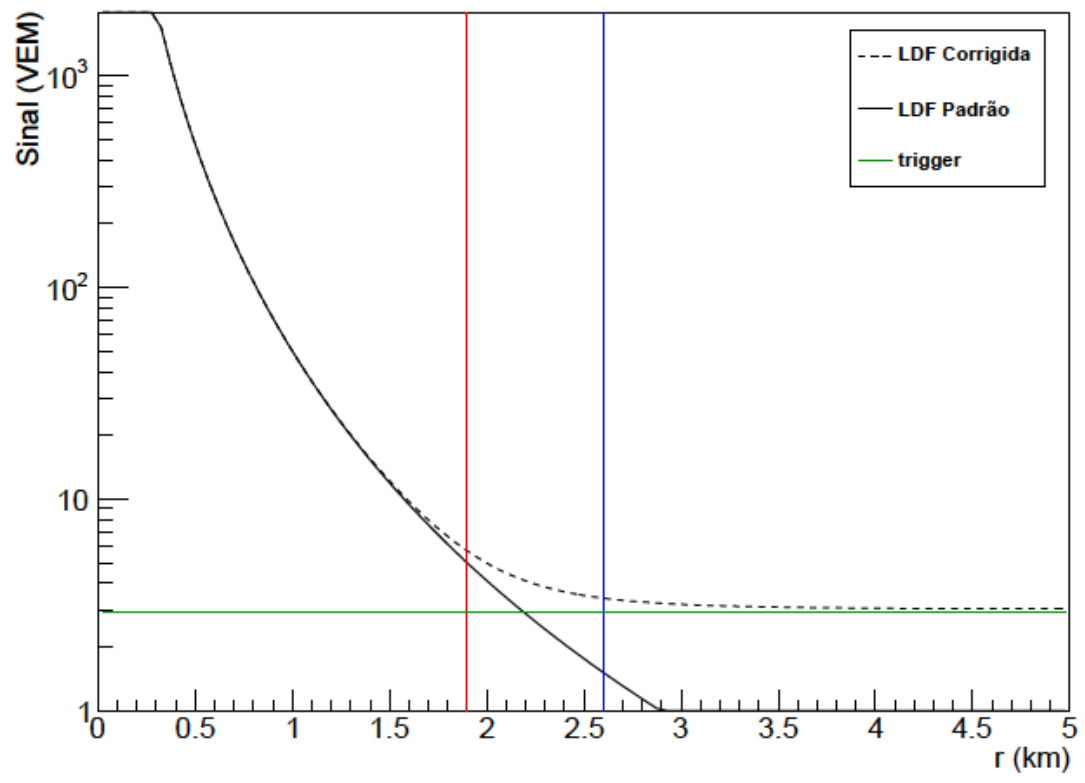

(b)

Figura 5.22: Ilustração do viés na LDF observada devido ao trigger das estações. No gráfico superior são plotadas as f.d.p. que descrevem os sinais de estações em duas distâncias ao centro do chuveiro; as áreas hachuradas acima do trigger representam os sinais medidos que contribuem para as médias corrigidas. No gráfico inferior são mostradas a LDF padrão e a LDF com as médias corrigidas. 


\subsubsection{Alteração no $\overline{\text { Offline }}$}

Visto que esse efeito está relacionado apenas com o valor do sinal da estação e não tem nenhuma relação com os parâmetros relacionados à LDF ( $S_{1000} \mathrm{e}$ $\theta$ ), foi construída uma função, que dado um valor de sinal, retorna o valor do sinal corrigido, para que, num segundo passo, fosse implementada uma correção na LDF. Essa função está plotada na figura 5.23, juntamente a uma curva do sinal não corrigido.

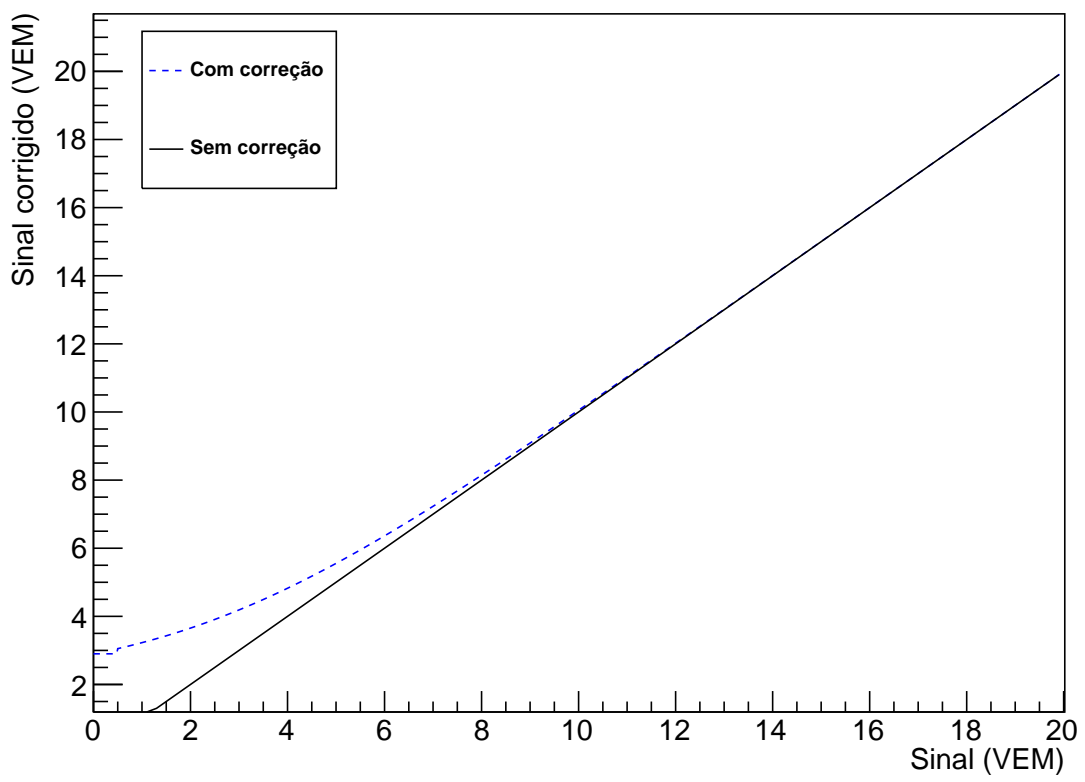

Figura 5.23: Gráfico de comparação entre o sinal corrigido e não corrigido.

$\mathrm{Na}$ função para correção do sinal, foi utilizado $f_{c}=0,90$, calculado na seção 3.3, e trigger de 2,9 VEM. Apesar do valor do trigger ser de 3 VEM, muitos dos ajustes preliminares indicaram que esse valor é muito alto. A função do sinal corrigido possui uma descontinuidade de sua derivada em 0,5 VEM. Isso acontece porque, quando o sinal é menor que esse valor, a área de f.d.p. acima do trigger é praticamente zero, e, portanto, o valor médio é indefinido. Para evitar divergências, se optou por definir que valores menores que 0,5 VEM são corrigidos sempre para o valor do trigger. 
Foram implementadas no módulo LDFFinder modificações nas linhas que calculam o valor da LDF. Esses valores são interceptados e passados para a função que faz a correção descrita anteriormente. Note que esse método não depende da parametrização utilizada para a LDF, do valor do $S_{1000}$, do valore de $\theta$ ou de qualquer outro parâmetro do ajuste. Na figura 5.24 é apresentada uma comparação do ajuste de um mesmo evento, com a correção e sem a correção. Observa-se que a LDF corrigida descreve melhor o evento.

Para exemplificar como a LDF corrigida descreve melhor os eventos, foram calculados a média e o RMS dos valores de $\chi^{2}$ dos ajustes com e sem correção, que são apresentados na tabela 5.4, juntamente com o número de eventos ajustados. Os valores médios do $\chi^{2}$ são pelo menos metade nos ajustes com a LDF corrigida, e a dispersão também é significativamente menor. Entretanto, o número de eventos reconstruídos também é menor, principalmente no caso dos eventos reais. Foram observados problemas de convergência nos ajustes, mas, como esta análise ainda é muito recente, não se sabe se os eventos que não podem ser reconstruídos são aleatórios ou se possuem alguma característica em comum, como, por exemplo, se estão em uma faixa de energia específica. O fato desse problema não afetar com mesma intensidade as simulações permite supor que deve estar relacionado a algum efeito que não é simulado corretamente ou não é esperado, como dificuldades na identificação de estações saturadas. Mas, de qualquer maneira, o fato de não afetar muito as simulações e de a diminuição do $\chi^{2}$ ser tão significativa quanto nos eventos reais reforça que esse método para a correção da LDF tem potencial para ajudar uma melhor compreensão da LDF.

Uma característica importante dessa correção é o fato dela não invalidar os resultados obtidos para $S_{1000}$ de ajustes sem a correção. Na figura 5.25 são apresentados os valores de $S_{1000}$ de ajustes com a correção em função de $S_{1000}$ dos ajustes sem correção. Com a intenção de observar alguma correlação foi ajustada a esses dados uma reta $\left(S_{1000}\right.$ Corrigido $\left.=a_{0}+a_{1} \cdot S_{1000}\right)$, sendo $a_{0}=-0,4108(21)$ VEM e $a_{1}=1,00003(13)$. Nota-se que o coeficiente angular é compatível com 1, o $S_{1000}$ nos ajustes corrigidos é, em média, 0,4108 VEM menor que nos ajustes sem correção. 


\begin{tabular}{lcccccc}
\hline & \multicolumn{3}{c}{ corrigida } & \multicolumn{3}{c}{ padrão } \\
\cline { 2 - 7 } & $\left\langle\chi^{2}\right\rangle$ & $R M S\left(\chi^{2}\right)$ & $\mathrm{N}$ & $\left\langle\chi^{2}\right\rangle$ & $R M S\left(\chi^{2}\right)$ & $\mathrm{N}$ \\
\cline { 2 - 7 } eventos-reais & 1.51 & 9.26 & 260826 & 3.60 & 16.14 & 330804 \\
proton-aires & 1.15 & 3.16 & 263639 & 2.71 & 6.13 & 266946 \\
proton-corsika & 1.47 & 4.08 & 64858 & 3.53 & 7.54 & 68481 \\
ferro-aires & 1.68 & 5.85 & 317825 & 4.69 & 9.01 & 321122 \\
ferro-corsika & 2.18 & 7.63 & 73869 & 5.80 & 10.71 & 77184 \\
\hline
\end{tabular}

Tabela 5.4: Valores médios e RMS do $\chi^{2}$ e número de eventos reconstruídos utilizando a LDF corrigida e a LDF padrão. 


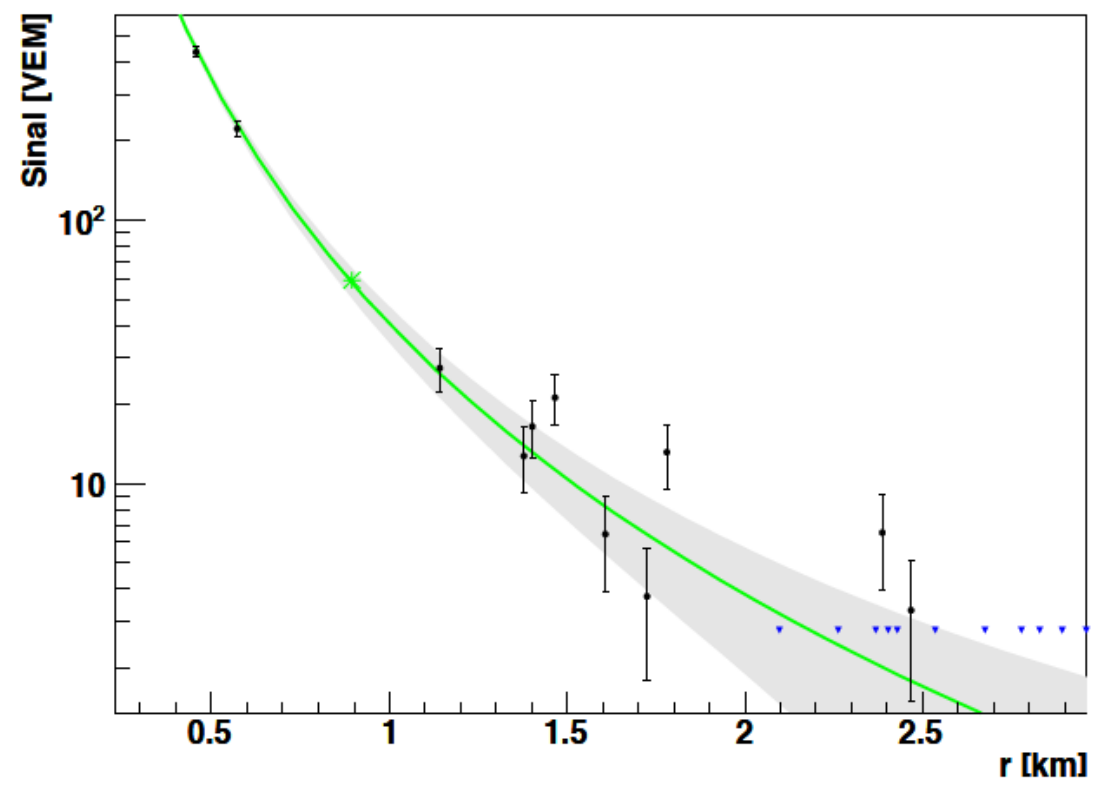

(a) sem correção

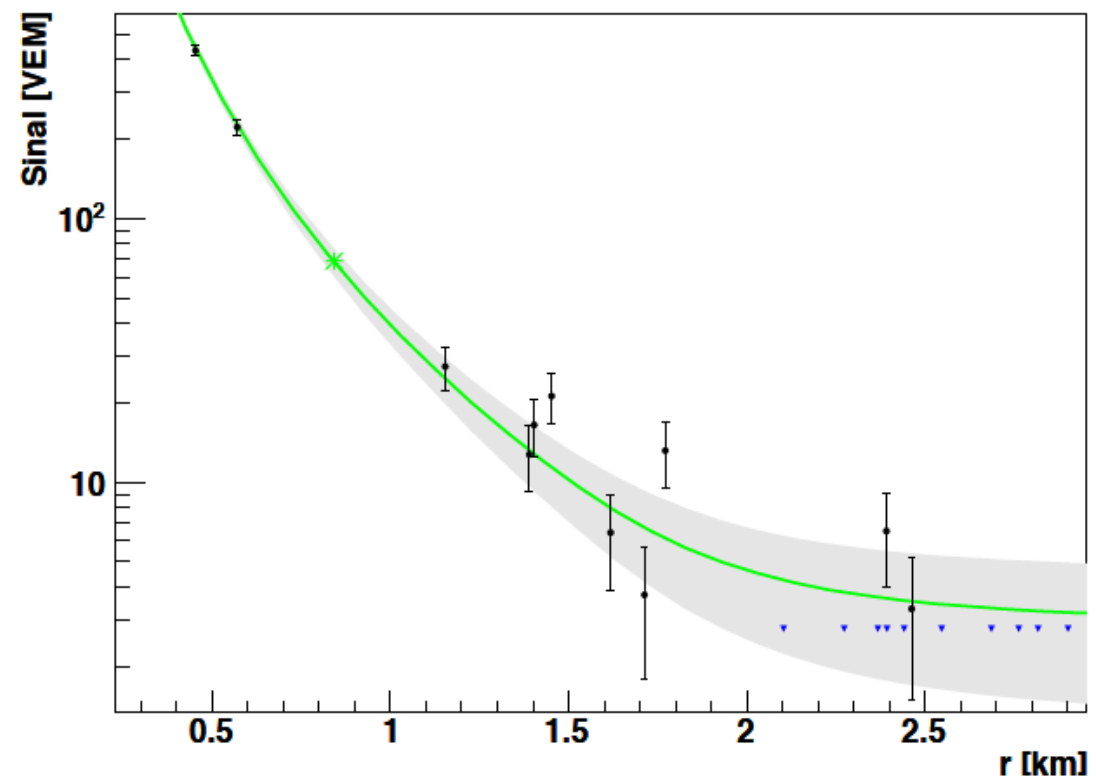

(b) com correção

Figura 5.24: Gráficos do ajuste do mesmos evento com LDF original (a) e corrigida (b). Evento real com energia em torno de $10 \mathrm{EeV}$ e $\theta=50^{\circ}$. A faixa cinza representa o intervalo de 1 desvio padrão e os triângulos azuis são as estações silenciosas presentes no evento. 


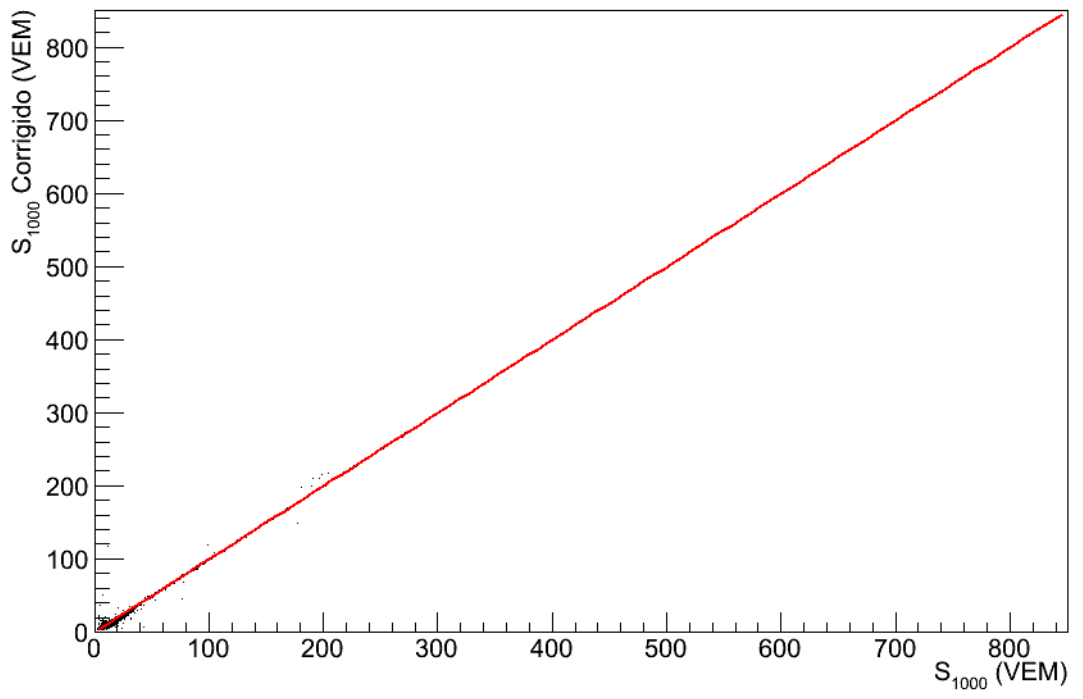

Figura 5.25: Comparação do $S_{1000}$ de ajustes em que a LDF é corrigida com ajustes da LDF padrão. A linha vermelha é uma reta ajustada com parâmetros $a_{0}=-0,4308(21)$ e $a_{1}=1,00003(13)$. 


\subsubsection{Perfil dos resíduos em ajustes com sinal corrigido}

Após a exposição do problema no sinal próximo ao trigger, uma proposta para solucioná-lo e um exemplo do impacto dessa solução nos conjuntos de eventos, nesta subseção é apresentado o impacto nas conclusões obtidas com os ajustes que utilizam a NKG corrigida.

Na figura 5.26 estão os perfis dos resíduos de todos os ajustes com energia maior que $1 \mathrm{EeV}$ e ângulo zenital menor que $60^{\circ}$, assim como na figura 5.17. É importante notar que a escala do eixo dos resíduos, que era entre -2 e 16 incertezas, agora varia entre -1,5 e 1,5 incertezas. Houve uma redução substancial dos resíduos acima de $1 \mathrm{~km}$, e, com o uso da correção, os resíduos são quase compatíveis com zero. Entretanto, houve um leve aumento dos resíduos entre 0,5 e 1 km, além de resíduos mais negativos na região mais central, a menos de $250 \mathrm{~m}$ ao centro do chuveiro. Os eventos reais têm resíduos mais semelhantes aos das simulações que possuem prótons como partículas primárias. Essa nova sistemática presente nos resíduos poderia já estar presente nos resíduos dos ajustes sem correção da NKG, mas "mascarados" pelo efeito predominante do trigger.

Nos resíduos em relação ao ângulo zenital, quando são comparados os ajustes com a LDF corrigida, figura 5.27, com a LDF padrão, figura 5.18, observa-se que a região 1 não apresenta diferenças significativas. Na região 2 há uma mudança de comportamento, e os resíduos são crescentes com o aumento de $\theta$ e sistematicamente positivos mas a amplitude da variação não aumentou significativamente. O comportamento da região 3 se manteve o mesmo, mas a amplitude de variação dos resíduos diminuiu em três vezes. Como se espera, os resíduos da região 4 sofrem a maior alteração, com uma diminuição na amplitude de quase dez vezes com os resíduos se concentrando em torno de zero, a flutuação é bem menor, e não se observa uma dependência com o ângulo.

Os gráficos com os resíduos em função da energia reconstruída dos ajustes que utilizam a LDF corrigida estão nas figuras 5.28 e 5.29, e devem ser comparados com os gráficos de resíduos dos ajustes com a LDF padrão que se encontram nas figuras 5.19 e 5.20. Na região 1 não houve alteração signi- 


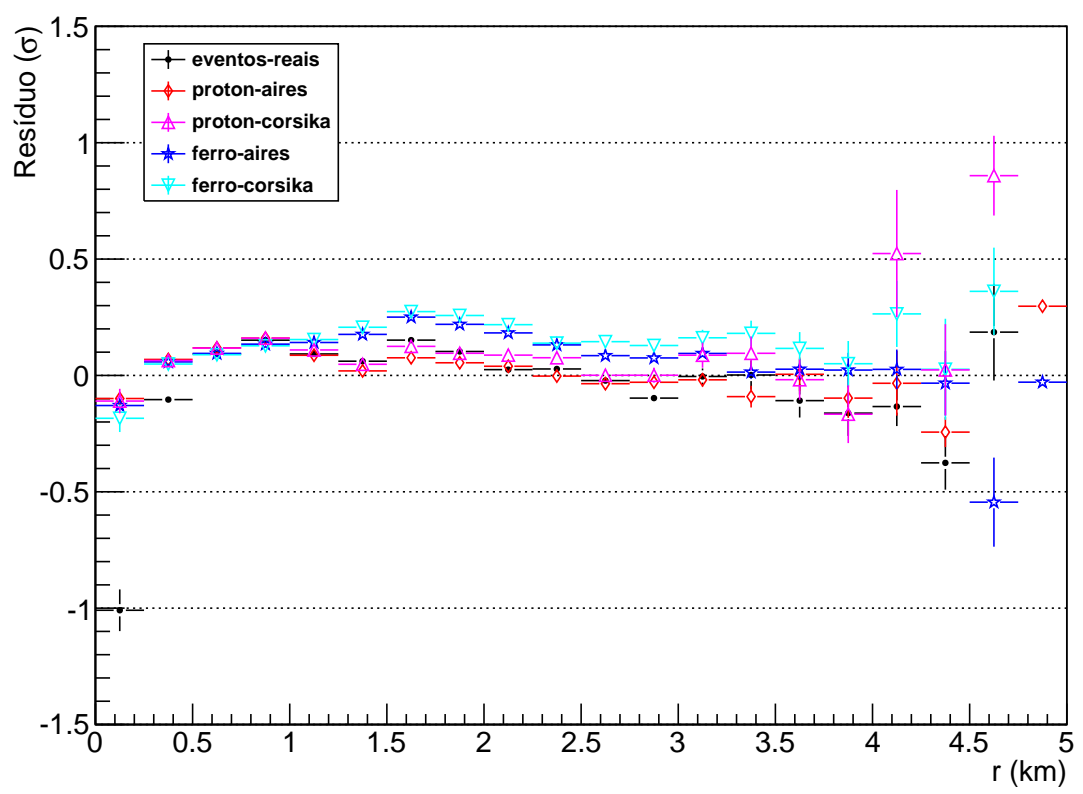

Figura 5.26: Perfil dos resíduos dos ajuste de LDF com a NKG corrigida em eventos reais e simulados em função da distância da estação ao centro do chuveiro. Este gráfico deve ser comparado ao contido na figura 5.17.

ficativa e os problemas com saturação continuam dificultando a comparação dos eventos reais com os simulados. Novamente, a região 4 é a que apresenta maiores diferenças em relação aos resíduos da reconstrução padrão, com resíduos praticamente constantes e compatíveis com zero. Os resíduos acima de $100 \mathrm{EeV}$ permanecem praticamente inalterados. Os eventos reais são compatíveis com simulações que têm prótons como iniciadores em praticamente todo espectro.

As diferenças na região 2 são significativas apenas para energias menores que $10 \mathrm{EeV}$, onde os resíduos passam a ser sistematicamente positivos ao invés de compatíveis com zero. Além disso, não é possível diferenciar entre resíduos de eventos reais e simulados abaixo de $5 \mathrm{EeV}$. Na região 3 as diferenças significativas também ocorrem apenas nas energias menores que $10 \mathrm{EeV}$. Os eventos reais continuam sendo compatíveis com os eventos simulados iniciados por prótons nas energias mais baixas, entretanto, a diferenciação ocorre 
em energias mais baixas quando a LDF corrigida é utilizada, ou seja, em torno de $4 \mathrm{EeV}$. Nas energias maiores é observado o mesmo comportamento, os resíduos dos eventos reais estão entre os resíduos das simulações de próton e ferro.

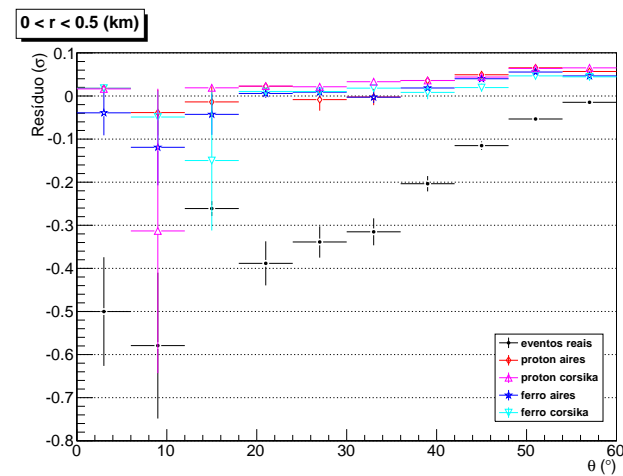

(a) região 1

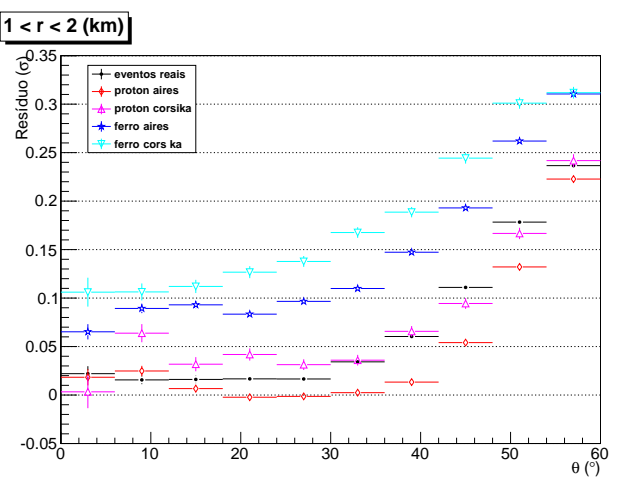

(c) região 3

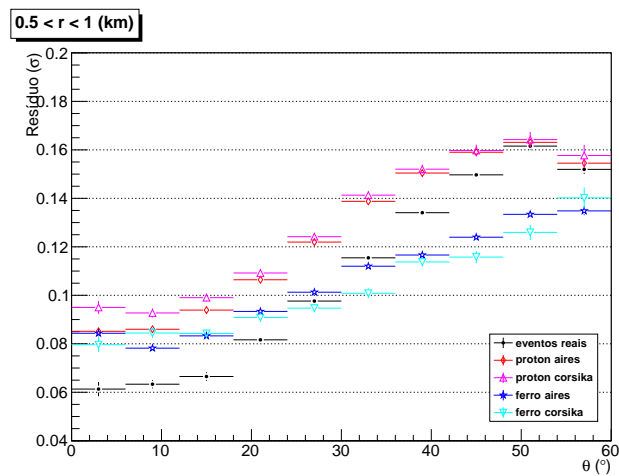

(b) região 2

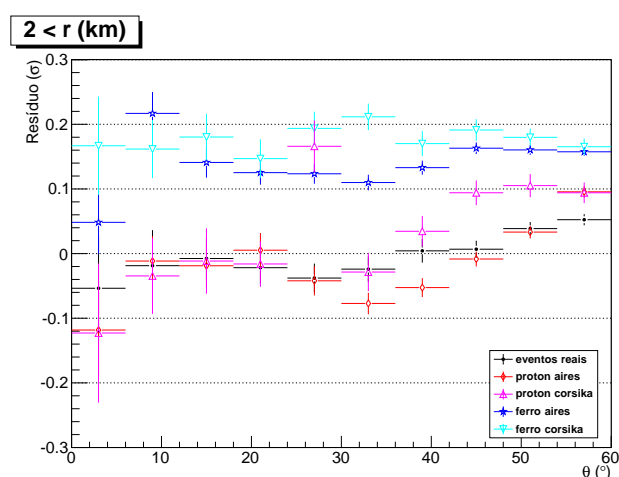

(d) região 4

Figura 5.27: Gráficos do perfil dos resíduos reduzidos para as diferentes regiões de distâncias entre as estações e o centro do chuveiro $(r)$, em função do ângulo zenital $(\theta)$. Os ajustes utilizam a NKG corrigida. Contêm eventos reais e simulados com o AIRES/SIBYLL e o CORSIKA/EPOS utilizando como partículas primárias núcleos de ferro e prótons. Estes gráficos devem ser comparados aos da figura 5.18.

De maneira geral, a forma dos resíduos sofreu uma grande mudança, seja na dependência com a energia ou com o ângulo zenital, e/ou na amplitude e valor absoluto. Entretanto, a conclusão em relação ao indicativo da compo- 
sição dos eventos reais continua praticamente a mesma. Os eventos reais são compatíveis com eventos simulados que têm prótons como partícula primária até aproximadamente $5 \mathrm{EeV}$, e dessa energia em diante há uma alteração no comportamento e os resíduos do eventos reais começam a tender para os resíduos das simulações que têm ferro como partícula iniciadora.

De todas as análises que foram realizadas neste trabalho, esta correção proposta para a LDF é a que tem o maior potencial de contribuição para o processo de reconstrução de eventos, mas ela deve ser estudada com mais detalhes para que se compreenda suas implicações em outras grandezas, como, por exemplo, no $S_{1000}$. Não foi possível realizar um estudo mais detalhado pois a sistemática nos resíduos das estações com sinal próximo ao trigger só foi percebida a menos de trinta dias da entrega deste trabalho. 


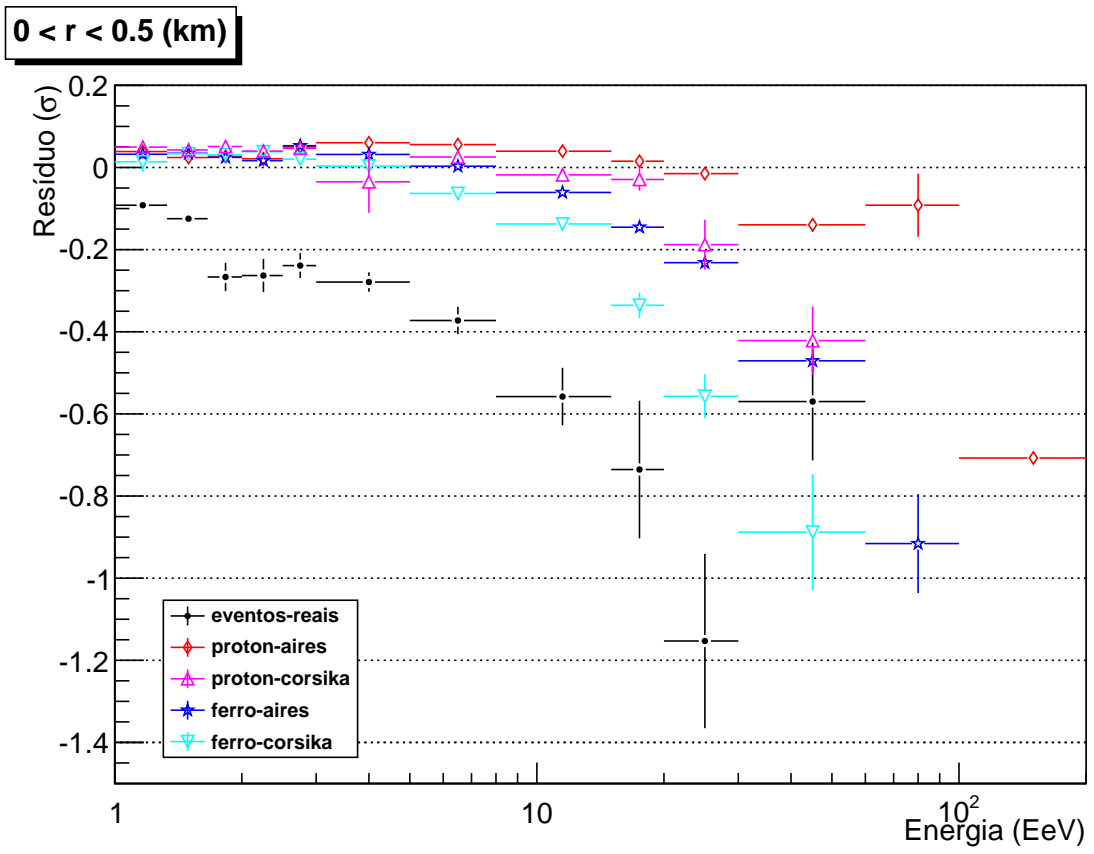

(a) região 1

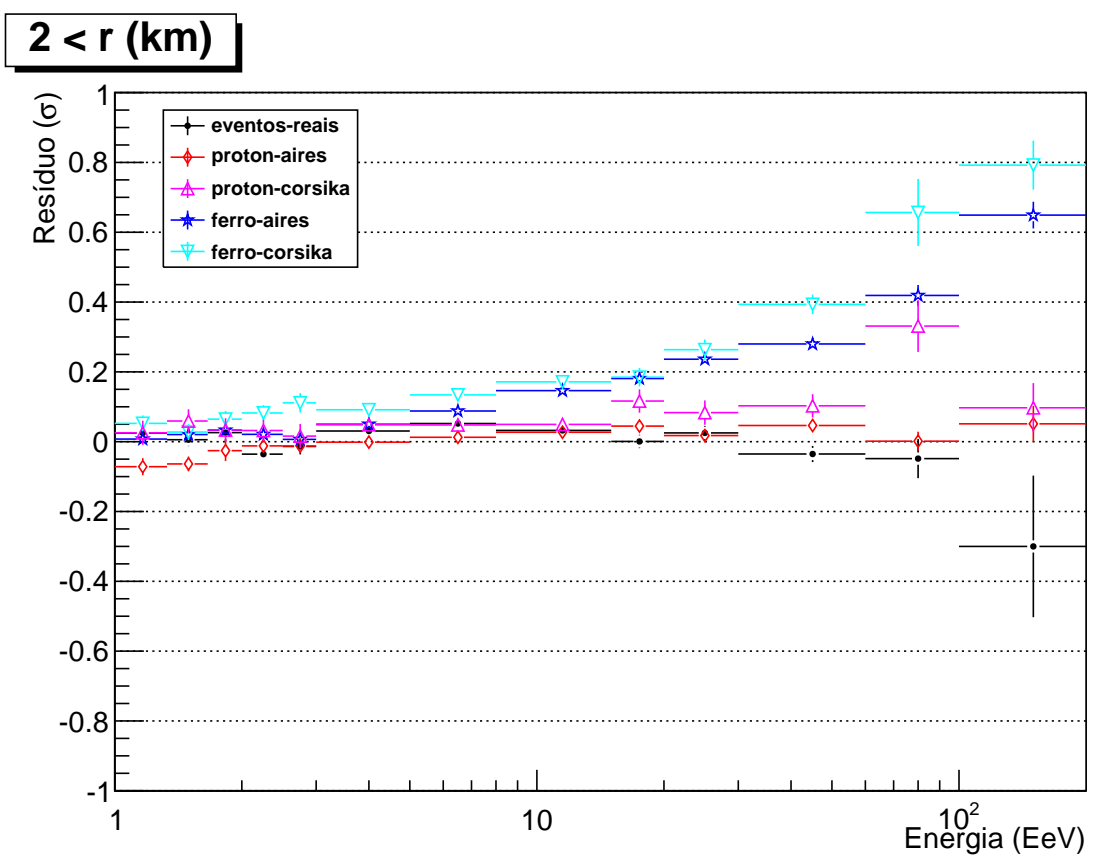

(b) região 4

Figura 5.28: Gráficos do perfil dos resíduos reduzidos em função da energia reconstruída para os eventos reais e da energia simulada para eventos simulados nas regiões 1 e 4 . As barras de incerteza representam o desvio padrão da média, os ajustes utilizam a NKG corrigida. Esses gráficos devem ser comparados com os da figura 5.19. 


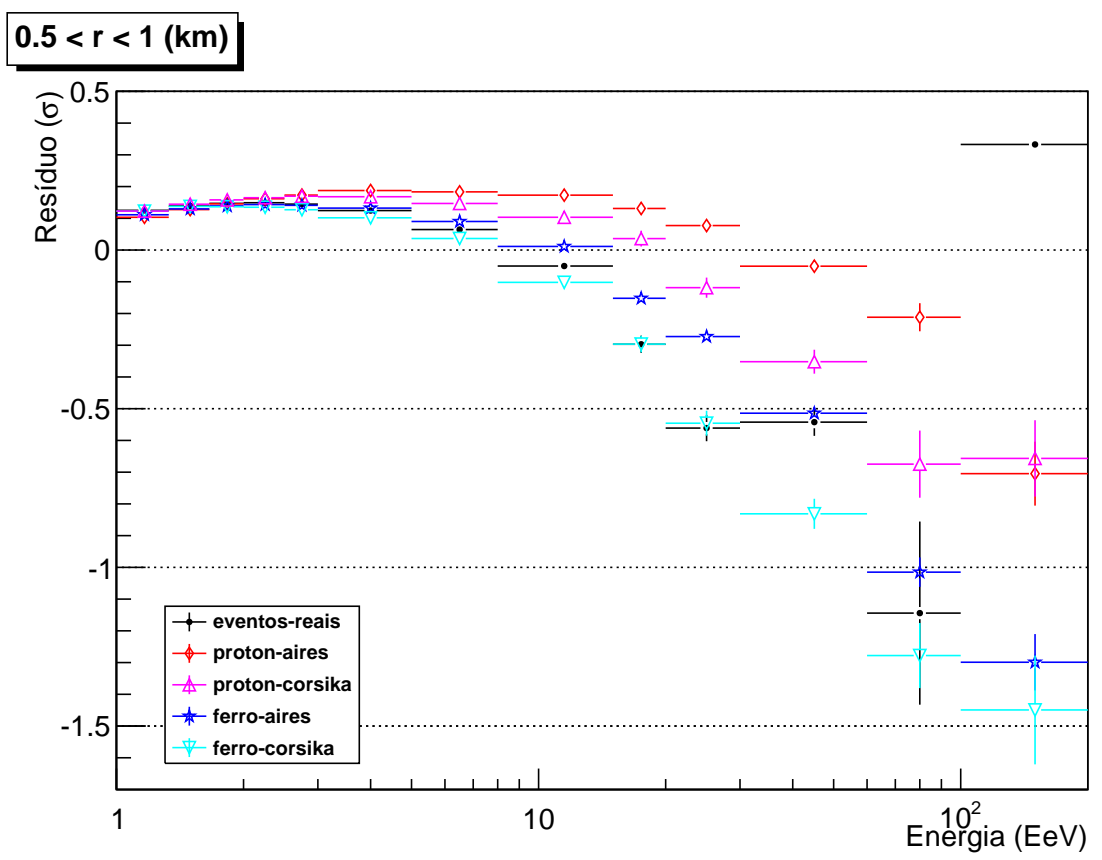

(a) região 2

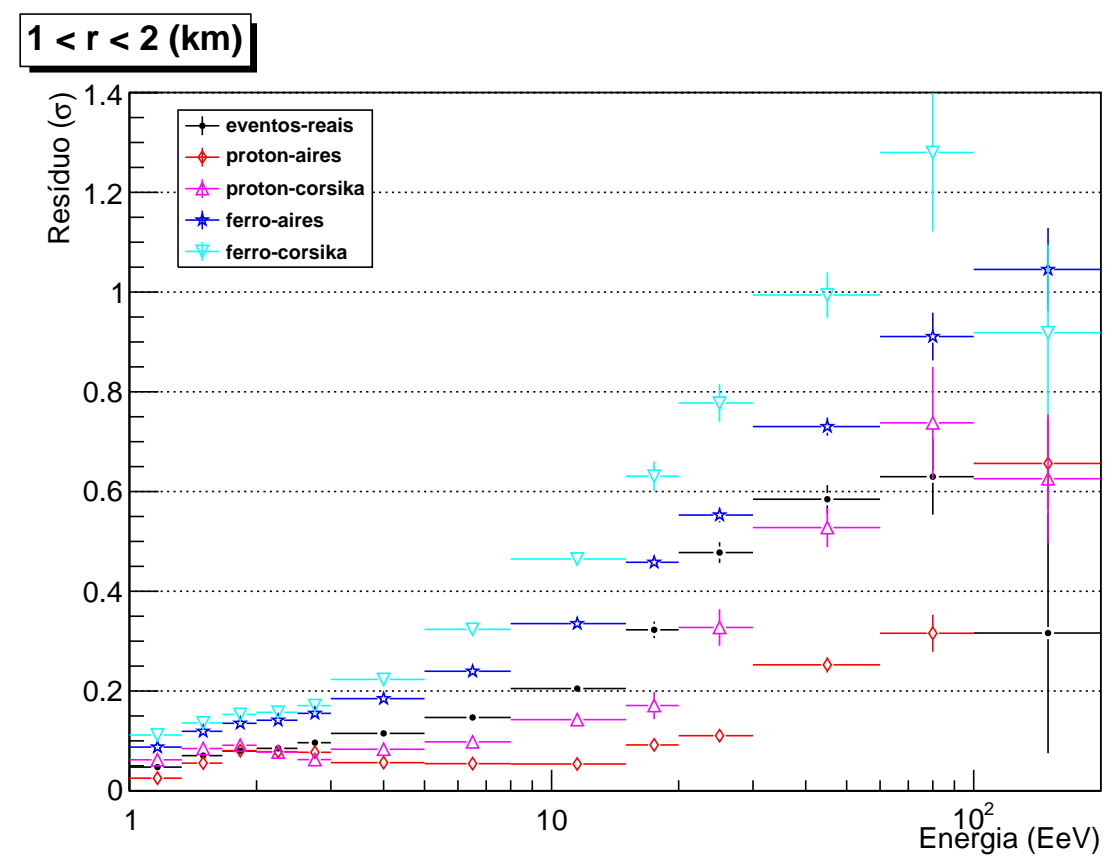

(b) região 3

Figura 5.29: Gráficos do perfil dos resíduos reduzidos em função da energia reconstruída para os eventos reais e da energia simulada para eventos simulados nas regiões 2 e 3 . As barras de incerteza representam o desvio padrão da média, os ajustes utilizam a NKG corrigida. Esses gráficos devem ser comparados com os da figura 5.20. 


\section{Capítulo 6}

\section{Conclusão}

Neste capítulo final são apresentadas as principais conclusões do trabalho, organizadas dentro dos dois grandes tópicos da tese, a flutuação da LDF e a composição das partículas primárias. Esse modelo de organização foi adotado para deixar mais evidente as contribuições de cada análise dentro do contexto desses tópicos.

\subsection{Flutuações da distribuição lateral}

Na seção 3.4 foi constatado que os resíduos dos eventos reais no período I apresentam um comportamento médio muito diferente do que no período II e, por isso, foram excluídos das análises realizadas neste trabalho. Entretanto,

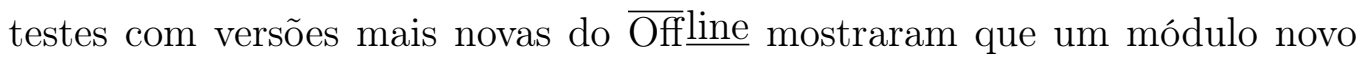
consegue identificar as estações que apresentam esse problema e as retira dos ajustes, eliminando essa grande diferença observada na figura 3.9 e a impossibilidade de utilizar os eventos anteriores a 2007.

A incerteza do sinal das estações foi estudada em detalhes e na seção 3.3 foi apresentada uma explicação estatística para a correção obtida empiricamente que é utilizada pelo Offline. A necessidade da correção está relacionada com a função de probabilidade que descreve o sinal, que neste caso não é uma simples Poisson, mas uma composição de processos Poisson intercalados com um processo binomial. 
O resultado mais importante em relação à flutuação da LDF e um dos mais importantes desse trabalho está relacionado aos resíduos sistematicamente positivos das estações mais distantes do centro do chuveiro. Na seção 5.1 foi demonstrado que, diferentemente do afirmado na referência [72], as estações silenciosas não são responsáveis por esses resíduos positivos, mas sim, como apresentado na seção 5.5, devido à influência do trigger que não é levando em conta pela função que ajusta a LDF. Devido ao trigger, a função de densidade de probabilidade que descreve o sinal das estações, aproximadamente uma gaussiana, é truncada, possuindo apenas valores acima do trigger. As parametrizações da LDF não consideram essa característica das estações, mas a correção proposta apresentou resultados satisfatórios. Com uma correção de no máximo o valor do trigger, foi possível obter uma redução expressiva dos resíduos nas regiões mais distantes do centro do chuveiro, onde o sinal está mais próximo do valor do trigger. Com a correção, os resíduos, que eram em torno de 2 desvios padrão, passam a flutuar em torno de 0 , mas como a identificação e correção deste efeito foi realizada a menos de um mês da entrega deste trabalho, não foi possível explorar todas as suas possibilidades e limitações.

\subsection{Composição das partículas primárias e mo- delos de interação hadrônica}

Neste trabalho foram utilizadas simulações com dois modelos de interações hadrônicas, o SIBYLL e o EPOS, descritos no capítulo 4. Eles apresentaram diferenças significativas principalmente na intensidade dos sinais em chuveiros semelhantes, o que é atribuído ao maior número de múons presentes nas simulações que utilizam o EPOS. Essa diferença já era conhecida e foi observada neste trabalho. Além disso, as simulações provenientes do EPOS apresentaram uma diferença menor em relação aos eventos reais e por isso foram utilizadas preferencialmente nas análises deste trabalho.

A função NKG, parametrização padrão da LDF utilizada pelo $\overline{\mathrm{Off}} \underline{\text { line }}$, teve suas variáveis $\beta$ e $\gamma$ estudadas na seção 5.2, com o objetivo de verificar 
se seria possível estimar a partir dela a composição dos chuveiros atmosféricos. Para isso, uma possibilidade seria ajustar esses parâmetros para cada chuveiro, mas isso não é possível, principalmente para eventos de baixa energia, pois não existem graus de liberdade suficientes. O número de eventos que podem ter esses parâmetros ajustados atinge um nível aceitável apenas em $10 \mathrm{EeV}$, em torno de 80\%, e, mesmo assim, dificilmente atinge os $100 \%$. Quando esses parâmetros são ajustados, a diferença entre eles e suas parametrizações são grandes, principalmente para $\gamma$, que, quando parametrizado vale 0 , e, livre, chega a ser ajustado em 10 . No caso de $\beta$, que é parametrizado em torno de -2 , seu valor nos ajustes varia de -2 e 3 . Não se deve esquecer que, quando essas duas variáveis são ajustadas, seus valores são altamente correlacionados. Mais um fato que foi observado e merece destaque é que a dependência dessas variáveis com a energia do chuveiro é diferente entre os eventos reais e os simulados, o que indica que as simulações não descrevem completamente os eventos reais. Acredita-se que esse cenário deve mudar consideravelmente se for aplicada a correção do efeito do trigger na NKG ajustada.

A comparação dos sinais de dois conjuntos de eventos (sejam eles reais ou simulados) utilizando o modelo baseado apenas no sinal (seção 5.3.1) se mostrou bastante relevante, pois uma de suas características de destaque é ser independente da LDF ajustada (a menos da estimativa de energia) e por isso não é afetada diretamente pelo efeito do trigger. Também foi possível ter uma percepção mais detalhada do chuveiro, em particular da divisão entre as partes eletromagnéticas e muônicas. Verificou-se que as simulações obtidas com AIRES/SIBYLL possuem aproximadamente 70\% dos múons contidos nas simulações obtidas com o CORSIKA/EPOS para a mesma partícula primária. Na comparação dos eventos reais com os simulados pelo CORSIKA/EPOS observou-se que os chuveiros iniciados por prótons possuem 84,5(6) \% dos múons presentes nos eventos reais enquanto os iniciados por núcleos de ferro possuem 113,7(6) \%. Entretanto, o $\chi^{2}$ dos eventos simulados com ferro $(2,29)$ é significativamente maior que dos eventos simulados com próton $(1,85)$. Isso indica que a simulação de próton possui uma LDF com a forma mais semelhante à dos eventos reais, em média. Dado que esta análise não considera 
dependências com a energia, baseado nos resultados de análises independentes sobre as estimativas de composição em função da energia uma maior compatibilidade com próton é esperada. Por outro lado, essa metodologia de análise pode ser adaptada para considerar a dependência com a energia, e assim, auxiliar em um estudo posterior sobre composição em função da energia.

Utilizar o modelo baseado na função NKG para a comparação dos sinais das estações (seção 5.3.2) foi importante para identificação do efeito do trigger. Esse efeito faz com que os resultados deste método de análise sejam enfraquecidos, principalmente para estações com sinal próximo ao trigger. Mas, apesar dessa limitação, seus resultados são consistentes com os das outras análises deste trabalho. Da mesma forma que o modelo baseado no sinal, essa análise não é sensível à energia e seu principal resultado é o menor $\chi^{2}$ reduzido na comparação dos eventos reais com as simulações de prótons, 5,9 contra 9,6 nas simulações com ferro, indicando uma maior semelhança entre os eventos reais e as simulações de próton do que nas iniciadas por ferro. Considerando todo o contexto, essa análise não apresenta perspectivas favoráveis para melhorias, visto que a correção da função NKG proposta não é analítica e seria muito difícil derivar uma relação entre dois conjuntos de dados como feito na seção 5.3.2.

A análise que apresentou mais informações sobre a composição das partículas primárias foi aquela dos gráficos de resíduos em função da energia. Na seção 5.4.3 estão os resultados obtidos nos ajustes com a função NKG padrão

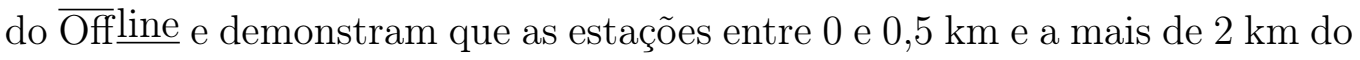
centro dos chuveiros apresentam resíduos com sistemáticas diferentes entre os eventos reais e simulados e não devem ser utilizadas para um estudo de composição, porque as estações na primeira região apresentam uma sistemática que indica saturação nas estações dos eventos reais e na segunda região ocorre o efeito do trigger. Já os gráficos de resíduos em função da energia para as estações entre 0,5 e $2 \mathrm{~km}$ apresentam uma compatibilidade dos eventos reais com os eventos simulados iniciados por prótons com energias de até $6 \mathrm{EeV}$ e um comportamento que tende para as simulações de ferro a partir desta energia, semelhante ao observado com o FD nas análises de $\left\langle X_{\max }\right\rangle$. 
A dependência dos resíduos com energia é diferente quando a função NKG é corrigida, como mostrado na seção 5.5, mas o comportamento relativo dos eventos reais e simulados não é alterado significativamente com exceção das estações a mais de $2 \mathrm{~km}$, que não apresentavam grandes diferenças entre eventos reais e simulados observadas nos ajustes com a NKG original, e que com a correção passam a apresentar eventos reais compatíveis com os eventos simulados por prótons. Para estações entre 0,5 e $2 \mathrm{~km}$ houve uma alteração na flutuação dos eventos, mas o comportamento dos eventos reais em relação aos eventos simulados se manteve inalterado. Isso indica que observar os resíduos para se obter uma estimativa da composição pode ser um método robusto, independente da função utilizada.

As diferentes análises utilizadas para estimar a composição dos raios cósmicos apresentaram resultados consistentes entre si, apesar das limitações encontradas em algumas delas. Mais do que isso, todos esses indicadores de composição da partícula primária obtidos com o detector de superfície são consistentes com os resultados obtidos pelas análises de $X_{\text {max }}$ obtidas com o detector de fluorescência, reforçando a tese de que a composição dos raios cósmicos é predominantemente próton entre 1 e $10 \mathrm{EeV}$ e entre próton e ferro para energias acima de aproximadamente $10 \mathrm{EeV}$. 


\section{Apêndice A}

\section{Funções de probabilidade e geratrizes}

Este apêndice tem o objetivo de deduzir a variância do sinal de uma estação do SD. Para isso, introduz o ferramental matemático necessário para tal tarefa. Parte do conteúdo apresentado aqui foi baseado na apostila do curso Tópicos Avançados em Tratamento Estatístico de Dados em Física Experimental, do Instituto de Física da USP.

\section{A.1 Função geratriz}

A definição de função característica [77] é:

$$
\phi_{r}(t)=\sum_{\Omega} P(r) e^{i t r}
$$

onde $\Omega$ é o espaço amostral da função de probabilidade $P(r)$. Tomado $Z=$ $e^{i t}$, obtém-se a função geratriz:

$$
G(Z)=\sum_{\Omega} P(r) Z^{r}
$$

Através da função geratriz, é possível obter a média de uma função de probabilidade:

$$
\frac{\mathrm{d} G}{\mathrm{~d} Z}=\sum_{\Omega} r Z^{r-1} P(r)
$$

calculando em $Z=1$ : 


$$
\left.\frac{\mathrm{d} G}{\mathrm{~d} Z}\right|_{Z=1}=\sum_{\Omega} r P(r)=<r>
$$

portanto:

$$
<r>=\left.\frac{\mathrm{d} G}{\mathrm{~d} Z}\right|_{Z=1}
$$

Calculando a segunda derivada:

$$
\frac{\mathrm{d}^{2} G}{\mathrm{~d} Z^{2}}=\sum_{\Omega} r(r-1) Z^{r-2} P(r)
$$

calculando em $Z=1$ :

$$
\left.\frac{\mathrm{d}^{2} G}{\mathrm{~d} Z^{2}}\right|_{Z=1}=\sum_{\Omega} r(r-1) P(r)=\sum_{\Omega} r^{2} P(r)-\sum_{\Omega} r P(r) ;
$$

portanto:

$$
\left.\frac{\mathrm{d}^{2} G}{\mathrm{~d} Z^{2}}\right|_{Z=1}=<r^{2}>-<r>
$$

Sabe-se que a variância $\left(\sigma^{2}\right)$ é:

$$
\sigma^{2}=<r^{2}>-<r>^{2}
$$

Manipulando as equações (A.3) e (A.4) e substituindo em (A.5) obtém-se a variância calculada através da função característica:

$$
\sigma^{2}=\left.\frac{\mathrm{d}^{2} G}{\mathrm{~d} Z^{2}}\right|_{Z=1}-\left(\left.\frac{\mathrm{d} G}{\mathrm{~d} Z}\right|_{Z=1}\right)^{2}+\left.\frac{\mathrm{d} G}{\mathrm{~d} Z}\right|_{Z=1}
$$

\section{A.2 Poisson}

A função de probabilidade Poisson é dada por:

$$
P(r ; \mu)=\frac{\mu^{r} e^{-\mu}}{r !}
$$

Substituindo na equação (A.2): 


$$
p(s ; \mu)=\sum_{r=0}^{\infty} \frac{\mu^{r} e^{-\mu}}{r !} s^{r}=e^{-\mu} \sum_{r=0}^{\infty} \frac{\mu^{r} s^{r}}{r !}=e^{-\mu} \sum_{r=0}^{\infty} \frac{(\mu s)^{r}}{r !}=e^{-\mu} e^{\mu s}
$$

portanto a função geratriz da Poisson é:

$$
p(s ; \mu)=e^{-\mu+\mu s}
$$

É fácil ver que:

$$
p^{\prime}(s ; \mu)=\frac{\mathrm{d} p}{\mathrm{~d} s}=\mu p(s ; \mu)
$$

\section{A.3 Soma de um número aleatório de variáveis aleatórias}

Considere a soma, $S_{N}$, de $N$ variáveis aleatórias independentes $X$

$$
S_{N}=\sum_{i=1}^{N} X_{i}
$$

onde $N$ é uma variável aleatória cuja função geratriz é $g(s)$. Sendo a função geratriz da variável $X, f(s)$, a função geratriz de $S_{N}$ será [77]:

$$
h(s)=g(f(s))
$$

\section{A.4 Binomial onde $\mathrm{N}$ é Poisson}

No caso de uma binomial com probabilidade de sucesso $p$, a função geratriz para $N=1$ é:

$$
b(s ; p)=\sum_{\Omega} P(r) s^{r}=(1-p) s^{0}+p s^{1}=(1-p)+p s
$$

A função geratriz da composição da binomial com a Poisson de média $\mu$ é:

$$
\begin{gathered}
g(s ; \mu, p)=p(b(s ; p) ; \mu)=\exp [-\mu+\mu(1-p+p s)]= \\
g(s ; \mu, p)=e^{\mu p+\mu p s}=p(s ; \mu p)
\end{gathered}
$$




\section{A.5 Poissons compostas}

Considere-se um processo composto de $K$ estágios idênticos concatenados, em que cada um deles possui a função geratriz $p(s, \mu)$.

Define-se então a função geratriz quando $K=1$ como:

$$
p_{1}(s ; \mu)=p(s ; \mu)
$$

quando $K=2$, utilizando a equação (A.10), obtém-se a função geratriz:

$$
p_{2}(s ; \mu)=p(p(s ; \mu) ; \mu)
$$

A função geratriz de um processo de $K$ estágios pode ser definida recursivamente por:

$$
p_{K}(s ; \mu)=p\left(p_{K-1}(s ; \mu) ; \mu\right)
$$

Sendo:

$$
p_{K}^{\prime}(s ; \mu)=\frac{\mathrm{d} p_{K}}{\mathrm{~d} s}=\mu^{K} \prod_{i=1}^{K} p_{i}(s ; \mu)
$$

O valor médio desse processo é:

$$
p_{K}^{\prime}(s=1 ; \mu)=\mu^{K}
$$

pois $p_{K}(s=1 ; \mu)=1$.

A derivada segunda para o cálculo da variância é: 


$$
\begin{gathered}
p_{K}^{\prime \prime}(s ; \mu)=\frac{\mathrm{d} p_{K}^{\prime}}{\mathrm{d} s}=\mu^{K} \frac{\mathrm{d}}{\mathrm{d} s} \prod_{i=1}^{K} p_{i}(s ; \mu)= \\
=\mu^{K}\left\{\frac{d}{d s} p_{1}(s ; \mu) \prod_{i=2}^{K} p_{i}(s ; \mu)+p_{1} \frac{d}{d s} \prod_{i=2}^{K} p_{i}(s ; \mu)\right\}= \\
=\mu^{K}\left\{\mu p_{1} \prod_{i=2}^{K} p_{i}(s ; \mu)+p_{1}\left[\frac{d}{d s} p_{2}(s ; \mu) \prod_{i=3}^{K} p_{i}(s ; \mu)+p_{2} \frac{d}{d s} \prod_{i=3}^{K} p_{i}(s ; \mu)\right]\right\}= \\
=\mu^{K}\left\{\mu \prod_{i=1}^{K} p_{i}+p_{1} \mu^{2} \prod_{j=1}^{2} p_{j} \prod_{i=3}^{K} p_{i}+p_{1} p_{2}\left[\frac{d}{d s} p_{3} \prod_{i=4}^{K} p_{i}+p_{3} \frac{d}{d s} \prod_{i=4}^{K} p_{i}\right]\right\}= \\
=\mu^{K}\left\{\mu \prod_{i=1}^{K} p_{i}+\mu^{2} p_{1} \prod_{i=1}^{K} p_{i}+\mu^{3} p_{1} p_{2} \prod_{i=1}^{K} p_{i}+\ldots+\mu^{K} \prod_{j=1}^{K} p_{j} \prod_{i=1}^{K} p_{i}\right\} \\
p_{K}^{\prime \prime}(s ; \mu)=\mu^{K} \sum_{i=1}^{K} \mu^{i} \prod_{j=1}^{i-1} p_{j} \prod_{l=1}^{K} p_{l}
\end{gathered}
$$

Portanto a variância é:

$$
\begin{aligned}
& \sigma^{2}=p_{K}^{\prime \prime}(s=1 ; \mu)-\left(\mu^{K}\right)^{2}+\mu^{K}= \\
&=\mu^{K} \sum_{i=1}^{K} \mu^{i}-\left(\mu^{K}\right)^{2}+\mu^{K}=\mu^{K} \sum_{i=1}^{K-1} \mu^{i}+\mu^{K}= \\
&=\mu^{K}\left(\sum_{i=1}^{K-1} \mu^{i}+1\right) \\
& \sigma^{2}=\mu^{K} \frac{1-\mu^{K}}{1-\mu}
\end{aligned}
$$

\section{A.6 Variância do sinal de uma estação do SD}

O processo de multiplicação dos foto-elétrons da PMT pode ser aproximado por Poissons compostas como a da seção A.5. Sua função geratriz é:

$$
q(s)=p_{K}(s ; \delta)
$$

com $K$ estágios de aceleração e um fator de multiplicação $\delta$ a cada estágio. 
O número de fótons produzidos por cada partícula no tanque é descrito por um processo Poisson com média $\gamma$. Entretanto, cada um desses fótons tem uma probabilidade $\epsilon$ de produzir um foto-elétron. Portanto a distribuição de foto-elétrons para cada partícula no tanque é uma binomial com um número de tentativas que é Poisson. Como descrito na seção A.4, sua função geratriz é uma Poisson de média $\gamma \epsilon, p(s ; \gamma \epsilon)$. A função geratriz da distribuição da carga coletada quando uma partícula atravessa o tanque é a composição de (A.17) com a função geratriz dos fótons:

$$
f(q)=p(q(s) ; \gamma \epsilon)
$$

O número de partículas na estação é bem descrito por uma Poisson com média $\pi$ e sua função geratriz $p(s ; \pi)$. Compondo sua função geratriz com a equação (A.18) obtém-se a função geratriz do sinal de uma estação SD:

$$
h(f)=p(f(q) ; \pi)
$$

O valor médio pode ser obtido de:

$$
\frac{\mathrm{d} h}{\mathrm{~d} s}=\frac{\partial h}{\partial f} \frac{\partial f}{\partial q} \frac{\partial q}{\partial s}
$$

onde,

$$
\begin{aligned}
& \frac{\partial h}{\partial f}=\pi h \\
& \frac{\partial f}{\partial q}=\gamma \epsilon f \\
& \frac{\partial q}{\partial s}=\delta^{K} \prod_{i=1}^{K-1} p_{i}(s ; \delta) q
\end{aligned}
$$

portanto

$$
\frac{\mathrm{d} h}{\mathrm{~d} s}=\pi \gamma \epsilon \delta^{K} h f q \prod_{i=1}^{K-1} p_{i}(s ; \delta)
$$

E a média:

$$
\left.\frac{\mathrm{d} h}{\mathrm{~d} s}\right|_{s=1}=\pi \gamma \epsilon \delta^{K}
$$

A segunda derivada: 


$$
\begin{aligned}
& \frac{\mathrm{d}^{2} h}{\mathrm{~d} s^{2}} \frac{1}{\pi \gamma \epsilon \delta^{K}}=f q \prod_{i=1}^{K-1} p_{i}(s ; \delta) \frac{\mathrm{d} h}{\mathrm{~d} s}+h \frac{\mathrm{d}}{\mathrm{d} s}\left[f q \prod_{i=1}^{K-1} p_{i}(s ; \delta)\right]= \\
& =\pi \gamma \epsilon \delta^{K} h\left(f q \prod_{i=1}^{K-1} p_{i}\right)^{2}+h\left[q \prod_{i=1}^{K-1} p_{i} \frac{\partial f}{\partial q} \frac{\partial q}{\partial s}+f \frac{\mathrm{d}}{\mathrm{d} s}\left(q \prod_{i=1}^{K-1} p_{i}\right)\right]= \\
& =\pi \gamma \epsilon \delta^{K} h\left(f q \prod_{i=1}^{K-1} p_{i}\right)^{2}+h q \prod_{i=1}^{K-1} p_{i} \gamma \epsilon q f \delta^{K} \prod_{i=1}^{K-1} p_{i}+ \\
& \quad+h f\left[q \delta^{K}\left(\prod_{i=1}^{K-1} p_{i}\right)^{2}+q \frac{\mathrm{d}}{\mathrm{d} s}\left(\prod_{i=1}^{K-1} p_{i}\right)\right]= \\
& =\pi \gamma \epsilon \delta^{K} h\left(f q \prod_{i=1}^{K-1} p_{i}\right)^{2}+\gamma \epsilon \delta^{K} h f\left(q \prod_{i=1}^{K-1} p_{i}\right)^{2}+\delta^{K} h f q\left(\prod_{i=1}^{K-1} p_{i}\right)^{2}+ \\
& \quad+h f q \frac{\mathrm{d}}{\mathrm{d} s}\left(\prod_{i=1}^{K-1} p_{i}\right)
\end{aligned}
$$

Da equação (A.15) temos:

$$
\frac{\mathrm{d}}{\mathrm{d} s}\left(\prod_{i=1}^{K-1} p_{i}(s ; \delta)\right)=\sum_{i=1}^{K-1} \delta^{i} \prod_{j=1}^{i-1} p_{j} \prod_{l=1}^{K-1} p_{l}
$$

portanto:

$$
\begin{aligned}
& \frac{\mathrm{d}^{2} h}{\mathrm{~d} s^{2}} \frac{1}{\pi \gamma \epsilon \delta^{K}}=\pi \gamma \epsilon \delta^{K} h\left(f q \prod_{i=1}^{K-1} p_{i}\right)^{2}+\gamma \epsilon \delta^{K} h f\left(q \prod_{i=1}^{K-1} p_{i}\right)^{2}+ \\
& \quad+\delta^{K} h f q\left(\prod_{i=1}^{K-1} p_{i}\right)^{2}+h f q \sum_{i=1}^{K-1} \delta^{i} \prod_{j=1}^{i-1} p_{j} \prod_{l=1}^{K-1} p_{l}
\end{aligned}
$$

e

$$
\left.\frac{\mathrm{d}^{2} h}{\mathrm{~d} s^{2}}\right|_{s=1}=\pi \gamma \epsilon \delta^{K}\left\{\pi \gamma \epsilon \delta^{K}+\gamma \epsilon \delta^{K}+\delta^{K}+\sum_{i=1}^{K-1} \delta^{i}\right\}
$$

Substituindo (A.24) e (A.25) em (A.4): 
140 APENDICE A. FUNÇÕES DE PROBABILIDADE E GERATRIZES

$$
\begin{aligned}
\sigma^{2} & =\pi \gamma \epsilon \delta^{K}\left\{\pi \gamma \epsilon \delta^{K}+\gamma \epsilon \delta^{K}+\delta^{K}+\sum_{i=1}^{K-1} \delta^{i}\right\}-\left(\pi \gamma \epsilon \delta^{K}\right)^{2}+\pi \gamma \epsilon \delta^{K}= \\
& =\pi \gamma \epsilon \delta^{K}\left[\gamma \epsilon \delta^{K}+\delta^{K}+\sum_{i=1}^{K-1} \delta^{i}+1\right]
\end{aligned}
$$

Calculando a soma da p.g.:

$$
\sigma^{2}=\pi \gamma \epsilon \delta^{K}\left[\gamma \epsilon \delta^{K}+\delta^{K}+\frac{\delta^{K}-1}{\delta-1}\right]
$$




\section{Apêndice B}

\section{Gráficos complementares}

Neste apêndice são apresentados os gráficos de resíduos dos eventos reais e simulados ajustados com a NKG sem correção e corrigida. Os resíduos são separados em diversos cortes de energia. 


\section{B.1 Ajustes com a função NKG sem correção}

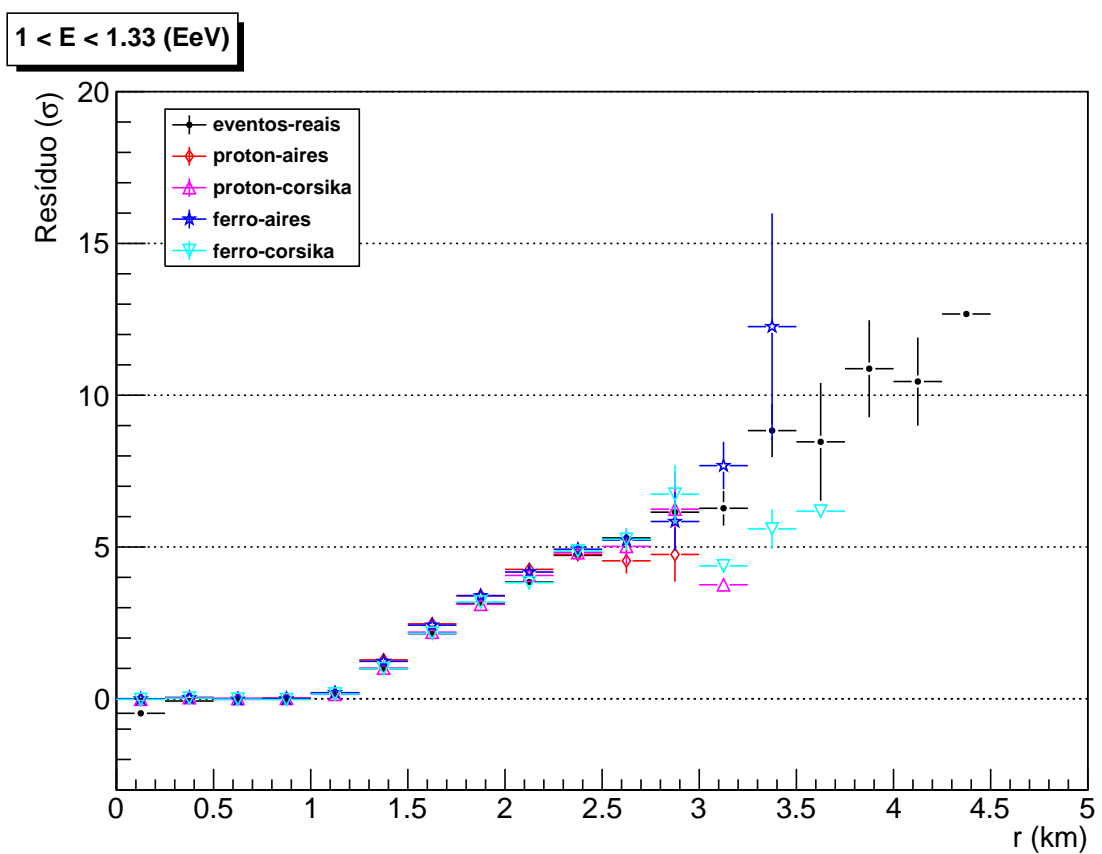

(a)

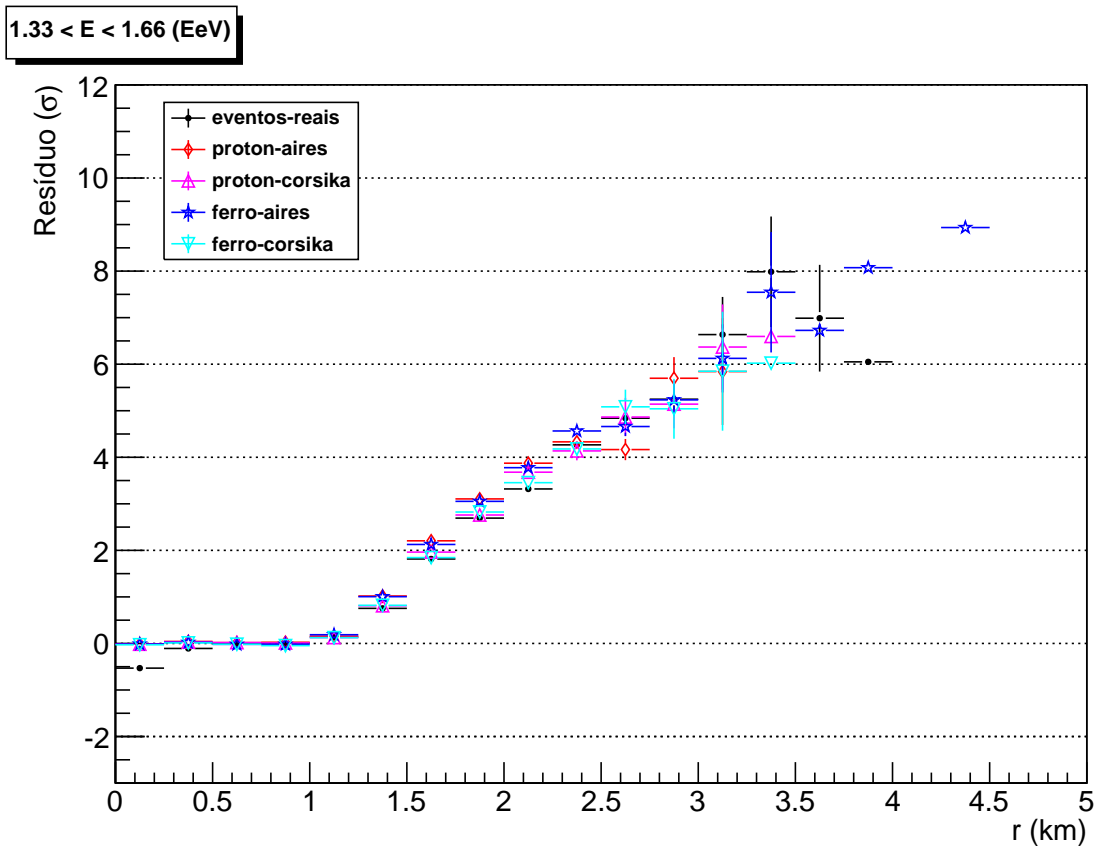

(b)

Figura B.1: Perfil dos resíduos dos ajuste de LDF para eventos com energia entre 1 e 1,66 EeV. 


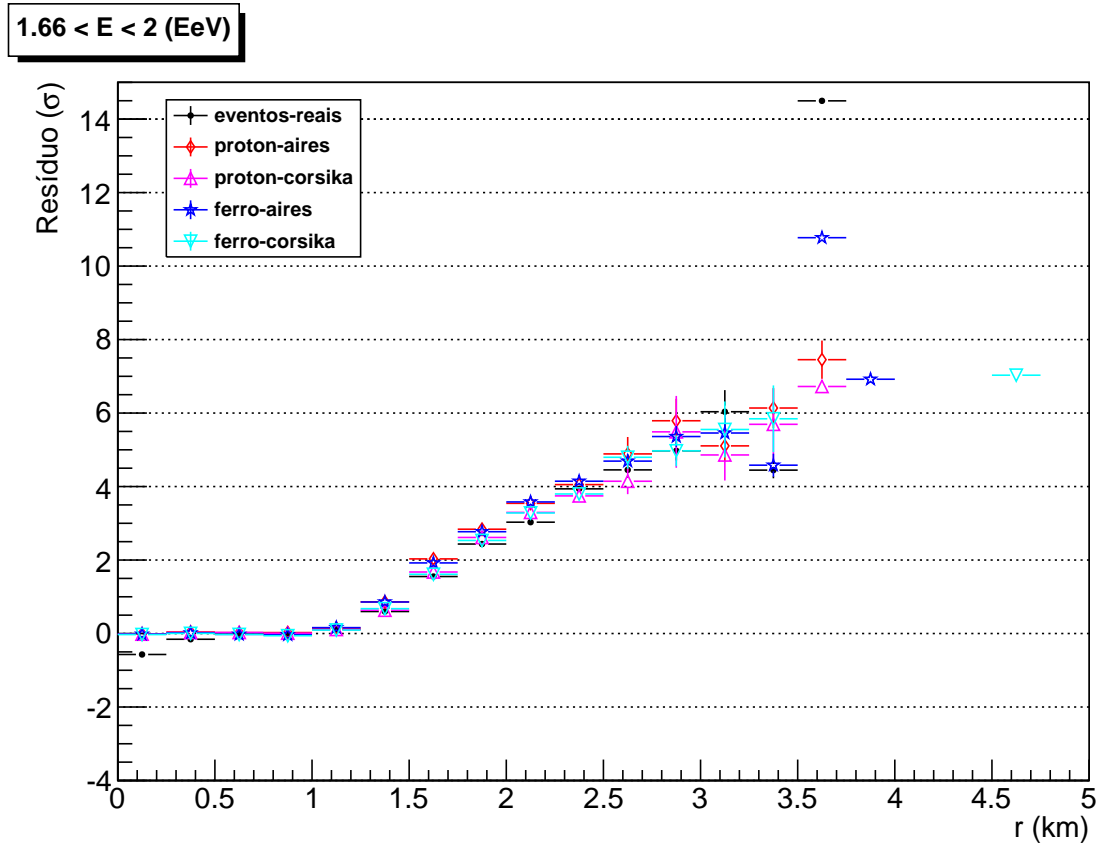

(a)

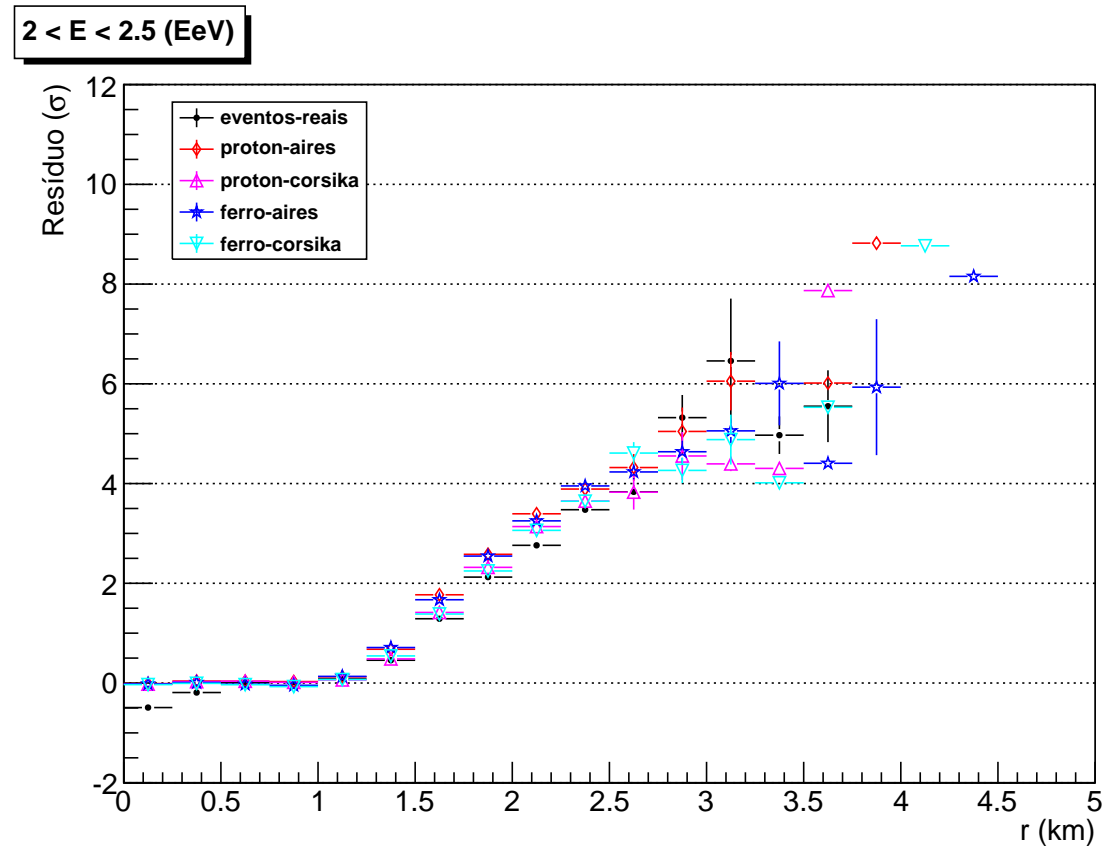

(b)

Figura B.2: Perfil dos resíduos dos ajuste de LDF para eventos com energia entre 1,66 e $2,5 \mathrm{EeV}$. 


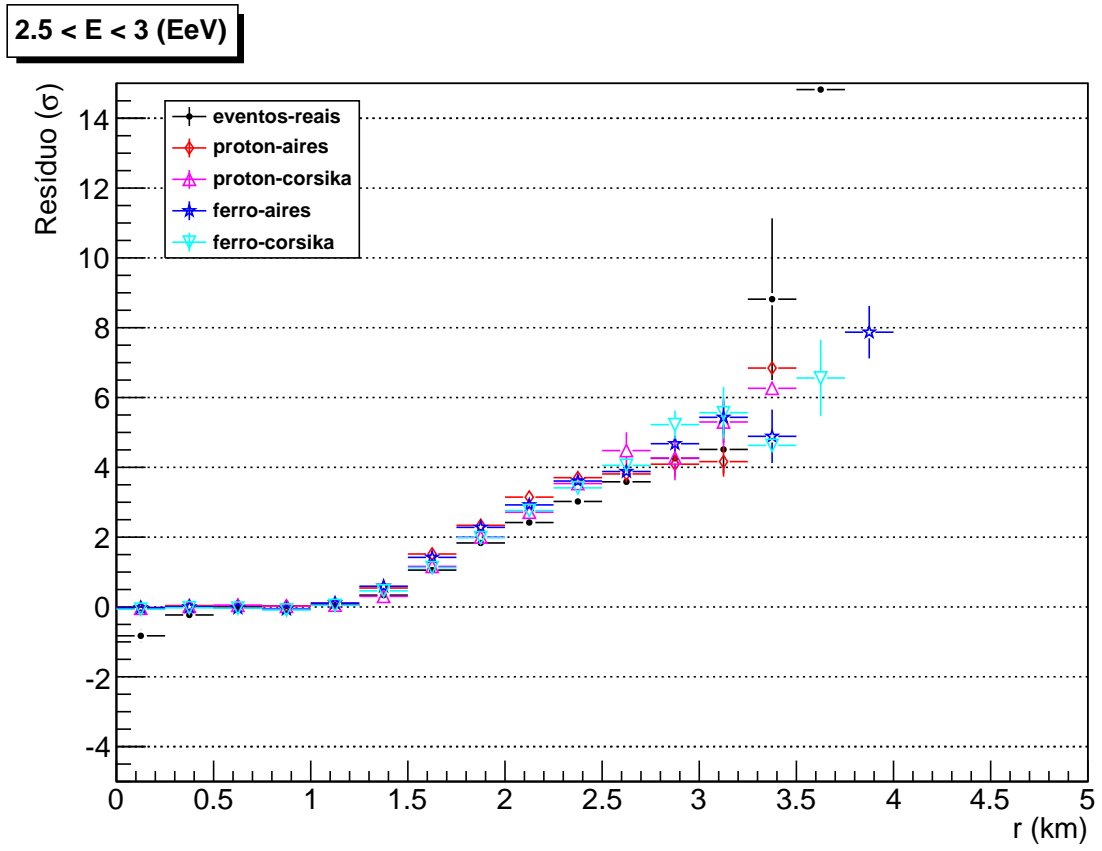

(a)

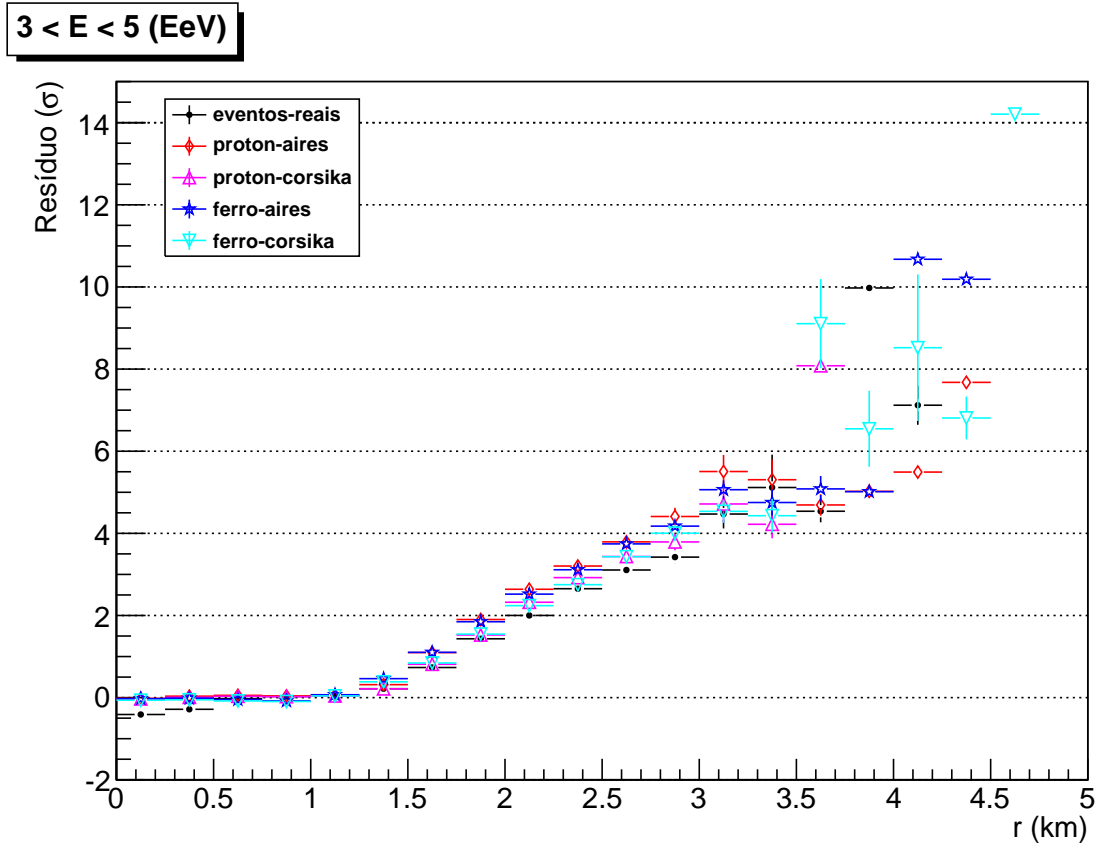

(b)

Figura B.3: Perfil dos resíduos dos ajuste de LDF para eventos com energia entre 2,5 e $5 \mathrm{EeV}$. 


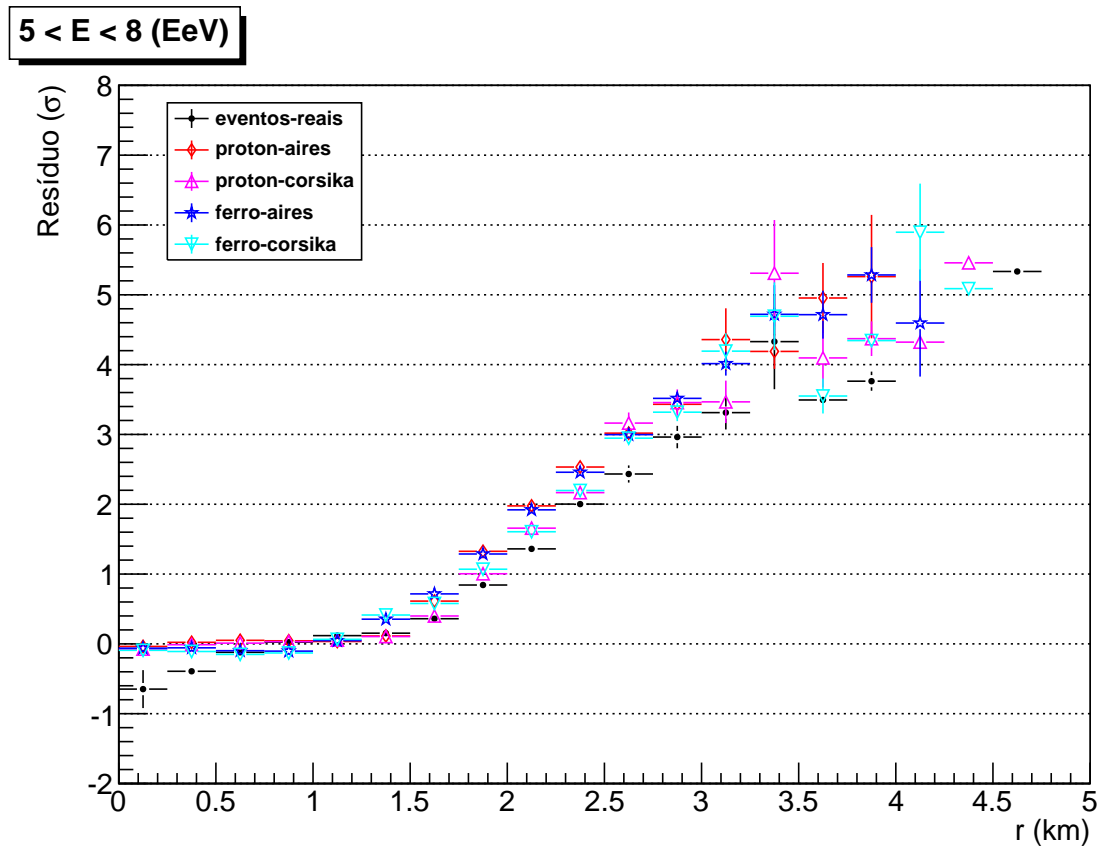

(a)

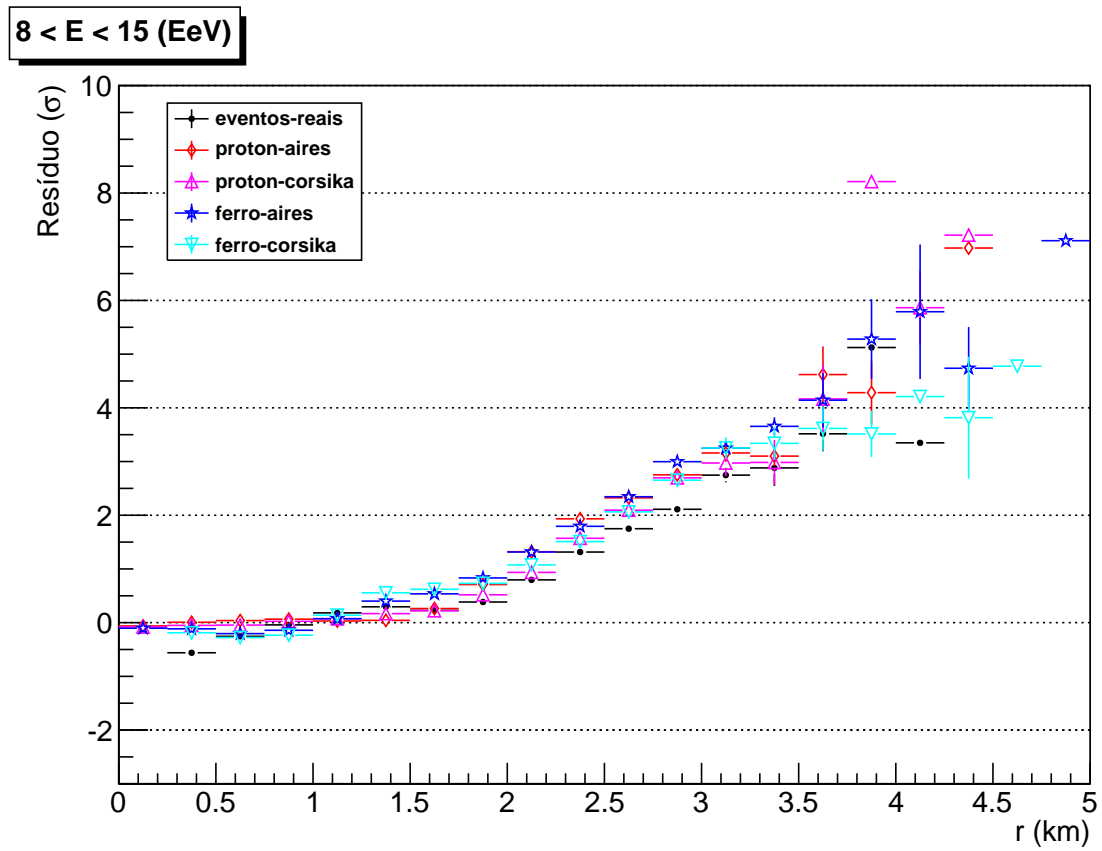

(b)

Figura B.4: Perfil dos resíduos dos ajuste de LDF para eventos com energia entre 5 e $15 \mathrm{EeV}$. 


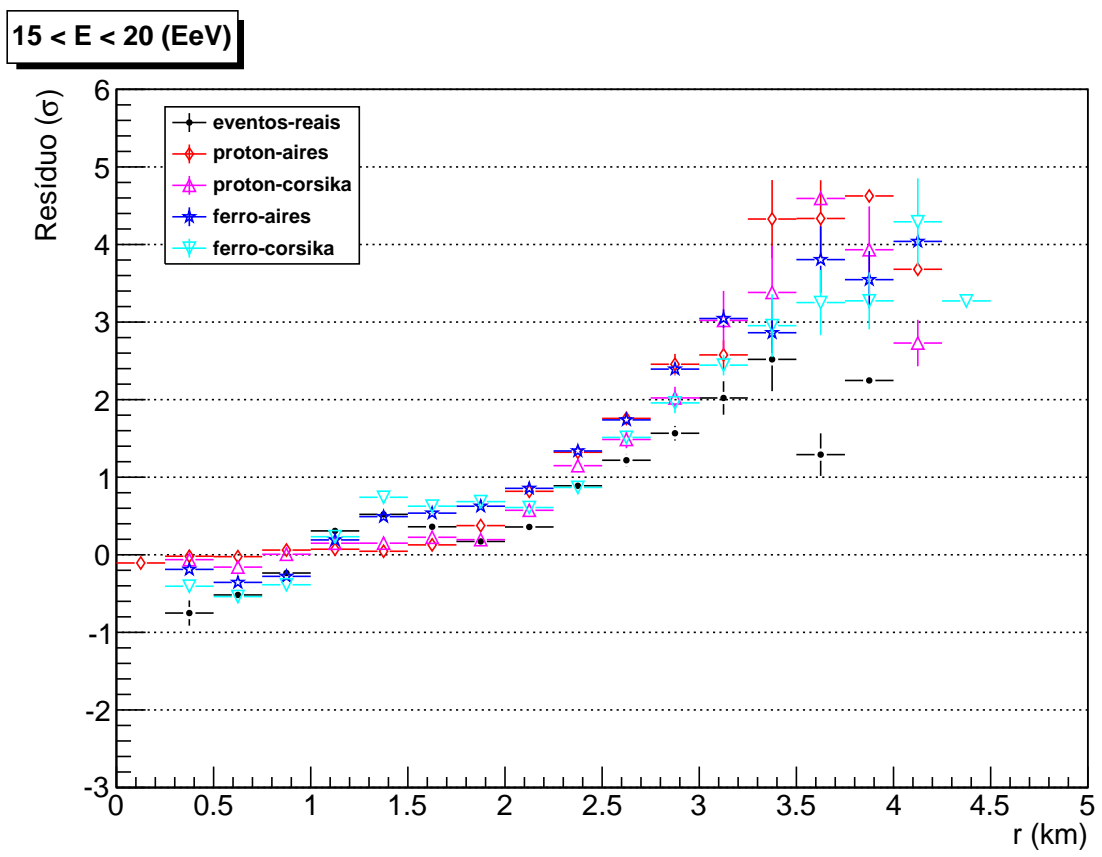

(a)

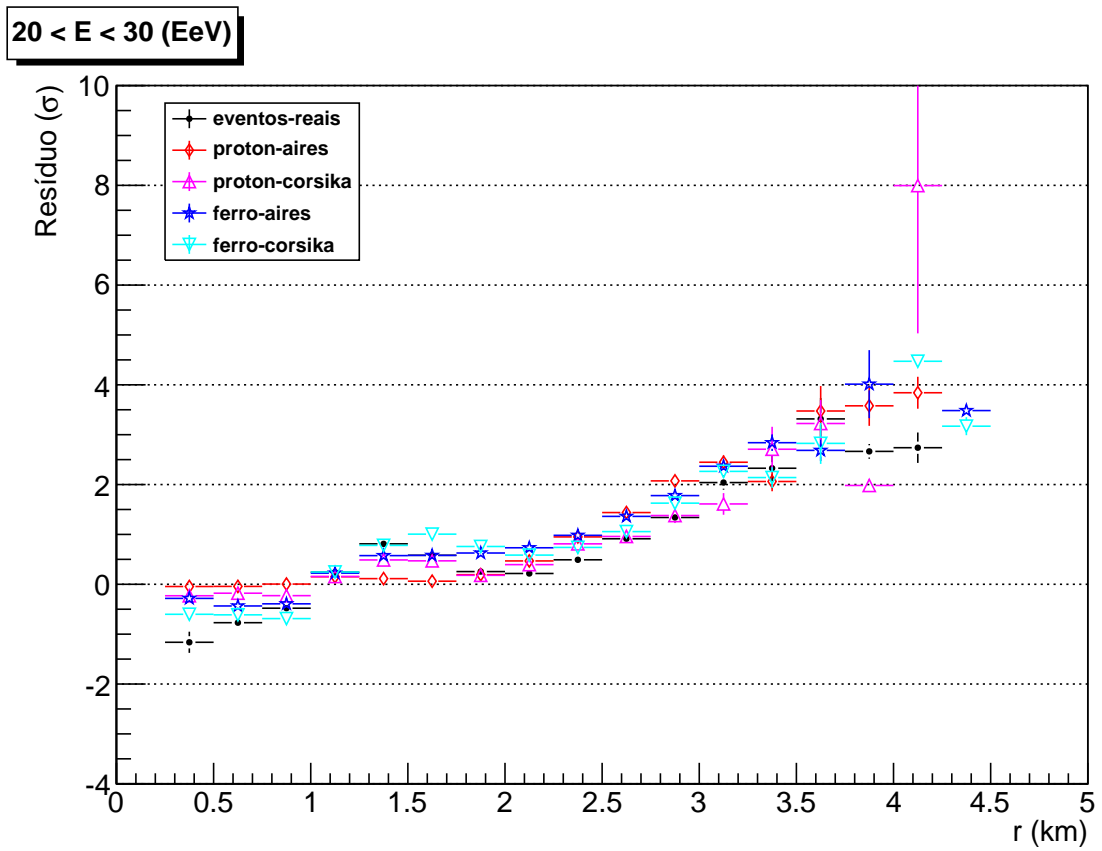

(b)

Figura B.5: Perfil dos resíduos dos ajuste de LDF para eventos com energia entre 15 e $30 \mathrm{EeV}$. 


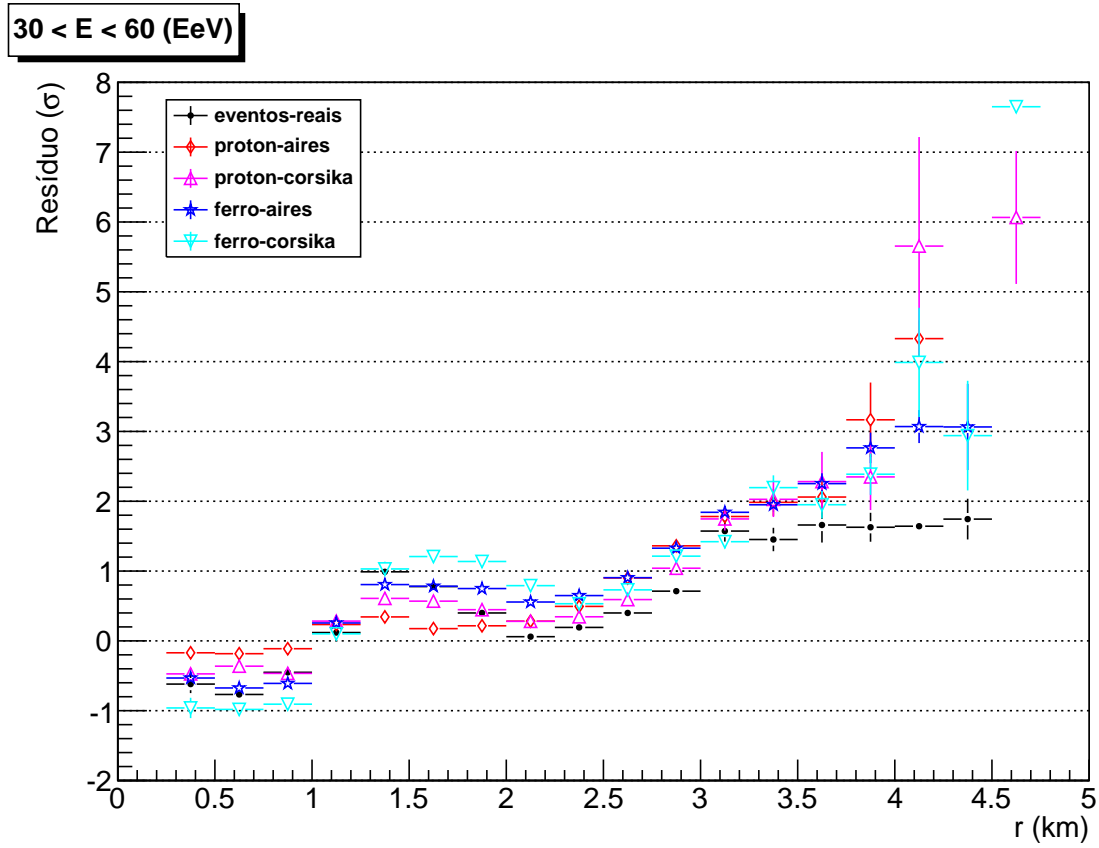

(a)

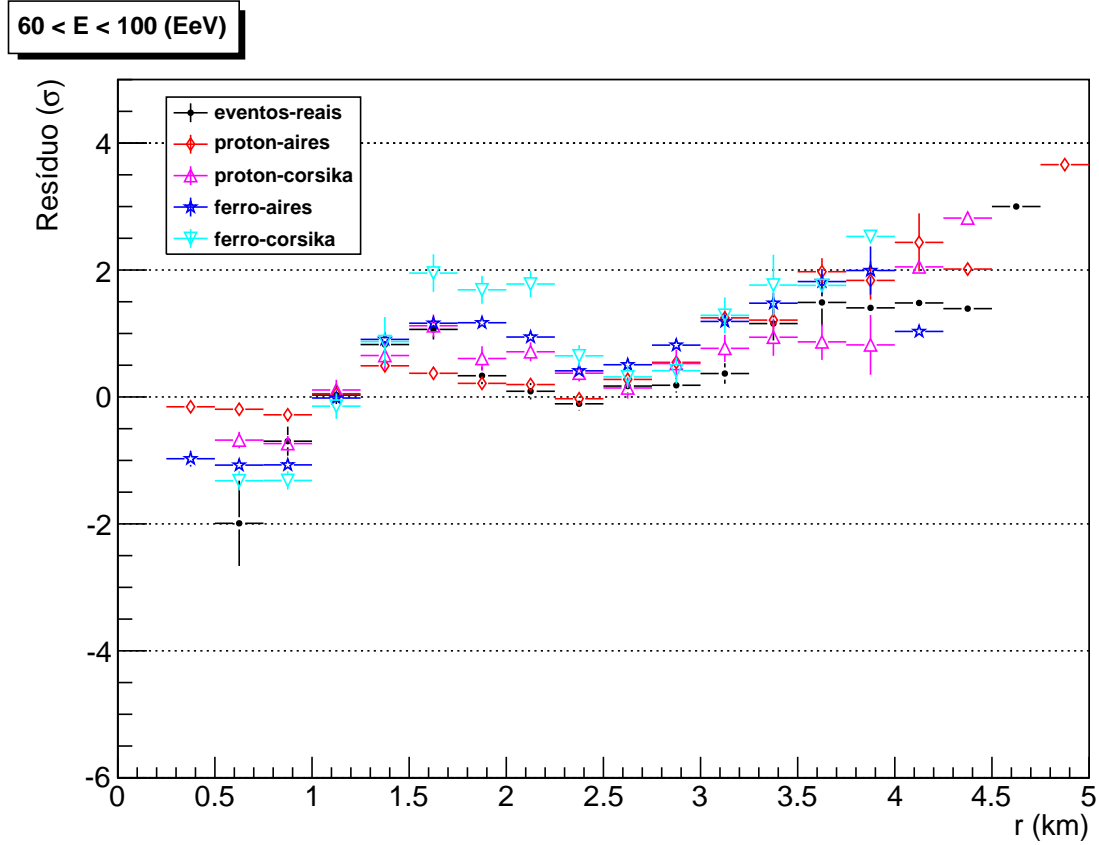

(b)

Figura B.6: Perfil dos resíduos dos ajuste de LDF para eventos com energia entre 30 e $100 \mathrm{EeV}$. 


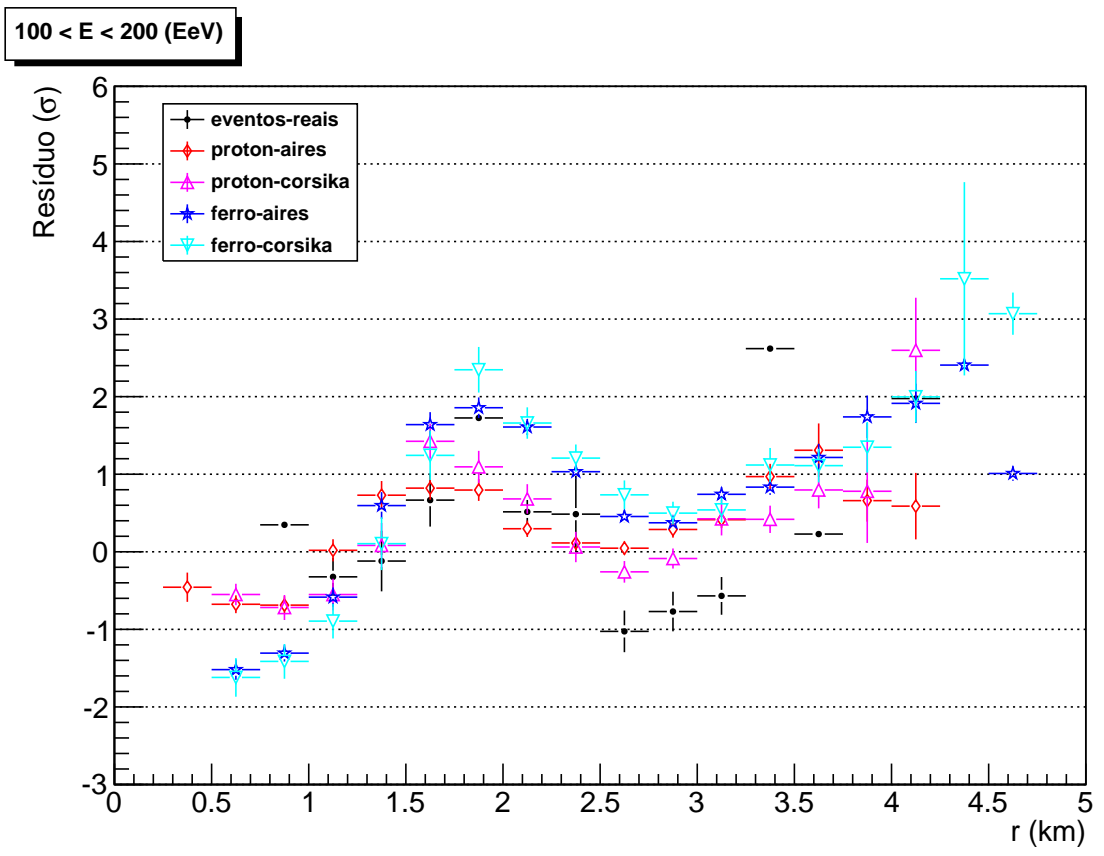

(a)

Figura B.7: Perfil dos resíduos dos ajuste de LDF para eventos com energia entre 100 e $200 \mathrm{EeV}$. 


\section{B.2 Ajustes com a função NKG corrigida}

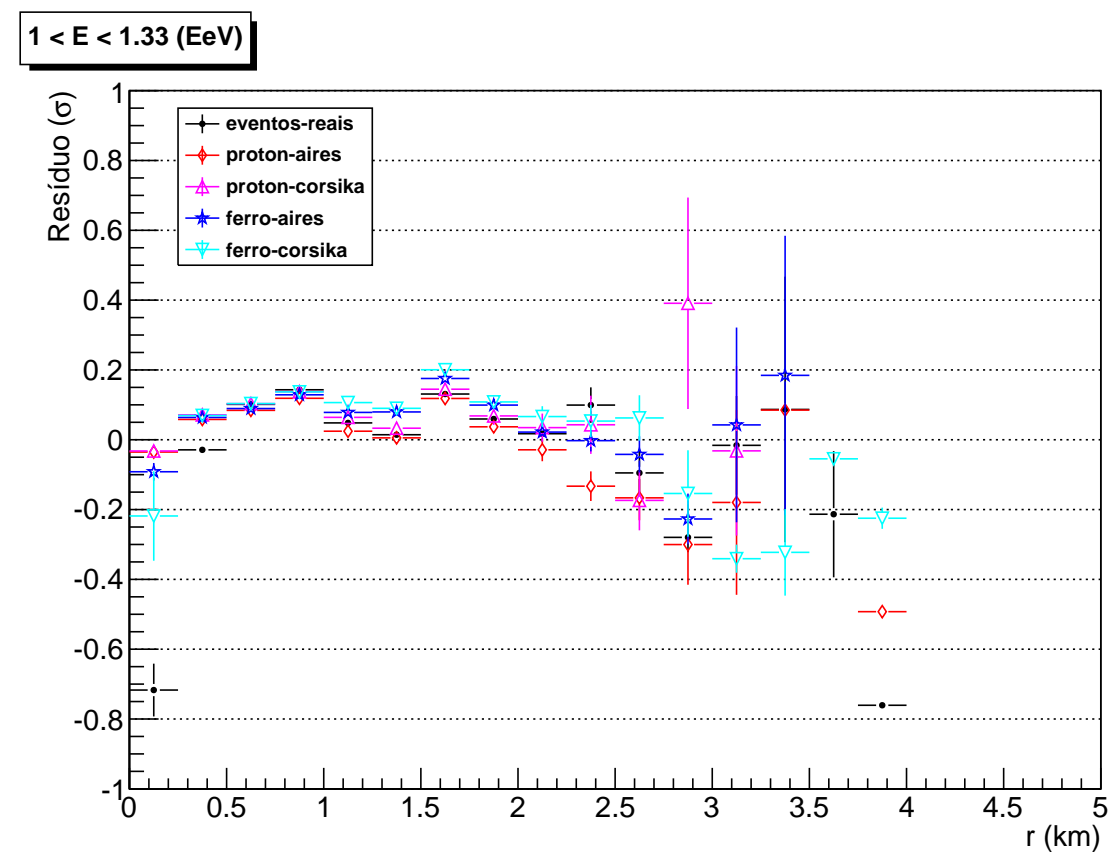

(a)

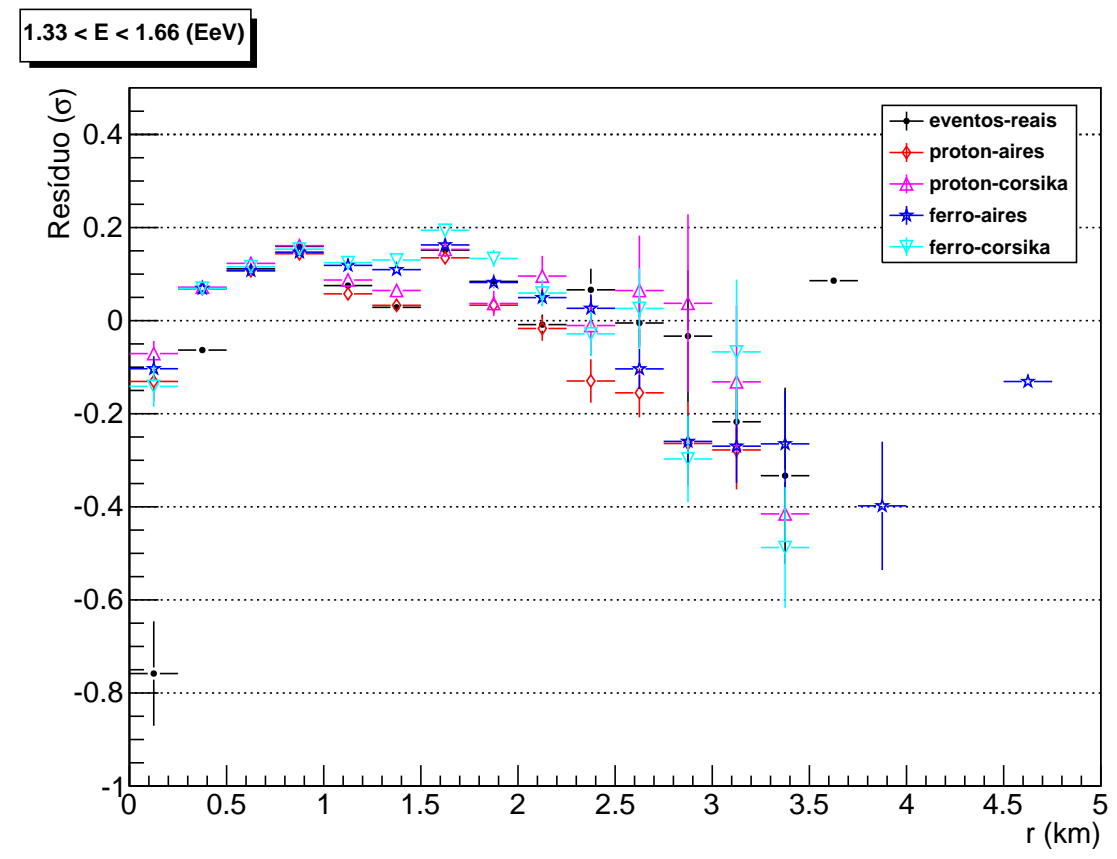

(b)

Figura B.8: Perfil dos resíduos dos ajuste de LDF com correção da NKG para eventos com energia entre 1 e 1,66 EeV. 


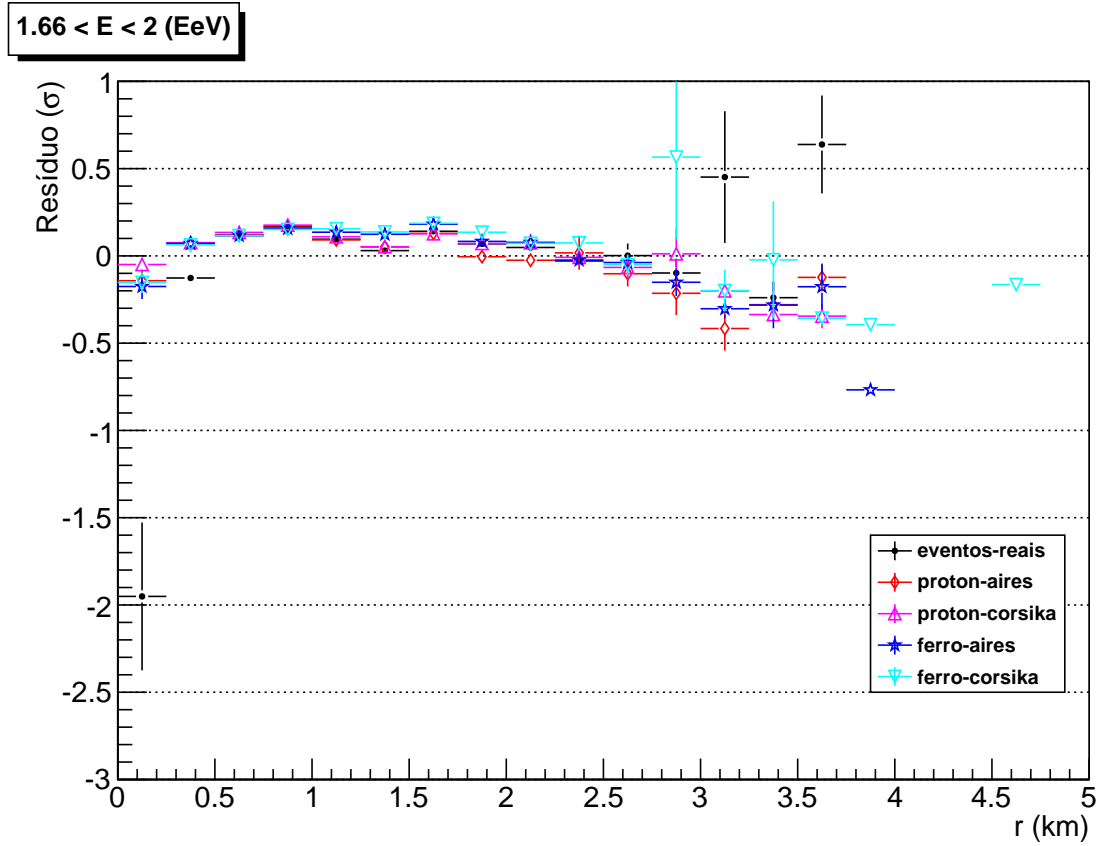

(a)

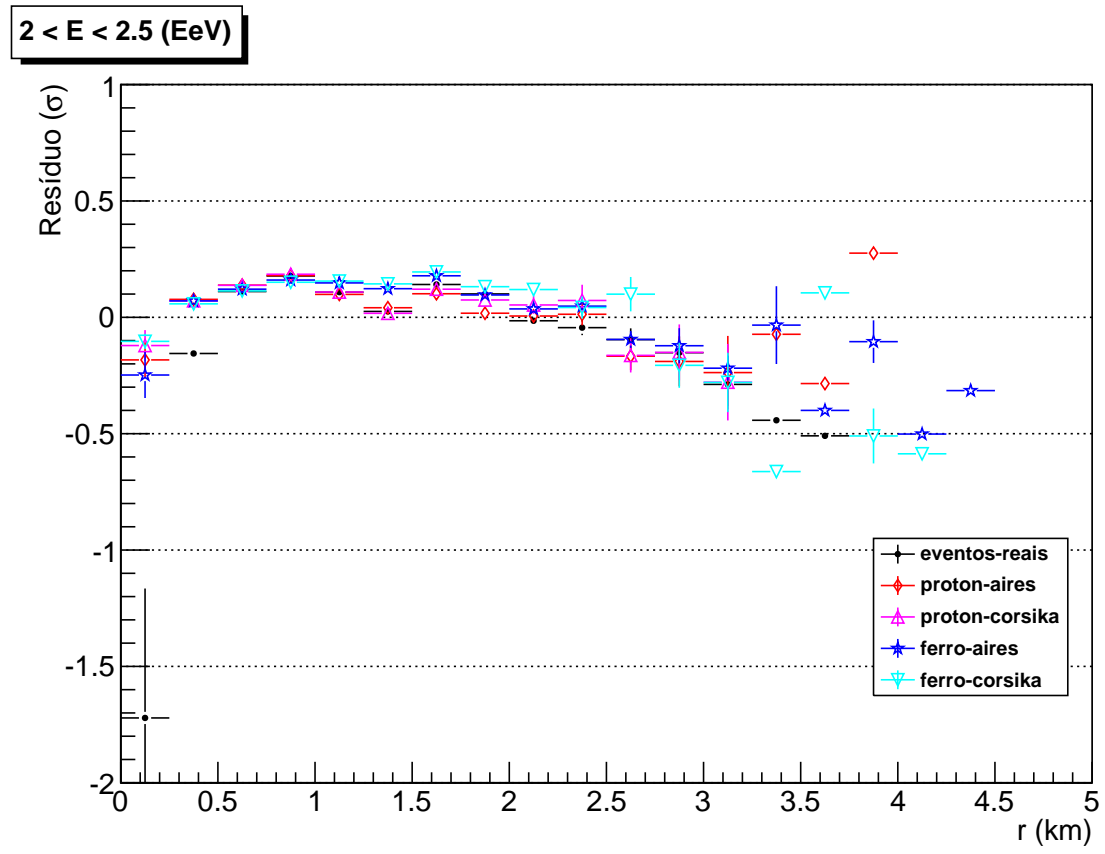

(b)

Figura B.9: Perfil dos resíduos dos ajuste de LDF com correção da NKG para eventos com energia entre 1,66 e 2,5 EeV. 


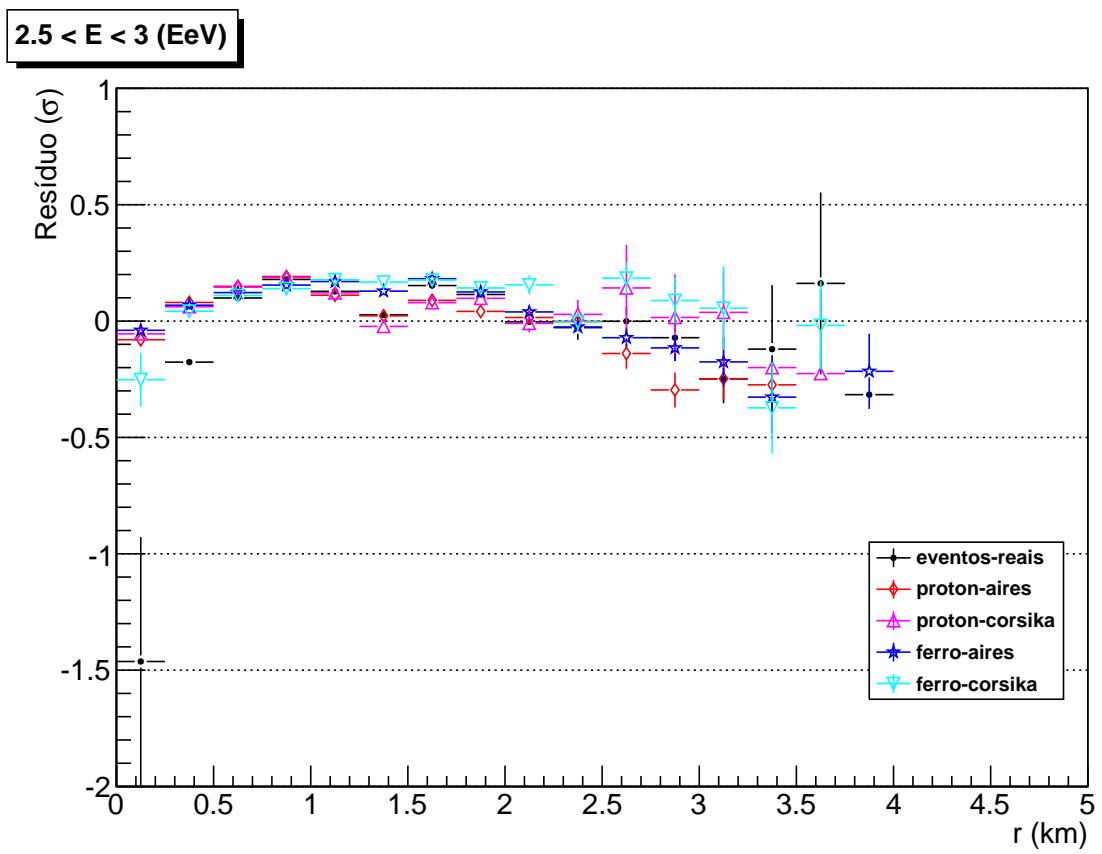

(a)

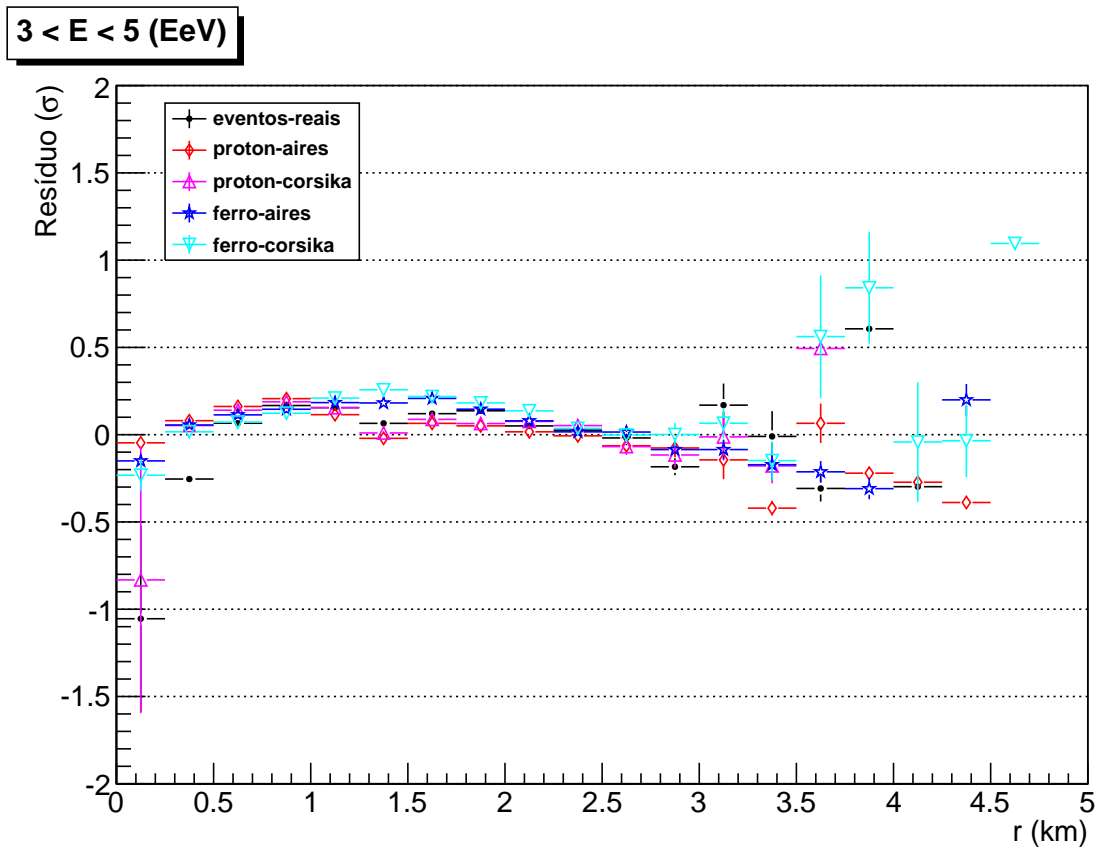

(b)

Figura B.10: Perfil dos resíduos dos ajuste de LDF com correção da NKG para eventos com energia entre 2,5 e $5 \mathrm{EeV}$. 


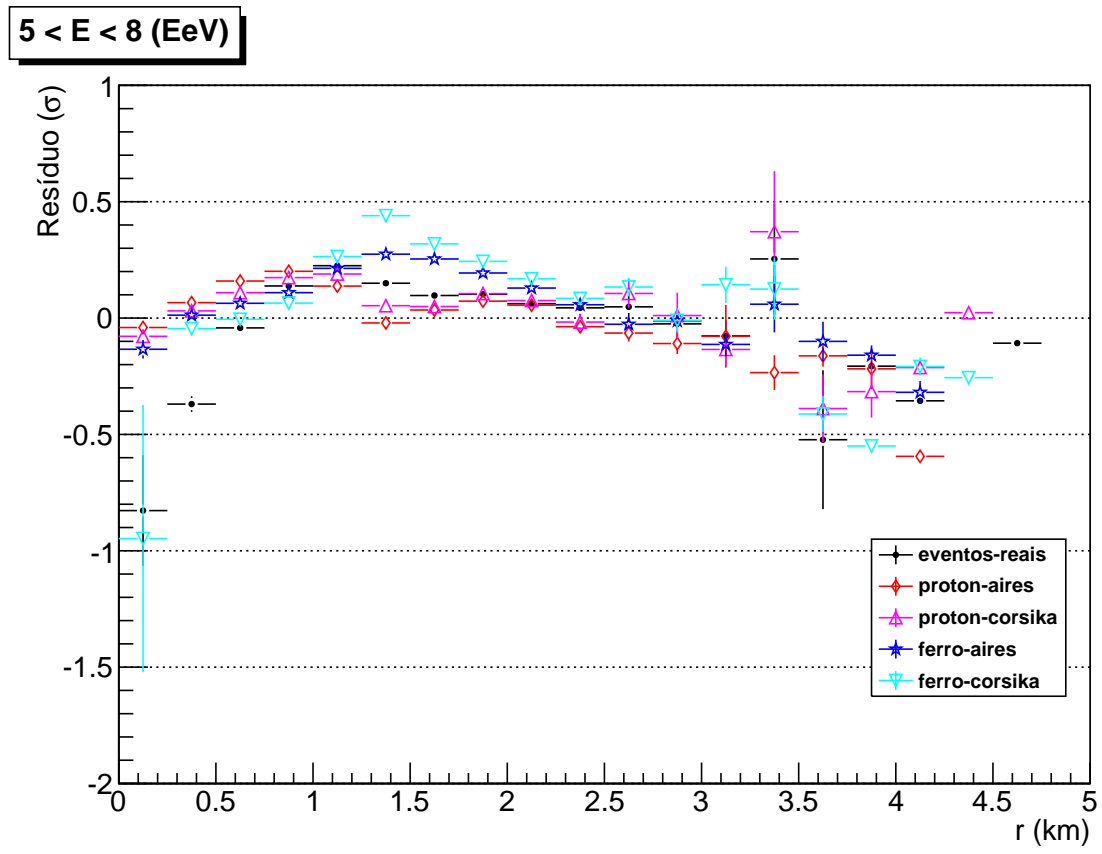

(a)

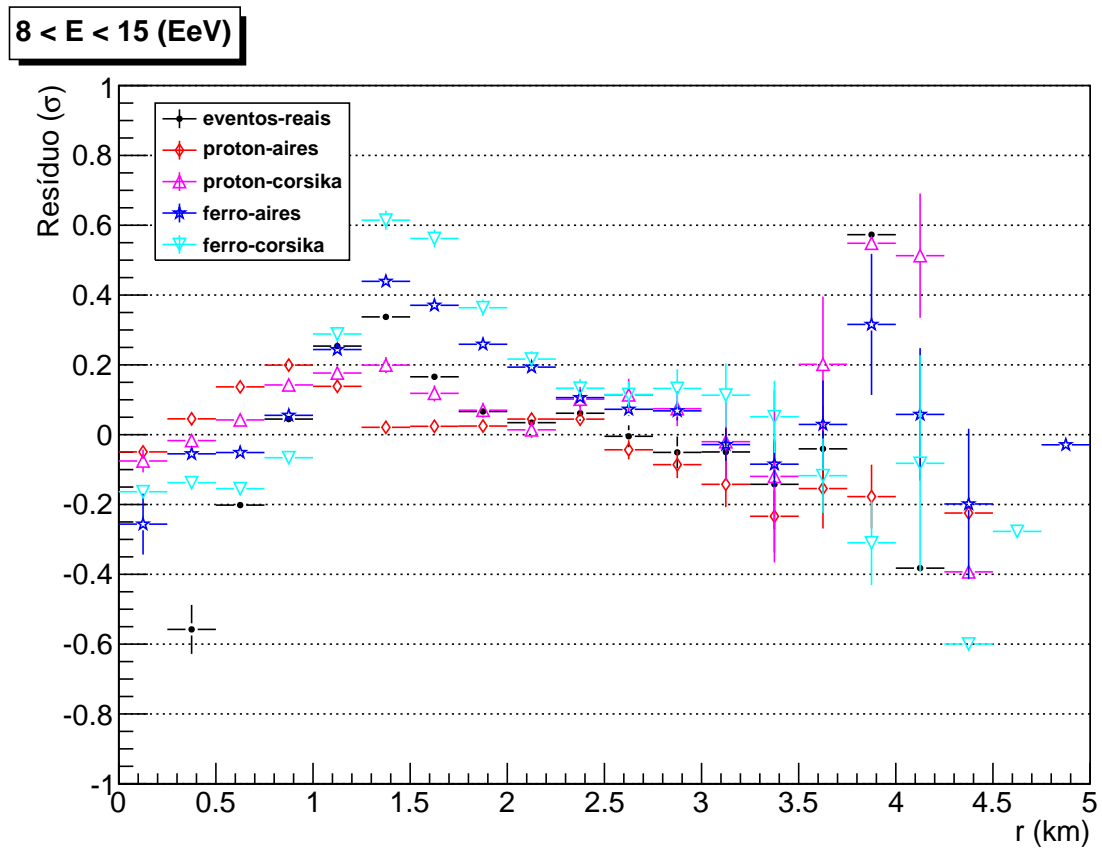

(b)

Figura B.11: Perfil dos resíduos dos ajuste de LDF com correção da NKG para eventos com energia entre 5 e $15 \mathrm{EeV}$. 


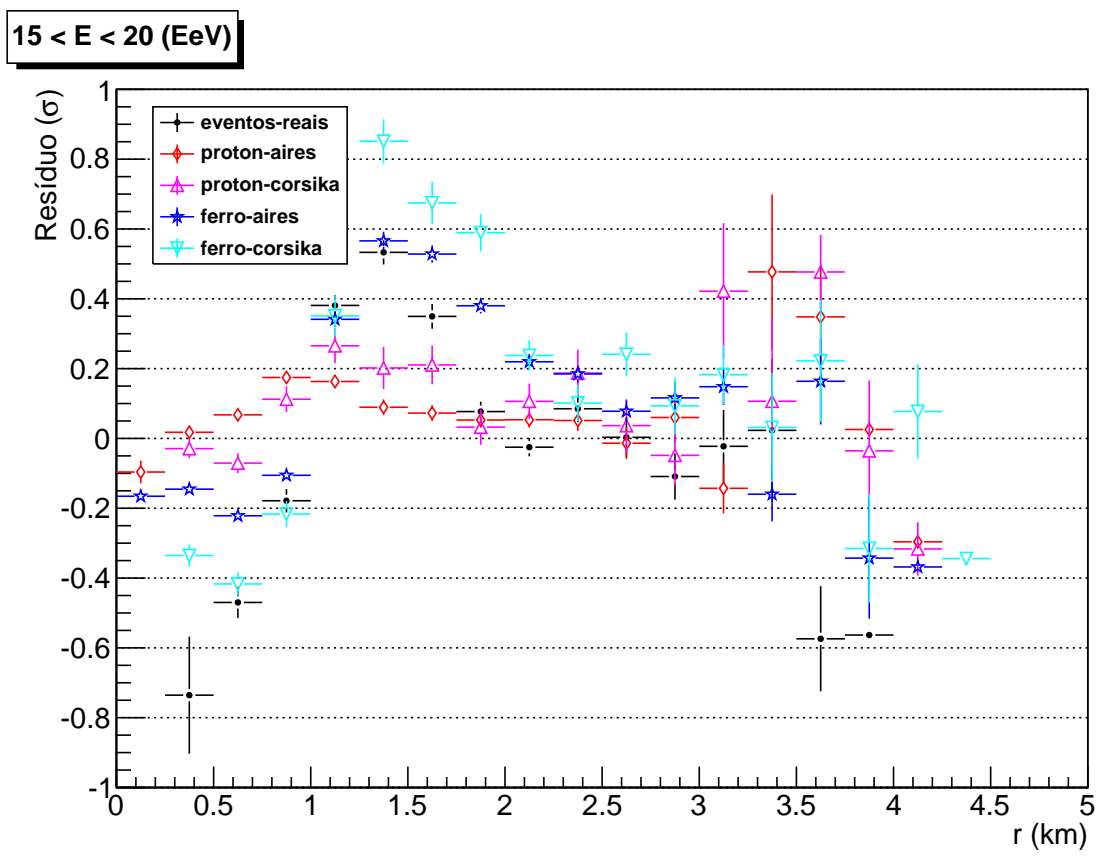

(a)

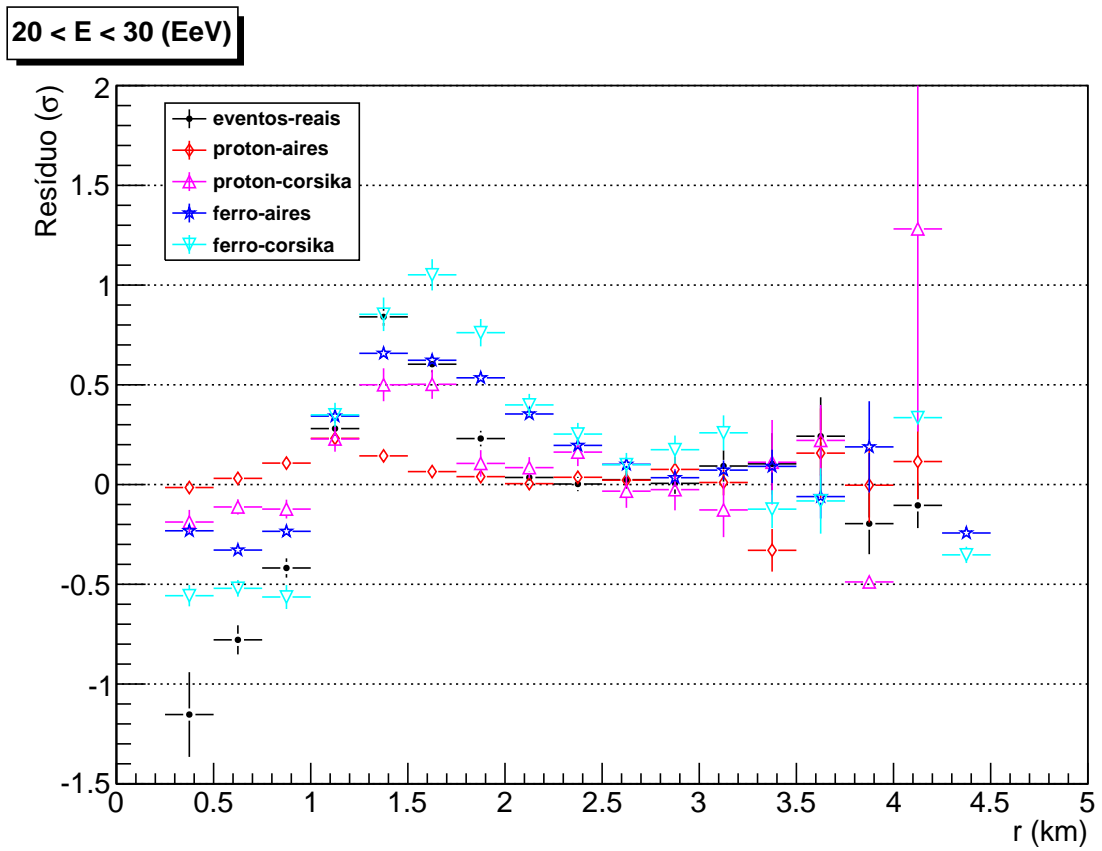

(b)

Figura B.12: Perfil dos resíduos dos ajuste de LDF com correção da NKG para eventos com energia entre 15 e $30 \mathrm{EeV}$. 


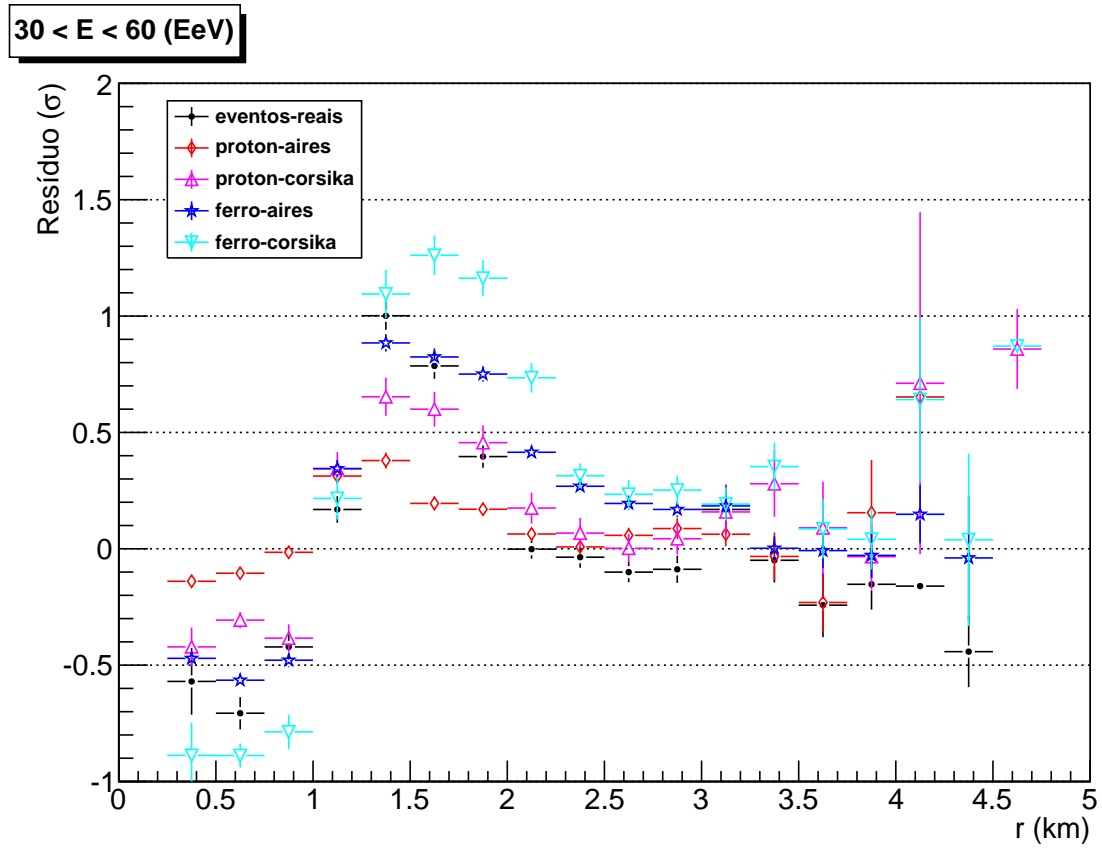

(a)

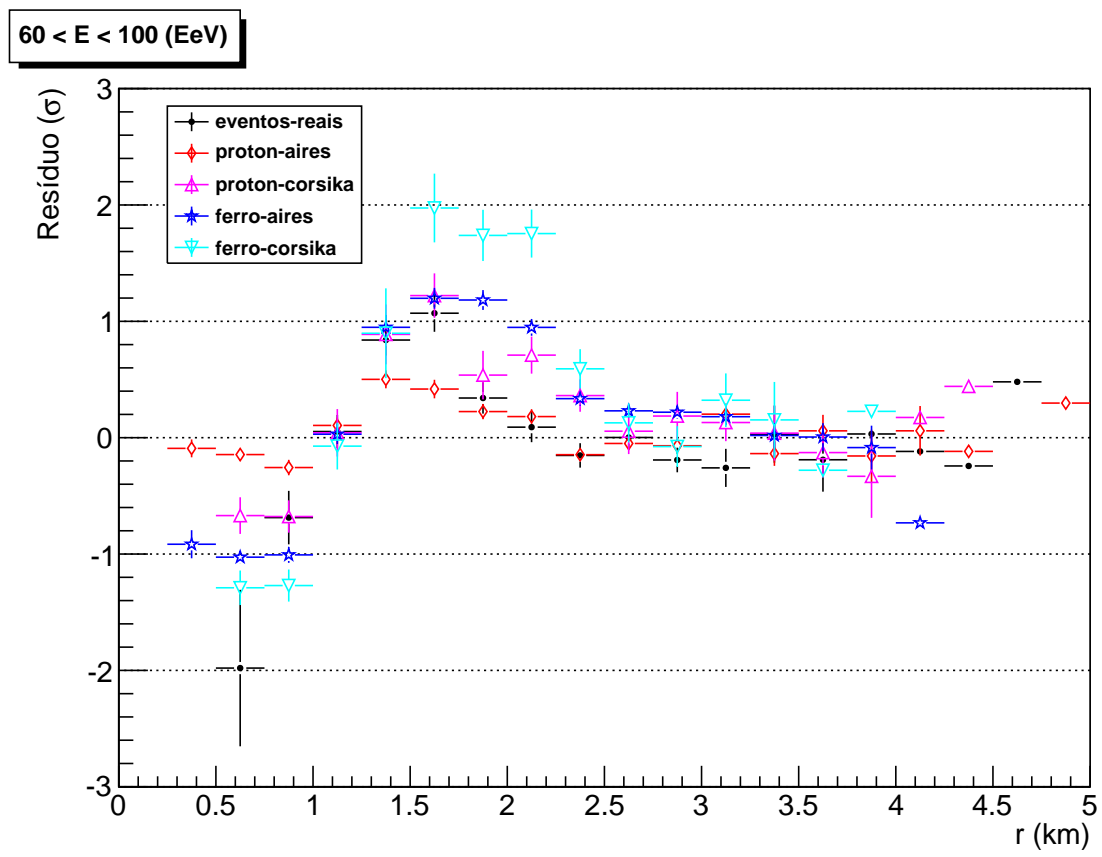

(b)

Figura B.13: Perfil dos resíduos dos ajuste de LDF com correção da NKG para eventos com energia entre 30 e $100 \mathrm{EeV}$. 


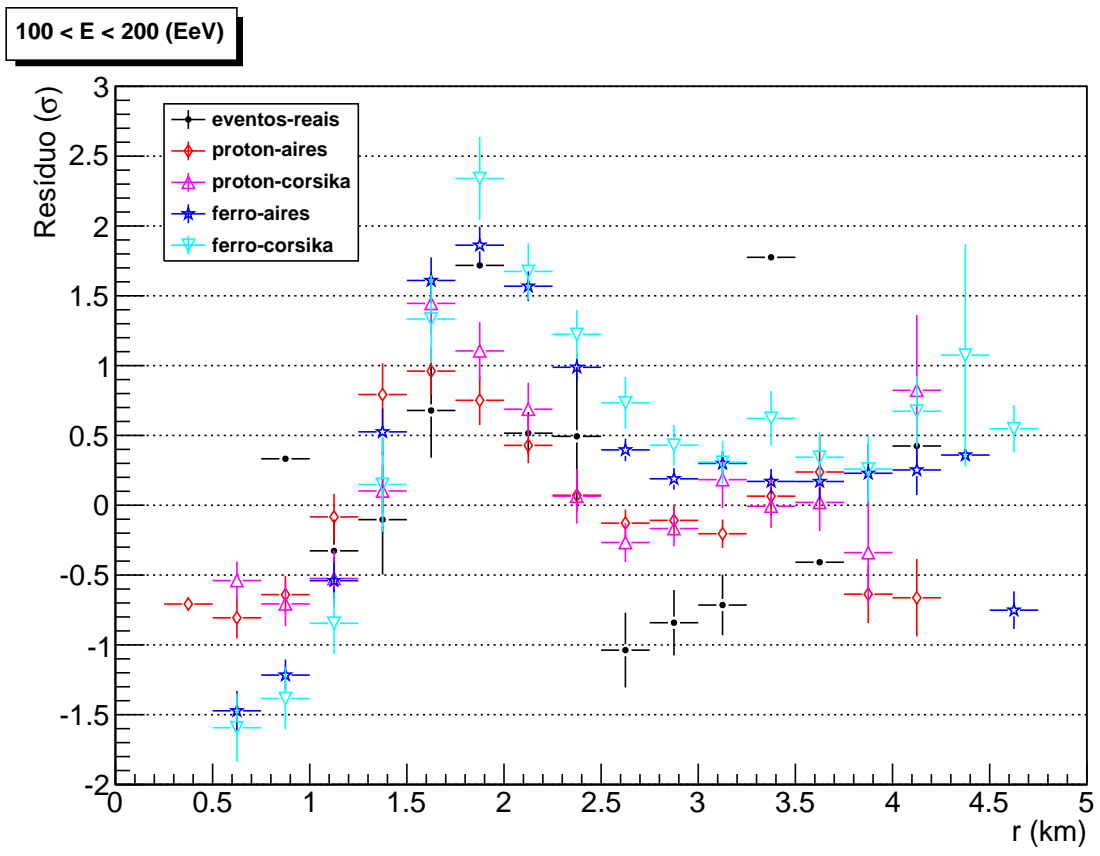

(a)

Figura B.14: Perfil dos resíduos dos ajuste de LDF com correção da NKG para eventos com energia entre 100 e $200 \mathrm{EeV}$. 


\section{Apêndice C}

\section{Cálculo do Q para ajuste}

Para usar do MINUIT para ajustar uma função qualquer é necessário implementar uma função que calcula o $Q$ entre os dados e a função ajustada. O $\mathrm{Q}^{2}$ nada mais é que o $\chi^{2}$ calculado com parâmetros que estão fora do mínimo da função. Neste apêndice é deduzida o valor do Q para a implementação do ajuste da seção 5.3.2.

$$
Q=\frac{S_{1}-S_{2} K^{1+b(\theta) \log (X)}}{\sigma_{Q}}
$$

onde $\sigma_{Q}$ é:

$$
\begin{aligned}
\sigma_{Q}^{2}= & \left(\sigma_{S_{1}} \cdot \frac{\partial Q}{\partial S_{1}}\right)^{2}+\left(\sigma_{S_{2}} \cdot \frac{\partial Q}{\partial S_{2}}\right)^{2}+ \\
& +\left(\sigma_{\theta} \cdot \frac{\partial Q}{\partial \theta}\right)^{2}+\left(\sigma_{r} \cdot \frac{\partial Q}{\partial r}\right)^{2}
\end{aligned}
$$

e as derivadas são:

$$
\begin{gathered}
\frac{\partial Q}{\partial S_{1}}=1 \\
\frac{\partial Q}{\partial S_{2}}=K^{1+b(\theta) \log (X)}
\end{gathered}
$$




$$
\begin{aligned}
& \frac{\partial Q}{\partial \theta}=S_{2} \frac{\partial}{\partial \theta}\left(K^{1+b(\theta) \log (X)}\right)= \\
& =S_{2} K^{1+b(\theta) \log (X)} \ln (K) \frac{\partial}{\partial \theta}(1+b(\theta) \log (X))= \\
& =S_{2} K^{1+b(\theta) \log (X)} \ln (K) \log (X) \frac{\partial b(\theta)}{\partial \theta}= \\
& =S_{2} K^{1+b(\theta) \log (X)} \ln (K) \log (X) \tan (\theta)\left(b_{1} \sec (\theta)+b 2 \sec ^{2}(\theta)\right) \\
& \frac{\partial Q}{\partial r}=S_{2} K^{1+b(\theta) \log (X)} \ln (K) \frac{\partial}{\partial r}(1+b(\theta) \log (X))= \\
& =S_{2} K^{1+b(\theta) \log (X)} \ln (K) b(\theta) \frac{\partial \log (X)}{\partial r}= \\
& =S_{2} K^{1+b(\theta) \log (X)} \ln (K) b(\theta) \frac{\log (e)}{X} \frac{\partial X}{\partial r}= \\
& =S_{2} K^{1+b(\theta) \log (X)} \ln (K) b(\theta) \frac{\log (e)\left(2 r+r_{0}\right)}{r^{2}+r_{0} r}
\end{aligned}
$$




\section{Lista de Tabelas}

4.1 Número de chuveiros simulados com o AIRES e CORSIKA utilizando próton e ferro como partículas primárias. ${ }^{*} \mathrm{O}$ tempo é expresso em número de dias que seriam necessários para simular todos os chuveiros em 1 núcleo de processamento (equivalente a um core 2 duo de $3 \mathrm{GHz})$. . . . . . . . . . . . 55

4.2 Número de eventos simulados utilizando chuveiros provenientes do AIRES e do CORSIKA utilizando prótons e núcleos de ferro como partículas primárias. ${ }^{*} \mathrm{O}$ tempo é expresso em número de dias que seriam necessários para simular todos os chuveiros em 1 núcleo de processamento. . . . . . . . . . . 56

5.1 Número de eventos reconstruídos utilizados neste trabalho, sejam eles provenientes de simulações do AIRES e do CORSIKA ou de eventos reais. Entretanto nem todos os eventos reconstruídos satisfazem os cortes de energia e ângulo zenital utilizados neste trabalho. . . . . . . . . . . . . . . . 64

5.2 Compilação das grandezas físicas estimadas com ajustes das figuras 5.7, 5.8, 5.10 e 5.11. As duas primeiras linhas são comparações entre eventos simulados e as duas últimas entre eventos simulados e reais. A variável $\rho\left(f_{\mu}, S_{e m}\right)$ é a correlação

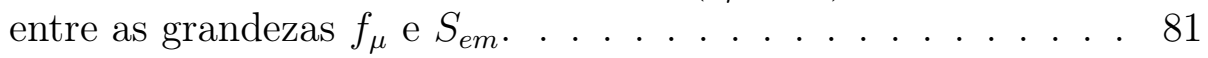

5.3 Compilação dos valores de $K$ estimados com ajustes entre simulações, primeira e segunda linhas, e eventos reais e simulados, duas últimas linhas. . . . . . . . . . . . . . . . . . . 91

5.4 Valores médios e RMS do $\chi^{2}$ e número de eventos reconstruídos utilizando a LDF corrigida e a LDF padrão. . . . . . . . . . . 117 


\section{Lista de Figuras}

1.1 Compilação de medidas do fluxo de raios cósmicos em função da energia. A linha tracejada indica uma lei de potência do tipo $\mathrm{E}^{-3}$, figura obtida da referência [9]. . . . . . . . . . . . 4

1.2 Diagrama de Hillas, com tamanho e intensidade do campo magnético de alguns objetos astrofísicos que seriam capazes de acelerar raios cósmicos de ultra alta energia. As retas mostram o limite inferior de tamanho/campo para aceleração de partículas carregadas com energia de $10^{20} \mathrm{eV}$. Obtido da referência [15]. . . . . . . . . . . . . . . . . . . 6

1.3 Seção de choque total para fotoprodução de píons para prótons (linha contínua) e para nêutrons (linha tracejada), em função da energia do fóton incidente (referencial do núcleon). Figura obtida da referência $[20] \ldots \ldots$. . . . . . . . . . 8

1.4 Simulação da perda de energia de prótons em função da distância percorrida [21]. Figura obtida da referência [9]. . . . . . 9

1.5 Fluxo dos raios cósmicos ultra energéticos compatíveis com o corte GZK. Gráfico obtido de [8]. . . . . . . . . . . . . . . 10

1.6 Simulação de um chuveiro atmosférico causado por um próton de $10^{15} \mathrm{eV}$. Os traços vermelhos representam elétrons, pósitrons e fótons; os traços verdes representam múons; e os azuis, hádrons. Obtida da referência [26]. . . . . . . . . . . . . . 11

1.7 Esquema do desenvolvimento de um chuveiro atmosférico gerado por um raio cósmico de altíssima energia, figura obtida da referência [27]. . . . . . . . . . . . . . . . . . . . . . . 12

1.8 Observatório Pierre Auger do hemisfério Sul. Os pontos indicam os 1600 detectores de superfície, a área em azul indica a região coberta pelos estações SD em operação no 11 de junho de 2008. As regiões de observação dos telescópios de fluorescência são indicadas pelas linha verdes. . . . . . . . . . . . . 14 
1.9 Ajuste da função de distribuição lateral de um evento do Observatório Pierre Auger. A energia estimada desse evento é de $3,76(19) \cdot 10^{19} \mathrm{eV} \ldots \ldots \ldots \ldots \ldots \ldots$

1.10 Correlação entre a energia estimada pelo FD $\left(E_{F D}\right)$ e o parâmetro $S_{38}$ do SD em 387 eventos híbridos. A linha cheia mostra o ajuste, a linha tracejada, o corte para inclusão no ajuste. Figura obtida da referência [30]. . . . . . . . . . . . 17

2.1 Gráfico da equação (2.12), fator multiplicativo da incerteza do sinal das estações SD . . . . . . . . . . . . . . . . 25

2.2 Gráfico do fator Poisson, equação (2.21), em função do ângulo zenital $\theta \ldots \ldots \ldots \ldots \ldots$. . . . . . . . . . . . . . . . 28

3.1 Distribuição da energia dos eventos na figura (a) e a distribuição de ângulo zenital $(\theta)$ na figura (b). Eventos T5 de 2004 a

3.2 Perfil do ângulo zenital $(\theta)$ em função da energia, nesse caso a barra de incerteza corresponde ao desvio padrão da média.

3.3 Gráfico dos resíduos absolutos, a diferença entre o valor experimental e o valor da função ajustada, dos ajustes de LDFs dos eventos T5 de 2004 à 2010. Os pontos vermelhos representam o perfil da distribuição. . . . . . . . . . . . . . . . 36

3.4 Gráfico dos resíduos relativos, resíduo absoluto divido pelo valor experimental, dos ajustes de LDFs dos eventos T5 de 2004 a 2010. Os pontos vermelhos representam o perfil da distribuição. . . . . . . . . . . . . . . . 3

3.5 Gráfico dos resíduos reduzidos, resíduo absoluto dividido pela incerteza do valor experimental, dos ajustes de LDFs dos eventos T5 de 2004 a 2010. Os pontos vermelhos representam o perfil da distribuição.

3.6 (a) Perfil do sinal das estações em função da distância ao centro do chuveiro. (b) Histograma das posições das estações. Eventos T5 de 2004 a 2010.

3.7 Gráfico dos resíduos reduzidos obtido por simulação. Os pontos vermelhos representam o perfil da distribuição. . . . . . . . 40

3.8 Gráfico dos resíduos reduzidos dos ajustes de LDFs dos eventos T5 de 2004 à 2010, zoom na região entre -5 e 5 desvios padrão. Os pontos vermelhos representam o perfil da distribuição. . . . 41 
3.9 Gráfico de resíduos reduzidos de LDFs em função do tempo. As setas indicam o início dos anos e os pontos vermelhos representam o perfil da distribuição. . . . . . . . . . . . . . 44

3.10 Gráfico de resíduos reduzidos de LDFs em função da distância ao centro do chuveiro. O gráfico superior contém apenas eventos anteriores a 1 de janeiro de 2007, e no gráfico inferior estão os eventos posteriores a esta data. . . . . . . . . . 45

3.11 Gráfico dos perfis dos resíduos reduzidos de LDFs em função da distância ao centro do chuveiro. A curva vermelha é o perfil utilizado a equação (2.2) (NKG) como parametrização da LDF e a azul corresponde à equação $(2.7)(\mathrm{PL})$. . . . . . . . . 46

4.1 Gráfico da seção de choque próton-ar em função da energia para diferentes modelos de interação hadrônica comparados com dados de aceleradores. A área hachurada é uma estimativa da incerteza desse modelos [69] . . . . . . . . . . . . 53

4.2 Gráfico do perfil da energia reconstruída em função da energia simulada para os eventos simulados com o AIRES/SIBYLL e CORSIKA/EPOS; as barras de incerteza são o desvio padrão da média. Os valores abaixo da reta possuem energia reconstruída menor que a energia simulada. . . . . . . . . . 57

4.3 (a) Perfil do sinal das estações em função da distância ao centro do chuveiro; as barras de incerteza são os desvios padrão das médias. (b) Histograma das posições das estações. Eventos simulados. . . . . . . . . . . . . . . . . . 58

4.4 Distribuição da energia dos eventos simulados na figura (a) e a distribuição de ângulo zenital $(\theta)$ na figura (b) . . . . . . . 59

4.5 Perfil do ângulo zenital $(\theta)$ em função da energia da partícula primária; as barras de incerteza correspondem ao desvio padrão da média, entretanto sabe-se que este está subestimado, para detalhes vide texto. . . . . . . . . . . . . . . . . . 59

4.6 Gráfico de resíduos reduzidos da LDFs em função da distância ao centro do chuveiro. As marcas coloridas representam os perfis das distribuições. Os gráficos da esquerda são de chuveiros simulados pelo AIRES/SIBYLL e os da direita pelo CORSIKA/EPOS. . . . . . . . . . . . . . . . 60

4.7 Sobreposição dos perfis dos resíduos contidos na figura 4.6. . . 61 
5.1 Diferença entre os perfis dos resíduos de ajustes com estações silenciosas e sem estações silenciosas (SS). O gráfico inferior é um zoom na escala do gráfico superior para facilitar a visualização das diferenças das estações mais próximas ao centro do chuveiro. . . . . . . . . . . . . . . . 66 66

5.2 Gráfico com a fração dos eventos que têm $\beta$ ou $\gamma$ ajustados em função da energia e $\theta$. . . . . . . . . . . . . . . . . . 70

5.3 Gráficos de $\Delta \beta$ e $\Delta \gamma$ médios, em função da energia reconstruída da partícula primária. . . . . . . . . . . . 71

5.4 Gráficos de $\Delta \beta$ e $\Delta \gamma$ médios, em função do ângulo zenital $\theta$. . 72

5.5 Várias LDFs com S1000 diferentes, para $\theta=0^{\circ}$ e $60^{\circ}$. A função é a NKG, (2.2), e foi utilizada a parametrização de $\beta$ da $(2.3)$ e $\gamma=0$. Um evento com $S_{1000}=1900 \mathrm{VEM}$ e $\theta=0^{\circ}$ tem energia de $430 \mathrm{EeV}$. Um evento que tem $S_{1000}=10 \mathrm{VEM}$ $\operatorname{com} \theta=0^{\circ}$ possui $1,5 \mathrm{EeV}$ e $\operatorname{com} \theta=60^{\circ}, 3,8 \mathrm{EeV}$. . . . . . 73

5.6 Gráfico do sinal de uma estação SD em função da distância ao centro do chuveiro, destacados os sinais das componentes eletromagnética e muônica do chuveiro. Simulações realizadas com AIRES/QGSJET-II com $10 \leq E \leq 12 \mathrm{EeV}$ e $0^{\circ} \leq \theta \leq$ $33^{\circ}$. Gráficos obtidos da referência [73]. . . . . . . . . . . .

5.7 Gráfico do sinal médio das simulações do AIRES/SIBYLL em função do sinal médio das simulações do EPOS/CORSIKA para chuveiros iniciados por próton. Os pontos coloridos correspondem a estações utilizadas no ajuste; no gráfico inferior estão os resíduos reduzidos.

5.8 Gráfico do sinal médio das simulações do AIRES/SIBYLL em função do sinal médio das simulações do EPOS/CORSIKA para chuveiros iniciados por ferro. Os pontos coloridos correspondem a estações utilizadas no ajuste; no gráfico inferior estão os resíduos reduzidos. . . . . . . . . . . . . .

5.9 Ilustração hipotética das distribuições de energia de píons carregados em chuveiros simulados. A área indicada por "Limite" representa a região de transição entre os píons que decaem na atmosfera (energia mais baixa) e a região dos píons que não decaem na atmosfera (energia mais alta). . . . . . . . . .

5.10 Gráfico do sinal médio das simulações com EPOS/CORSIKA para chuveiros iniciados por prótons em função do sinal médio de eventos reais. Os pontos coloridos correspondem à estações utilizadas no ajuste; no gráfico inferior são apresentados os resíduos reduzidos. . . . . . . . . . . . . 86 
5.11 Gráfico do sinal médio das simulações com EPOS/CORSIKA para chuveiros iniciados por ferro em função do sinal médio de eventos reais. Os pontos coloridos correspondem à estações utilizadas no ajuste; no gráfico inferior são apresentados os resíduos reduzidos. . . . . . . . . . . . . . . .

5.12 (a) Gráfico com os perfis em duas dimensões do ajuste de $K$ para simulações com próton como partícula primária. O resíduo reduzido médio está indicado pela escala de cor. (b) Zoom no perfil dos resíduos em função da energia e da distância ao centro do chuveiro; a energia está em escala logarítmica. . . .

5.13 (a) Gráfico com os perfis em duas dimensões do ajuste de $K$ para simulações com ferro como partícula primária. O resíduo reduzido médio está indicado pela escala de cor. (b) Zoom no perfil dos resíduos em função da energia e da distância ao centro do chuveiro; a energia está em escala logarítmica. . . . 95

5.14 Perfil do logaritmo do sinal das estações em função da distância ao centro do chuveiro e da energia da partícula primária. Eventos gerados com simulações do AIRES para chuveiros iniciados por prótons. . . . . . . . . . . . . . 96

5.15 (a) Gráfico com os perfis em duas dimensões do ajuste de $K$ para simulações do CORSIKA/EPOS com próton como partícula primária e eventos reais. O resíduo reduzido médio está indicado pela escala de cor. (b) Zoom no perfil dos resíduos em função da energia e da distância ao centro do chuveiro; a energia está em escala logarítmica. . . . . . . . . . . . 98

5.16 (a) Gráfico com os perfis em duas dimensões do ajuste de $K$ para simulações do CORSIKA/EPOS com ferro como partícula primária e eventos reais. O resíduo reduzido médio está indicado pela escala de cor. (b) Zoom no perfil dos resíduos em função da energia e da distância ao centro do chuveiro; a energia está em escala logarítmica. . . . . . . . . . . . . 99

5.17 Perfil dos resíduos dos ajuste de LDF com a NKG em eventos reais e simulados em função da distância da estação ao centro do chuveiro. . . . . . . . . . . . . . . . . 103

5.18 Gráficos do perfil dos resíduos reduzidos para as diferentes regiões de distâncias entre as estações e o centro do chuveiro $(r)$, em função do ângulo zenital $(\theta)$. Contêm eventos reais e simulados com o AIRES/SIBYLL e o CORSIKA/EPOS utilizando como partículas primárias núcleos de ferro e prótons. . . . . . 105 
5.19 Gráficos do perfil dos resíduos reduzidos em função da energia reconstruída para os eventos reais e energia simulada para eventos simulados nas regiões 1 e 4 . As barras de incerteza representam o desvio padrão da média. . . . . . . . . . . . 107

5.20 Gráficos do perfil dos resíduos reduzidos em função da energia reconstruída para os eventos reais e energia simulada para eventos simulados nas regiões 2 e 3 . As barras de incerteza representam o desvio padrão da média. . . . . . . . . . . . . 110

$5.21\left\langle X_{\max }\right\rangle$ (a) e $R M S\left(X_{\max }\right)$ (b) em função da energia reconstruída. Os pontos são eventos reais medidos pelo Observatório Pierre Auger, e as linhas são simulações com diferentes modelos de interação hadrônica. Os números representam a quantidade de eventos utilizados no canal. Estes gráficos foram apresentados no ICRC de 2011 [76] . . . . . . . . . . . . . . 111

5.22 Ilustração do viés na LDF observada devido ao trigger das estações. No gráfico superior são plotadas as f.d.p. que descrevem os sinais de estações em duas distâncias ao centro do chuveiro; as áreas hachuradas acima do trigger representam os sinais medidos que contribuem para as médias corrigidas. No gráfico inferior são mostradas a LDF padrão e a LDF com as médias corrigidas. . . . . . . . . . . . . . . . . 114

5.23 Gráfico de comparação entre o sinal corrigido e não corrigido. 115

5.24 Gráficos do ajuste do mesmos evento com LDF original (a) e corrigida (b). Evento real com energia em torno de $10 \mathrm{EeV} \mathrm{e}$ $\theta=50^{\circ}$. A faixa cinza representa o intervalo de 1 desvio padrão e os triângulos azuis são as estações silenciosas presentes no evento. . . . . . . . . . . . . . . . . . . . . 118

5.25 Comparação do $S_{1000}$ de ajustes em que a LDF é corrigida com ajustes da LDF padrão. A linha vermelha é uma reta ajustada com parâmetros $a_{0}=-0,4308(21)$ e $a_{1}=1,00003(13) . \quad \ldots 119$

5.26 Perfil dos resíduos dos ajuste de LDF com a NKG corrigida em eventos reais e simulados em função da distância da estação ao centro do chuveiro. Este gráfico deve ser comparado ao contido na figura 5.17. . . . . . . . . . . . . . . . . . . 121

5.27 Gráficos do perfil dos resíduos reduzidos para as diferentes regiões de distâncias entre as estações e o centro do chuveiro $(r)$, em função do ângulo zenital $(\theta)$. Os ajustes utilizam a NKG corrigida. Contêm eventos reais e simulados com o AIRES/SIBYLL e o CORSIKA/EPOS utilizando como partículas primárias núcleos de ferro e prótons. Estes gráficos devem ser comparados aos da figura 5.18. . . . . . . . . . . . . . 122 
5.28 Gráficos do perfil dos resíduos reduzidos em função da energia reconstruída para os eventos reais e da energia simulada para eventos simulados nas regiões 1 e 4 . As barras de incerteza representam o desvio padrão da média, os ajustes utilizam a NKG corrigida. Esses gráficos devem ser comparados com os da figura 5.19. . . . . . . . . . . . . . . . . . 12

5.29 Gráficos do perfil dos resíduos reduzidos em função da energia reconstruída para os eventos reais e da energia simulada para eventos simulados nas regiões 2 e 3 . As barras de incerteza representam o desvio padrão da média, os ajustes utilizam a NKG corrigida. Esses gráficos devem ser comparados com os da figura 5.20 . . . . . . . . . . . . . . . . 125

B.1 Perfil dos resíduos dos ajuste de LDF para eventos com energia entre 1 e $1,66 \mathrm{EeV}$. . . . . . . . . . . . . . . . . . . 143

B.2 Perfil dos resíduos dos ajuste de LDF para eventos com energia entre 1,66 e $2,5 \mathrm{EeV}$. . . . . . . . . . . . . . . . . . 144

B.3 Perfil dos resíduos dos ajuste de LDF para eventos com energia entre 2,5 e 5 EeV . . . . . . . . . . . . . . . . 145

B.4 Perfil dos resíduos dos ajuste de LDF para eventos com energia entre 5 e $15 \mathrm{EeV}$. . . . . . . . . . . . . . . . . 146

B.5 Perfil dos resíduos dos ajuste de LDF para eventos com energia entre 15 e $30 \mathrm{EeV}$. . . . . . . . . . . . . . . . 147

B.6 Perfil dos resíduos dos ajuste de LDF para eventos com energia entre 30 e $100 \mathrm{EeV}$. . . . . . . . . . . . . . . . . . . 148

B.7 Perfil dos resíduos dos ajuste de LDF para eventos com energia entre 100 e $200 \mathrm{EeV}$. . . . . . . . . . . . . . . . . . . . 149

B.8 Perfil dos resíduos dos ajuste de LDF com correção da NKG para eventos com energia entre 1 e 1,66 EeV. . . . . . . . . 151

B.9 Perfil dos resíduos dos ajuste de LDF com correção da NKG para eventos com energia entre 1,66 e 2,5 EeV . . . . . . . . . . 152

B.10 Perfil dos resíduos dos ajuste de LDF com correção da NKG para eventos com energia entre 2,5 e $5 \mathrm{EeV}$. . . . . . . . . 153

B.11 Perfil dos resíduos dos ajuste de LDF com correção da NKG para eventos com energia entre 5 e $15 \mathrm{EeV}$. . . . . . . . . . 154

B.12 Perfil dos resíduos dos ajuste de LDF com correção da NKG para eventos com energia entre 15 e $30 \mathrm{EeV}$. . . . . . . 155

B.13 Perfil dos resíduos dos ajuste de LDF com correção da NKG para eventos com energia entre 30 e $100 \mathrm{EeV}$. . . . . . . 156

B.14 Perfil dos resíduos dos ajuste de LDF com correção da NKG para eventos com energia entre 100 e $200 \mathrm{EeV}$. . . . . . . . 157 


\section{Referências Bibliográficas}

[1] Victor Francis Hess. Phys. Zeit., 12:998, 1911.

[2] Victor Francis Hess. Phys. Zeit., 13:1084, 1912.

[3] R. A. Millikan e I. S. Bowen: High Frequency Rays of Cosmic Origin I. Sounding Balloon Observations at Extreme Altitudes. Phys. Rev., 27(4):353-361, 1926.

[4] Pierre Auger e R. Maze: The great atmosphere cosmic shower. Compt. Rend. Acad. Sci., 207:228-229, 1938.

[5] Pierre Auger, P. Ehrenfest, R. Maze, J. Daudin, e Robley A. Fréon: Extensive Cosmic-Ray Showers. Rev. Mod. Phys., 11(3-4):288-291, 1939.

[6] T. K. Gaisser: Cosmic Rays and Particle Physics. Cambridge University Press, 1990.

[7] J. R. Hörandel: Models of the knee in the energy spectrum of cosmic rays. Astroparticle Physics, 21(3):241 - 265, 2004, ISSN 0927-6505.

[8] D. D'Enterria, R. Engel, T. Pierog, S. Ostapchenko, e K. Werner: Constraints from the first LHC data on hadronic event generators for ultrahigh energy cosmic-ray physics. Astroparticle Physics, 35:98-113, 2011.

[9] The Pierre Auger Collaboration: Auger Project Design Report, 1997. http://www . auger.org/technical_info/design_report.html.

[10] F. A. Aharonian, P. Bhattacharjee, e D. N. Schramm: Photon/proton ratio as a diagnostic tool for topological defects as the sources of extremely high-energy cosmic rays. Phys. Rev. D, 46:4188-4192, 1992.

[11] The Pierre Auger Collaboration: The Pierre Auger Observatory III: Other Astrophysical Observations. 32nd ICRC, 2011. http://arxiv. org/abs/1107.4805. 
[12] E. Fermi: On the Origin of the Cosmic Radiation. Phys. Rev., 75:1169$1174,1949$.

[13] A. M. Hillas: THE ORIGIN OF ULTRA-HIGH-ENERGY COSMICRAYS. ANNUAL REVIEW OF ASTRONOMY AND ASTROPHYSICS, 22:425-444, 1984, ISSN 0066-4146.

[14] A. M. Hillas: The Origin of Ultra-High-Energy Cosmic Rays. Annual review of astronomy and astrophysics, 22:425-444, 1984.

[15] J. Blümer, R. Engel, e J. R. Hörandel: Cosmic rays from the knee to the highest energies. Progress in Particle and Nuclear Physics, 63:293-338, 2009.

[16] The Pierre Auger Collaboration: Correlation of the Highest-Energy Cosmic Rays with Nearby Extragalactic Objects. Science, 318(5852):938-943, 2007.

[17] R. Beck, A. Brandenburg, D. Moss, A. Shukurov, e D. Sokoloff: Galactic magnetism: Recent developments and perspectives. ANNUAL REVIEW OF ASTRONOMY AND ASTROPHYSICS, 34:155-206, 1996, ISSN 0066-4146.

[18] K. Greisen: End to the Cosmic-Ray Spectrum? Phys. Rev. Lett., 16(17):748-750, 1966.

[19] G. T. Zatsepin e V. A. Kuz'min: Upper Limit of the Spectrum of Cosmic Rays. Soviet Journal of Experimental and Theoretical Physics Letters, 4:78-80, 1966.

[20] P. Bhattacharjee e G. Sigl: Origin and propagation of extremely highenergy cosmic rays. Physics Reports, 327(3-4):109-247, 2000.

[21] F. A. Aharonian e J. W. Cronin: Influence of the universal microwave background radiation on the extragalactic cosmic-ray spectrum. Phys. Rev. D, 50(3):1892-1900, 1994.

[22] High Resolution Fly's Eye Collaboration: First Observation of the Greisen-Zatsepin-Kuzmin Suppression. Physical Review Letters, 100(10):101101, 2008.

[23] N. Sakaki for the AGASA Collaboration: Cosmic Ray Energy spectrum above $3 \cdot 10^{18} \mathrm{eV}$. Volume 1, página 333. 27th ICRC, 2001. 
[24] D. De Marco, P. Blasi, e A. V. Olinto: On the statistical significance of the GZK feature in the spectrum of ultra-high energy cosmic rays. Astroparticle Physics, 20(1):53-65, 2003.

[25] The Pierre Auger Collaboration: Observation of the Suppression of the Flux of Cosmic Rays above $4 \cdot 10^{19} \mathrm{eV}$. Physical Review Letters, 101(6):061101, 2008.

[26] CORSIKA Shower Images. http://www.ast.leeds.ac.uk/ fs/ showerimages.html, último acesso 2008/12/05.

[27] W. R. de Carvalho Junior: Deteç̧ão de chuveiros atmosféricos iniciados por hádrons massivos. Tese de Doutoramento, Instituto de Física da Universidade de São Paulo, 2008. http://www.teses.usp.br/teses/disponiveis/43/43134/ tde-13102008-102648/publico/teserevista.pdf.

[28] T. Abu Zayyad et al.: The prototype high-resolution Fly's Eye cosmic ray detector. Nucl. Instr. and Meth. A, 450(2-3):253-269, 2000.

[29] N. Chiba et al: Akeno Giant Air Shower Array (AGASA) covering 100 km2 area. Nucl. Instr. and Meth. A, 311(1-2):338-349, 1992.

[30] M. Roth: Measurement of the UHECR energy spectrum using data from the Surface Detector of the Pierre Auger Observatory. 30th ICRC, 2007. http://br.arxiv.org/abs/0706.2096.

[31] R. Sato: Desenvolvimento e produção das lentes dos telescópios do Observatório Auger. Tese de Doutoramento, Instituto de Física 'Gleb Wataghin' da Universidade Estadual de Campinas, 2005. http://webbif . ifi. unicamp.br/teses/apresentacao. php?filename=IF371.

[32] C. J. T. Peixoto: Reconstrução de chuveiros atmosféricos extensos detectados pelo Observatório Pierre Auger utilizando métodos robustos. Tese de Doutoramento, Instituto de Física 'Gleb Wataghin' da Universidade Estadual de Campinas, 2008. http://webbif.ifi.unicamp.br/teses/ apresentacao . php? filename=IF99.

[33] CDAS Web Page. http://www. auger.org.ar/CDAS/download/, último acesso e de abril 2009.

[34] S. Argirò et al.: The offline software framework of the Pierre Auger Observatory. Nucl. Instr. and Meth. A, 580(3):1485-1496, 2007. 
[35] CDAS Herald. http://auger.colostate.edu/private/herald/, último acesso 2 de abril 2009.

[36] The Auger Observer Home Page. http://augerobserver.fzk.de, último acesso 2009/04/02.

[37] S. Argirò et al.: The offline software framework of the Pierre Auger Observatory. 29th ICRC, 2005.

[38] The Pierre Auger Collaboration: The trigger system of the Pierre Auger Surface Detector: operation, efficiency and stability. 29th ICRC, 2005.

[39] I. C. Maris, F. Schüssler, R. Ulrich, e M. Unger: Data Summary Trees and Shower Visualization for Reconstructed Auger Events. GAP Note 2006-081, Pierre Auger Observatory.

[40] D. Verberic e M. Roth: Offline Reference Manual: SD Reconstruction. Distribuído com o código fonte do Offline.

[41] K. Kamata e J. Nishimura: The Lateral and the Angular Structure Functions of Electron Showers. Progress of Theoretical Physics Supplement, 6:93-155, 1958.

[42] K. Greisen: Cosmic Ray Showers. Annual Review of Nuclear Science, 10(1):63-108, 1960.

[43] D. Barnhill: Measurement of the lateral distribution function of UHECR air showers with the Auger Observatory. 29th ICRC, 2005.

[44] M. Roth: The Lateral Distribution Function of Shower Signals in the Surface Detector of the Pierre Auger Observatory. 28th ICRC, 2003.

[45] Maximo Ave, P. Bauleo, e Tokonatsu Yamamoto: Signal Fluctuation of the Auger Surface Array Detector. GAP Note 2003-030, Pierre Auger Observatory.

[46] P. Bauleo, A. Castellina, R. Knapik, G. Navarra, e J. Harton: Auger Surface Detector Signal Accuracy - Results from production tanks data. GAP Note 2004-047, Pierre Auger Observatory.

[47] M. Ave, P. Bauleo, A. Castellina, A. Chou, J. L. Harton, R. Knapik, e G. Navarra: The accuracy of signal measurement with the water Cherenkov detectors of the Pierre Auger Observatory. Nucl. Instr. and Meth. A, 578(1):180-184, 2007. 
[48] M. Aglietta et al.: Calibration of the surface array of the Pierre Auger Observatory. 29th ICRC, 2005.

[49] R. Brun e F. Rademakers: ROOT - An Object Oriented Data Analysis Framework. In Nucl. Instr. and Meth. A, volume 389, páginas 8186, 1997. http://root.cern.ch/, Proceedings AIHENP'96 Workshop, Lausanne, Sep. 1996.

[50] E. Parizot, I. Lhenry, D. Allard, P. Ghia, e G. Navarra: First steps towards the definition of a "quality trigger" (T5) for the SD acceptance calculations. GAP Note 2004-023, Pierre Auger Observatory (note interna).

[51] N. R. Draper e H. Smith: Applied Regression Analysis. John Wiley \& Sons, segunda edição, 1980.

[52] K. Nakamura e Particle Data Group: Review of Particle Physics. J. of Phys. G, 37(7A):075021, 2010.

[53] G. F. Knoll: Radiation detection and measurement. Wiley, terceira edição, 2000, ISBN 9780471073383.

[54] A. M. Hillas: Shower simulation: lessons from MOCCA. Nuclear Physics B - Proceedings Supplements, 52(3):29-42, 1997, ISSN 0920-5632.

[55] S. J. Sciutto: The AIRES system for air shower simulations. An update, 2001. http://arxiv.org/abs/astro-ph/0106044.

[56] AIRES Home Page. http://www.fisica.unlp.edu.ar/auger/aires/ eg_Aires.html, último acesso 2011/05/11.

[57] R. Engel, T. K. Gaisser, e T. Stanev. Volume 1, página 415. 26th ICRC, 1999.

[58] N. N. Kalmykov e S. Ostapchenko. Phys. Atom. Nucl., (56):346, 1993.

[59] S. Ostapchenko: QGSJET-II: results for extensive air showers. Nuclear Physics B - Proceedings Supplements, 151(1):147 - 150, 2006, ISSN 0920-5632.

[60] D. Heck, J. Knapp, J. N. Capdevielle, G. Schatz, e T. Thouw: CORSIKA: A Monte Carlo Code to Simulate Extensive Air Showers. http://www-ik.fzk.de/corsika/physics_description/ corsika_phys.html, último acesso 2010/12/27. 
[61] P. Doll, J. Engler, P. Gabriel, H. J. Gils, D. Heck, W. Heeringa, N. Heide, H. O. Klages, J. Knapp, H. J. Mayer, H. Rebel, G. Schatz, T. Thouw, e B. Zeitnitz: The Kascade project. Nuclear Physics B - Proceedings Supplements, 14(1):336-339, 1990, ISSN 0920-5632.

[62] J. Ranft: Dual parton model at cosmic ray energies. Phys. Rev. D, 51(1):64-84, 1995.

[63] H. J. Drescher, M. Hladik, S. Ostapchenko, T. Pierog, e K. Werner: Parton-based Gribov-Regge theory. Physics Reports, 350(2-4):93-289, 2001, ISSN 0370-1573.

[64] K. Werner, F. M. Liu, e T. Pierog: Parton ladder splitting and the rapidity dependence of transverse momentum spectra in deuteron-gold collisions at the BNL Relativistic Heavy Ion Collider. Phys. Rev. C, 74(4):044902, Oct 2006.

[65] K. Werner: Strings, pomerons and the VENUS model of hadronic interactions at ultrarelativistic energies,. Physics Reports, 232(2-5):87-299, 1993, ISSN 0370-1573.

[66] P. Billoir e O. B. Bigas: About a possible muon excess in real data compared to simulations. GAP Note 2006-055, Pierre Auger Observatory.

[67] Maximo Ave, Nicolas Busca, Lorenzo Cazon, Fabian Schmidt, e Tokonatsu Yamamoto: Determining the SD Energy Scale and Number of $\mathrm{Mu}$ ons Using Air Shower Universality. GAP Note 2007-021, Pierre Auger Observatory.

[68] The Pierre Auger Collaboration: Comparison of data from the Pierre Auger Observatory with predictions from air shower simulations: testing models of hadronic interactions. 31st ICRC, 2009.

[69] R. Ulrich, R. Engel, e M. Unger: Hadronic Multiparticle Production at Ultra-High Energies and Extensive Air Showers. 2010. http://arxiv. org/abs/1010.4310.

[70] T. Pierog e K. Werner: Muon Production in Extended Air Shower Simulations. Physical Review Letters, 101(17):171101, 2008.

[71] M. Ave, N. Busca, L. Cazon, F. Schmidt, e T. Yamamoto: Can EPOS Reproduce the Auger SD and Hybrid Data? GAP Note 2007-098, Pierre Auger Observatory. 
[72] Talianna Schmidt, Ioana C. Maris, e Markus Roth: Fine Tuning of the LDF parameterisation and the Influence on S1000. GAP Note 2007-106, Pierre Auger Observatory.

[73] G. Ros, A.D. Supanitsky, G.A. Medina-Tanco, L. del Peral, J.C. D'Olivo, e M.D. Rodríguez Frías: A new composition-sensitive parameter for ultra-high energy cosmic rays. Astroparticle Physics, 35(3):140-151, 2011, ISSN 0927-6505.

[74] Hans Joachim Drescher e Glennys R. Farrar: Dominant contributions to lateral distribution functions in ultra-high energy cosmic ray air showers. Astroparticle Physics, 19(2):235-244, 2003, ISSN 0927-6505.

[75] T. Pierog e K. Werner: Hadronic Interaction Model EPOS and Air Shower Simulations: New Results on Muon Production. 30th ICRC, 2007.

[76] The Pierre Auger Collaboration: The Pierre Auger Observatory II: Studies of Cosmic Ray Composition and Hadronic Interaction models. 32nd ICRC, 2011. http://arxiv.org/abs/1107.4804.

[77] W. T. Eadie e F. James: Statistical methods in experimental physics. World Scientific Publishing, segunda edição, 2006, ISBN 9789812567956. 